\title{
NATURAL HISTORY OF AQUATIC INSECTS
}
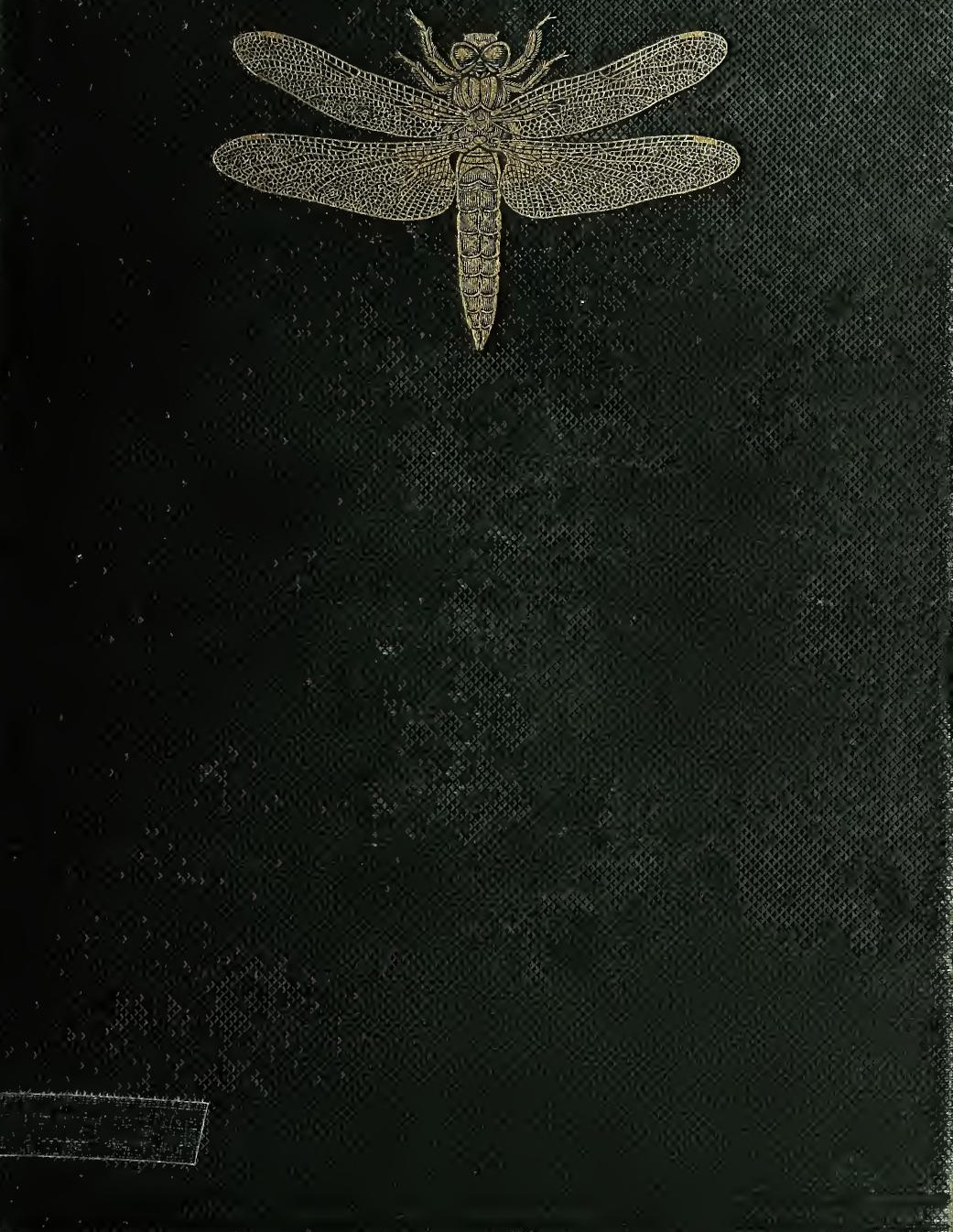
Ox umbats

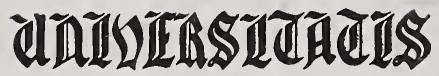

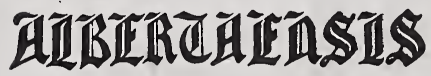

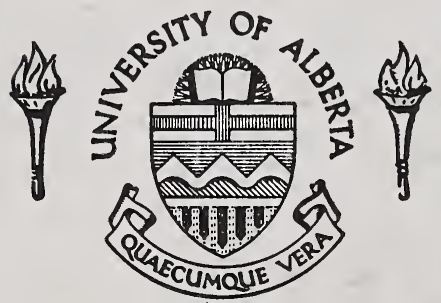


Digitized by the Internet Archive in 2017 with funding from University of Alberta Libraries 


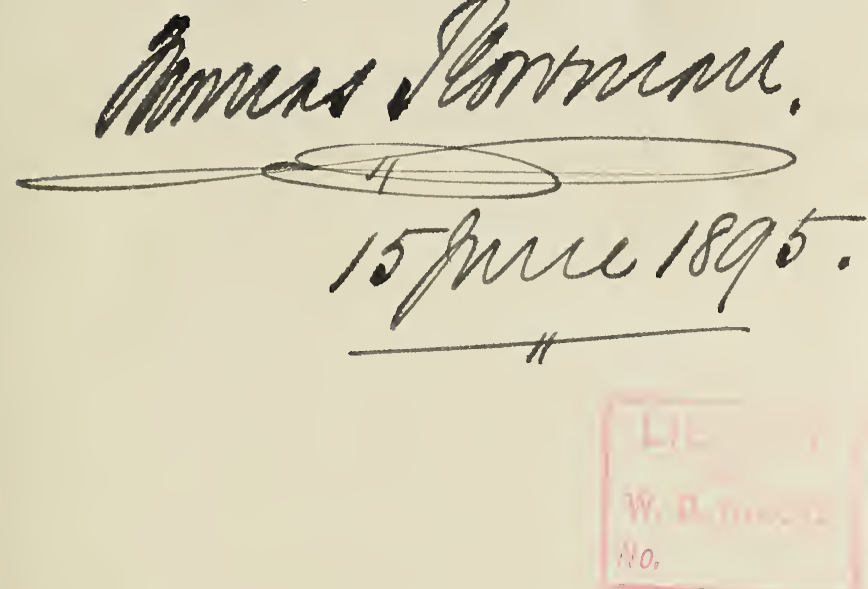

THE NATURAL HISTORY

OF

AQUATIC INSECTS 
s.x. 


\section{THE NATURAL HISTORY}

OF

AQUATIC INSECTS

BI

PROFESSOR L. C. MIALL, F.R.S.

IITH ILLUSTRATIONS BY A. R. HAMIIOND. F.L.S.

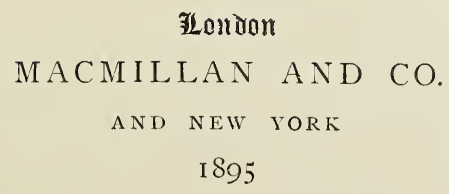

The Right of Translation and Reproduction is Rescrved 
Richard Clay and Sons, Limited, LONDON AND BUNGAY.

\section{UNIVERSITY \\ OF ALBERTA ITY}




\section{PREFACE}

I HAVE here attempted to help those naturalists, especially those young naturalists, who take delight in observing the structure and habits of living animals. It has also been my hope that I might do something to revive an interest in the writings of certain old zoologists-Swammerdam, Réaumur, Lyonnet, and De Geer-who are at present unjustly neglected; I have tried to carry on as well as to popularise their work. It would be much if I could persuade some few working naturalists to lay aside their technical lists and records of parish distribution, and study the works of Nature with open eyes, seeking above all things to know more of life in its infinitely varied forms.

Some passages in this book, if taken alone and read hastily, may appear to disparage systematic Zoology. This is far from my intention. No one can study the great naturalists of the seventeenth and eighteenth centuries without feeling how seriously their work is impaired by the defective systems of the time. It is 
not systematic but aimless work that I deprecate -work which springs from no real curiosity about Nature, and attempts to answer no scientific questions. I have great pleasure in acknowledging the advice and contributions of several friends, and especially of Messrs. W. F. Baker, T. H. Taylor, and J. J. Willinson. The drawings made by Mr. Hammond, in most cases direct from the Insects, are a valuable feature of the book, and I could say more in their praise if they did not speak for themselves.

L. C. M.

LEEDS, February 1895. 


\section{TABLE OF CONTENTS}

\section{INTRODUCTION}

Water as a Sphere of Life, p. I. The Invasion of the Waters by Insects, 3. The Dominance of Insects, 8. Degrees of Adaptation to Aquatic Conditions, II. The Surface-film of IVater, I2. Equilibrium of Aquatic Insects, 15. The Wintering of Aquatic Insects, I8. Some Cases of Abridged Life-histories, 20. Live Natural History, 24. The Groups to which Aquatic Insects belong, 28.

\section{CHAPTER I \\ AQUATIC BEETLES}

The Whirligig Beetle (Gyrinus), p. 3o. Respiration by Tracheal Gills, 36 . Dytiscus, 39. The Great Water-beetle (Hydrophilus), 61. Life of Lyonnet, 62. Hydrobius, 87. Donacia, 93.

\section{CHAPTER II \\ FLIES WITH AQUATIC LARVA}

The Gnat (Culex), p. 97. Experiment on Surface-tension, 100. Corethra, I 13. Collecting Tackle, I14. Mochlonyx, I21. Chironomus, I22. Microscopic Study of Salivary Glands, I 27. Hæmoglobin in Blood, 130. Development of the Winged Insect within the Larva, I34. Animals which coat their Eggs with Jelly, 148. Tanypus, I52. Ceratopogon, 155. Dixa, 157. Dicranota, 164. Pupal Armature for enabling the Insect to creep to the Surface, I69. Ptychoptera, I70. Simuluum, I75. Stratiomys, I89. The Rat-tailed Larva (Eristalis), 198. J. J. Wilkinson on the Tail of Eristalis, 20I ; on the Pharynx of ditto, 206. Baron Osten Sacken on the Oxen-born Bees of the Ancients, 215. 


\section{CHAPTER III}

QUATIC HYMENOPTERA

Lubbock on Polynema, p. 219. Klapálek on Agriotypus, 223.

CHAPTER IV

AQUATIC CATERPILLARS

Hydrocampa, p. 226. Paraponyx, 231.

\section{CHAPTER V \\ CADDIS-WORMS (TRICHOPTERA)}

Life of Réaumur, p. 236. T. H. Taylor on Plectrocnemia, 265. Casebearing Insects, 270.

CHAPTER VI

SIALIDE

The Alder Fly (Sialis), p. 273.

\section{CHAPTER VII}

PERLID $\Phi$

Stone Flies (Perla), p. 279.

CHAPTER VIII

MAY-FLIES (EPHEMERIDA)

Life of Swammerdam, p. 285. Swammerdam on Palingenia, 287. Réaumur on Polymitarcys, 304. De Geer on Ephemera, 318. Pictet on Larræ of Ephemeridx, 322.

CHAPTER IX

I)RAGON-FLIES (ODONATA), P. 32 S 


\section{CHAPTER X}

POND-SKATERS, WATER-SCORPIONS, AND WATER-BOATMEN

(RHYNCHOTA), P. 346

Hydrometra, 349. Gerris, 349. Velia, 35I. Nepa and Ranatra, 353. Notonecta and Corixa, 355 .

\section{CHAPTER XI}

THE WATER SPRING-TAIL (PODURA)

Life of De Geer, p. 362. Podura, 364. Isotoma, 366. Leaping upon Water, 367 .

\section{CHAPTER XII}

INSECTS OF THE SEA-SHORE, P. 370

Diptera, 373. Beetles, 374. W. F. Baker on Tibial Comb of Beetles, 376. Caddis-worms, 379. Hymenoptera and Rhynchota, 380.

\section{CHAPTER XIII}

THE CONTRIVANCES OF AQUATIC INSECTS

Modes of Locomotion, p. 382. Modes of Feeding, 385 . Modes of Respiration, 385. Attack and Defence, 386 . Egg-laying, 387 . 

THE NATURAL HISTORY

OF

AQUATIC INSECTS 



\title{
THE NATURAL HISTORY
}

\author{
OF \\ AQUATIC INSECTS \\ INTRODUCTION
}

WATER as a Sphere of Life

WATER offers many advantages to the simpler animals and plants. The vast extent of the seas, lakes, and rivers is in itself a sufficient motive for their occupation by living things, considering the crowded state of the land. But more special inducements are not wanting. The density of water supports the weight of the most fragile organisms, and enables them to move from place to place by such éasily contrived means as cilia, which may be mere drawnout threads of protoplasm, or fins, which may be shaped out of a fold of skin or a row of bristles. Some of the very simplest aquatic animals, such as Amœba, move along in the water by an act which can only be described as flowing, the stream of living protoplasm gathering itself up continually in the 
rear, and rolling forward to the front. All the very simplest animals and plants are aquatic, and a fair degree of complexity of structure is implied in the mere fact of residence out of water.

Shallow waters are easily penetrated by the sun's rays, and are therefore often occupied by green plants, whose nutrition depends upon the decomposition of carbonic acid by sunlight. Upon these green plants plant-feeding animals establish themselves, and many predatory animals come in turn to devour the vegetable-feeders. The shallow waters are probably richer in living things of all kinds than any other part of the earth's surface. But the organic products of the plants and animals of the shallow waters may be transported by moving water to great distances. The great depths of the ocean and the bottom of our large lakes have been explored by the dredge, and are found to support a population of their own, which subsists upon a nutritive sediment originally formed at or near the surface.

The conditions of life in fresh waters are materially different from those afforded by the sea. The chemical difference between fresh and salt waters is of small importance in itself-so small that many animals have been able to adapt themselves gradually to a change from one to the other. A degree of saltness far greater than that of sea-ivater is perfectly compatible with animal life, as is shown by the fact that Crustacea and Insects are often found quite at home in brine-pits and vats. There are even a few animals, like the Salmon, which can pass suddenly from fresh water to salt, or from salt to fresh. 
More important from many points of view is the fact that the seas are of vast size and, for the most part, continuous; while the fresh-water areas are relatively inconsiderable in extent, and broken up into countless small areas. Every lake and river-system is an isolated territory, and most of the plants or animals found therein can only make their way into another territory by help of a rare opportunity. This particular circumstance has governed the course of life to a material degrec, and has brought about some of the most marked differences between the fluviatile and the marine populations. It is also worth while to notice that in the large fresh-water areas, which in nearly every part of the world are the rivers, the water is in motion, and flowing steadily towards the sea. Immersion in the sea is quickly fatal to most fresh-water animals and plants, so that here is a special danger to which the smaller and more helpless fluviatile animals are exposed. We have reason to believe that this special danger has helped to bring about one of the most noteworthy peculiarities in the life-history of fluviatile animals, viz., the suppression of free-swimming and ciliated larval stages. ${ }^{1}$

\section{The Invasion of the Waters by Insects.}

The waters, both fresh and salt, have been successfully invaded by Insects, and this not in one or two cases only, but many times over, and by the most diverse kinds of Insects. The aquatic Insects do not

1 This has been pointed out by Professor Sollas (Proc. Roy. Dublin Society, 1884 ). 
form an order or a family, but comprise a miscellaneous selection of genera and species from many families and several orders. Let us consider what may be the significance of this remark. A family or an order of Insects is a group which the naturalist supposes to have descended from a common stock. An order may include many families, and the common stock of the order is therefore presumed to be much more remote than that of any of its component families. Now if all Insects were at one time terrestrial (and of this we have no sort of doubt, for reasons which will shortly be given), and if we find aquatic Insects in two different orders, which cannot be supposed to be derived one from the other, we believe that the adaptation to aquatic life must have been effected independently. For the common origin of both orders is a stock unknown to us by observation, but which we have good reason to suppose was not aquatic. When we have a smaller group, such as an aquatic family, to consider, we must ask whether it is more likely that the common stock from which it is descended was aquatic or not. In a few cases there is reason to believe that two or more aquatic families have descended from a common stock which was aquatic also, but this is unusual. The aquatic families of Insects are seldom wholly aquatic, they generally include some terrestrial forms, and these are primâ facie the more primitive, or less altered in the matter of habitat. We do find some cases of families all of which are aquatic, and so related to allied families which are in the same case, that it is most likely that the common stock in which all originated was aquatic 
too. But this is not very frequent, and the naturalist, exercised in cases of affinity, who studies a table of aquatic Insects, is likely to conclude that different families, and different genera within one family, and different species within one genus have betaken themselves independently to an aquatic life. I think we can say with a considerable degree of probability that this change of habitat from terrestrial to aquatic has taken place in the class of Insects at least a hundred times quite independently, and the number may be very much higher than a hundred.

I have spoken with confidence of the original terrestrial habitat of Insects, and this requires some further discussion. Writers have been found to maintain the very high antiquity of the aquatic habitat, and to suppose that many, if not all, of existing Insects had aquatic ancestors. What can be found out on this point? It is of no use to appeal to the geological history of the earth, for the fossil remains of Insects are too few and scattered to justify any conclusion as to the mode of life of the first Insects which appeared on the globe. But we are not altogether without the means of forming an opinion. One of the most universal features of Insects in all stages of growth is the aëration of the tissues by air-tubes or tracheæ, which ordinarily open on the outside of the body by special valvular inlets, the spiracles. Even in aquatic Insects the spiracles are commonly present and functional, and we can hardly name an Insect which has not tracheal tubes, though they may in rare instances be greatly reduced. This is pretty good 
proof that Insects were primarily air-breathing animals, but the distribution throughout the different orders and families of the species which breathe gaseous air and of those which breathe only air dissolved in water, leaves no doubt that the last-named species are those which deviate from the general and primitive rule. I think that every entomologist would agree that the Insects which exhibit the most generalised and presumably the most primitive structure are terrestrial rather than aquatic.

Insects are just the sort of animals that might have been supposed likely to change from one medium to another with great ease and advantage. They are active, hardy and ingenious. The plan of their bodily structure has lent itself to a multitude of special adaptations of other kinds. Notice the various shapes of Insects. We find among Beetles, for instance, some so round and fat that they can hardly creep, some long-legged and nimble, one as flat as a wafer for convenience of creeping under the adherent bark of fallen trees, some with long wings, others with short wings, others with no wings at all. Then among caterpillars what a range of shapes! They may be long and narrow, or egg-shaped, hard or soft, with many feet or with none, hairy or smooth, and in special cases with the oddest horns, warts, brushes, tentacles and hooks. Notice too, the extraordinary variety in their food. Insects can be found which live upon wood, upon earth and the things contained in earth, upon fungi, upon decaying seaweed, upon paper. upon fur and wool, upon leather, upon argol (crude potassium tartrate), in addition to the animal and 
vegetable products which are the ordinary food of the higher animals.

Equally remarkable is the facility with which Insects adapt themselves to various conditions. The most primitive Insects are terrestrial, running about on the surface of the earth to seek their food. But many have learnt to burrow into the earth, and this in a great variety of ways. A large proportion have learnt to fly. Some run their galleries in the wood of trees; others eat out slender mines in the thickness of a leaf; others live in the bodies of dead animals; and there are not a few which burrow in the bodies of living animals - a painful example of the cruelty of Nature! The adaptations of Insects to aquatic life, varied and ingenious as we shall find them to be, are only fresh examples of the versatility which characterises the whole class.

Even if we confine our attention to the Insects which pass part or the whole of their lives in water, we shall find a great diversity in their habitats. Still water abounding in vegetation is suitable to many; others like running water, and some few prefer torrents or cascades, though in this case they are seldom exposed to the full force of the current. The most rapid parts of an English mountain brook will, however, often be found to harbour certain kinds of Caddis-worm and the larvæ of Simulium. Water loaded with dead organic matter is congenial to other Insects, and the larva of Eristalis tenax prefers water which is putrid and stinking. Salt water is selected by others. The sea nourishes a considerable number, and brine-pits, notwithstanding the bitterness and 
density of the water with which they are filled, have an Insect population of their own. Hot springs are preferred by some, arctic snows by others $;^{1}$ some few Dipterous larvæ live immersed in the juices which flow from wounded trees and many in the fluids of living animals. Some attach themselves to the roots of submerged plants, and several bury themselves in the substance of the freshwater sponge.

\section{The Dominance of Insects.}

The countless adaptations of Insects to the most various conditions not only illustrate the extraordinary elasticity of their plan of structure, but also their power in competition. The profuse variations of the Insect type would never have been called forth, had not the type been eminently successful in the struggle for existence.

Such success may be shortly named dominance, and Insects are an excellent example of a dominant class. They are able to drive out their rivals, able to maintain and even to enlarge their territory in spite of all competition. We cannot ascertain such qualities by direct observation of the struggles which are going on everywhere around us. Human experience is too short and too blind for direct measurement of these secular changes. But though we cannot see for ourselves the turns of the slow and infinitely complex struggles of the races of animals and plants, we have before us the results of ages of such strife. The com-

1 Examples are given by Kirby and Spence, Introduction to Entomology, Vol. II., p. 23I (1826). 
monest animals of to-day are those which have so far proved victorious, and numerical strength is one mark of dominance, a sure one, when it can be clearly ascertained.

Any group of animals or plants which is numerically very strong will be found to include a large number of species, and these will be finely graded, one species being with difficulty distinguished from those which most nearly approach it. Dominant species are usually combined into what we may call continuous groups. It is only when a group is dominant, or so to speak in easy circumstances, that many nearly allied forms can maintain themselves side by side within it. For declining groups there is a rigorous selection. The principle applies to other things beside natural species. It has become a proverb that even bad workmen find employment when trade is good. Growing industries, such as lithography or paper-making, turn out an immense variety of forms and qualities ; but articles which are going out of use, say tallow candles or sand-glasses, can only be bought in one or two patterns. Sealing-wax thirty years ago was sold in an endless variety of colours, but the competition of adhesive envelopes has now reduced the number to one or two. I am told that while you can get ample choice of cloth-covered buttons, you can hardly buy more than one kind of polished steel buttons, which have now gone out of fashion.

All prosperous species, families, orders and classes at least hold their ground. If they can be successfully invaded, they are no longer dominant. Dominant groups are therefore geographically continuous; they 
lie within a ring-fence, and the facts of distribution will soon tell us whether a group is dominant or not. It is especially characteristic of the most dominant groups that they can hold their own in the wider areas, where the struggle for existence is most severe. Groups which can maintain themselves in the wide continents of the northern hemisphere, will easily prevail over the populations of the southern islands; groups which can maintain themselves in the vast fresh-water lakes of North America, will easily occupy the small fresh-water lakes and ponds of England, if ever they are brought into competition with the indigenous population.

All the various marks of dominance are united in Insects, and are there exhibited in a striking degree. Numerical abundance, zoological continuity, or the co-existence of many allied forms, geographical continuity, and predominance in the widest areas of competition distinguish the whole class. There are, of course, degrees of dominance among them. The Diptera are eminently dominant among Insects, the Muscidæ dominant among Diptera, and so on. The extraordinary variety in form, size, and habitat which Insects present is in keeping with all that we know of their range and frequency.

What are the qualities which confer dominance upon Insects or any other group of animals? The question is too hard for us. It may be one quality here, and another there. But though we must not speak with confidence on so difficult a question, there is some likelihood in the supposition that adaptability to new conditions would be one ground of success. If 
two groups of animals, both terrestrial, were to have a supply of food opened up to them in the water, it seems probable that the group which had proved itself the stronger by land would be more likely to appropriate it. The past success of the European in competition with the Hottentot gives us some reason to believe that Europeans will occupy any country at present uninhabited before the Hottentots will. But we soon get out of our depth in such discussions as this.

\section{Degrees of Adaptation to Aquatic Conditions.}

How did Insects ever come to seek the water, seeing that their mode of respiration is primarily adapted to another element? We can see almost all the steps of the adaptation on the shores of our rivers, lakes and seas. We can see Dipterous larvæ which, like the "leather jacket" (the larva of the Daddy-longlegs), burrow in the ground for their vegetable food, and devour the roots of grasses. Other larvæ of the same family (Tipulidx) prefer moist earth in the neighbourhood of streams. Others again live immersed in water, or mud saturated with water, though they come to the surface at times and push their tails, which carry the spiracles, into the air. Some few have become so completely aquatic that they seldom, if ever, come to the surface, and all their supply of oxygen is obtained from the water. Again we find on any sandy sea-shore little Beetles, which hide in the decaying seaweed. Some of the species only 
venture a little way below the level of the very highest spring-tides; others are found a little below the ordinary high-water mark, and these are immersed for a few minutes twice a day. But others withstand prolonged immersion, and cannot be drowned in salt water. There is vegetable and animal food in the water, and some creatures will find it, and devour it. Insects, nimble, enterprising, and ingenious, have ventured in and have succeeded in wresting a share from the slow Mollusks to whom it might seem more properly to belong.

The life of some aquatic animals is greatly complicated by the peculiar properties of the surface-film of water. Like other external conditions, the surfacefilm may be either a hindrance or an advantage, according to the way in which it is treated. Those who have had experience of the extraordinary versatility of living things, and of their power to adapt themselves to the most various conditions, will be prepared to find that plants and animals have been able in various ways to turn to account the properties of the surface-film.

\section{The Surface-Fili OF WATER. ${ }^{1}$}

I fear that it is not quite safe to presume that the properties of the surface-film are familiar to every reader. Let me, at the risk of superfluous explanation, run over some of the elementary facts.

Take a tumbler and pour water into it until it is

1 A fuller but quite elementary account of this subject will be found in Prof. Boys' charming little book on Soap Bubbles. 
full to the brim, i.e. until the water-level is as high as the edge of the tumbler. Then we say that the tumbler is full of water. But it will still hold a good deal more without spilling. Add water by teaspoonfuls, or drop coins in, one by one. The level rises well above the edge, and still if due care is taken, no water is spilt. The tumbler can be made over-full of water. It is plain that something restrains the natural tendency of water to seek the lowest level, and to escape by flowing over the edge.

Can it be that the water is sensibly viscous, like glycerine or thick treacle? This can hardly be the explanation, for the excess of water does not level down gradually, but takes up a position of rest in less time than it costs us to focus the eye upon it. It is not the want of fluidity in the water which prevents it from flowing over the edge. There is a film overspreading the surface, even of the purest water, which prevents it from escaping until the pressure becomes considerable.

Dip your finger into water and lift it out again. The water does not all run off, but flows down to the tip of the finger, and there forms a big drop. What holds up the drop? It is the surface-film, which does not differ in its composition from the water within, but is for the moment in a peculiar physical state. The film is incredibly thin. It can be renewed in an instant, fresh water-particles taking its place, while the old film loses all its peculiar features, and mingles with the water beneath the surface.

The surface-film can be made evident in another way. Take a clean needle, poise it horizontally on 
the prongs of a fork, and lower the fork and needle steadily upon the surface of the water in a basin. If the fork is taken away from beneath, the needle will be left floating on the surface. Steel is many times heavier than water, but the resistance of the surfacefilm prevents the needle from sinking. Once beneath the surface, the needle sinks rapidly to the bottom.

The surface-film is in a state of tension, i.e. it exerts a pull. It behaves like a drum-head, or a sheet of stretched india rubber. This may be made evident in various ways. One of the simplest is this. Take two lucifer matches, which are to form opposite sides of a square. Tic their ends together with pieces of sewing-cotton, which will form the remaining sides. Then run a needle into the middle of one of the matches to make a handle. If this frame is dipped into soapy water (a strong solution is required) and then lifted out, a transparent film of soapy water will overspread the square. This film will be in a state of tension, as you will see by holding the frame upright with the two matches horizontal. The threads will be curved inwards by the pull of the film. Why do we use soapy water in this experiment? Because the film of pure water will not last long enough for us to examine it. It breaks up instantly into a crowd of small drops. The film of soapy water, lifted off in this way, is not a simple surface-film. It consists of a double film, with an appreciable quantity of water imprisoned between the two layers.

The two or three experiments just described will, if actually performed, establish in the reader's mind some elementary truths, which have a good deal to do 
with the behaviour of Insects living at the surface of water. The particles close to the surface are in a peculiar condition of aggregation, and temporarily cohere to form a film. The film, as we have seen, offers resistance to the passage of solid bodies, and can therefore support a weight or keep a buoyant object from rising through it. It also exerts a pull, and we shall find that advantage is taken of this pull by certain aquatic Insects. The extreme tenuity of the film, which is thinner than our imagination can realise, helps us to understand how it is that only small objects are affected by it. Ships, boats, swimming quadrupeds, and all objects whose weight is large in comparison with their contour, are practically uninfluenced, but objects whose dimensions are given in fractions of an inch may be largely controlled by the peculiar properties of the surface-film. The larva of the Gnat turns these properties to account in a peculiarly interesting way, as do many other aquatic Insects, Crustacea and floating plants. On the other hand, minute aquatic animals, approaching the surface of water without precaution, may find it a death-trap, as we learn by observation of certain small Crustacea. ${ }^{1}$

\section{Equilibrium of Aquatic Insects.}

The density of water is so much greater than that of air as to require peculiar adjustments in the equilibrium of aquatic animals. A simple case is presented by the airøbreathing aquatic Insects. These,

1 D. J. Scourfield, Linn. Journ., Zool., Vol. XXV., pp. I-I9, pl. 1, 2, 1894 . 
with few exceptions, are lighter than water. ${ }^{1}$ Hence, if by loss of respirable air, or from any other cause, they are disabled, they have only to cease to struggle in order to come to the surface, and it will in all cases be found that they float upwards in such a position that the part of the body by which air is taken in comes to the top.

Locomotion in any medium by an animal of complex structure involves some power of orientation, and especially a rapid and instinctive judgment as to the horizontal plane and the upward and downward directions. The pull of gravity may furnish the necessary indication, but an animal which swims in water, or flies in air, may be unable to determine the horizontal plane with facility, especially if its body is nearly of the same density as the surrounding medium, since the pressure will be approximately equal on all sides. The semi-circular canals of Vertebrates and the so-called auditory organs or otoliths of many Invertebrates are probably organs for the perception of the horizontal position. Some animals, however, such as Insects, possess no organs of this kind, although they are excellent fliers or swimmers. How are they enabled to maintain their course at a fixed distance above the surface of the earth or below the surface of the water? Sight may help, but that sight does not furnish the sole indication may be inferred from the behaviour of sightless animals, such as the inhabitants of dark caverns, or animals temporarily blinded for the purpose of

1 Among the exceptions are Corixa, and the larvæ of the Gnat, Agabus, and Hydrobius. 
experiment. These have been found to be capable of maintaining a horizontal course, or of ascending and descending according to need. Their perception of the upward and downward directions is, as experiment shows, falsified by artificially induced changes in the specific gravity of the medium, so that it is probable that they are guided chiefly, if not altogether, by the action of gravity.

We have seen that air-breathing aquatic animals are, as a rule, lighter than water, and that when they come to rest they float upwards in one particular position. The normal attitude is maintained by the distribution within the body of two or more substances of very different density, such as air and flesh or shell. Whatever the density of the medium, and whether the body rises or falls, it will tend to maintain the same position, the lighter tract tending to rise.

Ground-feeders, and swimmers which do not breathe gaseous air, maintain the normal attitude in a different way. Here the body is of nearly uniform specific gravity, and the normal attitude is secured by the movements of the limbs and the form of the external surface.

In ground-feeding aquatic animals, whose bodies are a little heavier than water, the legs are usually placed ventrally, and the back is rounded from side to side. A Lobster is a familiar example. Here the convex dorsal surface tends to move foremost, and the action of the limbs treading the water, helps to maintain the same direction of movement. As a rule the limbs are turned down, and the body con- 
sequently rises when they are energetically moved, but the attitude is very easily reversed.

If such an animal ceases to use its limbs, and is moved through the water by a current or by its own weight, it will tend to move back foremost. Hence a dead Lobster or Crayfish thrown into water will commonly come to rest lying on its back. Swimmers in water, such as some Ephemera-larvæ, find it easy to invert their bodies. Some Crustacea swim in all sorts of attitudes, back upwards, back downwards, or sideways, and change incessantly from one position to another. This is effected by the bending of the body. If the body is much curved, the centre of gravity will lie outside it, in the concavity and well below the line about which the moments on both sides form a couple. The convex side will tend to sink. If the ventral side is made convex it will tend to turn downwards, and so with any other side. ${ }^{1}$

The Wintering of Aquatic Insects.

Winter, of course, brings many hardships upon aquatic Insects, as the great reduction in their numbers proves. The enormous number of eggs laid by so many of them is doubtless connected with the heavy risks to which they are exposed during half the year. I find comparatively little information recorded even upon so fundamental a point as the stage in which particular Insects pass the winter. It is much

I have derived useful notions on this subject from a short paper by Bethe ("Erhaltung des Gleichgewichts," Biol. Centralblatt, I 894), which contains, however, some serious mistakes. 
to be desired that observing persons would attend to this and like subjects instead of piling up lists of species, which tell us so little that signifies.

The common rule is, I think, that aquatic Insects winter as larvæ. Nearly all aquatic Diptera, Dragonflies, May-flies, Stone-flies and Caddis-flies do this. Occasionally, however, the winged individuals hibernate. Examples are furnished by the Gnat, and one of the Dragon-flies (Lestes).

Fully armoured aquatic Insects, such as Beetles and Bugs, commonly pass the winter in the winged state, burying themselves in the mud or in the earth during unusually severe weather.

Aquatic Insects which have wintered as larvæ usually undergo transformation and lay their eggs in the following spring. From these eggs a summer generation proceeds, which becomes ready for egglaying in September, and so the cycle comes round. This is the usual course with aquatic Diptera of small size. There may be more than one summer-brood, and sometimes the new generations appear so frequently that larvæ, pupæ and flies can always be found during the summer half-year. This is the case with Chironomus, for instance. Large Insects, and the great majority of the aquatic Beetles, produce at most one brood in the year. ${ }^{1}$ Egg-laying takes place in spring or early summer, and the transformation takes place in the height of summer, though not always in the summer which immediately follows the hatching-out of the eggs. Upwards of a year may be spent in the larval stage.

1 Hydrobius produces a second brood in autumn. 


\section{Some Cases of AbRidged Life-historres}

In the following pages many instances will be given of Insect larvæ which have become completely adapted to aquatic conditions. The spiracles or inlets of the air-tubes are closed; some kind of gill takes their place; fins useful only in water are developed. The pupa, which succeeds to the larva, is occasionally wholly aquatic too, though it is much more common for the Insect when the time of pupation is at hand to creep out of the water and to begin to breathe gaseous air. Still there are a very few cases of pupæ whose respiration is adapted to a completely submerged life. The pupæ of Chironomus and Simulium obtain their whole supply of oxygen from the water. But there is as yet no one instance of an imago, or adult Insect, which breathes the air dissolved in water. All, when they reach their final stage, become air-breathers, drawing in gaseous air by open spiracles. This is true of the aquatic equally with the terrestrial imago. A Dytiscus, a Hydrophilus, a Water-scorpion or a Water-boatman must be able occasionally to reach the air with some part of its body, and will perish if prevented from doing so. Some fully developed Insects can, it is true, remain submerged for many hours together, but all require to take in gaseous air at intervals. Why, we may ask, could not that adaptive power of Nature which has enabled so many larvæ and some few pupæ to subsist upon dissolved air, have furnished us with one or two examples of an adult Insect capable of doing the same? 
I am not bold enough to say that the case is theoretically impossible, but if it is ever realised by the discovery of actual examples, we may expect to find that the whole advantage of the transformation has been sacrificed. For transformation is merely a step to the acquisition of wings, and wings would be useless except in air. The power of flight implies great muscular activity, keen senses, food which can be quickly absorbed and highly nutritious in proportion to its bulk, mouth-parts adapted to such food. Hence the striking difference which so often arises between the slow, heavy and voracious larva and the nimble, honey-sucking imago. There is a division of labour between the two stages, and each becomes specialised for its own purposes until the extremes can only be reconciled by a prolonged resting-stage. The pupa and all that relates to it are subordinate to the acquisition of wings.

The acquisition of wings is not however an ultimate purpose, but only a means to an end. That end is, primarily, the dispersal of the eggs in fresh sites. Where the food consists of the foliage of a particular thinly distributed plant, all the eggs must not be laid together, lest the larva, being over-crowded, should consume their whole supply of food and perish of starvation, leaving other plants of the same species untouched. If the female were endowed with the power of flight, able to absorb some highly nutritious food which would neither require much time to collect nor over-load her body, and gifted with adequate powers of perception, she might find out a number of scattered plants, and lay her eggs upon them a few at 
a time. Again, the many Insects which frequent small pools, liable to disappear in summer drought, will enjoy a great advantage if they are able to fly abroad, and lay eggs in places which offer a supply of food and yet are not permanently habitable. Where these considerations do not apply, as for instance in the case of Moths whose food-plants (grass, heather, \&c.) are social and not easily exhausted, or of Moths whose larvæ are indiscriminate in their food (the Vapourer is a good example) we often find that the female is wingless. ${ }^{1}$

The mating of the male with the female is another motive for the acquisition of wings. Were the fully developed Insect restricted, like the larva, to one pool or to one food-plant, choice of mate and mixture of families would be hard to obtain. Hence even in those cases (wingless Moths, Scale-insects, Strepsiptera) where abundance of food or parasitic life has led to the suppression of the wings of the female, and where the eggs are not widely dispersed, the male Insect is nearly always capable of flight.

Though no Insect is so completely aquatic in its final stage as to be unable to live in the air, we do find, as a rare exception, that the final stage is suppressed, and that the pupa becomes capable of laying fertile, though unfertilised eggs. This is the case with Chironomus: Grirnm ${ }^{2}$ found in his aquarium a small species which in spring and summer laid un-

1 Weismann, Biological Memoirs. Essay on the "Duration of Life."

2 "Die ungeschlechtl. Fortplantzung einer ChironomusArt." Mém. Ac. St. Petersb. VII. Ser., Tom. XV. (I870). 
fertilised eggs while still a pupa. These eggs produced larvæ. The egg-laying pupa had on the under side of the last abdominal segment a pair of speçial orifices for the passage of the eggs. Occasionally, after laying a few eggs, the pupa was transformed into a fly. In autumn the normal stages were gone through, and eggs were laid by winged females after being fertilised by the males. Many other cases are known of the production of fertile though unfertilised eggs (Parthenogenesis) among Insects and other animals. Reproduction by immature animals (Pædogenesis), as in Grimm's Chironomus, is rare but not unparalleled. The larva of a minute fly (Miastor metroloas) found under the bark of the poplar, willow and beech, was observed to produce viviparously small larvæ, which escaped by tearing open the body of their parent and in turn produced other larvæ after the same fashion. 'This went on throughout the greater part of the year, but in summer winged males and females appeared, which laid a very few eggs of large size. When these facts were first published by Wagner ${ }^{1}$ they were received with a good ${ }^{\circ}$ deal of incredulity, which has been completely removed by the independent verification of the facts, and by the discovery of two other allied species of similar lifehistory. Parthenogenesis, Pædogenesis and viviparous reproduction are all methods of abridging the tedious operations by which in Insects a new generation is normally produced. Where food is plentiful and time precious, the mating of the sexes, the full

1 "Beitr. z. Lehre v. d. Fortpflanzung der Insectenlarven," Zeits. f. wiss. Zool. Bd. XIII. p. 513 (1863). 
development of the winged imago, and the development of the eggs after mating may all be omitted or shortened. But the normal process is never wholly suspended. Fertilised eggs are produced at regular intervals by fully developed males and females, and most commonly towards the end of summer, as if the approaching season of scarcity and cold could only be faced by fertilised eggs or their product. We cannot but speculate on these curious deviations from the familiar course of nature, but let us hold our speculations cheap. Before long we may expect some impracticable fact to start up, as if maliciously, and confound our theories.

\section{Live Natural History.}

I hope to persuade some of my readers to take up the study of aquatic Insects in a practical way, and it will be desirable to tell them what they may expect if they do. Aquatic Insects are not a definite group of animals from the point of view of zoologists, but a chance lot. The grave labours of the anatomist or systematist would be better bestowed upon a special order or family. Aquatic Insects, however, make a capital study in Natural History. While you are looking for one kind you will come across another. The same methods and the same tackle will do for all. If a young student wants to observe the ways of living creatures, we may recommend aquatic Insects to him as an accessible and very imperfectly explored ficld. He will find plenty of undescribed forms and 
plenty of beautiful contrivances which no one has ever taken the trouble to observe. But to make out the way in which the exquisite machinery of nature is meant to work is no childish pursuit. The very attempt will lead the naturalist to acquaint himself with scientific laws which seem altogether foreign to Natural History; it will exercise his industry and sagacity; it will extend his knowledge of the possibilities of life.

This is a study, I mean the study of living animals, which is not very seriously prosecuted in our time. The naturalists of old, Swammerdam and Réaumur, and De Geer, made this their great interest. The needful work of classification has since drawn off many students, and exciting questions concerning the descent of animals have drawn off others. But Natural History, which I use here to denote especially the study of living animals and plants, will surely revive, and charm mankind once more.

The zealous naturalist, setting out upon a voyage of discovery, will generally be too ambitious at first. He will try to cover too much ground, and to do too much with his own hands. Let us consider what he may fairly hope to do. The first aim of the beginner is usually to collect and name. He likes to see a growing store of properly classified Insects. He likes to give the right name to any one that is shown him. But this feeling must be checked if he is to do much work upon habits or structure. The man who can name many Insects can seldom do anything but name them (there are some conspicuous exceptions!). Useful it is to all of us to have such 
men, and to benefit by their knowledge. They give us the key to what has been found out and set down in books by many generations of observers. But the student of Natural History or Anatomy will not, as a rule, be even moderately good in naming. He will, it is to be hoped, be able to place an Insect approximately in its right place, but he will not carry generic and specific characters in his head. If it is the Natural History of Insects which attracts him, he will do well not to seek to add all the attainments of the Entomologist. The collection that he should possess will not be extensive or showy. He will use up his specimens to see how they are made; he will have no time for the niceties of the professed collector.

I hope it will not be too discouraging if I add that if he is bent upon increasing knowledge he will work slowly, and will cover little ground. It takes a man who has other occupations to mind about a year to get a fair notion of the structure and mode of life of a new Insect. But to verify the descriptions of good observers, and so to be guided over the ground, is of course a far more rapid business, and this is enough for most of us. Still we do not taste the full delight of Natural History unless we attempt to walk where no one has walked before.

It is necessary to warn the beginner that unless he has that sure perception of truth and error which belongs to very few among men, he will continually make mistakes, and very humiliating these mistakes are, especially when they have been published with full confidence. There is no department of human 
enquiry with which I am even slightly acquainted which presents so many pitfalls as the interpretation of natural contrivances. I have learnt by sad experience to believe that my own first attempts to interpret a new structure are nearly always wrong, and it would not be hard to show that some very eminent naturalists have had an experience not altogether unlike mine. The only remedy is to be patient, and to go on working until your explanation has stood the test of time and wider experience. Above all, do not print anything the moment you have come to believe in it. When you have done your utmost, you have not taken away the possibility of being seriously wrong, but to print in haste is to invite disaster.

This is a discouraging reflection, and may lead some to prefer studies where surer if less interesting results are to be won. But it will never do to turn away from the interpretation of natural contrivances merely because the task is difficult and risky. This is one of the permanent interests of mankind; to know how the wonderful adaptations of plants and animals came into existence, and what purposes they serve, is the great aim of the study of Nature. And experience shows that though many investigators fail at times, and though some fail altogether, substantial progress is made in nearly every generation. We now know much more about natural contrivances than was known before Charles Darwin, and almost infinitely more than was known to Swammerdam or Leeuwenhoek. 


\section{The Groups to winch Aquatic Insects BELONG.}

The aquatic Insects are here described in the following order :-

I. Coleoptera (Beetles).

2. Diptera (Two-winged Flies).

3. Hymenoptera (Ichneumons, \&c.).

4. Lepidoptera (Moths).

5. Trichoptera (Caddis-flies).

6. Sialidæ (Alder-flies).

7. Perlidæ (Stone-flies).

8. Ephemeridæ (May-flies).

9. Odonata (Dragon-flies).

I0. Rhynchota (Water-scorpions, \&c.).

I I. Thysanura (Spring-tails).

The names employed by anglers should be noted, as much information respecting the habits of aquatic Insects can be extracted from anglers by those who speak their language. Ronalds' Fly-fishers' Entomo$\log y$ and other books give the zoological names of every species imitated by the angler. In the following short list each is merely referred to its proper order.

2. Diptera.-Golden Dun Midge.

5. Trichoptera.-Blue Dun, Little Red Spinner, Sand Fly, Grannom, Turkey Brown, Dark Spinner, Silver Horns, Cinnamon Fly.

6. Sialidæ.-Alder or Orl Fly.

7. Perlidæ.-Red Fly (Old Joan), Stone Fly, Willow Fly (Shamrock Fly). 
8. Ephemeridæ.-March Brown (Dun Drake), Great Red Spinner, Yellow Dun, Iron Blue Dun, Jenny Spinner, Little Yellow May Dun (Silk Fly), Sky Blue, Green Drake (May Fly, Cardew), Grey Drake, Orange Dun, Black Drake, Dark Mackerel, Pale Evening Dun, July Dun, August Dun, Whirling Blue Dun, Little Pale Bluc Dun (Willow Fly). 


\section{CHAPTER I}

\section{AQUATIC BEETLES}

The Whirligig Beetle (Gyrinus) ${ }^{1}$

GYRINUS, also called the Whirligig Beetle or Steelcoat, is a small blue-black Beetle, about a quarter of an inch long, which abounds on the surface of still streams. It is sometimes seen disporting itself on a clear pond or small puddle, but it prefers gently running water. During the summer months, the Whirligigs congregate in swarms, darting swiftly to and fro like Swallows or Bats with movements so rapid that the eye can scarcely follow them. Now and then, especially when alarmed, they dive to the bottom of the water, or swim about beneath the surface. When they descend, they carry with them a bubble of air attached to the hinder end of the body, which glitters like quicksilver. They may be often seen clinging to submerged weeds, but as soon as all is still again they let go their hold, rise without effort to the surface, and resume their gyrations. It

1 I have to thank Mr. W. F. Baker for some useful observations on this Insect. 
is particularly easy to observe them from a low bridge crossing a still stream.
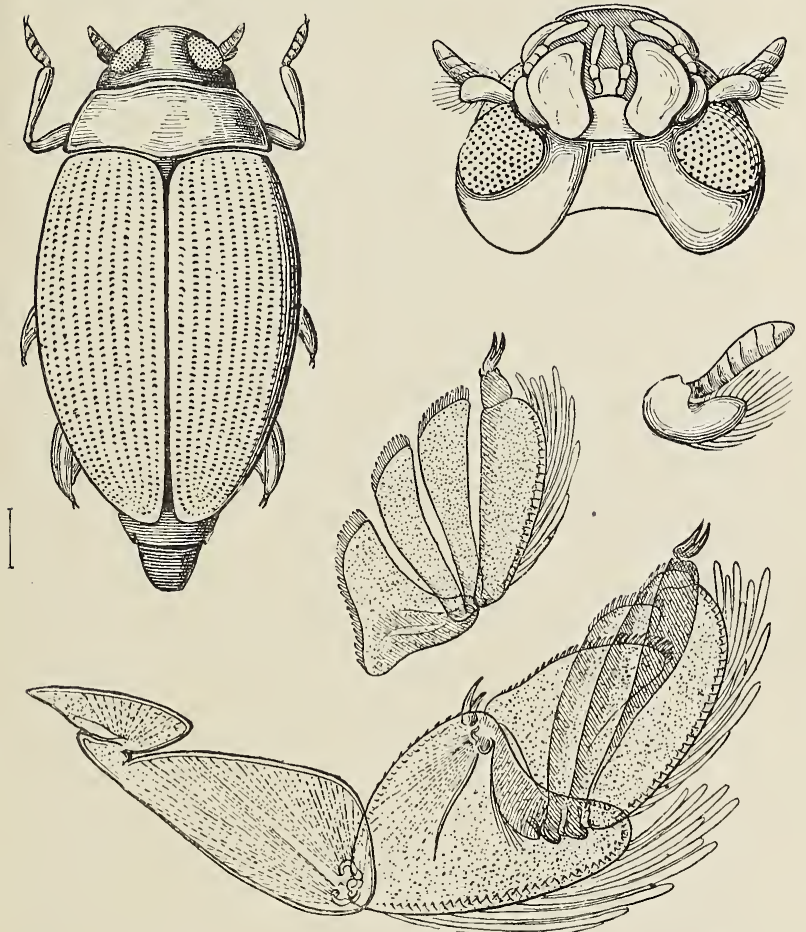

FIG. I.-Gyrinus marinus (G. natator hardly differs). Head, seen from beneath, showing mouth-organs and lower pair of eyes ; antenna ; third leg; and tarsal joints of do. separate and extended.

The Gyrinus appears quite early in the season, but only in twos and threes. Those which appear in 
early spring have passed the winter in a torpid condition as full-grown Insects. A new generation of larvæ is now produced. They grow rapidly, pass through their transformations, and emerge as perfect Insects when the height of the summer is passed. They are most plentiful about the beginning of September; after that, their numbers steadily decrease, and by the middle of November very few can be found; most of them have now retreated to their winter quarters, though a spell of fine weather, even in the depth of winter, will tempt a few to the surface. They pass the winter months buried in mud among the roots of water-plants, and can be dug out with a scoop. If kept indoors in an aquarium, they do not become torpid, except in the severest weather. Under such conditions their numbers rapidly decrease, for food is scarce, and when the Insect is active, its tissues waste.

The full-grown Gyrinus, like most other adult Beetles, flies with ease. It seems to be unable to take flight from the surface of the water, but finds it necessary first to climb up the stem of some waterplant, where it rests for a time. Then it slowly opens its wing-covers, extends its long wings, and takes to flight. When kept in captivity, they are unwilling to remain very long at a time upon the surface of the water. They will climb up the glass sides of an aquarium with great effort, making use chiefly of the hindmost pair of legs, and struggling with the tenacious film of water which they bring up with them. ${ }^{1}$ They will creep nearly an inch up the 1 The action is more fully explained on page 162 . 
perpendicular sides of the glass, and it takes them about half an hour to rise so high. Failures do not discourage them, and no matter how long they have been kept in captivity they are never weary of endeavouring to creep out of the tank.

When handled, they give off a milky fluid of unpleasant odour from nearly all the joints of their body, but especially from the fore and hind edges of the thorax. The scent is rather like that given off by Cockroaches. According to most authors, the perfect Gyrinus is largely carnivorous. Westwood says that he has ascertained that its food consists of small dead floating Insects. Fowler remarks that the broad blunt mandibles point to a partially vegetable diet, though the sharp sickle-shaped maxillæ favour a different conclusion. In captivity they feed upon water-plants. ${ }^{1}$

The body of the adult Beetle is of oval shape, convex above and flat beneath. The head is sunk in the thorax. The end of the abdomen projects, and forms a short tail upon which are carried two small retractile prominences. Between the tips of the wing-covers and the extremity of the body rests the air-bubble which the Beetle carries with it when it dives.

$1 \mathrm{Mr}$. W. F. Baker favours me with the following observation: "I was once watching some Gyrini, when a gad-fly came flying round my head. I struck at it, and knocked it into the water, stunned if not dead. Two or three Gyrini seized it, and shortly afterwards the whole swarm clustered round. In a short time nothing was left except the wings of the fly, which were allowed to drift away. This is the only occasion on which I have seen anything of the sort. I could never get captive Gyrini to eat dead flies." 
The compound eyes are each divided into two separate portions, the socket of the antenna being interposed. Since one mass of facets is above and the other beneath, it has been ingeniously conjectured that one serves for vision in air and the other in water. This conjecture has never been tested with the care necessary to confirm or refute it. I once endeavoured to determine by direct observation whether the lower patch is actually submerged or not, but found that the capillary curves about the head and body render it very difficult to decide where the water-line comes. These curves must greatly obscure or at least limit vision by the lower lenses. The occurrence of divided eyes in some Dragon-flies, in Adelotopus, a Carabid beetle, which is found under the bark of trees, ${ }^{1}$ as well as in many Dipterous Insects which never approach the surface of water, ${ }^{2}$ must be accounted for in some other way. The antenna has a very unusual shape. The basal joint is small, the second larger, the third much bigger, looking like a second antenna outside the other. The remaining part of the shaft is club-shaped and indistinctly jointed. The tip is provided with pits and hairs, and is probably highly sensitive. In the Dytiscidæ the antennæ, as I learn from Dr. Sharp, want the usual sensory structures and are always wet. The peculiar form of the Gyrinus-antenna is probably a means of keeping it dry. ${ }^{3}$ The Insect-antenna, when highly

1 Dr. Sharp, Ent. Month. Mag. V. p. 52.

${ }^{2}$ Osten Sacken, Characters of the three Divisions of Diptera, p. 447.

3 "In some aquatic Beetles (Gyrinus, Parnus) they [the 
specialised, seems to require air for the discharge of its peculiar functions.

The wings and wing-covers of the adult Insect are much like those of other Beetles, but the legs are very peculiar. The third pair are broad and shaped like paddles. They can deal a powerful backward stroke upon the water with the broad side, and can be drawn up again edgewise with greatly less resistance. The effectiveness of the paddle is enhanced by the long stiff hairs which fringe it, and especially by the peculiar form of the tarsal joints. These are expanded, and so articulated that the fulcra upon which they turn come near together. The effect is like that of the ivory tablets used for memoranda, which are held together by a pin, so that they can either be opened fanwise or closed in a moment. It is impossible to study the action of the limb in the swift darting movements of the Gyrinus, but the power of instantancous extension or collapse must be of great practical service. The middle legs are also expanded, but in a less degree. The fore legs are prehensile. In the male the tarsal joints are dilated, and bear a great number of circular organs, commonly called suckers, which are, it is belicved, used to grasp the female.

Several Beetles have been observed to make a squeaking noise, and among the number are Dytiscus and Gyrinus. The sound is produced by rubbing the

antennæ] are furnished with an auricle at their base, which like the lid of a box, shuts them in when unemployed, and protects them from the water."-Kirby and Spence, Vol. III, p. $516(1826)$. 
under side of the wing-covers against the end of the body, and is probably a call to other Beetles of the same species. Gyrinus always makes this sound before taking flight. A flying Gyrinus hums like a Bee, apparently in consequence of the whistling of the air about its hollow wing-covers.

The female Bectle lays a number of elongate oval eggs, end to end, upon the leaves of water-plants. They are found beneath the surface of the water, and sometimes at a considerable depth.

Schiödte $^{2}$ has given an excellent set of figures of the larva of Gyrinus. It is $14 \mathrm{~mm}$. ( $\frac{3}{5}$ in.) long. Behind the head come three thoracic segments, of which the foremost is protected by a dorsal plate, as is usually the case with burrowing larvæ. The legs are long and slender. Each of the eight foremost abdominal segments carries a pair of gills, and the ninth two pairs. A small tenth abdominal segment is armed with two pairs of long, sharp, curved hooks, which are believed to be of use in climbing. The general appearance of the larva is that of a small Centipede. The mouth-parts are those of a carnivorous larva, the mandibles especially being pointed, perforated by a slit beneath the apex, and suctorial. The gills are long, tapering, and fringed with fine hairs. A tracheal tube traverses each, and gives off many fine branches to the delicate walls.

It is generally thought to be casy to understand the principle of such a respiratory organ. The water

1 "De metamorphosi Eleutheratorum, Bidrag. til Insekternes Udviklings-historie." Pt. I. pl. iii., figs. I-9. Kröyer. Naturh. Tikskr. (1862). 
in which the gills are bathed contains much dissolved oxygen, and this oxygen is supposed to diffuse through the delicate wall, while the carbonic acid formed within the body passes out. Little attention has been paid to the circumstance that in a number of aquatic Insects the tracheal tubes become thereby filled with a gas, probably rich in oxygen. How this is accomplished I for one cannot understand. I believe that no physicist would undertake to set up an apparatus which would without rise of temperature or diminution of pressure remove dissolved oxygen from water, and store it up in a gaseous form within a closed chamber. To imitate the apparatus of the Insect, there should be no gas whatever within the closed chamber to begin with. In the fresh-hatched larva of certain aquatic Insects, or in the young pupa of others, tiny bubbles can be seen to form inside the air-tubes, and gradually expel the watery fluid, with which they were previously filled.

The separation of a gas from

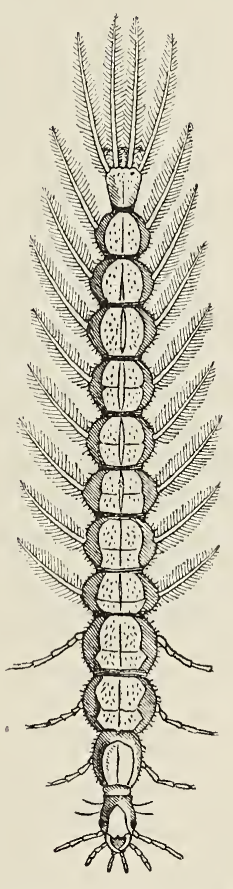

FIG. 2.-Larva of Gyrinus marinus. From Schiódte. water or blood is not peculiar to Insects. Fishes fill their swim-bladders, the Pearly Nautilus the 
chambers of its shell, some Zoophytes their floats, some aquatic Crustacea and Polyzoa their eggs with air or some other gas. Even the microscopic Protozoon, Arcella, possesses the same faculty. ${ }^{1}$ Green plants, under the influence of sunlight, liberate gaseous oxygen from their tissues. This is probably not due to the direct action of the sun's heat, for it can be observed in cold running water, just escaped from the fissures of a limestone hill.

The passage of dissolved gas through living membranes is equally mysterious. Direct experiment upon the freshly excised lung of the Frog shows that no diffusion takes place until the cells are dead. ${ }^{2}$

It is well known to the makers of microscopic preparations that tissues will not take up colouring matter so long as the cells are alive, nor will the natural colouring matter, e.g. of Beet-root, pass out into water, until the cells are killed.

Bohr ${ }^{3}$ finds that the air-bladder of a Fish refills after puncture and complete emptying, the new gas containing as much as 80 per cent. of oxygen. But if the branches of the vagus nerve which supply the

1 In this case the gas is carbon dioxide, whereas in others it is apparently oxygen or some mixture in which oxygen predominates. Our information as to the composition of the gases concerned is unfortunately most imperfect. Biot in 1807 showed that the gas in the air-bladder of Fishes is rich in oxygen.

2 Tigerstedt und Santesson. Bihang till K. Svenska Vet. Akad. Handl. Bd. XI. No. 2 (1886). $\mathrm{NaCl}$ could not be made to diffuse through the wall of the lung so long as the epithelial cells were alive.

3 C. R. CXIV. p. 1560 (1892). 
bladder are cut, no more gas is formed. Oxygen could not be made to diffuse into the air-bladder of a Pike, which was filled with atmospheric air and surrounded by pure oxygen, but when the epithelium was killed by maceration in distilled water, oxygen readily passed through by diffusion. Bohr accordingly adopts Moreau's view, viz. that oxygen is not passed into the air-bladder by diffusion, but is formed within it by "specific secretion."

The Gyrinus larva feeds upon water-insects, and possibly upon other aquatic animals. Failing these, it will eat the tender parts of submerged plants. It has been noticed that well-fed larvæ produce larger Beetles than those which have had a poor supply.

The pupa of Gyrinus is so well hidden that few naturalists have ever seen it. Modeer, quoted by De Geer (Tom. IV. p. 364), says that about the beginning of August the larva creeps out of the water by climbing up the water-plants, and then spins a grayish cocoon pointed at both ends. Enclosed in this cocoon it changes to a pupa, and emerges as a perfect Insect towards the end of the same month. Modeer adds that the pupa is very liable to the attacks of Ichneumons.

\section{DyTiscus. ${ }^{1}$}

No one can hunt long for water-insects without coming across the rapacious Dytiscus. There are

1 Dytiscus is the name given to this Insect in almost all systematic books, but the word thus spelt is unmeaning. Since the time of Geoffroy a minority of authors has adhered to the true spelling, Dyticus (fond of diving). 
many species and several genera in the family of Dytiscidæ, but it will be best to devote our space chiefly to the life-history of $\mathrm{D}$. marginalis, one of the biggest and the commonest of them all.

Both the larva and the imago are aquatic; the pupal stage is however passed in the earth. This is the case with other aquatic Coleoptera too. The explanation is not hard to discover. These Insects are air-breathers throughout their whole life. As larvæ or adults they can come to the surface at pleasure, and renew their supply of air. But the pupa is almost motionless. Its limbs are being reconstructed, and cannot effect more than a slight change of attitude. Under these circumstances, the Insect passes its pupal stage where air can be procured at all times. For the sake of protection it buries itself in the earth, but so near to the surface that air can easily reach it.

Lyonnet observed that captive females of Dytiscus laid their eggs at random in the water. ${ }^{1}$ For several years in succession he watched the eggs so laid, and none were ever hatched. At last one egg produced a larva, but this soon died. Lyonnet was not aware that the eggs of his captive Dytisci had been laid under unnatural conditions. The female, when at liberty to obey her own instincts, lays her eggs in rushes or other aquatic plants beneath the surface of the water. She makes an incision in the stem, which reaches the

1 This would agree better with Acilius than with Dytiscus. Acilius lets the eggs drop upon the mud while swimming about. Colymbetes arranges its eggs upon leaves, \&c., to which they adhere strongly (Régimbart). 
pith, and then lays a single egg in the cleft. The ovipositor, which projects from the hinder end of the body, is armed with two small, hard, pointed plates, which enclose the oviduct, and it is with these that the incision is made. ${ }^{1}$ March or April is usually the time. From eggs so laid minute larvæ proceed, hatching out in about three weeks. They grow very fast
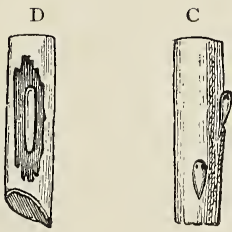

B
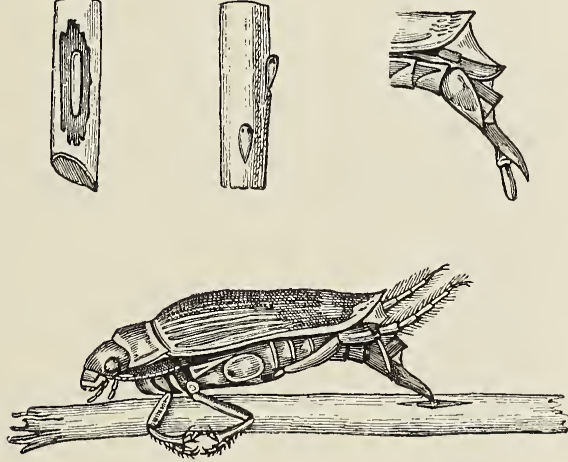

A

F1G. 3.-A. Female Dytiscus, laying eggs. B. The ovipositor, protruded. C. Eggs of Notonecta, attached to stem of rush. D. Egg of Dytiscus, laid in excavation in rush. From Régimbart.

when well supplied with food, and attain their full larval development in four or five weeks, changing

1 Régimbart, Ann. Soc. Ent. France, 1875. The eggs are very elongate. Dr. Sharp informs me that they are often accompanied by a white maggot, exactly like them, but rather shorter. In Yorkshire the eggs are more commonly laid in the midribs of Pond-weed (Potamogeton natans). 
their skins from time to time, like other Insects. The larva when full-grown is more than two inches long. It is yellow-brown in colour, and of cylindrical shape,

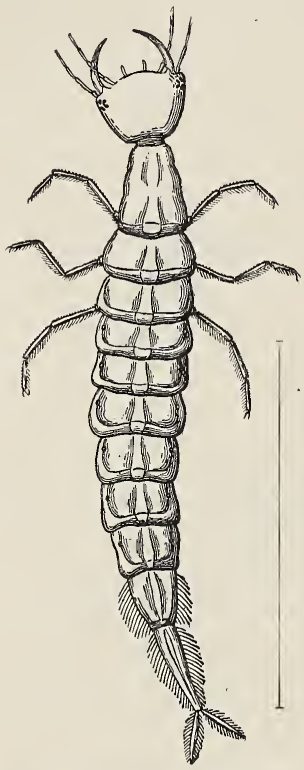

Fig. 4.-Larva of Dytiscus, dorsal view. tapering towards the head and tail.

The head is nearly circular, flat, and joined to the thorax by a distinct neck. The mouth-parts are those of a carnivorous Insect. The mandibles in particular are slender, curved, and pointed. On the inner or concave side of each is a longitudinal slit, which was long supposed to possess a very special importance as being the only passage leading in to the mouth.

Swammerdam says of the Dytiscus larva, and his account is, I believe, exactly true: "When it feeds, it seizes its prey with the mandibles, and pierces it with their sharp, curved points. Now the tips of the mandibles are hollow, and through them the larva sucks the blood in a singular fashion into the mouth, into which the channels of the mandibles open. Since the larva and its jaws are in some degree transparent, we can see the blood flow from the mouth into the 
stomach, especially if the victim has red blood. . . . When the mandible is examined by the microscope, we see that it runs out into a sharp point and is somewhat curved. In cross section it appears sharp-edged, flattened on both sides, and convex along its outer border. The opening by which fluids are drawn in is

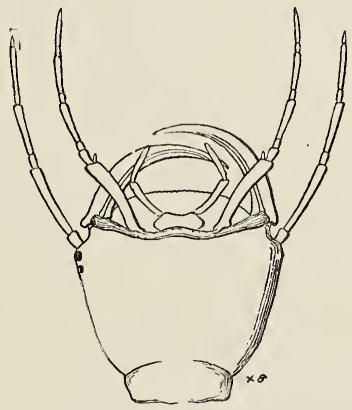

Fig. 5,-Head of larva of Dytiscus, from bencath.

near the tip, and forms an elongate slit, fringed by fine hairs." 1

De Geer tells us that on examining the mandible by the microscope he found the slit described by Swammerdam. "But," he continues, "is there no other mouth? I believe that there is, and that this mouth lies between the lips (labrum and labium). As proof of this I have seen a Dytiscus larva not only suck a Crustacean, ${ }^{2}$ but little by little devour all its

1 Biblia Natura, Vol. I. p. 325.

${ }^{2}$ Cloporte; the word is elsewhere applied to an Asellus. 
solid parts, which assuredly could not pass through the fine openings of the mandibles." 1

Other examples of perforated mandibles were also described. Réaumur, ${ }^{2}$ in his account of the Ant-lion (Myrmeleon), affirmed that this predatory larva had no true mouth, and that the juices of its victims could be absorbed only through the hollow mandibles. When he comes to the lace-winged flies (Hemerobida) ${ }^{3}$ he says of them that they have mandibles like those of the Ant-lion. This statement has been confirmed by Ratzeburg, who compares the mandible of the Hemerobius-larva to the poison-fang of a serpent, and says that he saw fluids pass along the internal cavity. The larva of Gyrinus furnishes us with another instance.

Siebold ${ }^{5}$ at length combined these statements in the following sentence: "The mouth of the larvæ of Myrmeleontidæ, Hemerobidæ, and Dytiscidæ is of very singular construction. There is no oral opening, and the mandibles and maxillæ are altogether unfit for mastication, the mandibles being converted into two curved hooks, which are hollow and provided with a narrow fissure at their tips. The larva bury these hooks in the Insects which they seize, and through the cavities of the organs, which communicate at the base with the asophagus, suck the blood." Siebold's authority gave fresh currency to this state-

1 Mémoires, Tom. IV. p. 386.

2 Tom. VI. p. 340 (I742). 3 Tom. VI. p. 382 (I742).

${ }^{4}$ Ratzeburg, Forstinsekten., Bd. III, p. 243 (I844). He does not say that in this larva the mouth is closed.

s Lehrb. d. vergl. Anat. 
ment, which has been repeated many times in textbooks and popular treatises both in old times and very recently.

Meinert ${ }^{1}$ a few years ago was led to investigate all these larvæ afresh. In Myrmeleon and Hemerobius he found that the mandibles are not truly perforated, but only grooved along the inner edge. The groove is converted into a tube by the maxilla. Sections prove that there is a narrow cleft in the usual position of the mouth. In the Dytiscus-larva too a vertical section from back to front reveals the existence of a mouth-passage, and Meinert showed that pressure on the head not only causes the contents of the alimentary canal to flow out drop by drop from the orifices in the mandibles, but also causes an exudation from the true mouth. He passed a fine hair into the slit at the tip of the mandible, and found that it came out at the base, where Westwood had long ago figured a second orifice. In the Dytiscus larva the mandible is traversed by a complete tube, into which the maxilla does not enter at all.

Meinert's description and explanation were fiercely disputed by Schiödte, but confirmed by Dewitz and Redtenbacher. Burgess ${ }^{2}$ adds some curious details of structure. He confirms the existence of a narrow passage between the upper and under lips, but finds that this is ordinarily closed by a "mouth-lock"-a grooved joint such as is used for dust-proof doors.

1 "Om Mundens Bygning hos Larverne af Myrmeleontiderne, Hemerobierne og Dytiscerne." ITid. Medd. Nat. Foren., I 879 , p. 69.

2 Proc. Boston Soc. Nat. Hist., Vol. XXI. p. 223 (1881). 
When the mandible is extended, its basal opening is outside the mouth, but when it is closed the basal opening is brought into the corner of the mouth, and then the larva sucks up the blood of its victim as a
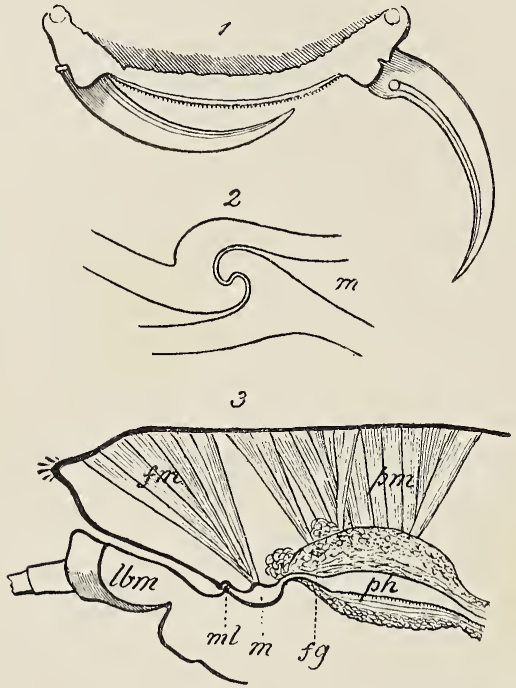

FIG. 6.-Structure of mouth of Dytiscus larva. x. The mandibles, one extended, the other closed. 2. Section of mouth-lock ; $m$, mouth. 3. Section through mouth and pharynx ; $l \mathrm{~lm}$, labium ; $m l$, mouth-lock ; $m$, mouth ; $p h$, pharynx ; $f m, p m$, muscles. From Burgess.

man might suck up water through a straw. It is easy, he adds, to open the mouth with a pair of forceps. The fitting must be extremely good. Mr. W. F. Baker tells me that when a Dytiscus larva preserved with alcohol is placed in strongly heated 
paraffin, the vapour of the alcohol escapes by the tips of the mandibles and by every other opening, as trains of minute bubbles, but none appear at the mouth.

I have lately verified by dissection the chief points of Burgess's description. While doing so it occurred to me to try whether the mouth-lock acted automatically, opening when the mandibles opened, and closing when they close. Accordingly two larvæ were taken, one having the mandibles closed, while in the other they were forcibly extended by a piece of pith. Longitudinal median sections of each were cut and mounted, when it appeared that in the larva with closed mandibles the mouth was completely closed, while in the larva with open mandibles a passage about $05 \mathrm{~mm}$. deep in the narrowest part was immediately apparent. There has not been time to repeat the trial, but I believe that reliance may be placed upon this test case.

It seems that the mouth-apparatus of the Dytiscuslarva is employed in the following way. When a living victim has been seized by the mandibles, they close upon it and pierce it, the base of the mandible with the hinder orifice of the canal being at the same time brought into the corner of the mouth. The mouth-lock is by the same action closed, and then the pharyngeal pump can be employed to suck the blood. But if the larva should require to swallow solid morsels, as it occasionally, though rarely, seems to do, the separation of the mandibles would immediately relax the mouth-lock and give them passage into the stomach.

Almost ail kinds of aquatic animals, Snails, Worms, 
Insects, Tadpoles, and Fishes are devoured by the insatiable Dytiscus larvæ. Many a raw naturalist has put them into his collecting-bottle or aquarium, to find after a few hours that they have destroyed or mutilated almost his whole live stock.

The legs are long, and fringed with hairs, so that they form efficient oars. When the larva swims about in a leisurely way, the legs are the chief means of propulsion. But it can also make a sudden spring, by throwing its body into serpentine curves. It may also be seen to creep on submerged leaves, and to cling to them when resting or lying in ambush. The legs end in double claws, which are probably useful in seizing the prey as well as in supporting the body. Some other predatory Coleopterous larvæ (Carabidæ and Gyrinidæ) have them too, but they are not common in larvæ of this order.

The last segment but one is much narrowed, and the last still more so. The tip of the tail carries two small appendages. These, as well as the two last segments of the abdomen, are fringed with hairs, which no doubt increase the effect of a stroke given to the water. But these appendages are chiefly used to buoy up the tail, when the larva requires to breathe. The larva is lighter than water, and can only remain below by grasping solid objects. When it lets go, it slowly ascends to the surface, and pushes the tip of its tail into the air. The water rolls off the hairy appendages in a moment, and then the larva is suspended by its tail from the surface-film. The success of the operation depends upon the circumstance that the particles of water hold more power- 
fully to one another than to the chitinous hairs. Chitin, the hard substance of which Insect integuments are formed, is not, as a rule, easily wetted by water. A vigorous effort is required when the larva seeks to draw its tail under water again. While it remains suspended, air can be taken in by two spiracles which occupy the extreme tip of the tail, and lead to the great longitudinal air-tubes. There are seven other pairs of spiracles on the sides of the body, but these are rudimentary and closed. It is only at the time of pupation that they become functional.

At length the larva ceases to feed, creeps into moist earth near the edge of the water, makes a roundish cell there, and changes to a pupa. It is then soft, yellowish in colour, and much shorter and broader than before. In summer the pupal stage lasts only a fortnight or so. In cold weather advanced larvæ bury themselves in the banks, probably pupáting only when spring is at hand. There is however some difficulty in getting full information respecting the process of pupation in the winter or early spring. The full-grown Beetles live through more than one winter, and except in very cold weather they swim about and feed. In this Insect, as in most others, the parts

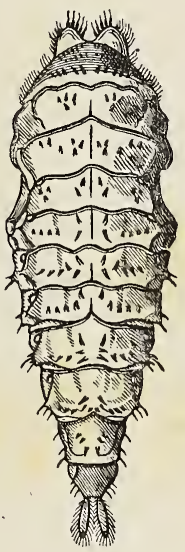

Fig. 7.-Pupa of Dytiscus, dorsal view. From Schiödte. of the imago are all present in the pupa, and are at least externally perfect, though still shrouded in a 
temporary pupa-skin. The head is bent forwards upon the thorax, while the legs and wings are disposed symmetrically on each side of it. There are spines on the prothorax of the pupa, resembling those of the Hydrophilus pupa, but far smaller.

At length the full-formed Beetle creeps out from its dark cell. Though its ultimate form is now attained, the new skin is at first soft and palecoloured. A week passes before it completely assumes the dark chestnut colour, the polished surface, and the firm texture which it is destined to

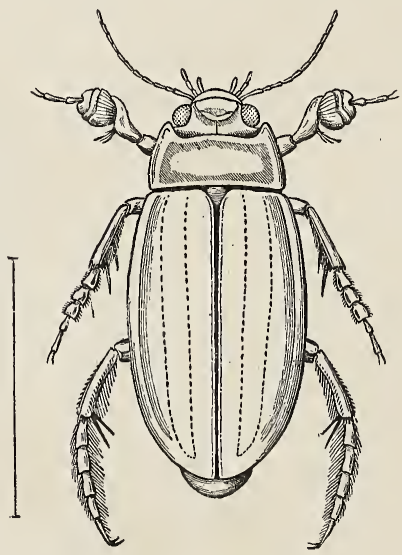

FIG, 8.-Dytiscus marginalis (male), showing suckers on fore legs and smooth elytra.

acquire. The outline of the body as seen from above is regularly oval. The back is gently rounded, the under side angulated along the middle line. The 
head is deeply sunk into the thorax, and does not break the outline. A body so shaped is obviously well fitted for rapid movement through the water,

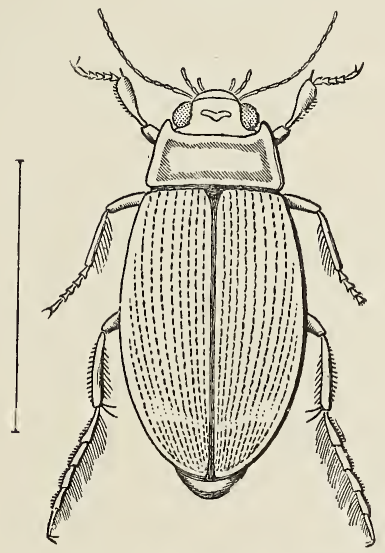

FiG. 9.-Dytiscus marginalis, female.

as well as for easy entrance into narrow spaces. Dytiscus marginalis takes its name from the yellow stripe, which runs along the border of the thorax, the outer edge of the wing-cover, and the front of the head. Many other species of the genus Dytiscus are ornamented in a somewhat similar way.

The mouth-parts are adapted to a predatory life, for the full-grown Beetle is not less voracious than the larva. The mandibles are no longer slender and perforated, but stout and double-toothed. The antennie are rather long and slender, and the compound eyes large. 
On the under side of the first ring of the thorax the keel-like prominence is formed by a backwarddirected spine, which fits into a cavity in the second ring. This spine contributes to the rigidity of the body, like the deeply sunk head, the peculiar fixation of the thighs of the hind limbs, and the fusion of the first and second rings of the abdomen (see Fig. II, p. 6o.)

The wing-covers are very stout, smooth in the male, and often furrowed along their length in the female. Beneath them lie crumpled up the ample wings, which can upon occasion easily bear the body through the air. When food grows scarce, the Dytiscus takes to flight, choosing twilight or dark for its journey, and seeks out a fresh pond.

The hind legs are long and specially adapted for swimming. The tibia and five-jointed tarsus are flattened, and furnished with a fringe of long and stiff hairs along one edge. These spread out during the stroke, and are depressed during the return of the leg through the water. The tarsus is so articulated that it rotates a little upon its own axis when moved through the water, presenting its broad face during the stroke and its edge during the return; " in other words, what rowers call feathering the oar is performed by the tarsus of the Dytiscidæ in a most perfect manner." 1 In swimming the hind legs are chiefly used for propulsion. They strike the water together. The middle legs aid the movement, and appear also to guide the animal's course. There is no

${ }^{1}$ Dr. Sharp, on "Aquatic Carnivorous Coleoptera or Dytiscidæ," Trans. Roy. Dublin Society, Ser. II. Vol. II. p. 254. 
sole to the hind foot, and the usual pair of stout claws become rudimentary. ${ }^{1}$ The fore and middle legs are shorter and stouter, the fringe of hairs less conspicuous, and the terminal claws usually well developed.

In Dytiscus marginalis, as in most other species of the family, we find a curious modification of the tarsus of the fore legs of the male, which forms a circular sucker. A similar structure is visible, though much less prominent, in the middle leg of the male. The restriction of these suckers to the male Insect at once suggests that they are accessory reproductive organs, to be distinguished from the many cases of suckers or like organs merely used in creeping on inclined or vertical smooth surfaces. These last occur in Insects of many kinds, in both sexes, and on all the six legs. The clasping suckers, on the other hand, are restricted to the male, are borne only on the fore, or fore and middle legs, and are peculiar to the Coleoptera.

In the fore leg of the male Dytiscus the three first joints of the tarsus are enlarged to form a circular disc ; beyond these are two small and ordinary joints, of which the last bears the usual pair of claws. The same three joints are somewhat enlarged in the middle leg also, and can be used as suckers. They are not however formed into a disc, nor does their peculiar structure catch the cye at the first glance. When the circular disc of the fore leg is carefully examined, we find that its under surface is roughened by a number of minute stalked bodies, which are

1 In some other Dytiscidæ, e.g. in Cybister, the swimming legs are much more powerful than in Dytiscus marginalis. 
54 NATURAL HISTORY OF AQUATIC INSECTS $\mathrm{CH}$. outgrowths of the chitinous integument (cupules, or tenent hairs). The great majority of these are small and close-set, but on the under side of the first tarsal

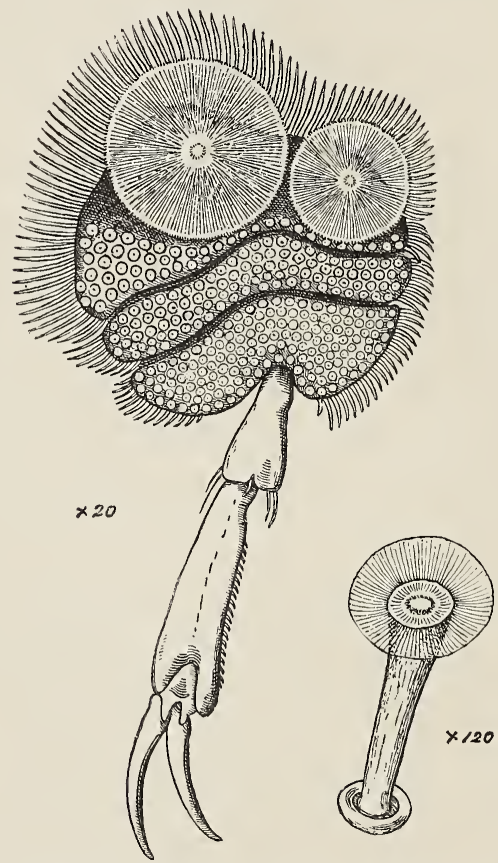

Fig. Io.-Fore leg of male Dytiscus, under side, with sucker, formed of three enlarged tarsal joints. A small cupule, highly magnified.

joint they are replaced by two much larger structures of the same nature (see Fig. IO). The whole sucker, consisting of the three enlarged joints, is fringed 
by stiff pointed hairs. The two large cupules are of unequal size, and carried on stalks which are decply sunk into the integument. Each ends in an umbrella stiffened by many radiating ribs, which project beyond the edge. The umbrella is elastic, and can be pressed out flat without injury to its shape. The smaller and more numerous cupules exhibit the same structure, but the stalk is longer in proportion, and the umbrella much smaller; the ribs minute, and enclosed in the web. The enlarged joints of the middle leg of the male are also furnished with many small cupules. Simmermacher ${ }^{1}$ says that the malc of Dytiscus marginalis has I 70 sucking hairs on each fore leg, and 1590 on cach middle leg.

The adhesive power of the suckers is very great. Plateau ${ }^{2}$ found by actual experiment that a Dytiscus marginalis, fresh killed by ether, when its suckers were applied to a cylinder of smooth glass, could support more than thirteen times its own weight.

Mr. Lowne ${ }^{3}$ has pointed out several facts respecting the suckers of Dytiscus which have escaped the notice of other observers. The cavity of the tarsus, he says, contains a large sac, which is filled with a gelatinous fluid. The bases of the cupules open into this sac, and pressure upon their free ends causes the fluid to cxude. The stalks of the cupules are hollow, and serve as channels for the passage of the fluid.

1 Zcils.f. wiss. Zool. Bd. XI, p. 493. This memoir contains an excellent account of the suckers of Insects in general, and especially of Dytiscus.

2 Ann. Entom. Soc. Belg., Vol. XV. p. 205 (187 I-2).

3 Month. Mirr. Joum., Vol. V. p. 267 (1871). 
When one of the suckers of the fore or mid leg is pressed upon a clean slip of glass, a rather copious deposit of liquid is left behind. It is coagulable and insoluble in water; it solidifies under water, and is not wetted by water. To this account I may add that it becomes opalescent on exposure to air. Mr. Lowne points out that the adhesion of the suckers suffices to support the weight of the Beetle in vacuo, a proof that atmospheric pressure is not the cause of the adhesion of the sucker. Nor can it be the surfacetension of a thin film of water, for the suckers act perfectly well when applied to a glass plate under vater. Since they act in water, in air, and in a vacuum, we can hardly doubt that they act by means of the tenacity of the coagulable secretion. I have tried to exhaust the supply of the secretion by attaching and detaching the suckers many times in succession. After thirty such repetitions, which occupied about half an hour, the adhesive power of the suckers was greatly diminished; when wetted with water, they recovered some of their efficiency, but were much weaker than at first; after thirty more trials they adhered very fecbly indeed.

The cupules discharge the viscid secretion when pressed against a smooth surface, and it becomes a question of some interest how the secretion is discharged at the right moment. The act must be mechanical, not depending upon any nervous stimulus, for the fluid is discharged as freely in a freshly killed Dytiscus as in a living one. It is to be observed that each of the smaller cupules consists of a cylindrical shaft, perforated by a duct, and surmounted by 
a nearly hemispherical umbrella, in the centre of which the duct opens. We can roughly imitate its form by taking half of a hollow india-rubber ball and applying to the centre of its convex surface the end of a glass tube. Pass the tip of a pen-knife through the india-rubber to represent the orifice of the duct. If this rough model is placed on the table, with the edge of the hemisphere downwards, the glass tube may be pressed against the centre of the convex surface until the hemisphere is deeply sunk in the middle. It will then be found that the slit made by the pen-knife gapes, and I believe that this contrivance is employed to discharge the contents of the gland, though direct observation of the action of the natural organ is hardly practicable.

Mr. Lowne finds that the cupules are occasionally torn off by the cementing action of the secretion. On examining with a lens four females taken at hazard, I found that one of them had a number of cupules firmly adhering to the prothorax. ${ }^{1}$

The suckers are no doubt chiefly employed to retain the female, as their restriction to the male sex indicates. They are, however, occasionally used to hold the prey, though this is generally grasped by the middle legs, and torn to pieces by the fore legs. Mr. W. F. Baker tells me that he has seen a male Dytiscus

${ }^{1}$ In the Cypris stage of all Cirripedes the antennule bears an organ which has something in common with the cupules of the male Dytiscus. It takes the form of a cup, and adheres by means of a coagulable secretion, which attaches the animal to its future support. In Cirripedes, however, the cup is a modified joint, whereas the cupules of Dytiscus are modified hairs. 
hold a Gyrinus with the suckers of the fore tarsi until it was devoured. It may be doubted, however, whether the peculiar suctorial structure is useful in this connection; it is certainly not necessary, for the females have no suckers at all. When grasping the female, the fore suckers are applied to the smooth prothorax, and the middle suckers to the unfurrowed margin of the elytra.

The males of many land Beetles (Carabidæ, Cicindelidæ, Silphidæ, and Meloidæ) possess suckers, as well as male Dytiscidæ and Hydrophilidæ, which are aquatic.

We have next to notice the time-honoured explanation of a contrivance supposed to be accessory to the action of the suckers of the male Dytiscus. Kirby and Spence ${ }^{1}$ tell us that "the elytra of the females of many of the larger water beetles (Dytiscus) are deeply furrowed, while those of the males are quite smooth and level. . . A Another aquatic Beetle, Acilius sulcatus, Leach, has not only its elytra sulcated, but the furrows of these and a transverse one of the thorax are thickly set with hair; while the male is smooth and quite naked. Particular care seems to have been taken by the Creator that when all the above inhabitants of the water are paired, the male should be able to fix himself so firmly, by means of his remarkable anterior tarsi ... and these asperities, etc., in the upper surface of his mate, as not to be displaced."

Further inquiry has greatly shaken an interpreta-

1 Vol. III. p. 305 (1826). The authors mention the occasional occurrence of smooth females. 
tion which was at its first promulgation likely enough. Plateau ${ }^{1}$ in particular has pointed out a number of facts hard to be got over, which tell strongly against the old view. (I) Furrows on the elytra diminish instead of increasing the holding power of the suckers. Ground glass and paper do not on trial act so well as polished glass. (2) The suckers of the male are not applied to the furrowed part of the elytra at all, but to the prothorax and the smooth edges of the elytra. (3) Females with smooth elytra occur now and then in England, and the male can hold these as well as the common form. Sometimes the male has furrowed elytra, and it is said that this is apt to be the case in cold ponds, ill supplied with food. Camerano ${ }^{2}$ says that the sculpturing on the elytra of the female is not constant, but becomes less marked in southern countries, and Redtenbacher ${ }^{3}$ adds that around Vienna the smooth females are as common as the furrowed ones. Many new explanations have been offered of the furrowed elytra, but none seem to carry conviction. It is to be noted that the Carabidæ (carnivorous land-beetles allied to Dytiscidx) commonly have furrowed elytra in both sexes.

The bases of the hind legs are very broad, and soldered to the under side of the body. This increases the rigidity of the body, and also removes the articulation of the hind legs from the margin to the centre of the Insect. There is no doubt some mechanical advantage in this, but I am unable to explain what

1 Ann. Entom. Soc. Belg., Vol. XV. p. 205 (187I-2).

2 Atti. R. Acc. Torino, Vol. XV. Quoted from Simmermacher.

${ }^{3}$ Fauna Austriaca, Die Käfer. 
it is. If the bases of the hind legs were frec, water

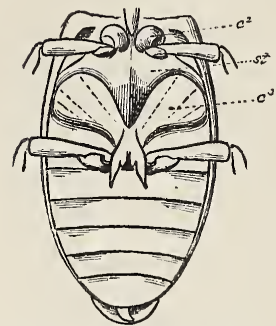

FIG. Ir.-Under side of Dytiscus, showing the bases of the middle and hind legs, $c^{2}$, coxa (basal joint) of middle leg; $c^{3}$, coxa of hind leg, very large and immovably united to its fellow and to the metasternum, st. would be squeczed out between them and the body with some force. The progress of the Insect through the water would probably be impeded, especially if the escaping water passed out forwards.

When the Dytiscus wishes to come up to breathe, it need only ccase to exert itsclf in any way. Its body, which, like that of the larva, is lighter than water, then rises slowly and steadily to the top. The tail is tilted a little upwards, which shows that this end of the body is more buoyant than the rest. A quantity of air is always lodged beneath the wingcovers. This clings to the felted hairs which cover the back of the abdomen, and forms a large flattened bubble. When the Beetle reaches the surface, its tail-end at once pushes through the air. Then the wing-covers are slightly raised, and the air concealed by them is renewed. The two last spiracles, which rise above the surface of the water when the Beetle is engaged in breathing,

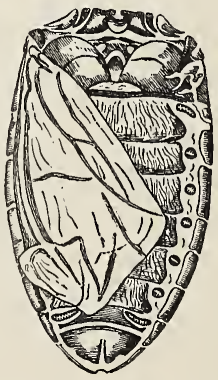

FIG. 12.-Abdomen of Dytiscus, seen from above after removal of wing. covers and one wing; the spiracles are seen on the right border. are unusually large. The smaller spiracles in front 
of these draw air from the supply which is lodged beneath the wing-covers, and this they can do at all times even if the Beetle is submerged.

When a Dytiscus is captured, it often discharges a milky fluid from the thorax, just behind the head. The fluid smells like sulphuretted hydrogen ; whether it has any peculiar taste or not, naturalists have not, I believe, tried to ascertain. At the tail-end again are two anal glands which can suddenly discharge an unpleasant ammoniacal fluid of yellow colour, and this, there can be little doubt, is a startling proceeding, which may often cause a bird to drop the Beetle which it has seized. ${ }^{1}$ The white fluid is most abundant in fresh-caught specimens; the yellow fluid in captives.

The Dytiscidx are long-lived and have been kept several years in captivity.

\section{The Great Water-beetle (Hydrophilus).}

The Great Water-beetle, Hydrophilus piceus, has attracted the attention of some of the most eminent

1 Many Carabidæ and some other Beetles, e.g. Timarcha, eject a fluid, often of unpleasant odour, from the mouth, when first captured. Brachinus discharges a pungent and explosive liquid from the anus. Cantharis, Meloe, Gyrinus, etc., emit a fluid from the leg-joints. Ilybius fuliginosus emits a strongsmelling fluid. Ponds containing the Beetle can be distinguished by the smell, even if the Insect is not visible. Gyrinus, besides the fluid emitted from its joints, secretes a sticky white paste, of pungent odour, from its tail. It is probably this which is used to fasten the eggs to leaves. 
naturalists of past generations. Chief among them is the celebrated Lyonnet; who gives an interesting account of the larva and pupa. In this, as in other cases where classical memoirs are cited, I think that a short account of the author may be acceptable to some readers.

The work on which Lyonnet's fame mainly rests is his memoir on the larva of the Goat Moth (Traite Anatomique de la Chenille qui ronge le bois de Saule I760). No anatomical study shows greater fidelity and skill. The dissections of the head of the larva are truly an extraordinary feat, and will never be surpassed. Modern treatises on Comparative Anatomy continue to reproduce some of these figures, such as the general view of the viscera, the structure of the leg, and the digestive tract. Nearly the whole interest of the volume lies in the plates, for the text is little more than a voluminous explanation of the figures.

It is not without surprise that we find that Lyonnet was an amateur, who had received no regular training either in anatomy or engraving, and that he had many pursuits besides the delineation of natural objects. He was brought up for the Protestant ministry, turned to the bar, and finally became cipher-secretary and confidential translator to the United Provinces of Holland. He is said to have been skilled in eight languages. His first published work in Natural History consisted of remarks and drawings contributed to Lesser's Insect Theology (1742). About the same time, Trembley was prosecuting at the Hague his studies on the freshwater Polyp, and 
Lyonnet gave him some friendly help in the work. Those who care to turn to the preface of Trembley's famous treatise (Mémoires pour servir à l'histoire des Polypes d'eau douce, I744) will see how warmly Lyonnet's services are acknowledged. He made all the drawings, and engraved eight of them himself, while Trembley is careful to note that he was not only a skilful draughtsman, but an acute and experienced observer. When the work was begun, Lyonnet had never seen the operation of engraving a plate. Wandelaar, struck by the beauty of his drawings, persuaded him to try what he could do with a burin. His first essay was made upon the figure of a Dragonfly, next he engraved three Butterflies, and then, without longer apprenticeship, he proceeded to engrave the plates still required to complete the memoir on Hydra.

Lyonnet tells us that the larva of the Goat Moth was not quite his earliest attempt in Insect Anatomy. He began with the Sheep Tick, but suspecting that the subject would not be popular he made a fresh choice for his first memoir. Enough interest was excited by the Traité Anatomique to call for the fulfilment of a promise made in the preface that the description of the pupa and imago should follow. But though Lyonnet continued for some time to fill his portfolio with drawings and notes, he never published again. Failing eyesight was one ground of his retirement from work. What he had been able to finish, together with a considerable mass of miscellaneous notes, illustrated by fifty-four plates, was published long after his death in the Mímotres du 


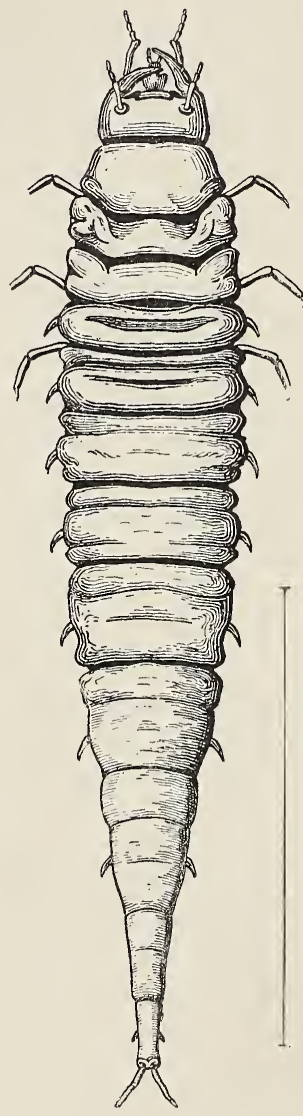

Fig. 13-Larva of Hydrophilus piceus, dorsal view.
Museum (Vols. XVIII-XX). The following account of Hydrophilus is taken from that source.

"A larva, three inches long," says Lyonnet, "was discovered in the middle of August on the grass at the foot of a tree. Its body was soot-coloured, flattened from above downwards, tapering behind and ending in a blunt point. The head was broad, black, and polished. The tip of the tail was provided with two hooks of unknown use, ${ }^{1}$ which possibly enclose the two filaments which the pupa bears in the same place. From the sides projected short and stout spines, directed obliquely backwards. The legs were short and appeared unfit either for running or for swimming with rapidity. The head, armed with

1 It is believed that these tail appendages are accessory to respiration, as in the Dytiscuslarva. 
powerful mandibles, seemed to indicate that the larva was carnivorous, but the slowness of its movements was hardly to be reconciled with this notion. I offered it Insects and plants, but it refused to touch them. This made me conclude, taking into account its uncommon size, that the time for its transformation had come. I therefore put it upon freshly turned up soil, on which I scattered some grass. It made a hole, which it lined with the grass, and remained within it several days in a curved position, lying on its back. When touched it moved actively, but soon resumed its first attitude.

"On the 2nd September, by which time the larva had greatly diminished in size, the skin split along the back up to the head, and there came out a white pupa, which had been wounded on the right side, from which a brown fluid exuded. This wound, how caused I do not know, led to the death of the animal, which happened some weeks afterwards without further change of form.

"Some naturalists would not hesitate to conclude from these facts that the larva in question must be terrestrial, since it was found upon the earth ; further, that it must be a vegetable feeder, for it was creeping among the grass and was too heavy to pursue other animals. It is wise, however, to suspend our judgment until the facts are perfectly ascertained. Both these conjectures prove to be erroneous. The larva is not terrestrial but aquatic; it does not feed upon grass but upon animals.

"In the beginning of July I had noticed in the ditches a kind of cocoon which I did not recognise. 
It was whitish, of the size of the end of the finger, nearly spherical but rather oval and flattened. The surface, which looked like tow, was not quite smooth.
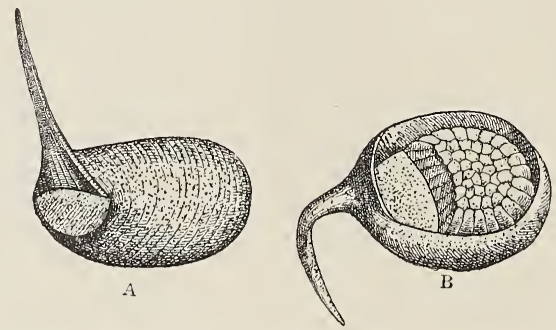

FIG. 14.-Cocoon of Hydrophilus. A shows the mast; B is opened to expose the eggs. From Miger.

One of the two ends was flatter than the other, and furnished with a raised rim. From the space within this rim projected a sort of little tapering mast, about as long as the cocoon.

"I opened several of these cocoons, and found in each about a hundred eggs. They were white and oblong, regularly arranged side by side with the points upward, and though provided with a double covering were so transparent that a day or two before they were hatched one could see the animal within. The head appeared bent upon the thorax as in a pupa.

"The larvæ, when hatched out, remained one day enclosed in the cocoon before escaping. Then they made an oval aperture in the lower part of the flattened end of the cocoon, and escaped through this into the water.

"One remarkable circumstance was that before 
they had taken any food they swelled out to three or four times the size of the egg from which they had emerged. The young larva is mouse-coloured, and the whole of the body transparent except on the sides.

"I took about thirty larvæ from the brood on the 8 th of July, and fed them with very small watersnails, which they devoured in the same way as the full-grown larvæ do. The larva seizes the snail with its mandibles, then bends its body backwards, and rests the snail upon the broad back, which serves as a table. In this position, holding the snail in its legs, the larva breaks up and devours it. When small snails were not to be had, the larvæ managed very well with large ones cut into pieces, and also with tadpoles. If food ran short, they devoured one

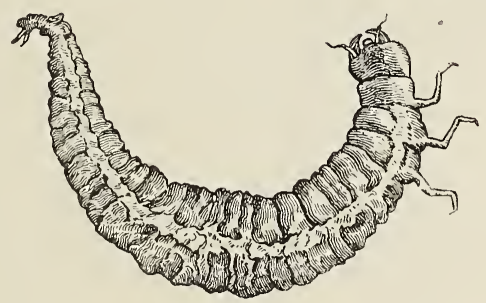

FIG. 15.-Larva of Hydrophilus piceus, from Lyonnet, showing characteristic bent att itude.

another, though at other times they lived quietly together, so that I have seen them share tadpoles without disputes. They appeared even to like one another's society. 
"They never remain long at the bottom of the water. Air is necessary for them, and this they take in by the tail, which they raise from time to time to the surface of the water. If they are by any means prevented from passing their tails into the air they become greatly agitated." [As in the larva of Dytiscus, the only functional spiracles are the last pair, opening at the tail.]

"The larva," continues Lyonnet, "moults three times after escaping from the cocoon. It is well known that when Insects

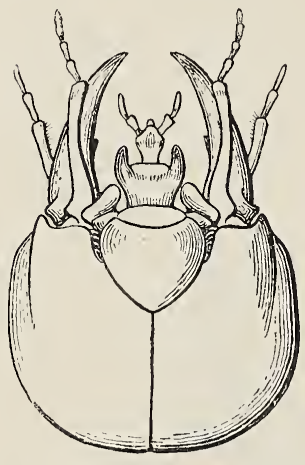

FIG i6.-Hexd of Hydrophilus larva from under side. are about to moult they remain for some time inactive and without feeding. At this time there is forming within the old head, the neck, and the hard envelopes of the legs, a new armour, destined to replace that which is about to be cast off. The new armour, before it has been exposed to the air, is often quite soft. As soon as the body is freed from the old skin, it becomes considerably dilated. The Insect is still obliged to remain two or three days without eating or exerting itself actively, because many of its muscles are not as yet firmly attached. Just after a change of skin the head and thorax of Hydrophilus are white, and one can then see distinctly on each side of the 
head six small black points, which are the eyes. The head, as it becomes hard, turns black, and it is then difficult to see without a microscope that there are any eyes at all."

Lyonnet reared Hydrophilus larvæ in order to observe the process of pupation and the form of the pupa, but found unexpected difficulties in his way. "One larva," he says, "left the water on the Ist of July, and travelled about my room. I put it back into the aquarium. Some hours later another came out, which I put into a trough with earth and grass. It lived only two days, and such was also the fate of two others. On the 2oth of July I supplied earth to two more, freshly emerged from the water, one of which was larger by a quarter of an inch than the other. They burrowed into the earth, and remained there seven or eight days, when the smaller one came out, and burrowing again at least three inches deep, made a cell in which it stayed for two or three days, lying on its back. Either my too frequent attempts to see it, or some other circumstance, caused it to destroy its cell, and this Insect also perished. About the same time another larva which had begun to make a cell destroyed it, apparently for the same reason, and formed a fresh hiding-place in the earth. There it made a new cell with a place of escape on one side. On the 24th of August I removed the earth which concealed it, and found the Insect changed into a white pupa, though it was unable to free itself from the larval skin. I endeavoured to help it. It was easy to remove the bits of old skin which clung to its body, but I did not venture to 
free the legs for fear of breaking them off. The head was still entirely enclosed in the larval integument, and this was so hard that I had great difficulty in removing it. I succeeded, however, without wounding the pupa, but the head, being too tightly packed in the corresponding part of the larva, had not assumed its natural form, and instead of being bent upon the thorax was stretched out. Moreover, the legs, some of the tips of which I had broken off in trying to free them from the larval skin, had taken neither the form nor the arrangement suitable to the pupa. Hence this Insect also was unable to complete its transformation.

"The difficulties which I had encountered in procuring healthy pupæ made me suspect that I had not given them earth sufficiently damp, and that the skin of the larva must be slightly moistened in order that the parts of the pupa may free themselves without injury. I therefore took a larva which had been wandering for fifteen days here and there on the ground without offering to enter it. I placed it in a large leaden box filled with earth much damper than before. The larva entered the earth, and some days after changed to a well-formed white pupa. On each side of the head (on the fore part of the prothorax) were three brown strong hooks. Two others of the same kind were found at the hinder end of the body. These hooks being solid can contain no part of the perfect Insect. I can imagine a would-be philosopher saying, 'Tell me, you who suppose that everything has its purpose, and that nothing comes by chance, what is the usc of these hooks? It seems hardly 
possible that they can have any use at all, seeing that they are possessed for a few days only by a pupa buried in the earth, and that they are left behind when the beetle emerges.' Such reasoning only carries

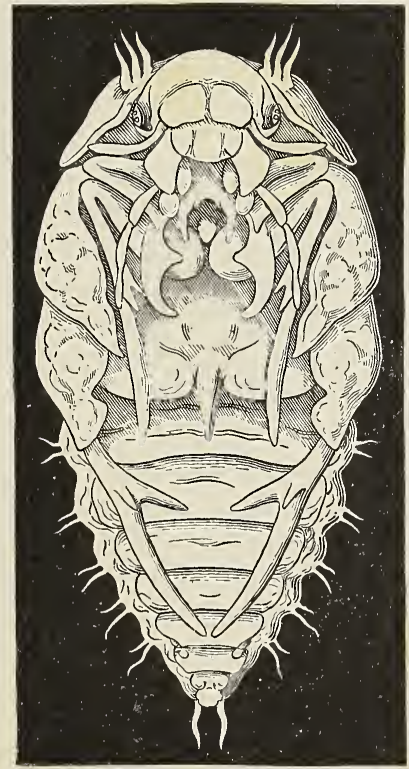

Fig. 17.-Pupa of Hydrophilus piceus, ventral view. $\times 2$.

weight when it is employed by one who has a minute and intimate knowledge of the structure of the animal, and of all its external circumstances. Since neither the questioner nor myself possesses this knowledge, 
we should do better to say to ourselves: 'Every time that our weak perceptions have enabled us to read the purpose of Nature, we have found the marks of a wisdom superior to our own. It is therefore rash and arrogant to pronounce useless structures whose purpose we are unable to assign. Although we cannot imagine of what use these hooks can be to a pupa buried in the earth, we may be well assured that they have a definite purpose.' We shall presently see that these parts are so necessary that the pupa would run some risk of perishing if it were deprived of them.

" This Insect, although aquatic, breathes air. In its larval condition, as we saw, it brings its tail from time to time to the surface of the water. In the pupal state it can no longer move its limbs, and it is this apparently which compels it to leave the water in order to undergo its transformation. It crecps out upon the shore of the pond or ditch in which it has hitherto lived, and there, in some moist place, it digs out a cell, whose walls it secures by pressure, and probably also by gluing them together with a tenacious substance which is seen to exude from the hinder part of the body when the Insect is annoyed. Within its cell the Insect rests for a time. Its body swells up, and at the same time shortens. The new parts form beneath the larval skin, which at length splits, and the pupa emerges. This it does with ease when the skin is moist, but with great difficulty, as we have seen, when it has become dry. It was the lack of moist earth which explained why several of my larve refused to enter the ground; why others, having entered it, came out again, and why yet others perished 
because they were unable to free themselves from the larval integument.

"In the damp earth which the pupa requires, the hooks described above fulfil a purpose unexpected by us, but at the same time of great importance. The skin of the pupa is very delicate. Lying on damp earth it could hardly escape injury, and the weight of the body might easily give it a distorted shape. But the pupa protects itself from these dangers by assuming an unusual attitude. It extends itself back downwards in a horizontal position, and supports the weight of its body by the three sets of hooks as upon a tripod. In this attitude, though surrounded on all sides by moist earth, it keeps its body from actual contact with any object until it has assumed its final shape.

"Thus we see how necessary are those hooks, which at first sight appeared so useless. To decide that this or that structure is superfluous because we cannot guess its use is truly ridiculous in beings whose information is so limited as ours."

Lyonnet's observations on the attitude of the pupa and the use of the hooks are confirmed by the later observations of Miger. The pupa of Hydrobius supports itself upon the floor of its cell in a similar way, though here the spines cover the whole of the back.

"The pupa," continues Lyonnet, " is provided with spiracles along the sides of the body, and these lead us to suppose that it changes its mode of respiration, and breathes in the pupal stage, not by the tail, but by the sides of the body, as in many other Insects.

"When the time for the last transformation arrives, 
the eyes assume their black colour. Then the tips of the mandibles, the claws of the foot, and lastly the head and thorax take a brown colour. The legs darken, the pupal skin is torn open, and a darkcoloured Beetle emerges, destined to live henceforth in the water."

Miger adds that the perfect Insect remains several days underground before attempting to escape. At length it forces a passage through the earth, being aided by the flexibility of its wing-covers, and the compressibility of its segments, which have not as yet acquired any considerable degree of firmness.

The adult Hydrophilus may attain a length of over $\mathrm{I} \frac{3}{4}$ inches, and a breadth of about half as much $(45 \times 20 \mathrm{~mm}$.). With the exception of the Stagbeetle it is the largest British beetle. The elytra or wing-covers are, like the rest of the upper surface, of a dark olive green. They are marked with faint longitudinal sunk lines alternating with rows of dots. The male Beetle is distinguished by the last joint of the tarsus, which is dilated into a triangular plate, and is believed to serve as a clasper. The species is not uncommon in stagnant water near London, and in the southern counties.

Hydrophilus often leaves the water by night, and flies abroad. In winter it hibernates, burying itself in the banks of the ponds which it inhabits. It is by no means so powerful a swimmer as a Dytiscus. The legs are less expanded, and are worked alternately instead of simultaneously, so that the motion is wavering and unsteady. The thorax and abdomen are bevelled off to an angle on the middle line of the 
under surface, and here is found a stout and long spine projecting backwards from the last thoracic ring, which has been known to wound the hand when the Beetle is carelessly held.

The mode of respiration of the adult Hydrophilus is highly peculiar, and altogether different from that of Dytiscus. It was first adequately described by Nitzsch, ${ }^{1}$ whose account I find to agree in all essentials with the facts which I have myself observed.

In adult Beetles there are usually two pairs of thoracic spiracles (mesothoracic and metathoracic), and from six to eight pairs more are borne upon the anterior segments of the abdomen. Hydrophilus and Dytiscus have each seven pairs of abdominal spiracles. In Hydrophilus the foremost of these is large, and those behind small, while in Dytiscus the last of the series, near the hinder end of the body, is much larger than those in front. When the Insect rises to breathe, the hinder end of its body is inclined upwards towards the surface of the water. In this position the hindmost pair of spiracles give the readiest access to the great air-tubes which run along the body, and it is these which are enlarged. The large spiracles of Hydrophilus however are not found at the tail end of the body, but at the fore end (thoracic and first abdominal), an arrangement which is convenient for the taking in of air by the fore part of the tracheal system.

Both in Dytiscus and Hydrophilus a large part of the surface of the body is adapted to receive and

1 Archio fur die Physiologic, von Reil und Autenrieth. Bd. X. pp. 4†०-458, pl. 1X. (I811). 
retain a pellicle or flattish bubble of air. Close-set hairs are the simple means employed to prevent the wetting of these particular tracts. Wrap a strip of velvet round a stick, and dip it into water, or sprinkle a few drops of water on a scrap of velvet. You will see with what difficulty the water penetrates the narrow spaces between the threads which form the pile of the velvet. Close, outstanding hairs play the same part in many an aquatic Insect.

The air-space beneath the wing-covers of Dytiscus is described in connection with that Beetle. Hydrophilus has a similar reservoir of air upon its back, but it has in addition a peculiar and extensive reservoir on its ventral surface.

On the under side of a Hydrophilus we can readily see the hairy tracts which retain the film of air. They cover the thorax and fore part of the abdomen on each side. A prominent ridge along the middle line, which ends in the spine mentioned above, is free of hairs ; so are the greater part of the abdomen and the thighs. The rest of the ventral surface is overspread in the living and submerged Beetle with a film of air, which glistens like silver. The superficial airtracts extend also along the sides of the thorax and abdomen, being bounded above by the overhanging edges of the prothorax and wing-covers, and join the reservoir of air on the back. The air-tracts appear as transverse silvery streaks behind the head and across the base of the wing-covers.

The spiracles open into these air-spaces, and the submerged Hydrophilus replenishes from this source the air within its body by a gentle rhythmical move- 
ment of its abdominal segments, drawing in pure air and breathing out the air vitiated by the oxidation of the tissues. After a few minutes, more or less accord-

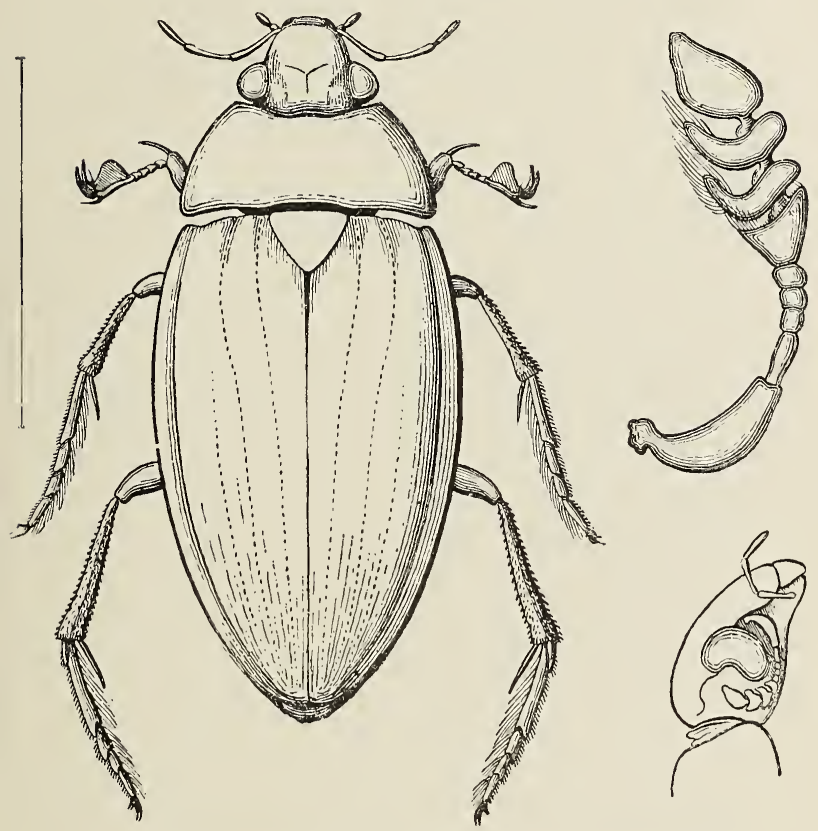

FIG. I8.-Hydrophilus piceus, male. Antenna (enlarged), and side view of head with antenna in place.

ing to the activity of the Insect, the imprisoned air within and without the body has become sensibly impure, and then a fresh supply must be obtained 
from the atmosphere. The Hydrophilus creeps or swims to the surface, and without difficulty assumes a nearly horizontal position. Then the body is inclined a little to one side, so as to bring the angle between the head and the prothorax on one side of the body to the surface. A funnel-shaped depression instantly appears at this angle. If the Beetle is alarmed or suspicious, it sinks after a momentary gulp of air, but if perfectly tranquil it may remain for several minutes at the surface, drinking in air energetically. The funnel-shaped depression remains unchanged throughout the whole operation; the abdominal segments appear to move in and out, and are alternately flattened and arched. There is also a corresponding depression or elevation of the wingcovers. During these various movements, which all co-operate to enlarge or contract the air-spaces enclosed within the body or lying beneath the wing covers, the air-film on the ventral side may be seen to dilate and contract alternately, and the body of the Insect rises and falls a little. The channel of communication between the spiracles and the funnel of admission is bounded only by water on the under side, yet the free passage of air is never checked.

We have next to consider how the funnel-shaped depression by which the air passes in and out is formed and maintained. The mere rising of the Insect to the surface is not enough, nor is it enough to bring one part of its air-bubble, where it is enclosed by a mere film of water, to the surface. A film of small extent might preserve its continuity for some time, and so exclude the air, especially if the water is 
in any degree impure, as must often be the case with the water of a ditch or pond. The convenience, and at times the safety, of the Hydrophilus require that the moment it rises to the surface the film should burst, and place the enclosed air in free communication with the atmosphere. Hydrophilus possesses in its antenna an instrument for breaking the film certainly and without delay.

This antenna consists of nine joints. The basal joint is large and curved, the next four joints smaller and forming a flexible stalk. All these are readily wetted by water, and serve, so far as is known, merely as a handle to direct the movements of the terminal joints. The terminal joints are four in number. Each is dilated, except just where it is attached to the joint beneath, and curved into a semicircular plate. The enlarged joints form what looks like the clubbed end of the antenna, which is not really by any means so solid as it appears at first sight. They are fringed on their concave sides with long bristles, and are uniformly covered with fine short hairs, which cannot be wetted by water.

The ordinary position of this antenna in the submerged Beetle is horizontal, and extended in a gentle curve. Springing just in front of the compound eye, it passes backwards to the overhanging edge of the prothorax. The four terminal joints lie in the air-space; the smooth basal joints are immersed and wetted by the surrounding water.

When the Hydrophilus comes up to breathe and directs upwards the very adjustable cleft between its head and prothorax, the antenna of the same side 
is bent outwards. At the same time the enlarged terminal joints hang downwards and form a well.. marked angle with the rest of the antenna. The film which bounds the imprisoned air is thus drawn upwards and outwards in the cleft, following the movement of the antenna to which it clings. As soon as any part of the unwetted terminal joints comes to the surface, the film breaks, and a passage is instantly opened from the air above to the air-space beneath. The air-passage is enclosed between the hairy side of the body and the vertically arranged antennal joints, neither of which can be touched by water. The size of the opening is determined by the relative position of the antenna and the side of the body; the shape of the opening mainly by the tension of the surface film and the varying pressure of the water. It may give a better idea of the action of the antenna to compare it to an arm, bent at the elbow and with the hand hanging down, held at a little distance from the side of the body, to ward off, not a blow, but the water which would otherwise enter the wider part at least of the cleft between the head and prothorax.

A Hydrophilus may take in air so energetically that the film enclosing the ventral air-space becomes over-distended. Then bubbles escape at the base of the third pair of legs every time the wing-covers descend. Sometimes the Beetle becomes much inconvenienced by the large quantity of air which it has attached to its body, and has to drag itself downwards by clutching the stems of aquatic plants. I once observed a Bectle thus rendered over-buoyant, 
which descended slowly and with great effort, until apparently by the action of the basal joints of its legs it dislodged a good-sized air-bubble. After this it swam about freely.

The antennæ are used only for breathing by the submerged Insect. Their place as feelers is supplied by the long and forward-directed maxillary palps.

The food of the adult Hydrophilus is largely vegetable, but it will prey upon small aquatic animals. As some recent authors have said that the adult Beetle feeds exclusively, or almost exclusively, on animal substances, I may say that four Hydrophili, kept in my aquarium, cleared it completely of small weeds, devouring Nitella especially in large quantities, and that in the absence of all animals bigger than Daphnia they remained healthy and active.

We now resume Lyonnet's narrative: "I was particularly anxious to ascertain how the females constructed the floating cocoon which encloses their eggs. For this purpose I placed a few of these Insects with some Duckweed in a large wooden trough on the last day of May. On the ist of June I saw that one of the females, contrary to its usual custom, was incessantly swimming about, and searching on all sides. I expected that this was because she did not find materials suitable for her work, and as I had often seer a filamentous alga attached to the cocoon, it occurred to me to give her some of this. I floated it on the water by means of wooden shavings, and next day, the 3 rd of June, I found the beginning of a cocoon, but: the Insect soon abandoned 
her work, apparently because she had been disturbed by several other kinds of aquatic Insects, which lurked in the weed. I took them out of the trough, and before long had the pleasure of seeing the female Hydrophilus betaking herself to work under my eyes. I found to my surprise that, like a Spider, she had her spinneret at the hinder end of the body. By extending the hinder rings ever so little, and opening the last of all, a nearly circular cavity appeared, in which I could discover a whitish disc. From this two small brown prominences were given off side by side. Each enclosed a delicate conical tube, about a line in length, and of dark-brown colour, stiff towards its base, flexible and elastic towards the tip. These two tubes formed the spinneret, and each contributed a separate thread. They moved both together, and exactly parallel to one another.

"The construction of the floating cocoon was effected in the following way. At first, lying upside down near the surface of the water, the Beetle buried the hinder part of her body and the two hindermost pairs of legs in the alga, leaving the first pair free, and making use of them to fit and mould the alga to the end of her body. She then began to weave the under side of her cocoon. While the weaving was going on, she was careful from time to time to press and flatten the growing cocoon, moulding it with her fore feet against her body, and so giving it the form of a flattened arch. After the first piece, which was intended to form the upper side of the cocoon, was finished, the Beetle turned over and wove another piece, exactly the reverse of the first, to 
form the under side of the cocoon. The two curved surfaces then were woven together, and the body of the cocoon was finished, the work having occupied about an hour and a quarter. For about two hours after this the Beetle remained still, her back being uppermost. At first her body was buried in the cocoon up to the thorax, but one could now see that she was gradually withdrawing it. During these two hours of apparent rest she laid her eggs, not at hazard, but in regular order, side by side, the pointed ends uppermost. When the work had advanced so far that her body was completely withdrawn from the cocoon, she began to spin about the open mouth of the cocoon, so as to gradually narrow the opening. Then by spinning up and down she closed the end of the cocoon, giving it a truncated appearance. The next thing was to spin a little mast, which gradually rose above the surface of the water, the fore part of the Beetle during this part of the work being constantly immersed.

"I do not know the use of this little mast. Perhaps it enables the Insect to get rid of an excess of silky matter. However this may be, the work was completed in about five hours, after which the cocoon was left floating.

"On the I $5^{\text {th }}$ of July I observed an opening at the foot of the mast, and saw, floating around, whitish skins, either egg-shells, or the envelopes of the larvæ. Next day I saw a small larva emerge, and the day after fifty more. From this point the history of the Beetle has already been traced."

More than fifty years after Lyonnet's observations 
on Hydrophilus, Miger ${ }^{1}$ described the life-history of the large Hydrophilus.

Miger remarks that he was curious to find out how an Insect living under water could construct a cocoon floating on the surface. Early in May 1807 he found several specimens, and placed them in a vessel of water, together with the aquatic plants on which they chiefly feed. At length a female was seen to undertake the formation of a cocoon. Miger saw her attach herself to the under side of a leaf which was floating on the water. She placed her body across the leaf, clasping it with her fore legs. The abdomen was applied to the under surface of the leaf, and the two tubes which form the spinneret could be seen to be pushed in and out rapidly, while a white gummy liquid was passed from them. This liquid was drawn out into threads, which were attached to the leaf, and gradually surrounded the abdomen, forming a semicircular pouch, in which the tip of the abdomen was contained. After about ten minutes the Hydrophilus turned sharply round, letting go the leaf and bringing her head downwards, but without withdrawing the abdomen from the cocoon. The leaf was now held by the hind legs only, one being placed on each side of the cocoon. The work went on steadily for nearly an hour and a half, and through the transparent wall of the cocoonthe movements of the spinneret could be distinctly seen, until the gradual addition of threads made it at last so thick and compact that the movements of the spinneret could no longer be distinguished.

${ }^{1}$ Miger's memoir is to be found in Ann. du Museum d'Hist. Nat., Tom. XIV. (i 809 ). 
Small bubbles of air were then seen to issue from the cocoon. This was due to the displacement of the contained air by eggs, which were laid side by side, and glued together with a white liquid. In three quarters of an hour the egg-laying was over. The Bectle closed the cocoon slightly, and began to form the pointed end. The wing-covers were now a little opened, and their tips brought to the surface of the water. The spinneret was uncovered, and its continuous and rapid movements could easily be followed. The formation of the projection took more than half an hour, at the end of which time the slender tapering point rose about an inch above the water. The whole operation took about three hours.

Miger observes that at the beginning of the work the Hydrophilus is easily disturbed, but when egglaying has once begun she may be removed from the water, and her cocoon cut open with scissors without creating a stoppage.

He placed three females in a vessel of water without any floating object. They were unable to form a cocoon at all, though there passed from their bodies a yellowish firm substance which contained no eggs.

The air which fills the cocoon is derived from the supply carried down by the Beetle. The cocoon is always fixed to a floating object. "It is a mistake," says Miger, "to suppose that the turned-up point of the cocoon serves as a mast. Such a notion could only be drawn from an empty cocoon. It is not unlikely that the drawn-out point serves for the supply of air to the cocoon." 
Miger observes that three kinds of secretions are made use of by the Hydrophilus. There is first a sticky liquid, which when drawn out into threads makes them cling to one another, and forms a compact though flexible envelope. Another fluid serves to glue the eggs together, while the third forms a silky shining tissue, like that of the cocoons of Lepidoptera. This tissue is well suited for the admission of air, but when submerged it allows the passage of water also. The eggs are regularly cemented together side by side in a vertical position. The whole mass of eggs is attached to the upper surface of the cocoon, and has beneath it an air-space, which leads to the opening by which the larvæ emerge. This air-space is only loosely closed by threads which are, however, sufficient to prevent the entrance of the water. Since the relatively heavy eggs are placed high in the cocoon, and an air-space lies beneath, the cocoon is liable to upset unless it is attached to a buoyant body.

As soon as the larvæ are hatched, they swell out to twice their previous size, free themselves from their integuments, and escape into the lower part of the cocoon, where for about twelve hours they move about, one over another.

Some additional particulars respecting the cocoon of Hydrophilus are furnished by Mr. A. G. Laker. ${ }^{1}$ He tells us that the average size is $\mathrm{I} I \frac{1}{2}$ lines $\times 1 \mathrm{IO}_{4}^{3}$ lines, and the height to the tip of the spike about I 7 lines. The cocoons are buoyant, and when floating freely about one third of their depth is out of water.

1 Entomologist, Vol. XIV. p. 82 (I88I). 
They are usually but not always attached to long grass or floating leaves. "The spike consists of a substance somewhat thicker and stronger than the rest of the cocoon, and is hollow throughout the greater part of its length, except that it is crossed and recrossed inside with a dark thread-like substance, thus somewhat resembling a horn stuffed with tow. The apex of the spike does not, however, appear to terminate in an orifice, but is closed. It does not seem to me that this spike can serve as a balance to the cocoon, because the nests are usually attached to some kind of support. I may, however, mention that I cut off the spike from two of the cocoons, and in both these cases the eggs did not hatch ; it is, however, possible that this may have arisen from some other cause, although these particular cocoons appeared to be similar in every respect to others of which the eggs matured in due course. The cocoons from which the spikes were removed subsequently sank. These nests are so constructed that when floating loose the spike retains its proper position, and even if the cocoon be held so that the spike is parallel with the water, and then suddenly released, it immediately rights itself; if, however, the spike be partially submerged and then released, the cocoon turns bottom upwards. The number of eggs contained in each nest is usually between fifty and sixty."

\section{HydROBIUS.}

In shallow, grassy ponds there may commonly be found a little blackish Beetle, about a quarter of an 
inch in length. The body has the oval convex form and shiny surface of a Hydrophilus. The ventral surface is overspread by a bubble of air. The antennæe are clubbed, and used in respiration as in Hydrophilus. On close examination, however, it will be found that the sharp spine, which projects backwards from the under side of the last thoracic segment of the great Hydrophilus, has disappeared in the smaller Beetle, which is the Hydrobius fuscipes of entomologists.

In spring and early summer the full-grown Beetles are abundant. They become scarce in July, and about a month later the new generation, distinguished for a time by the much lighter colour, makes its appearance. In cold weather they bury themselves in the mud. On watching a living Hydrobius, we shall see it bring the cleft between the head and thorax to the surface of the water when it requires to breathe. Here a small funnel-shaped depression forms, and leads air to the ventral surface. The antenna lies in the cleft, and is apparently employed just as in Hydrophilus, though the small size of the Beetle renders it difficult to affirm this with absolute certainty. Living as it does in very shallow water, Hydrobius finds it easy to expose the under side of its abdomen to the air. When this is done, the watery film bursts, and respiration goes on freely. Whether by accident or of set purpose, the Beetle often executes this movement. Even when floating on deep water, it can turn on its back and throw off the water from its abdomen.

The following note, together with a good deal of other information respecting Hydrobius, I owe to 
Mr. W. F. Baker: "Hydrobius is a vegetarian, and may be found in any weed-grown pond, being generally accompanied by another Bectle of like habits, Helophorus aquaticus. One or both of these is pretty sure to be found at the right season in any shallow pond covered with a carpet of Duckweed. In such a pond there will be few or none of the Dytis-

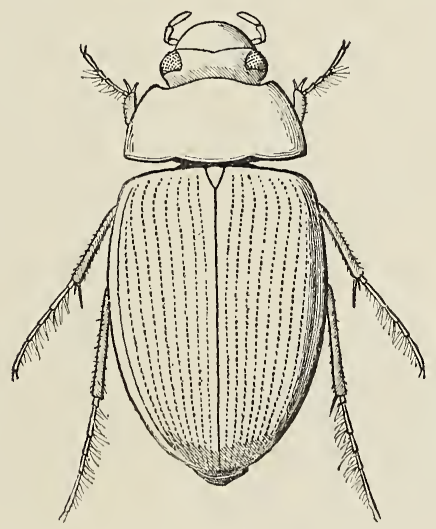

FIG. 19. - Hydrobius fuscipes. $\times 8$.

cidæ (Acilius, Agabus, Dytiscus, \&c.), which prey upon small Beetles, for the mode of respiration of the Dytiscidæ requires open spaces, where they may come to the surface and breathe without obstruction. Any circumstance which discourages these carnivorous Beetles favours the increase of Hydrobius and Helophorus." 
In April the female Hydrobius lays her eggs in white cocoons, which are to be found in great numbers at or close to the surface of the water. They are often slightly attached to blades of grass. The cocoon is about as large as the Beetle which constructs it, and is formed of silken threads woven together in various degrees of closeness. A female may sometimes be found with the unfinished cocoon attached to her body. One end of the cocoon (that first formed) is firm and smooth ; the other end, which the Hydrophilus shapes into a mast, is left loose and irregular by Hydrobius. ${ }^{1}$ From each cocoon several larvæ issue. They are of minute size, but active and intensely predatory. The large head, armed with formidable jaws, which are incessantly opened and closed, reveals at a glance the instincts of the creature. Though constantly immersed in water, the larva, like the pupa and the imago, requires a constant supply of gaseous air. This it draws in by the tail. On the dorsal surface of the tail a number of valves and flaps (see fig. 20) form a shallow cup fringed with longer and shorter setæ, and into this no water can enter. When, as is usually the case, the larva lies in very shallow water, the tail-end is quite dry, and air is freely drawn into the long tracheal tubes, which open under cover of the fore edge of the cup. If accidentally pushed into deep water, the larva hangs from the surface by its tail, breathing all the time, or creeps along the

1 The eggs of Hydrobius hatch out readily when completely submerged and wetted with water. The use of the cocoon in this case appears to be rather to conceal and protect the egg than to secure buoyancy. 
bottom with a large bubble attached to its tail, which clings to it with great tenacity and raises it above the ground. While hanging from the surface the larva
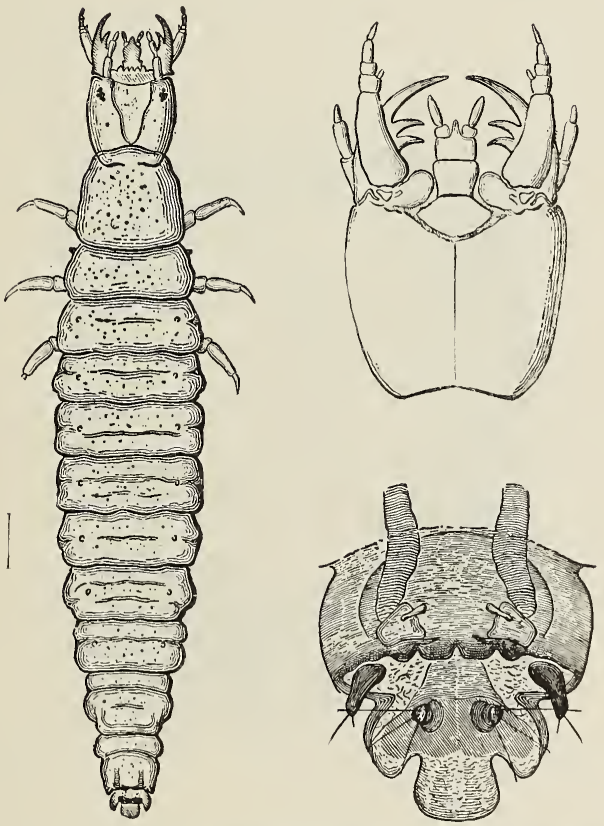

Fig. 20.-Larva of Hydrobius fuscipes (magnified) ; head of do., under side ; tailend, showing respiratory cup and tracheæ.

executes a great variety of movements, bending its body upwards, downwards, or sideways in search of its prey. If kept in deep water for a long time it drowns. 
Not a few aquatic Beetle larvæ breathe after the manner of Hydrobius, though the details of the mechanism exhibit great variety. The larva of the Dipterous fly, Stratiomys, employs the same principle in a somewhat different way. But the closest parallel is furnished by three other Dipterous larvæ, those of

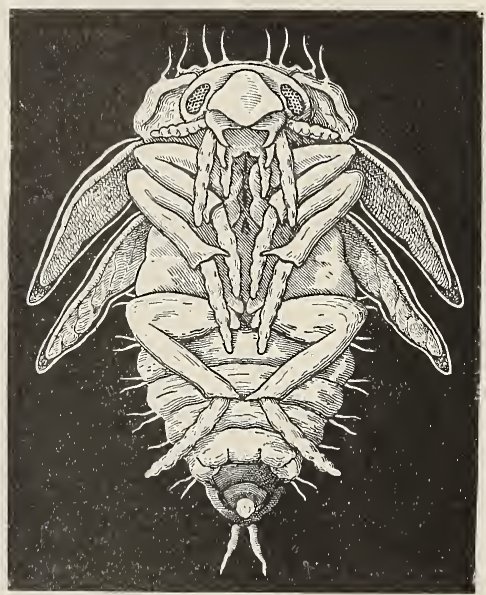

FIG. 21.-Pupa of Hydrobius fuscipes (magnified). The specimen drawn had been preserved in alcohol, which dissolved the cement by which the wings were glued down, and allowed them to be extended.

Dixa, Anopheles, and Pericoma, which are furnished with a respiratory cup much like that of Hydrobius, though more elaborate and more efficient. The older Hydrobius larvæ are altogether buoyant, and when out of their depth swim at the surface in a serpentine manner. 
By the end of June the larvæ begin to pupate, and during July the pupæ may be found in great abundance. The full-fed larva quits the water, and makes a globular hole about half an inch deep in the mud or clay of the bank, six inches or so above the waterlevel. In this hole the pupa lies upon its back, kept from contact with the moist earth by the long stiff spines which stand out from its body. The abdomen is flexible, and can be moved rapidly about when the Insect is disturbed. Some larvæ were found still unchanged six days after leaving the water. Early in August the fully developẹd Beetle begins to show itself in numbers. At first whitish, its colour darkens on exposure to light and air. It throngs the shallow waters until cold weather drives it into the mud, where it hibernates till spring.

Very soon after the emergence of the Beetle the cocoon is formed and the eggs are laid. Hence all the stages may be found together about the end of August-eggs, young larvæ, pupæ, and adult Beetles.

\section{DONACIA.}

The "leaf-eating Beetles" (Chrysomelidæ) include a number of species which pass their early stages upon submerged plants, and feed upon the roots. The white water-lily (Nymphæa), Potamogeton, the Arrowhead, the Sedges, the Marsh Marigold, the Bulrush, the Horse-tail, and other moisture-loving plants yield shelter to the various species of Donacia and its close ally Hæmonia. D. crassipes is often found abundantly upon Nymphæa or Sparganium. The 
female bites small round or oval holes in the leaves, and through these apparently passes the eggs to the under side, where she arranges them in a single or double circle around each hole. The larvæ, when hatched, descend to the bottom, and begin to feed on the roots. They exhibit no obvious adaptations to aquatic life-no swimming organs, no gills, no peculiar shape-but only the dirty-white colour, the semicylindrical figure, the small, hard head, and the three pairs of pointed legs, found in an ordinary larva which buries itself in earth. When full grown, they are about half an inch long. Their movements are very sluggish.

Close examination with a magnifying glass reveals just one peculiar structure. Towards the hinder end of the body, on the 8 th segment of the abdomen, there project from the dorsal surface two slender curved spines, and to the bases of these pass the longitudinal air-tubes, which traverse the whole length of the body. There are also two pairs of more flexible setæ, which fringe the last segments. At the roots of the spines are a pair of small openings, which look like spiracles.

Roots of Nymphæa frequented by Donacia were observed by Schmidt-Schwedt ${ }^{1}$ to exhibit peculiar scars. These were discovered with difficulty, owing to the dark colour and uneven surface of the roots. There was in each case a rough hole, made apparently by the jaws of the larva when feeding, and, at a distance corresponding with the length of the body, a pair

1 Berl. Entom. Zeits, Bd. XXXI. pp. 325-33+, Taf. V. figs. I-I I ( I 887 ). 
of small slits. On microscopic examination these slits were found to penetrate the epidermis of the roots, and to lead to the small irregular air-spaces, which occupy a considerable part of the interior of the roots. Something of this had been previously observed by Siebold, who in 1859 described the larva as biting a hole in the roots of Sparganium, passing the end of the abdomen into it, pressing the spiracles by the help of the curved spines close against the hole, and so drawing the contained air into its body. Schmidt-Schwedt believes that the pair of openings are made not by the mouth but by the spines, and that the air is drawn in by internal channels running along them. ${ }^{1}$

Aquatic Insects often find it a matter of some difficulty to procure a sufficient supply of air, and many ingenious contrivances appear as practical solutions of the problem. None perhaps are quite so remarkable as the present one. That the Donacialarva should have found out the air-reservoirs of submerged roots, and possess special organs for tapping them, is surely one of the curiosities of adaptation.

The pupal cocoon is a close-woven, oval capsule, attached to the same roots as those upon which the larva feed. On the attached side the wall of the cocoon is deficient, and a good-sized hole, previously closed by the root itself, appears when the cocoon is torn away. A number of small holes, penetrating into the

1 Dewitz (Berl. Entom. Zeits., Bd. XXXII. p. 5, 1888) believes that in Hæmonia, and presumably in Donacia also, the spiracles serve for the admission of air to the body, as Siebold maintained. Schmidt-Schwedt has (B.E.Z., I 889) reaffirmed his original statement. 
substance of the root, appear upon the plant when the cocoon is detached, and it is probably from this source that the pupa derives its supply of air. Wounds in the living tissues of the plant are as a rule quickly repaired by a corky growth, but Schmidt-Schwedt found that this was not the case with the holes bored by the Donacia-larva in the roots of the water-lily. They remain open so long as the access of water is precluded by the cocoon, and only become closed by cork when the cocoon is torn open by the emergence of the Beetle. The under side of the adult Insect is protected from wetting by a close covering of silky hairs.

The perfect Beetle appears in early summer; the larvæ feed until autumn, and then pupate. The perfect Insect is believed to remain throughout the winter in its pupal cocoon, for cocoons opened at this season generally contain fully developed Insects and not pupæ. 


\section{CHAPTER II}

FLIES WITH AQUATIC LARVE

\section{The Gnat (Culex)}

SMALL stagnant pools and ditches are the favourite haunts of the larvæ and pupæ of the Gnat. A ditch in a wood choked with fallen leaves is one of the best hunting grounds, and in the summer months they may be found by the thousand in such places.

The larva, when at rest, floats at the surface of the water. Its head, which is provided with vibratile organs suitable for sweeping minute particles into the mouth, is directed downwards, and, when examined by a lens in a good light, appears to be bordered below by a gleaming band. There are no thoracic limbs. The hind limbs, which are long and hooked in the burrowing Chironomus larva, and reduced to a hook-bearing sucker in Simulium, now disappear altogether. A new and peculiar organ is developed from the eighth segment of the abdomen. This is a cylindrical respiratory siphon, traversed by two large air-tubes, which are continued along the entire length of the body, and supply every part with air. The 


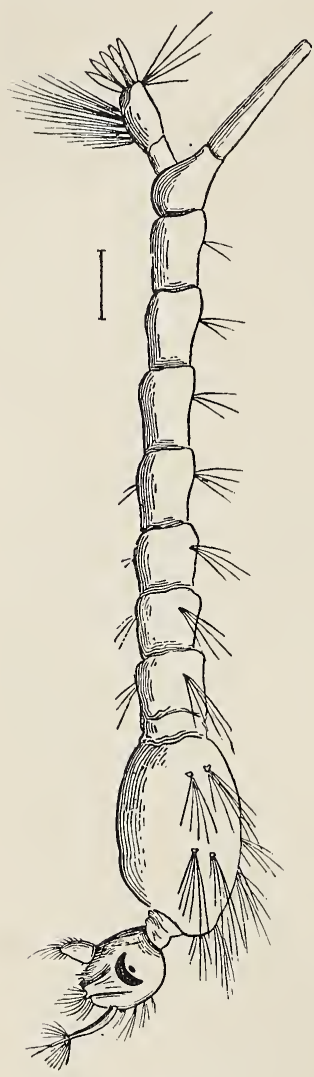

Fig. 22.- Larva of Gnat (Culex), in side view.

larva ordinarily rests in such a position that the tip of the respiratory siphon is flush with the surface of the water, and, thus suspended, it feeds incessantly, breathing uninterruptedly at the same time.

It is of obvious advantage to the larva that it should in this way divide the operations of breathing and feeding between the two ends of the body, for the breathing must be done at the surface, and the feeding beneath the surface. Observe that the arrangement requires one thing unusual in floating objects-viz., that the body shall be, in some parts at least, if not altogether, heavier than water. If it were lighter than water it could not maintain a vertical position, but would lie along the surface like a stick, and would be quite unable to sweep about in search of the minute organisms which inhabit the water beneath. When 
startled, the larva leaves the surface and sinks slowly to the bottom by gravity alone, which shows that the body is denser than the water. It does not willingly remain below for any length of time, but rises by a jerking movement, striking rapid blows with its tail, and advancing tail foremost. When it reaches the top, it hangs as before, head downwards, and resumes its feeding operations.

How is it possible for a larva heavier than water to remain floating at the surface without effort, as the larva of the Gnat certainly appears to do? The possibility of such a thing turns upon the existence at the surface of water or any other liquid of a contracttile surface-film. (See Introduction.) It is the contractile force, or tension, of the film which rounds the rain-drop and the soap-bubble. The film can be stretched over unwetted threads, such as the threads of a piece of dry muslin, or the fine wires of a piece of varnished gauze, and thus supported it will not only refuse to pass through fine meshes, but may be made to hold up a rather considerable weight of water.

If we take a solid body, capable of being wetted by water, and place it in water, the surface-film will adhere to the solid. If the solid is less dense than the water, it will float with part of its surface out of the water. Under such circumstances the surfacefilm will be drawn upwards around the solid, and will therefore pull the solid downwards. But if the solid is denser than the water, its upper surface will be lower than the water-level, and we can arrange matters so that the surface-film around it will tend to pull the 
solid upwards. Suppose that a solid of the same density as water floats with part of its surface in contact with air, and that weights are gradually added to it. The result will be that the surface of the water around the upper edge of the solid will become more and more depressed. The sides of the depression will take a more vertical position, until at last the upward pull of the film becomes unable to withstand further increase of weight. If this point is passed, the solid will sink. Before this point is attained, we shall have the solid, though denser than water, kept at the surface by the pull of the surface-film.

This explanation will be followed more readily with the help of a simple experiment.

Take a float made out of a large cork, weighted by a screw driven into its lower end. To the top of the cork a small glass tube may be attached in a vertical position. The lower end of the tube should be closed and the upper end open. The weight must be adjusted so that the top of the tube is only just out of the water. Then add small weights one by one. Small pieces of sheet metal can be placed by a forceps on the cork. As the weight increases, the tube slowly sinks until it becomes flush with the water. Still no water flows in. We can go on adding weights until the float depresses the surface, as the reflections show, and yet, if the weight is not excessive, the float does not sink. But if we take a loop of thread wetted with water, and draw it across the open mouth of the tube from side to side, the surface-film will be drawn over the hole : then there 
is nothing to keep the float at the surface, and it settles steadily to the bottom. ${ }^{1}$

It is by virtue of this contractile force of the surface-film that the Gnat-larva is enabled to maintain itself, against gravity, at the surface of the water. The tip of the respiratory siphon is provided with five flaps, which can be opened or closed by attached muscles. When open they form a minute basin, which, though its walls are cleft, does not allow the surface-film of water to enter. When closed, the air within the siphon is unable to escape. At the time when the larva rises to the surface, the pointed tips of the flaps meet the surface-film and adhere to it. The attached muscles then separate the flaps, and in a moment the basin is expanded and filled with air. The surface-film is now pulling at the edges of the basin, and the pull is more than sufficient to counterbalance the greater density of the body of the larva, which accordingly hangs from the surface without effort. When the larva is alarmed and wishes to descend, the valves close, their tips are brought to a point, and the resisting pull of the surface-film is reduced to an unimportant amount.

Swammerdam found it necessary, in explaining the flotation of the larva of the Gnat, to suppose that the extremity of its siphon was supplied with an oily secretion which repelled the water. No oil-gland can be discovered here or elsewhere in the body of the larva, and indeed no oil-gland is necessary. The peculiar properties of the surface-film explain all the

${ }^{1}$ I owe this pretty little experiment to the ingenuity of Dr. Stroud. 
2
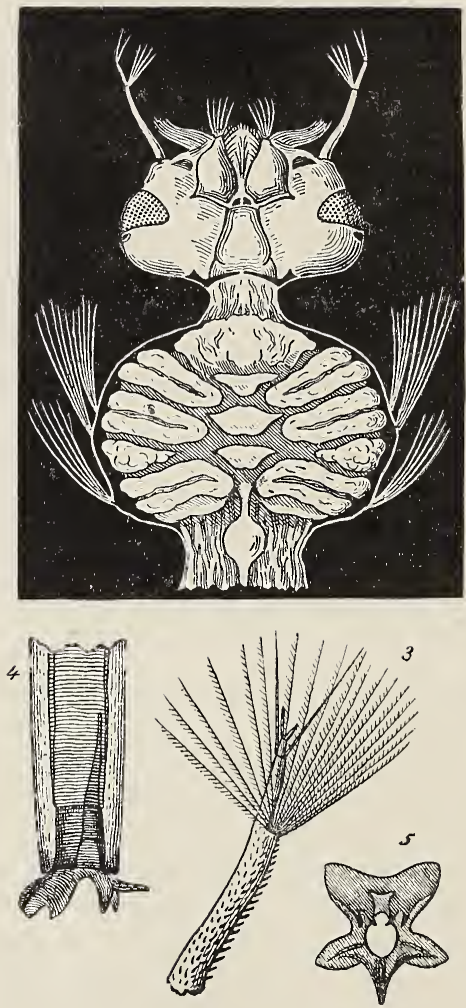

FIG. 23.-Larva of Gnat (Culex). 2, head and prothorax, ventral side. The compound eyes, the folded legs, and other parts of the future fly are seen through the transparent larval skin; 3, antenna of do.; 4, respiratory tube of do.; 5 , extremity of respiratory tube, end view. 
phenomena. The surface-film is unable to penetrate the fine spaces between the flaps for precisely the same reason that it is unable to pass through the meshes in a piece of gauze.

After three or four moults the larva is ready for pupation. By this time the organs of the future fly

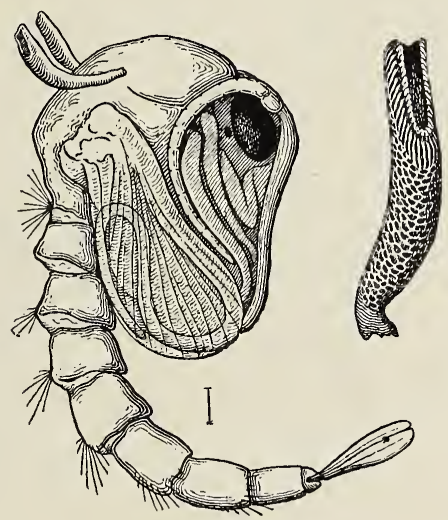

FIG. 24.-Pupa of Gnat (Culex). Respiratory trumpet of do.

are almost completely formed, and the pupa assumes a strange shape very unlike that of the larva.

At the head-end is a great rounded mass which incloses the wings and legs of the fly, beside the compound eyes, the mouth-parts, and other organs of the head. Each appendage has its own sheath (part of the proper pupal skin), and the appendages are cemented together by some substance which is dissolved or softened by alcohol. At the tail-end is 
a pair of flaps which form an efficient swimming-fan. The bod of the pupa, like that of the larva, is abundantly supplied with air-tubes, and a communication with the outer air is still maintained, though in an entirely different way. The air-tubes no longer open towards the tail as in the larva, but towards the head. Just behind the head of the future fly is a pair of trumpets so placed that in a position of rest the margins of the trumpets come flush with the surface of the water. Floating in this position, the pupa remains still so long as it is undisturbed, but if attacked by any of the predatory animals which abound in the fresh waters, it is able to descend by the powerful swimming movements of its tail-fin.

Water is prevented from entering the trumpets by the peculiar hairs which project in great numbers from their inner surface. When the pupa first comes up from below, the trumpets are overspread by a film of water, which, becoming thinner and thinner by evaporation, at length suddenly bursts. ${ }^{1}$

Why should the position of the respiratory organs be changed from the tail-end in the larva to the headend in the pupa? Not only the Gnat but Chironomus, Corethra and many other aquatic Insects exhibit the same phenomenon. Evidently there must be some reason why it is more convenient for the larva to take in air by the tail, and for the pupa to take in air by the head. We have already discussed the considerations which seem to have fixed the res-

1 Useful information respecting the respiratory trumpets and other organs of the Gnat pupa will be found in Dr. C. H. Hurst's papers. (See later, footnote to p. I44.) 
piratory organs at the tail of the larva. Why, then, need this arrangement be reversed when the Insect enters the pupal stage? There is now no feeding to be done, and it surely does not signify how the head

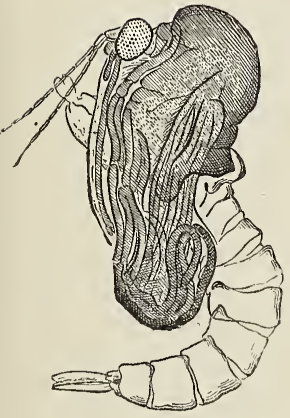

FIG. 25. - Pupa of Gnat (Culex nemorosus), showing the parts of the fly enclosed in the transparent pupa-skin. The head and thorax are just freed from the pupal skin.

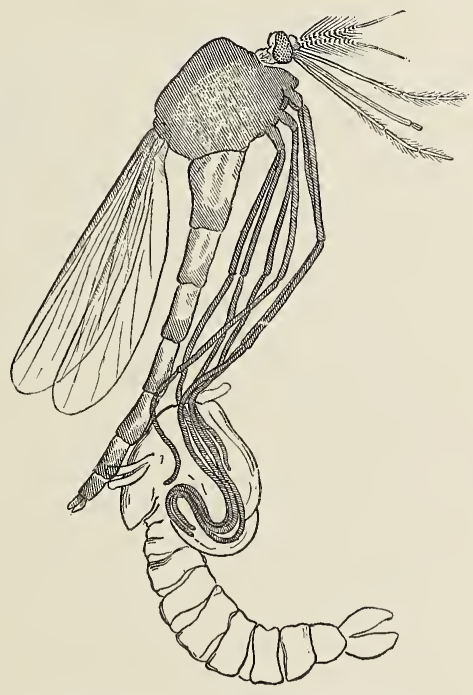

FIG. 26.-Fly o. Gnat (Culex nemorosus) escaping from puipa-skin. This and the preceding figure are from specimens mounted in Canada balsam.

is carried. Why should not the pupa continue to breathe like the larva, by its tail, instead of developing a new apparatus at the opposite end of its body, as if for change's sake? Well, it does not appear that, so far as the pupa itself is concerned, any good 
reason can be given why the larval arrangement should not continue. But a time comes when the fly has to escape from the pupa-case. The skin splits along the back of the thorax, and here the fly emerges, extricating its legs, wings, head, and abdomen from their close-fitting envelopes. The mouth-parts must be drawn backwards out of their larval sheaths, the legs upwards, and the abdomen forwards, so that there is only one possible place of escape-viz., by the back of the thorax, where all these lines of movement converge. If, then, the fly must escape by the back of the thorax, the back of the thorax must float uppermost. Otherwise the fly would emerge into the water instead of into the air. Granting that the back of the thorax must float uppermost in the pupal stage, it is clear that here the respiratory tubes must be set.

The mouth of the female Gnat is provided with a case of instruments for piercing the skin and drawing blood. The foremost of these is a tube split along its hinder side, which lies in front of the rest, and is used in suction. This, though long and slender, is stouter than the delicate parts behind it, and it serves to stiffen and protect them. Then come five long and slender blades of great delicacy. Two pairs correspond to the mandibles and maxillæ of other Insects, though here they are so simplified and attenuated that it is not easy to make out the correspondence. The maxillæ are furnished near their tips with a row of extremely minute saw-teeth. There is also a fifth unpaired implement, which is an extraordinary development of a part of the Insect's mouth which is 


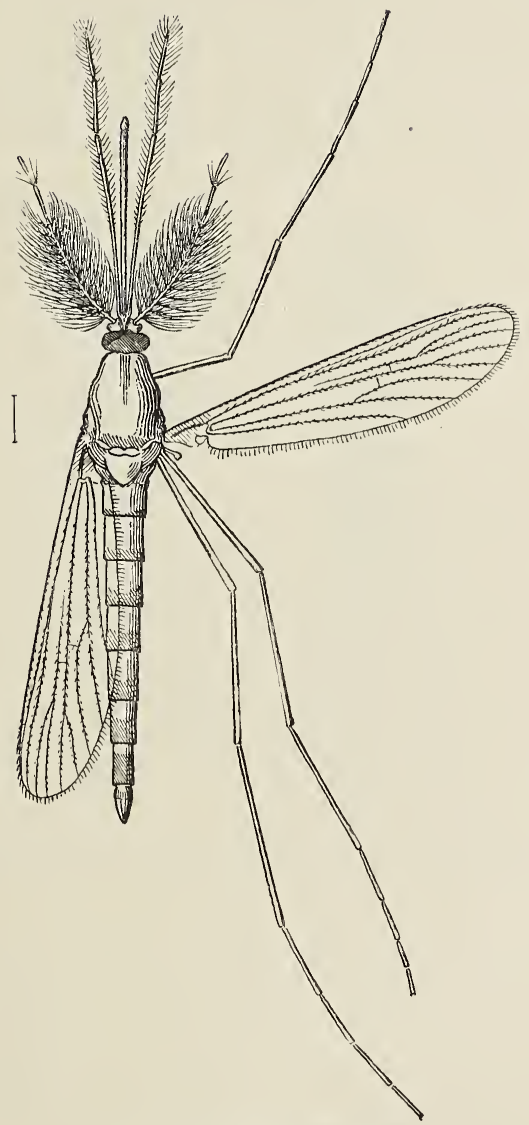

FIG. 27.-Fly of Gnat (Culex), male. 
IO8 NATURAL HISTORY OF AQUATIC INSECTS CH.

usually quite inconspicuous. Besides these piercing implements, the Gnat is provided with a soft flexible sheath, which represents the labium. This takes the shape of a tube, split along its fore side, which surrounds and protects the delicate parts within.
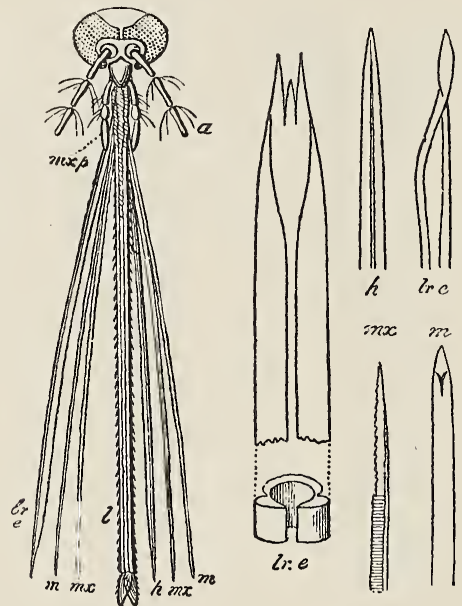

FIG. 28.- Head and mouth-parts of female Gnat. $a$, antenna (first three joints); $m x p$, maxillary palp; lre, labrum-epipharynx; $l$, labium; $m$, mandible ; $m x$, maxilla; $h$, hypopharynx. The separated mouth-parts are copied from Dimmock.

The extremity is divided into two lobes. When the female Gnat makes her attack upon the human skin, she plants the two divisions of the flexible labium upon the spot selected. Then the piercing implements make their puncture, being guided and supported by the labium, in the same way that the 
fingers would be used to support a needle or, other slender instrument which we wished to pass into a firm object, such as a piece of leather. As the piercing instruments penetrate further and further, the labium is bent backwards near the middle of its length, so as to shorten it without withdrawing its support from the piercing parts. When these preparations are completed, the Gnat is in a position to draw the blood into its mouth. One part of the œsophagus is dilated, and forms a sucking-bulb; in front of this is a minute valve which apparently prevents the escape of blood from the mouth. The momentary enlargement of the sucking-bulb reduces the pressure within, and the blood flows up along the front split tube. In the male Gnat these parts are a good deal simplified. The saw-teeth of the maxillæ, the unpaired lancet, and the sucking-bulb are all undeveloped, and it is probable that the male Gnat, if it feeds at all, obtains its food in a quite different manner from the female. Some writers, however, maintain that the male Gnat can bite. Why the female Gnat should draw blood at all is a difficult question. It has been surmised that a supply of highly nutritive fluid is ne cessary for the formation of the numerous eggs, but the force of this, as of every explanation which has hitherto been suggested, is a good deal weakened by the circumstance that Gnats abound in certain regions where no quadrupeds are found, and very few animals worth biting. They have been found in immense numbers in uninhabited parts of Labrador, on the tundras of Siberia and the desolate Kerguelen Island. "Of the millions of mosquitoes which in the 
I IO NATURAL HISTORY OF AQUATIC INSECTS $\mathrm{CH}$. short Norwegian summer often thicken the air of the Tromsdal-a wild valley within the Arctic Circle, practically uninhabited either by man or probably by beast - how few are ever likely to taste blood!"1 Sir James Ross and his men found it necessary in their

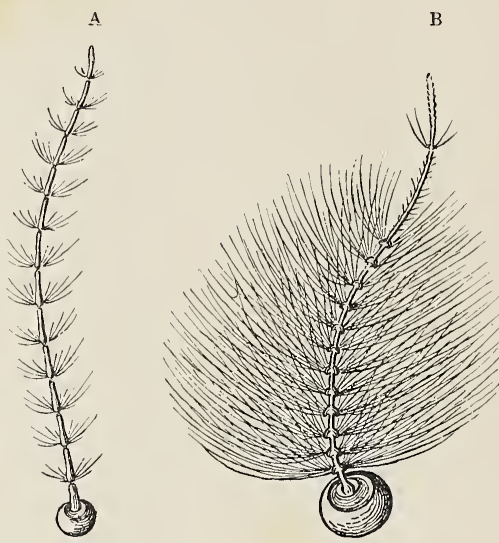

FIG. 29.-Antennæ of Gnat. A, male ; B, female.

polar expedition to wear gauze over their faces in the summer months as a defence against Gnats.

The irritation caused by the bite of the Gnat has naturally led to the belief that poison is injected into the wound. Whether this is true or not cannot be positively stated. No poison gland has hitherto been demonstrated, and there is some reason to believe that the irritation of the wound is slight in

1 A. D. Michael, in Natural Science, Vol. I. p. 203. 
cold weather, and only becomes intense during great summer heat. ${ }^{1}$

Nearly two hundred species of Gnats have been described. Some of these inhabit hot countries, and are popularly known as Mosquitoes, but to the zoologist there is no species of insect which can be defined as the Mosquito. Even in our own temperate climate a burst of hot summer weather has led persons who might be supposed to be pretty good judges to give the name of Mosquito to our common Gnat. "A few years ago a London Hotel, popular with American visitors, was said to harbour Mosquitoes, which some of the visitors had brought with them from the Southern States, but an examination revealed the fact that the cistern was uncovered and exposed, and was the breeding place for hosts of Gnats." 2

The piping sound which the Gnat utters, and which is often of itself enough to excite the greatest irritation in its victims, is said to be due to the vibration of the edges of its spiracles, occasioned by the passage

${ }^{1}$ It is probable that the Gnats originally acquired their piercing mouth-parts for the purpose of sucking the juices of plants. Many two-winged flies of the section Nemocera have the rostrum and mouth-parts remarkably prolonged, apparently for sucking sap or nectar. Apetz has observed a Campylomyza (Cecidomyidæ) sucking a caterpillar, and both Culex and Simulium are known to suck caterpillars. Cuiex and Anopheles (Culicidæ), some species of Ceratopogon (Chironomidæ) and Phlebotomus (Psychodidæ), are various examples of blood-sucking Nemocera. The substance of this note is taken from Baron Osten Sacken's "Characters of the Three Divisions of Diptera," \&c., Berl. Ent. Zeits. Bd. XXXVII. (1892).

2 Enc. Brit., Vol, II. p. 866. 
of a current of air, but this explanation has its difficulties.

The female Gnat lays her eggs on the surface of stagnant water, and the operation of egg-laying has been carefully described by Réaumur. The Gnat supports her body upon the four front legs, which rest upon the margin of the pool or upon any floating object. The long hind legs are crossed, and in the angle between them the eggs are received as they pass one by one from the end of the abdomen. At this time they are sticky and adhere to one another. As the mass of eggs increases in size, the hind legs alter their position and become more and more parallel to one another. The operation of egg-laying takes place in the early hours of summer days.

The egg-raft of the Gnat, though one of the commonest objects in Nature, is apt to escape our notice on account of its minute size, for it is less than
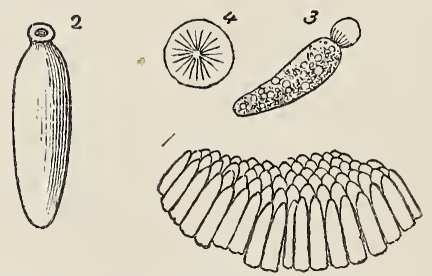

Fig. 30.-I, egg-raft of Gnat, from Réaumur; 2, a single egg; 3, egg removed from ovary, with bladder-like appendage ; 4 , end view of the appendage, showing radiating lines.

a quarter of an inch in length. It was beautifully described 150 years ago by Réaumur. The eggs of the Gnat are cigar-shaped, and 250 or 300 of them 
are glued together, so as to make a little concave float, shaped like a shallow boat. The upper end of each egg is pointed; the lower end is provided with a lid, through which the larva will ultimately issue into the water. The Gnat in all stages, even while still in the egg, requires an ample supply of air. It is therefore necessary that the egg-raft should float at the surface ; it is also necessary that it should always float in the samc position, so as to facilitate the escape of the larva. This is effectually secured by a provision of almost amusing simplicity. Let us first notice how efficient it is. If we take two or three of these tiny egg-rafts, and place them in a jug of water, we may pour the water into a basin again and again ; the egg-rafts float instantly to the surface, and the moment they come to the top they are seen to be as dry as at first. The fact is that the surface-film cannot penetrate the fine spaces between the pointed ends of the eggs. The cavity of the egg-raft is thus overspread by an air-bubble when accidentally submerged. The eggs are kept from contact with water; the proper upper surface is made so buoyant that the raft has great power of self-righting; while, the instant that it comes to the top, the excess of water drains off, and the film bursts, leaving the eggs perfectly dry on their upper surface.

\section{CORETHRA}

In still pools, especially such as are overhung by trees, there may often be found in considerable abundance the predatory larva of Corethra, also called the 
Phantom Larva from its remarkable and almost complete transparency. This larva is about two-thirds of an inch long. It often remains for a long time together extended horizontally in the water at a little distance beneath the surface, on the look-out for its prey. Suddenly it disappears from view, and when rediscovered is found to have moved an inch or two, and to point in a different direction. The movement is effected by a sudden lashing action of the body, and in its promptitude resembles the jerk of an electric telegraph needle.

By suitable tackle these larvæ can be taken in any required numbers, and it may be well shortly to describe the instruments which are employed to collect this and other aquatic forms of life. There is nothing more generally useful than a hoop, five or six inches in diameter, across which wire-gauze is stretched. The hoop is attached to a socket which receives the end of a long stick. It should be further provided with a rim, upon which a muslin bag of no great depth may be stretched. It is convenient to sew the edge of the muslin bag round an india-rubber ring, which can then be slipped over the metal rim. The object of the gauze is to prevent sticks, leaves, and other floating objects from entering the net. Provided with such an apparatus as this, the collector can sift the water in likely places until he supposes that sufficient material is collected. Then the muslin bag is slipped off from the hoop, and inverted into a vessel of water. On account of its portability, the vessel which I have found it most convenient to carry is half of a large hollow india-rubber ball. For 
fetching up mud from the bottom of a deep ditch or pool, the hoop and gauze may be used without the muslin. Another implement which is worth carrying is a large iron spoon with a long handle.

The Corethra larva feeds upon small aquatic animals, such as Ephemera-larvæ, Daphnia, or Cypris. The transparency of its body and its immobility, except when it instantancously changes its position, enable the larva to wait for its victims without risk of being observed. Limbs would be here superfluous, and nothing can be seen of them except a prominence provided with a double crown of minute teeth, which can be distinguished by the microscope, at the extreme end of the tail. This represents, in a greatly reduced form, the pair of hooked feet found at the hinder end of the body in Chironomus and Tanypus. A little farther in front, on
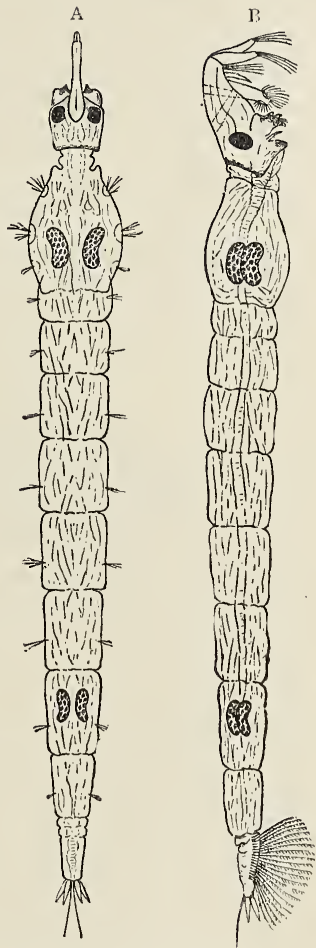

FIG. 3r.-Larva of Corethra. A, dorsal view. B, side view. $\times 8$. The two pairs of air-sacs are seen in the first and eighth segments behind the head. the lower surface of the body, is a vertical fin, 
composed of a row of feathered bristles. This no doubt increases the sculling effect of the rapid strokes of the tail, by which the larva exccutes its sudden movements. Each feathered bristle is inserted by a forked base, and the whole row is connected by the cuticle, which can be thrown into folds like the valves of a concertina, or separated at pleasure. The folds are independent in their action, and some of them may be closed while others remain open. This arrangement was first described to me by Mr. Hammond. There is a similar vertical

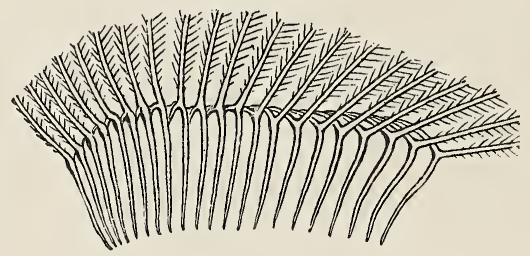

Fig. 32.-Details of fin of larva of Corethra.

fin on the tail of the Gnat-larva : both have evidently a common origin, and are used in the same way.

The head of the Corethra larva narrows forward. When the larva first emerges from the egg it is provided with a single pair of minute eyes, which are little more than pigment-spots. Subsequently a larger and many-facetted eye forms by the side of this. Weismann believes that this eye is directly converted into that of the fly. The antennæ project in front, and the mouth-parts lie beneath. The antennæ are not, as in most Insects, merely sensory organs, 
but are prehensile, and play a great part in the capture of the prey. Each consists of a simple basal joint, which ends in four or five long curved bristles. When at rest, these bristles are directed downwards and backwards, and are flexed upon the basal joint. A special muscle serves for the extension of the antenna, which is brought back to its ordinary resting position by the elasticity of the parts. The labrum is long and narrow, and assists in the capture of the prey. The mandibles resemble hands in shape, and bear

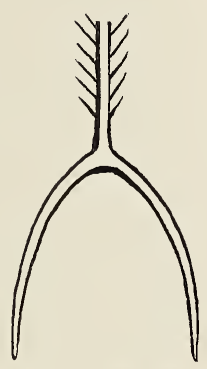

FIG. 33.- One element of fin of larva of Corethra. four or five long curved finger-like teeth. The maxillæ are mere stumps, and the labium is reduced to a small triangular plate. Any small animals captured by the antennæ are crushed by the mandibles and pressed into the mouth, but they are not swallowed, as we might naturally expect. The back of the mouth is closed by a circular fringe of stout bristles arranged like a lobster-pot, or what is in some parts of the country called a weel for catching fish. The body of the victim is thus imprisoned and acted upon by the salivary secretion, so that only the fluid products of digestion enter the stomach. If the larva is gently pressed between two glass slips, the pharyngeal tube can be everted, and by a more natural process of eversion the indigestible parts of the food are voluntarily expelled from the moutl of the living Insect. A somewhat 
similar weel may be found in the Gnat larva, and also in the fish-like Amphioxus.

Respiration must be carried on chiefly through the integument, for there are no spiracles. There is however an imperfect tracheal system, consisting mainly of two tubes which run the whole length of the body. In the greater part of their length these tubes contain no air, but in the thorax and again towards the end of the abdomen, each of them dilates and forms a good-sized air-sac (fig. 3I). In the living larva, as seen by the microscope, these air-sacs appear black, owing to spots of pigment as well as to the difference in refractive power between water and air. The imprisoned air is more important from its hydrostatic function than as a means of respiration. The four air-sacs serve in fact as floats, and maintain the larva without effort in a horizontal position near the surface of the water.

In a fresh-hatched larva the tracheæ and air-sacs are altogether empty of air. How are the air-sacs subsequently filled? We have no definite information on this subject. Gaseous air can be discharged from solution in a watery fluid either by rise of temperature or by diminution of pressure. Bring a glass of water fresh from the pump into a warm room. Bubbles of air shortly appear on its sides. Open a soda-water bottle which was corked under considerable pressure. The diminished pressure due to opening occasions a copious discharge of gas. It is hardly conceivable that the evolution of gas in the body of a small aquatic Insect can be due to rise of temperature. But there is no serious difficulty in supposing that it 
is caused by diminution of pressure. The sucker implies such local diminution, and if a Simulium larva, for instance, can employ negative pressure for the purposes of attachment, it is conceivable that a Corethra larva may be able to employ negative pressure to extract a gas from its own blood for hydrostatic equilibrium. But until some mechanism able to produce diminution of pressure has been found in the air-passages of an Insect, the discussion is very vague and unpractical. It will be remembered that many other aquatic animals besides Insects can fill some internal chamber of their bodies with a gas rich in oxygen (sec p. 37).

The pigment upon the air-sacs of the Corethra-larva may conceivably help in the respiratory process. Pigment is not unusual in the respiratory organs of Insects. The large tracheal trunks of some Dragonfly larvæ are tinged with purple, and the tracheal gills of some Caddis-worms show a pale violet colour. Gas may be secreted by a chemical process in which the pigment plays its part.

The pupa floats in an upright position at the surface of the water. At the head end is the great mass composed of the head, wings and legs of the future fly, all shrouded in the temporary larval skin. The tail is broad, and like the tail-fin of a Lobster in shape. It is the chief organ of locomotion possessed by the pupa. When alarmed, the pupa descends a few inches below the surface, by means of the powerful strokes of its abdomen and tail.

When pupation takes place the tracheal system of the larva becomes disorganised. Most of the air 
escapes to the exterior of the body, and lodges beneath the thorax, where it collects into a good-sized bubble; this is probably useful in maintaining the
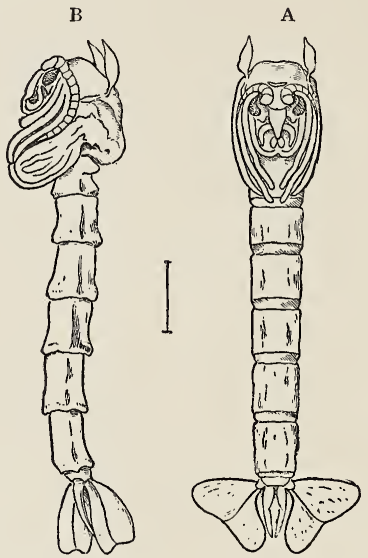

Fig. 34- Pupa of Corethra. A, ventral view ; B, side view.

upright position. The fore air-sac breaks up, but the hinder one remains, apparently not in a functional condition. A pair of respiratory trumpets, somewhat similar to those of the Gnat pupa, are now the chief means of communication with the outer air. They are narrowed at the extremity, and open by a very contracted slit.

The fly which issues from the pupa-skin is a small Gnat-like Insect. The male has beautiful plumed antennæ. The female deposits on the surface of water 
a flat, gelatinous sheet, in which the eggs are arranged in spiral lines.

I will add a few words about another Gnat-like Insect, with aquatic larva and pupa, which in its larval state was described and figured long ago by De Geer, and has since received the name of Mochlonyx. In habitat, mode of feeding, \&c., the earlier stages much resemble those of Corethra. Both larva and pupa are structurally as exactly intermediate between Corethra and Culex as can well be imagined. Thus

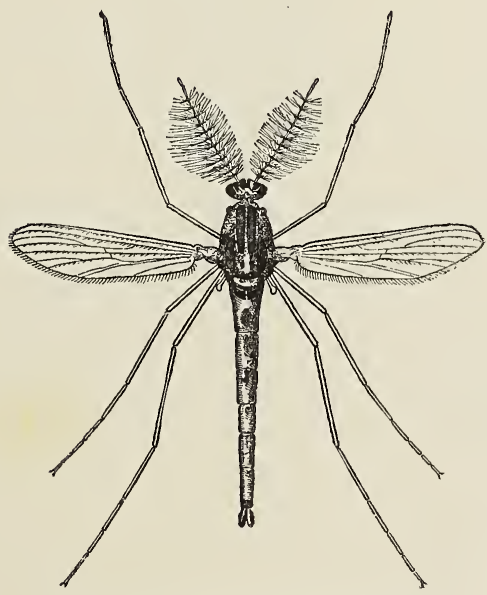

FIG. 35--Fly of Corethra plumicornis, male.

the tracheal trunks (air-tubes) are large in the Culex larva, reduced in Mochlonyx, and rudimentary in Corethra. The air-vesicles of the Culex larva are 
122 NATURAL HISTORY OF AQUATIC INSECTS CH.

slight dilatations of the air-tubes. In Mochlonyx they are greatly enlarged, and the connecting airtubes reduced in diameter, though filled with air. In Corethra the vesicles are the only reservoirs of air, the connecting tubes, though visible by the microscope, being filled with a watery fluid. The Mochlonyx larva retains in a reduced form the breathingtube, which is so conspicuous in Culex, and which

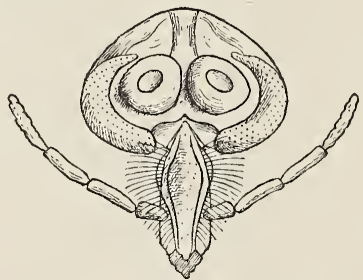

FIG. 36.-Head of Fly of Corethra. The antennæ (except their enlarged basal joints) are cut away.

disappears in Corethra. These and other facts of the same kind seem to indicate that the three larvæ have diverged from a common form, but what that common form was I do not venture to conjecture.

\section{Chironomus.}

One of the commonest, and certainly one of the most instructive, of aquatic Insects is the larva of Chironomus. It abounds in ditches, water-butts, and streams, especially dirty streams, and feeds upon decaying vegetable matter. It may be readily recognised by its crimson colour, which has suggested the 
popular name of Blood-worm. ${ }^{1}$ When of full size it is nearly one inch long. These larvæ protect themselves by making burrows out of particles of earth or leaves, which they weave together with the very abundant secretion of the salivary glands. When undisturbed, they may often be seen to push the head-end well out of the burrow tor purposes of feeding; at other times the tail-end is pushed out and waved to and fro in the water, as a help to respiration. Now and then they leave their burrows, and swim through the water with a lashing movement, twisting themselves into figures of eight. Occasionally they rise to the surface, as if to renew their supply of oxygen. They are careless about finding their way back to their burrows, for in a short time they can glue together enough fresh fragments to conceal themselves. 'The body of the larva consists of a head and twelve segments. The prothorax, or segment next behind the head, carries a pair of feet armed with

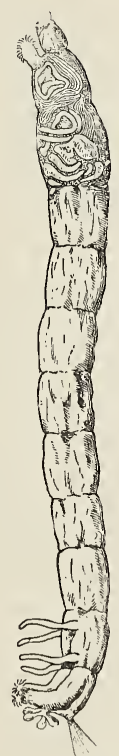

FIG. 37.-Larva of Chironomus. Near the head are seen the rudiments of the wings and legs of the fly, enclosed within the larval skin. numerous hooks. These are used for grappling.

1 Under this name are grouped the larva of several speciesC. plumosus, dorsalis, \&c. The specific distinctions, whether of the larva or of the fly, are in most cases very minute. 
Another pair of hook-bearing appendages is carried on the last segment of the body, and is probably used for holding on to the burrow. Caddis-worms too possess a pair of hooked feet at the hinder end of the body, and no doubt use them for the same purpose. The last segment but one bears two pairs of long and flexible tubes. These are filled with blood, which is continually renewed by the pulsations of the heart, and the exchange of gases necessary for respiration is probably effected through the thin wall of the tube. Four other smaller prominences on the last segment have a similar structure, and very likely are used in the same way. The last segment also carries on its upper surface two bunches of fine hairs, which are supplied by a pair of nerve-cells, and are believed to be sensory in function.

When the larva is concealed within its burrow and apparently at rest, an undulatory up-and-down movement of the body is kept up, which continually renews the water. At such times the four tubes are probably actively engaged in the exchange of gases. The same movement is practised by other case-dwelling aquatic larvæ, such as Caddis-worms and the caterpillar of Paraponyx.

The head, which is small in proportion to the body, bears a short pair of jointed antennæ, and two pairs of eye-spots, which are merc pigmented patches, without lenses. As usual, a sort of flap, the labrum, hangs down in front of the mouth. This is furnished with a very elaborate set of teeth, hooks and spines, some of which are probably used to guide the filaments of silk as they issue from the salivary glands. 
There is a pair of strong, toothed mandibles, which are the chief organs of mastication. The maxillæ are rudimentary, and the labium is represented by a crescentic plate with strongly toothed fore-edge.

The transparency of the Chironomus larva is sufficient to permit the study of its internal organs in a living and uninjured specimen. Small larvæ, say onequarter of an inch long, are best for the purpose. It is a good plan to make a little cell of cotton wool or

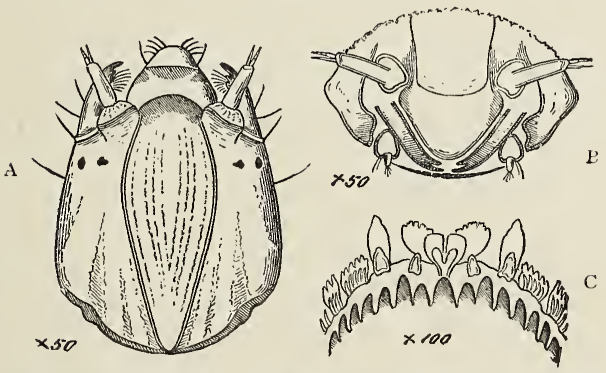

Fig. 38.-Larva of Chironomus. A, head, dorsal side ; B, head, front view ; C, edge of labium, with peculiar teeth and papillæ.

silk upon a microscopic slide, to fill this with water, place the larva in it by means of a fine brush, and then gently lower the cover-glass. The imprisoned larva can thus be studied microscopically. All the external organs, the nervous system, the alimentary canal, and the heart can easily be made out, and the action of the jaws can be studied.

The alimentary canal begins with a long, narrow œsophagus. This is telescoped behind into the crop or proventriculus, which is of much greater diameter 
than the œesophagus, and shows three rows of prominences on its outer surface. Behind the proventriculus comes the stomach, which extends through about half the length of the body. At its beginning the stomach is nearly of the same diameter as the proventriculus, but it narrows somewhat irregularly farther back. The intestine succeeds to the stomach: close to its beginning four long and slender tubes open into it. These are the Malpighian tubes or excretory organs. The vegetable food of the larva and the earthy particles sivallowed with it are usually to be seen as a black mass, which does not fill the stomach, but is restricted to a central channel of definite shape, a good deal narrower than the stomach itself. By dissection it can be made out that the stomach is lined by a transparent chitinous tube, which protects the delicate cellular wall from abrasion by rough vegetable fragments or gritty particles. In the Chironomus larva, as in other Insects, the œsophagus and intestine are both furnished with such a chitinous lining. The peculiarity of the Chironomus larva consists in the prolongation of the œsophagal lining as a free tube throughout the whole length of the stomach. ${ }^{1}$ Digestion is probably carried on in some such way as this. The vegetable food, already masticated, passes slowly along the chitinous tube. The fluid extracted from the food, containing most of the nutritious matter, escapes at the free end of the tube, and flows back into the outer compartment of the stomach, external to the chitinous tube. Here

1 This peculiarity is found in some other Dipterous larvæ, as well as in certain Crustacea. 
it is absorbed, while the insoluble refuse is passed directly into the intestine. A pair of salivary glands is found in the fore part of the body. These are hollow sacs lined by a single layer of cells. Each is furnished with a duct. The two ducts unite in front, and pour the salivary secretion into the mouth. Whether the saliva takes any direct part in the digestion of the food I do not know for certain, but it undoubtedly furnishes the material for the silken threads, with which the larva binds together the walls of its burrow.

The student who is provided with a microscope will find the cells which line the salivary glands an excellent subject for study. The nuclei of these cells are unusually large, and of complicated structure. Each nucleus is a transparent spherical mass, enclosing one or two smaller spheres, the nucleoli. Besides the nucleoli, the nucleus contains a long cord, which is wound into an irregular coil. This cord appears to be made up of a number of discs placed end to end like a pile of coins. If there are two nucleoli, each is joined to one end of the cord: if there is only one nucleolus, it receives both ends. The physiological meaning of this intricate structure has not yet been elucidated. It is an interesting but unexplained fact, that nuclei of similar structure, though of very much smaller size, occur in some plants, e.g. in the young seeds of Fritillaria. It may be that the large size and complex structure of the salivary nuclei of Chironomus is connected with the very abundant secretion poured forth by a comparatively small number of cells, but this is mere conjecture. 
An inexperienced worker with the microscope, looking for an interesting subject, which will neither tax his knowledge nor his practical skill too heavily, will find the salivary gland of Chironomus exactly suited to his wants. For it is an object of considerable biological interest, and yet it can be studied without mechanical appliances or special manipulative skill. A few words of explanation will enable a mere novice to make for himself most instructive preparations.

Lay a live larva on a clean glass slip, and cut off its head with a scalpel. The transparent salivary glands at once begin to flow out, together with the abundant red fluid, which is the blood of the larva. By simply laying a cover-glass on the glands, and examining them with a quarter-inch objective, the nuclei can be seen and studied. But the details of their structure cannot be made out unless the tissue is stained. A staining fluid applied to the yet living cells will not act. (See p. 38.) It is therefore desirable to kill the cells, and to do it rapidly without allowing disorganisation of the nuclear structure to take place. The reagents which accomplish this for us are called fixing agents. Heat, such as that of boiling water, will suffice in many cases. Momentary immersion in strong alcohol is another means. The preparation may be irrigated on the slide by a few drops of absolute alcohol, which are afterwards to be drained off and replaced by the staining fluid. Most microscopic workers prefer osmic acid. A weak solution is employed, say $\frac{1}{2}$ per cent. Precautions, especially with respect to the action of light, are requisite in the case of osmic acid. It becomes reduced, and turns black, 
and loses its action upon tissues if exposed to the light. The bottle in use, which should be of small size, must be coated with blackened paper, and kept in a wooden box when not immediately required. A drop of the solution fixes the cells and their nuclei very rapidly. After a minute's exposure to the osmic acid, wash the tissues in a few drops of dilute alcohol, and finally with absolute alcohol. Then the stain may be applied. Try methyl green, picro-carmine and hæmatoxylin upon as many salivary glands, and learn the best length of exposure. A few minutes will suffice. Until practice has been got, it is well not to attempt permanent preparations. Mount in dilute glycerine, and do not omit to draw everything noteworthy. The preparations will last for several days without further precautions. $^{1}$

In the living larva the heart may be seen busily at work. It is a transparent tube, situated at the hinder end of the body on the dorsal side. Two pairs of valvular inlets admit the blood to the heart; then the contraction of its muscular walls drives the blood along the narrow dorsal vessel, which passes above the alimentary canal to the head. Here the regular bloodchannel ceases; the blood escapes, and bathes all the organs of the body, ultimately making its way back again to the heart.

It is evidently a matter of some difficulty for the Chironomus larva to procure a sufficient supply of air. It lives in water, often in deep water, which abounds in decaying organic matter, and can contain but little

1 The salivary cells and nuclei of the Chironomus larva have been well described by Balbiani (Zool. Anzeiger, I88I). 
free oxygen. The burrows in which it lives furnish an important defence against Fishes and other enemies, but they still further increase the difficulty of securing a sufficient supply of air. The larva can only freely aerate its blood by leaving its burrow, and swimming about near the surface. The thin-walled and transparent appendages near the hinder end of the body are probably of special service in taking up dissolved oxygen. The tracheal system is rudimentary and completely closed, and hence gaseous air cannot be taken into the body. The dissolved oxygen, procured with much exertion and some risk, must be stored up within the body of the larva, and used with the greatest economy. It is apparently for this reason that the larva of Chironomus contains a blood-red pigment, which is identical with the hæmoglobin of vertebrate animals. The hæmoglobin acts in the Chironomus larva as it does in our own bodies, as an oxygen carrier, readily taking up dissolved oxygen, and parting with it gradually to the tissues of the body.

It is instructive to notice that only such Chironomus larvæ as live at the bottom and burrow in the mud possess the red hæmoglobin. Those which live at or near the surface have colourless blood, and a more complete, though still closed, tracheal system. The larva of the Gnat again, which has a large and open tracheal system, and in all stages of growth inhales gaseous air, has no hæmoglobin at all. A list of the many animals of all kinds which contain hæmoglobin, shows that for some reason or other each of them requires to use oxygen economically. Either the 
skin is thick, and the respiratory surface limited, or they are inclosed in a shell, or they burrow in earth or mud.

We might expect to find that hæmoglobin would always be developed in the blood of animals whose respiration is rendered difficult in any of these ways, but any such expectation would prove to be unfounded, and there are many animals whose mode of life renders it necessary that oxygen should be stored and economically used, which contain no hæmoglobin in their blood. Hence, while we have a tolerably satisfactory reason for the occurrence of hæmoglobin in a number of animals whose respiratory surface is limited, and whose surroundings make it a matter of difficulty to procure a sufficient supply of oxygen, we have to admit that many similar animals under the same conditions manage perfectly well without hæmoglobin. Such admission is not a logical refutation of the explanation. I might fairly put forward the baldness of mankind as at least the principal reason for wearing wigs, and this explanation would not be impaired by any number of cases of bald men who do not wear wigs. The fact is that the respiratory needs, even of closely allied animals, vary greatly, and further, there are more ways than one of acquiring and storing up oxygen in their bodies.

Either the storage-capacity for oxygen of the Chironomus larva is considerable, or it must be used very carefully, for the animal can subsist long without a fresh supply. I took a flask of distilled water, boiled it for three-quarters of an hour, closed it tight with an india-rubber bung, and left it to cool. 
Then six larvæ were introduced, the small space above the water being at the same time filled up with carbonic acid. The bung was replaced, and the larvæ were watched from day to day. Four of the larvæ survived for forty-eight hours, and one till the fifth day. Two of them changed to pupæ. Nevertheless, the water was from the first exhausted of oxygen or nearly so.

The special provisions which enable Chironomus larvæ, or at least many of them, to inhabit waters poorly supplied with oxygen, probably explain their occurrence at great depths. They have been fished up, together with larvæ of Tanypus, from the bottom of the lake of Geneva, and have been found alive at considerable depths in the sea in Denmark, Maine, and elsewhere.

I have described the adaptation of Chironomus larvæ to life at the bottom of slow streams and pools, but we must notice that some of the species have different habits, keeping near the surface of the water, and supporting themselves on confervæ, floating pieces of wood and similar objects. It is interesting to see the effect of this change of situation upon the respiratory organs. The surface-larvæ have no tubules at the hinder end of the body, and the blood rarely exhibits a red tinge. I believe that the pupæ which succeed to these surface-larvæ are similarly modified to their peculiar conditions.

As the time of pupation approaches, the thorax of the Chironomus larva becomes swollen, and its segments lose their distinctness. At this time the legs and wings of the future fly may be seen beneath the 
skin. The pupa is distinguished from that of most other aquatic Diptera by the tufts of respiratory filaments which project from the prothorax. It lies half buried in the mud at the bottom of the water with the thorax and respiratory filaments projecting. These are swayed to and fro by the continual bending of the body. At the tail-end two lateral flaps, fringed with long bristles, form a broad fin, which is used to a limited extent for locomotion. The pupa virtually consists of the body of the fly inclosed within a transparent skin. The organs are already complete externally, and even in microscopic detail they very closely resemble those of the perfect Insect. The parts are, however, as yet very imperfectly displayed. The wings and legs are folded up along the sides of the body, and are incapable of independent movement. The red colour of the blood gradually assumes a darker shade. After two or three days the tracheal system, which was rudi-

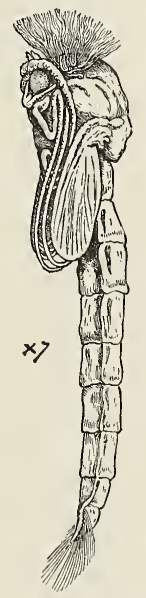

FIG. 39.-Pupa of Chironomus, sideview. mentary in the larvæ, but is now greatly enlarged and extended, becomes filled with air extracted from the water by means of the respiratory tufts, and the pupa floats at the surface. On the last day or so of the pupal stage, air passes through the spiracles, and inflates the pupal skin. At length the skin of the back splits, the fly extricates its limbs and appendages, pauses for a moment 
upon the floating pupa-case, as if to dry its wings, and then flies away. The whole business of extrication occupies less than a minute.

During the later larval stages, a number of new organs are developed, which only become useful in the winged Insect. Three pairs of long and slender legs ultimately replace the very different larval feet; a pair of gauzy wings are added, and the head becomes completely reconstructed. The powerful mandibles and spinning appliances of the larva are useless to the fly; on the other hand, the fly will want far more elaborate sense-organs than those of the larva. The larva is an animal of very simple mode of life, feeding upon dead vegetable matter at the bottom of dark and slow streams; the fly is a nimble, aerial Insect, requiring keen senses to escape danger and find a mate. The head of the larva is accordingly both simple and small; that of the fly not only quite different in shape and far more complex in structure, but absolutely larger. As a mere matter of dimensions the head of the fly could not be contained in the larval head.

Provision is made, not only in Chironomus, but in very many Insects, for the gradual development of new parts, differing materially from the old ones. An Insect elaborates by secretion from its epidermis a continuous integument or cuticle, which at length becomes hard and firm. Whenever the cuticle proves too small for the growing body within, the epidermis is retracted, and develops a new cuticle within the old one. The old cuticle ultimately bursts open, and the Insect emerges, clothed in its new and very flexible 
covering. Soon the new cuticle expands, and in the course of a few hours, or it may be in a few days, becomes as hard as that which has been cast. This periodical operation of moulting gives opportunity for gradual changes of shape. Some Insects, without ever ceasing to run about and procure their food, develop new organs, such as wings, by modification of the shape of the cuticle at certain places. In the later stages of a Cockroach, for example, the edges of two of the thoracic segments are found to project backwards at the sides of the body. Within these small projections wings are formed. They are necessarily crumpled up to allow of their being stowed away into small spaces, and it is only at the next moult that they become expanded. By the same process the long legs of a winged Insect may be developed beneath the unbroken surface of a footless larva.

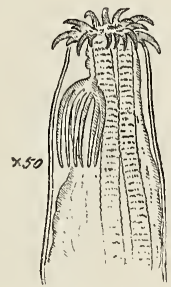

FIG, 40.--Larva of Chironomus. One of the hind legs, showing its crown of hooks, the retractor muscles, and the formation of a new crown of hooks, preparatory to change of skin.

There is a deep inward telescoping of the epidermis, and from the bottom of the fold the limb begins to grow outwards. (See Fig. 42.)

In a Chironomus larva the head, legs, and wings of the fly are formed by such a process of infolding. The operation occupies a considerable time, and begins soon after the last larval moult, some weeks before pupation sets in. The epidermis is retracted from the larval cuticle, and first secretes a thin, new cuticle, which will form the proper investment of 
the pupa. This appears to remain plastic for a long time, for it ultimately takes very exactly the shape of the imaginal parts which form within it. There is afterwards developed within it a second and inner cuticle, which will ultimately form the integument of the fly. The two structures are always distinct, but they are in most places in close contact, and can only be distinguished by the microscope. The pupal and imaginal cuticles do not at all closely follow the larval skin, but become at particular places folded far into the interior. The folds which give rise to the head of the fly are two in number and paired. They begin at the larval antenna on each side of the head, and gradually extend further and further backwards. The object of the folds is to provide an extended surface which can be moulded, without pressure from surrounding objects, into the form of the future head. On one part of each fold the facets of the large compound eyes are developed, another part gives rise to the future antenna, a large and elaborate organ, which springs from the bottom of the fold, and whose tip just enters the very short antenna of the larva. The folds for the head ultimately become so large that the larval head cannot contain them, and they extend far into the prothorax. Here a difficulty occurs. If the generating cuticle of the prothorax were also to be folded inwards, the future prothorax would take acorresponding shape. But the prothorax of the fly has a form dictated to it by the limbs which it bears, and by the muscles to which it gives attachment. These call for a great reduction in its length, and a peculiar 
shape, which it is not here necessary to describe. It will be enough to realise that the epidermis of the future prothorax cannot be sacrificed to the folds
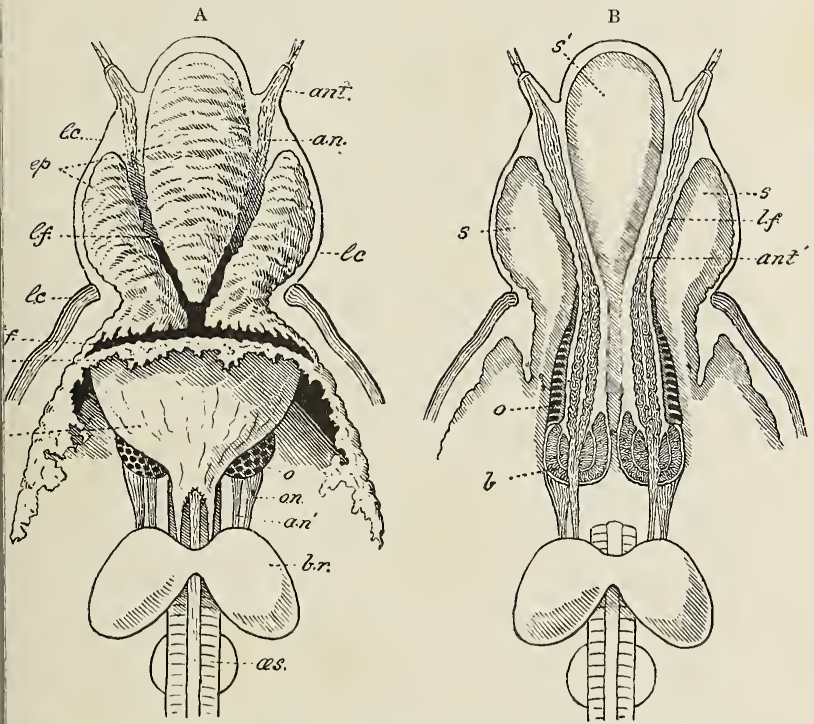

FIG. $4^{\mathrm{r}}$-Process of formation of the parts of the head of the fly in the larva of Chironomus (male). A, the new epidermis thrown into complicated folds, which have been cut away in places to show the parts within. B, the same parts in horizontal section. $l c$, larval cuticle ; $t f$, transverse fold ; $t f^{\prime}$, upper wall of do. ; $m$, cut edge of new epidermis ; ant, larval antenna ; $a n$, nerve to do. ; $a n t^{\prime}$, antenna of fly ; If, longitudinal fold ; $o$, eye of fly ; on, optic nerve ; $a n^{\prime}$, root of antennary nerve; $b r$, brain; $a s$, œsophagus; $b$, bulb of antenna of fly; $s, s, s^{\prime}$, blood-spaces.

which are to give rise to the head of the fly. All interference between the two developing structures is obviated by the provision of a transverse fold, which pushes into the prothorax from the neck, and forms a 
sort of internal pocket. The floor of the pocket forms two longitudinal folds, which prolong the folds originating in the laryal head. The roof of the pocket shrinks up and forms the connection between the head and thorax of the fly. Ultimately the head-part is drawn out, leaving the prothoracic structures unaffected.

The details of the formation of the head-parts of the fly are too complex for description here. ${ }^{1}$ The last stage of all, in which the paired folds, together with the intervening tract, become drawn forwards and moulded into a new head of simple convex shape, can, however, be observed without serious difficulty. Larvæ about to undergo pupation are easily distinguished by the thickened thorax. A number of such larvæ must be placed in saucers of water, and observed continuously. The epidermis and soft parts will be seen to be withdrawn from the fore-feet, and about a minute later from the appendages near the tail. Then a bulge appears just behind the head on the dorsal surface. The larval head, suddenly emptied of its contents, slips round to the lower surface. The deep infoldings described above are everted, as when a sleeve is turned inside out. The surface bearing the facets of the compound eyes, which was internal, and the antennæ of the fly, which were deeply buried, now project from the exterior of the newly protruded head. In the course of two or three minutes, the head of the fly, lately sunk into the body and forming a series of elaborate folds, is everted, and takes the form usual in Dipterous flies.

1 See Miall and Hammond on the Development of the imago of Chironomus. Linn. Trans., Vol. V. (1892). plotes XXVUI

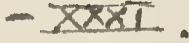


The head is apparently protruded by blood-pressure, set up by the contraction of other parts of the body. When the head, still covered by the pupaskin, is once protruded, matters go on more slowly. The old cuticle of the rest of the body is worked off bit by bit, and it is not until some hours have passed that the pupa gets completely rid of it.

It is interesting to the biologist to find various degrees of complication in the method of development of new parts by infolding. In some Dipterous and other larvæ the folds which give rise to the imaginal head are shallow, and the new parts are in close contact with the corresponding organs of the larva, where such exist. In the Muscidæ, i.e. the family to which the House-fly and Blow-fly belong, the formation of the imaginal parts is incredibly complicated, though the process is in principle the same as in Chironomus. The degree of correspondence between the larval and imaginal organs is one circumstance which affects the extent of the infoldings. In Muscidæ the fly differs in almost every particular of external and internal structure from the footless and almost headless larva, and here the folds attain their maximum both of number and complexity.

Nearly allied species of Insects, though closely similar in the winged state, may differ considerably as larvæ or pupæ. We may take an example of this from Chironomus. In this genus there are two types of larvæ, each of which is succeeded by a special kind of pupa. One group, which includes most of the larger species, such as Chironomus plumosus, has two pairs of respiratory tubules on the eleventh segment 
of the larva. The larva has red blood, and burrows in mud at the bottom of streams and pools. The pupæ of such species have two bunches of respiratory filaments. The second group, which is called by Meinert the Motitator Group, is found at the surface of the water on confervæ, floating logs, etc. The larva has no respiratory tubules; the blood is usually colourless; the pupa has respiratory trumpets instead of filaments. ${ }^{1}$

The origin of these two groups can only be conjecturally traced. Both probably originated in a Tipulid, which as a larva burrowed in the earth and breathed air, and as a pupa was provided with two respiratory trumpets opening by a very narrow cleft, like those of Tipula. We may suppose that such a larva betook itself to damp earth in the neighbourhood of streams, and gradually become more and more aquatic. Subsequently a divergence of habit arose in the aquatic forms. Some of the larvæ frequented the bottom of the water, while others preferred to live at the surface. The bottom-feeders developed the hollow tubes on the eleventh segment as organs of aquatic respiration, and also hæmoglobin in the blood, as a means of storing up oxygen. Those which took to life at the surface of the water, finding oxygen easy to obtain, were able to dispense with both tubules and hæmoglobin. Each group has its characteristic pupa. One is adapted for living at the

1 Our knowledge of the early stages of Chironomus at present extends to a very few species, and we do not know whether the whole genus can be divided into these groups, nor if so, how many species belong to each. 
bottom, and provided with bunches of fine branching filaments, which expose a considerable surface, and are well adapted to the abstraction of oxygen from the water, especially when waved to and fro by the contractions of the body. The pupæ of the surfaceforms on the other hand have respiratory trumpets, which are well suited for drawing-in gaseous air. Such tubes would obviously be quite useless at a depth of even one inch from the surface of the water. It seems most likely that the surface-form is the more primitive, and that the bottom-form is a special adaptation of this. The primitive Tipulid, we may be pretty sure, had neither respiratory tubules nor hæmoglobin in the larval stage. It is equally unlikely that it possessed respiratory filaments in the pupal stage. The majority of aquatic Diptera (Culex, Tanypus, Corethra, \&c.) still retain with slight modifications what we suppose to be the primitive form of pupal respiratory trumpet. The pupa of Simulium, on the other hand, which is immersed and fixed beneath the surface of the water, has bunches of filaments like Chironomus plumosus.

It is interesting to see in these Insects, how natural selection can act upon the earlier stages of the life of an Insect without materially affecting the structure of the adult. The naturalist who should attempt to classify aquatic Diptera by the larva and pupa, would place Chironomus plumosus and Chironomus motitator in different families, yet the flies seem to differ in nothing of greater importance than the length of the first joint of the fore tarsus. Other instances of the special modification of provisional organs brought about in 
one species, while other closely allied species are not so modified, are described by Fritz Müller ${ }^{1}$ as due to a process of falsification ${ }^{2}$ set up by the struggle for existence among free living immature forms. It is to be regretted that our ignorance of the early stages of nearly all the species of Chironomus prevents this interesting question from being fully worked out at present.

Certain facts in the development of the pupal respiratory appendages point to a particular explanation of the two forms, so widely different, which they assume in nearly allied genera. When we watch the developing thoracic appendages of the fly in such Dipterous larvæ as Chironomus, Culex or Simulium, we find that they form a dorsal and a ventral series each consisting of three pairs (see diagram).

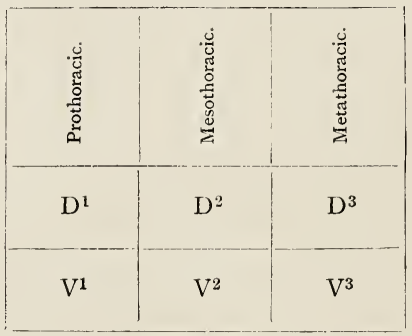

$\mathrm{D}^{2}$ and $\mathrm{D}^{3}$ will ultimately form the wings and halteres (poisers); $\mathrm{V}^{1}, \mathrm{~V}^{2}$ and $\mathrm{V}^{3}$ the legs of the fly.

${ }^{1}$ Facts for Darwin, Chapter xl.

2 The term falsification is not self-explanatory, and it is open to objection as introducing quite irrelevant associations. The obliteration of ancestral by adaptive characters is the thing meant. 
$\mathrm{D}^{2-3}$ very early assume the appearance of undeveloped wings, being broad, thin sheets, inclosed in folds of similar shape. $\mathrm{V}^{1-3}$ soon take the form of long, cylindrical processes, which in like manner, are inclosed in tight-fitting cases. The case or sheath, in both the dorsal and the ventral series, is merely the outer part of the same fold which gives rise to the appendage itself. Suppose the sleeve of a coat to be
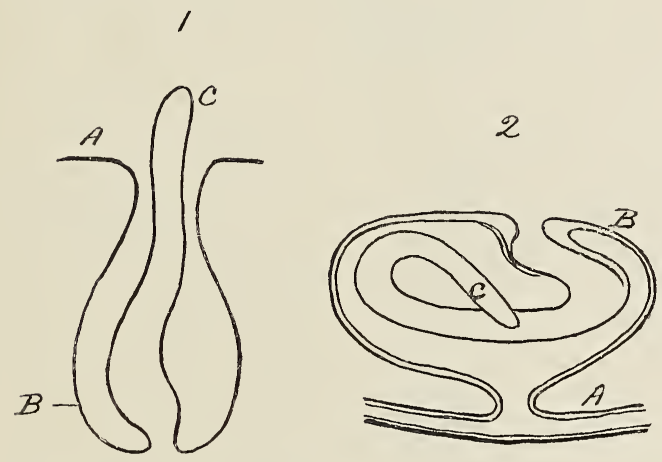

FIG. 42,- I, Diagram to illustrate the formation of a new appendage: 2 , one of the developing legs of the Crane Fly (Tipula) in section.

partly telescoped or withdrawn into the upper part. We shall then get an arrangement like that represented in the figure. A will be the shoulder of the sleeve, $\mathrm{C}$ the wrist end, and $\mathrm{B}$ the part which comes immediately in contact with $\mathrm{C}$, separating it from $\mathrm{A}$. This is not unlike the folded-in and developing thoracic appendage. A is a part of the new cuticle which will help to form the wall of the thorax, $\mathrm{C}$ is 
the appendage itself, $B$ the sheath of the appendage. Now it becomes necessary to remark that DI will give rise to the pupal respiratory organ, whether tubular or tufted, further that Di may be in an early stage somewhat wing-like, forming a thin, flat sheath. What was its original purpose we cannot even conjecture. No Insect is known with a functional prothoracic wing, and it is hard even to imagine an Insect with three pairs of wings. The sheet-like prothoracic appendage of the dorsal series may now curve round until its edges approach and at last become united. In this way the tubes or funnels which constitute the pupal respiratory siphons of the Gnat, ${ }^{1}$ Corethra, \&c. are formed. Or the sheet may become supplied with a network of large, branching tracheal tubes, which repeatedly fork, as tracheal tubes in general do. If we suppose that the intermediate substance, proving superfluous, shrinks or is absorbed, the tubes will then stand out as a tuft of forked filaments, exactly like the pupal respiratory tufts of Chironomus plumosus, Simulium, \&c. I believe that this is the way in which either a trumpet-shaped siphon or a tuft of branching tubes is derived from a wing-like fold of skin.

The fly of Chironomus is a common object upon

1 Dr. C. H. Hurst, The Pupal Stage of Culex. Studies from the Biological Laboratory of Owens College. This and the same author's "Life-history of a Gnat" (Trans. Manchester Micro. Soc., 1890) contain much interesting information.

I have adopted Dr. Hurst's view that "the first pair [of dorsal appendages] become rolled up to form tubes, the respiratory siphons, while the other two remain flat plates," as agreeing with the facts hitherto observed. I do not, however, consider that it has been definitely proved. 
our window-panes, and would be called a Gnat by most people. It can be easily distinguished from a true Gnat, by its habit of raising the fore-legs from

C

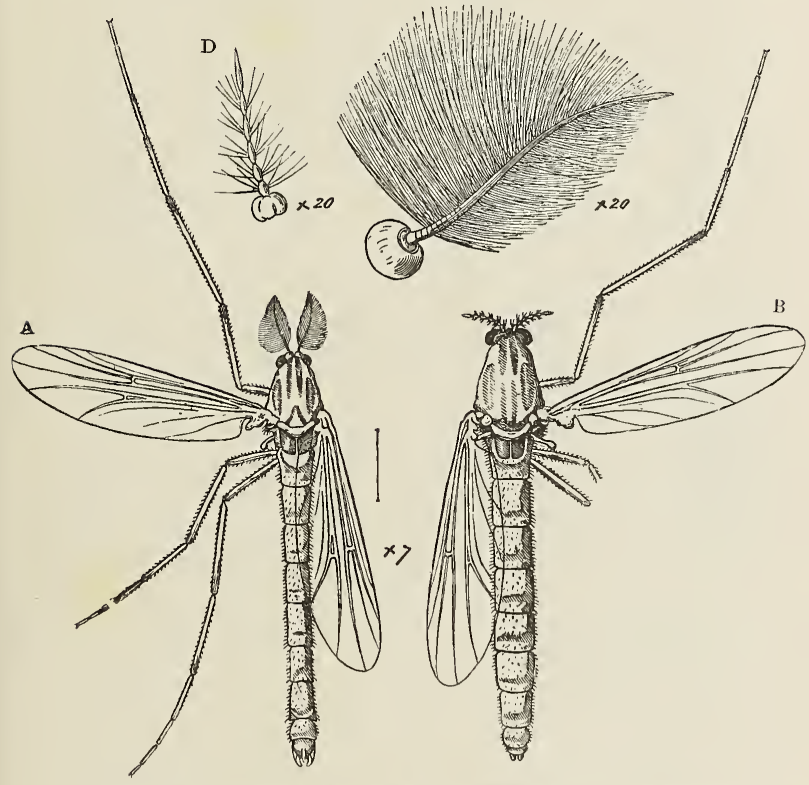

Fig. 43.-Fly of Chironomus. A, male fly ; B, female fly ; C, antenna of male; $\mathrm{D}$, antenna of female.

the ground when at rest. Gnats under like circumstances often keep the hind-legs raised. The Chironomus fly is entirely harmless, and the mouth-parts can neither pierce nor suck. Like many other Diptera, 
the flies of Chironomus associate in swarms, which are believed to consist entirely of males. The male fly has large plumose antennæe with their dilated bases almost in contact. In the female fly, the antennæ are smaller and simpler, and their bases are separated by an appreciable interval. The stomach of the fly is usually empty or nearly so, and it is probable that like many other winged Insects, it never feeds.

The laying of the eggs of Chironomus is attended with some special difficulties. It is convenient that the eggs should be laid in water, and that they should float on the surface, where they can get a fair supply of air, and run no risk of being smothered in silt or organic refuse, but they must not float free, for the water of a running stream would carry them to great distances, and perhaps lodge them in some very unsuitable place, or even sweep them out to sea. These requirements are met in the case of Chironomus and some other Insects by laying the eggs in chains, and mooring them at the surface of the water. The eggs are invested by a gelatinous envelope, which swells out the moment it reaches the water into an abundant transparent mucilage. This mucilage answers more than one purpose. In the first place it makes the eggs so slippery that Birds or Insects cannot grasp them : it also spaces the eggs, and enables each to get its fair share of air and sunlight. The gelatinous substance appears to possess some antiseptic property which prevents water-moulds from attacking the eggs. Long after the eggs have hatched out, the transparent envelope remains unchanged. During the summer 
months, the egg-ropes, nearly an inch long, of some very common species of Chironomus may readily be found on the edges of a stone fountain in a garden, or in a water-trough by the side of the road. The
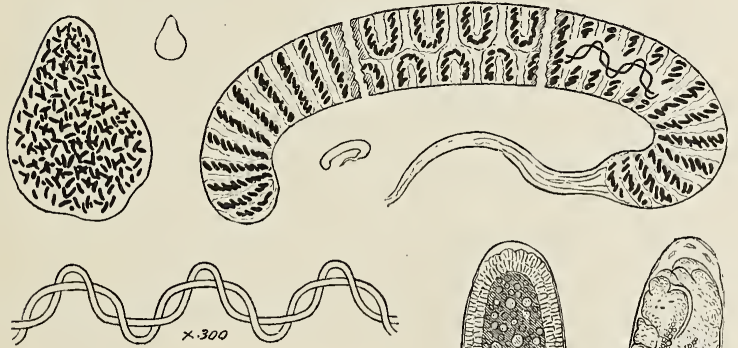

D
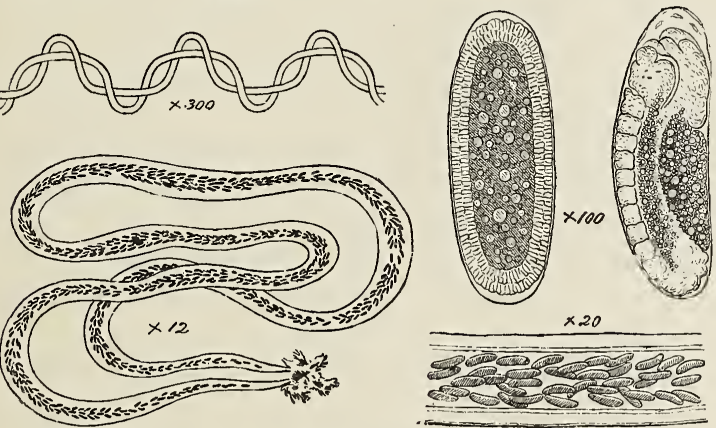

Fig. 44.-Egg-masses of Chironomus. A, egg-rope of C. dorsalis, divided into sections, to show both sides; B, twisted fibres, which traverse the egg-rope ; C, egg-mass of another species of Chironomus; D, egg-mass of a third species; E, part of do. (more highly magnified); F, developing eggs, two stages.

eggs are arranged upon the outside of the rope in loops, which bend to right and left alternately, forming sinuous lines upon the surface. Each egg-rope is moored to the bank by a thread, which passes through the middle of the rope in a series of loops, 
and then returns in as many reversed and overlapping loops, so as to give the appearance of a lock-stitch. The thread is so tough that it can be drawn out straight with a needle without breaking. If the eggrope is dipped into boiling water, the threads become apparent, but in the natural state they are invisible, owing to their transparency. The mucilage is held together by the threads interwoven with it. The loops can be straightened without injury until the length of the rope is almost doubled. If stretched beyond this point the threads become strained, and do not recover their original shape when released. By means of these threads the whole mass of many hundreds of eggs is firmly moored, yet so moored that it floats without strain, and rises or falls with the stream. The eggs get all the sun and air which they require, and neither predatory Insects, nor Birds, nor water-moulds, nor rushing currents of water can injure them. All the species of Chironomus are not alike in the formation of their egg-chains. See for example Fig. 44.

It is always interesting to the biologist to find the same contrivance made use of by animals of different kinds, and I have therefore thought it worth while to mention a number of other animals which coat their eggs with jelly.

Insects yield many examples. One of the most familiar is furnished by the Caddis-flies. Sometimes (Mystacides) they lay their eggs in a roundish gelatinous disc, a quarter of an inch across, which is attached to an aquatic leaf, and contains hundreds of eggs arranged within it in a regular spiral line. Some- 
times the egg-mass of a Caddis-fly takes the form of a rope. One such egg-rope (species unknown) I have examined. It was about two inches long, and contained very many grass-green eggs, which hatched out and yielded Caddis-worms.

The marine worm, Sagitta, also lays eggs imbedded in jelly.

Some aquatic Snails make use in a variety of ways of the same contrivance. The Pond-snails (Limnæa, Physa) lay their eggs in strips of jelly, which are attached to water-plants or submerged stones. Bythinia lays its eggs in three long rows on stones or water-plants (Jeffreys). In Planorbis the egg-mass takes a globular shape (Jeffreys). In Valvata the globular gelatinous mass is invested by a capsule, and attached by a short stalk (Jeffreys). Natica lays its eggs in broad strips of jelly upon shells or stones. The Sea-snail, known to zoologists as Philine or Bullæa, lays its eggs on mud-banks in the form of a small oval mass about as big as a hazel-nut. Upon the surface of this the eggs are disposed in intricate lines. There is a suspensory cord too, which superficially resembles that of the Chironomus egg-rope, and points to the necessity of mooring the eggs. Many Nudibranch Mollusca employ a transparent, gelatinous envelope for the protection of their eggs. The eggs of Pteropods are found floating at the surface of the sea, imbedded in a gelatinous substance, and forming long, cylindrical strings. Many Cephalopods lay their eggs in branched, gelatinous masses attached to fixed objects.

Fishes furnish several examples of the same thing. 
The spawn of the Angler Fish (Lophius) spreads out on the surface of the sea as a sheet, eight to ten feet square. The Perch discharges her eggs enveloped in a transparent substance, which she rubs off against stones. They form a mass of loosely interwoven strings, several feet long. The female Ceratodus also lays her eggs in long, gelatinous strings.

Lastly, the Frog furnishes the most familiar example of a transparent egg-mass. Laid in stagnant water, the Frog-spawn does not require to be moored. The eggs are so slippery that Insects or Birds, excepting only the broad-billed Duck, cannot grasp them. They are spaced so that each gets its fair share of sunlight and air. Then the slimy covering detains bubbles of air which expand in the warmth of the sun's rays, and buoy up the eggs. Frogs' eggs, when fresh-laid and free from bubbles, are slightly heavier than water, and sink. After no long time they float at the surface, except when the weather is unusually cold. The presence of antiseptic properties in Frog-spawn is attested by the persistence of the empty egg-envelopes for weeks after the Tadpoles have hatched out. In the end they often become overgrown by green cells, and in that condition are eaten by the Tadpoles. The spawn of the Toad forms long ropes. This is probably a provision for hatching in slow streams. The eggs of the Frog might possibly be carried away in such places, but the egg-ropes of the Toad, which are many yards long, get entangled in weeds, and never float far.

The egg-ropes of Chironomus are well worth the attention of the naturalist for another reason, viz :- 
the ease with which the development of the larva within the egg can be studied. In the first place, they can always be procured during the summer months. They are so transparent as to admit of examination under high powers of the microscope as living objects, and as they require no sort of preparation, they may be replaced in the water after each examination to continue their development. This saves all trouble in determining the succession of the different stages-a point which usually presents difficulties to the embryologist. The whole development of the egg of Chironomus is completed in a few days (three to six, according to temperature), and it is therefore an easy matter to follow the process throughout with the help of three or four chains of eggs.

The development of any complex animal is a diffcult study, and involves as a first requisite a good anatomical knowledge of the adult organs, but even a beginner can learn something from the study of living eggs of Chironomus. In an early stage he will see a transparent outer layer of cells, completely inclosing the granular yolk. ${ }^{1}$ A little later the outer layer thins away in one place, and in the end exposes the yolk at that point, cutting off what will ultimately be the head of the larva from the tail. Then the transparent body becomes segmented, and the rudiments of the antennæ and jaws begin to appear. The integument is pushed in at the head-end, so as to form a long narrow tube which reaches up to the yolk. This tube gives rise to the mouth and cesophagus. A similar pushing-in of the integument at the tail-

${ }^{1}$ See Fig. 44, F., left-hand embryo. 
end gives rise to the intestine. The stomach is formed out of the cells which immediately inclose the yolk. The hooked feet of the prothorax and of the last segment form comparatively late. The elcngate larva is eventually coiled up within the narrow egg; it escapes by the bursting of what we must call the egg-shell, and begins life on its own account. Until the first moult takes place, the larva differs in some respects from older larvæ. The four respiratory tubes on the ventral side of the eleventh segment have not yet been developed, and the blood has not yet assumed its red tinge. Moreover the head is larger in proportion to the rest of the body than at a later time, and contains, as in most Insects, the brain, or fore pair of ganglia. Before long the brain is slowly retracted into the prothorax, where it is found during the rest of the larval period. The relatively small head, which grows very slowly, could not apparently furnish the requisite space for a brain in addition to the powerful muscles of the jaws. It is only after pupation that the head, that is, the newformed imaginal head, once more incloses the brain.

\section{TANYPUS.}

Another larva, closely related to that of Chironomus, is found in similar situations. This is the larva of Tanypus. It is nearly colourless, but shows something of the red colour so conspicuous in the Chironomus larva. The same red tinge is found inside the alimentary canal, which suggests that the larva preys upon the small red worms known to naturalists as 
Tubifex, or some other small creature which contains hæmogoblin in its blood. The only animals which I

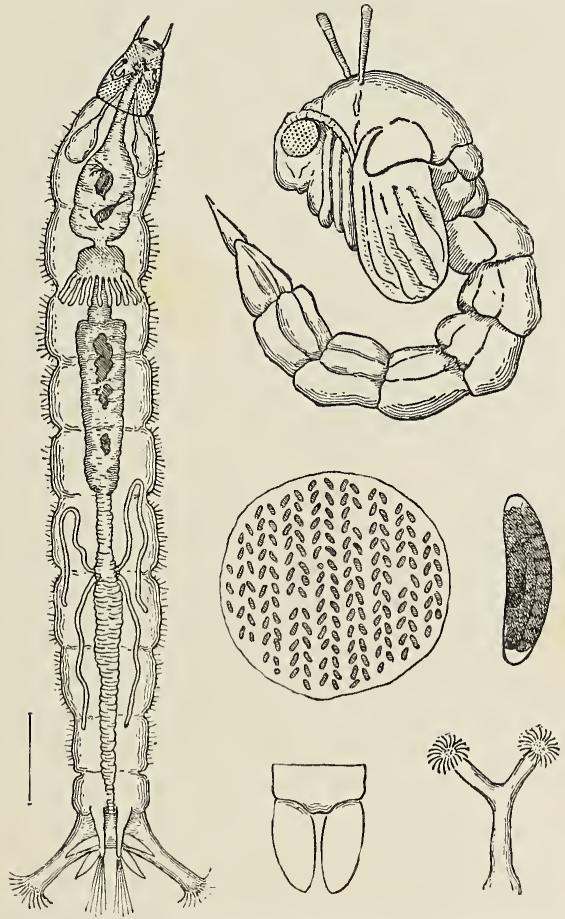

Fig. 45.- Larva and pupa of Tanypus maculatus. The four lower figures represent the circular gelatinous egg-mass; a developing egg, in side-view ; the tail plates of the pupa, front view ; and the partly united, hook-bearing, prothoracic feet of the larva.

have actually seen in the alimentary canal, however, are Crustacea, sometimes alive. The head is narrow, 
the antennæ rather long and completely retractile; they can be withdrawn into the head by means of a special muscle and protruded again by blood-pressure. Retraction of the sensitive organs and even of the entire head is not unusual in burrowing Insect-larvæ. The first joint of the thorax is unusually long, and is furnished with a pair of hooked feet, joined together at the base. These are used like a crutch to propel the body of the larva. At the hinder end of the body is another pair of hooked feet, also long, narrow and stiff. De Geer says very aptly that the larva moves about as if it had wooden legs. The extremities of the legs, which bear clusters of hooks, are however retractile. The tracheal system is better developed than in the Chironomus larva, but does not, so far as I can discover, open to the surface. The Tanypus larva makes tubes like those of Chironomus, but does not keep so close to them, and may often be found free, swimming through the water with a serpent-like movement or clinging to submerged objects. It occasionally thrusts the fore part of its body out of its tube or burrow, and strikes the water with it. The movement is rhythmical, and may be kept up for a long time. The object is no doubt to promote aëration of the blood. In captivity the larva seldom constructs tubes. The pupa generally keeps below the surface, but can come up to breathe by means of a pair of respiratory trumpets. When alarmed, it sinks, and often holds on to objects at the bottom of the water by means of its tail. The pupa is further provided with suckers on the abdomen, which enable it to hold on to solid objects with great 
ease. Meinert, who has given the best account of the larva and pupa of Tanypus, says that the suckers are circular depressions outside the dorsal shields of the abdomen. The pupa of Tanypus varius shows them most distinctly : here they are borne in pairs by four segments (3-6). When the pupa has attached itself by a single sucker, it can turn about without losing its hold. ${ }^{1}$

The eggs of Tanypus are described by Hammond ${ }^{2}$ as circular gelatinous masses, adhering to floating objects. The eggs are arranged in double rows, along about eight straight and parallel lines which extend across the disc.

\section{Ceratopogon.}

One of the commonest Dipterous larvæ found at the surface of ponds is the long slender worm-like larva of Ceratopogon bicolor. It is commonly met with entangled in the confervæ which float at the surface, and its extremely slender body seems well adapted for travelling in a serpentine way through a mass of vegetable threads. The head is very long and slender; there are no limbs. At the tail-end is a crown of long bristles, which can either be extended backwards or curved forwards at pleasure. These bristles are probably a means of attachment and locomotion. The surface of the body is marked with fine longitudinal lines, which look as if they had been cut upon the cuticle by a microscopic

1 De eucephale Myggelarver, p. 83 .

2 Postal Microscopical Journal. 
I56 NATURAL HISTORY OF AQUATIC INSECTS CH.

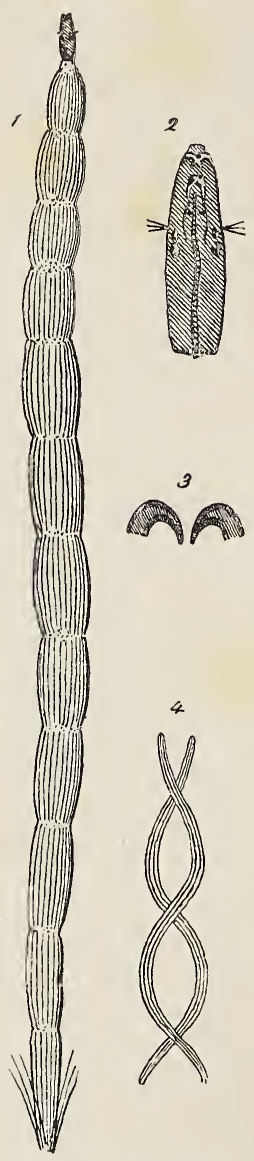

F1G. 46.-1, Larva of Ceratopogon; 2, head of do. ; 3 , mandibles; 4 , double outline, showing flexion of the body in opposite directions while swimming. graver. The digestive tube is straight and simple, and apparently adapted to the wants of a carnivorous animal. I have not been able to identify the small particles of food which are occasionally seen within it. There is a pair of very delicate air-tubes running along the body. The pupa swims at the surface, and can attach itself to floating objects by means of two spines, which project from the extremity of the abdomen. It does not completely free itself from the larval skin, but carries the loose and shrivelled envelope about, attached to its tail. Some other species, of quite different mode of life, do the same. Most species of Ceratopogon are not aquatic in their early stages, but live under the bark of trees. C. Dufouri is 
described, ${ }^{1}$ as living during its early stages in the sap which flows from wounded elms. It creeps and even swims about in this juice with great activity.

The flies hatched from aquatic larvæ have naked wings, while those produced from tree-haunting larvæ have hairy wings.

Some species of Ceratopogon sting, and inflict painful wounds upon man. They are occasionally to be found among other Tipulids upon the windowpane, but their natural resort is the branches of trees and shrubs.

Like most aquatic Diptera, Ceratopogon passes the winter in the larval form; the pupa and imago appear in May or June, and young larvæ abound in the latter part of summer. The eggs are laid 100 or more together in star-shaped clusters among the confervæ. ${ }^{2}$

\section{Dixa.}

The larva of Dixa was first described by Réaumur in a memoir published in $1714 .^{3}$ It is, he says, only seven or eight lines long. There are eleven segments behind the head. The larva is almost always bent double into the shape of a siphon, so that the head and tail come close together. The bend is at the

1 Laboulbène, Ann. Soc. Entom. de France, $4^{\mathrm{e}}$ Sér., Tom. IX. (1869).

2 Gercke, Verh. d. Ver. f. naturw. Unterhalt. Hamburg, Bd. IV., p. 222-8 (1877). The larva and pupa have been well figured and described by Meinert, De eucephale Myggelarver (I886).

${ }^{3}$ Mém. de l'Acad. Royale de Paris. 
sixth segment, and there are five segments on either side of it, but as the five segments towards the tail are longer than the five next to the head, the body is not bent exactly in the middle. The larva keeps close to the edge of still water. Only the head, the tail, and the segment next to the tail, he says, are constantly in the water. He observed that when the larva was attached to the side of a vessel, only the head and tail being in the water, if he inclined the vessel so as to cause the water to rise towards the larva, it immediately crept a little higher. If the vessel was inclined the opposite way, so that the larva was left dry, it made haste to regain the water. When creeping, the middle of the body moved foremost. The larva was provided with legs, though they were too small to be seen properly with a magnifying glass. The legs, he says, are attached to the back, and the Insect always lies on its back, with the mouth turned upwards. The legs were short, and resembled the prolegs of a Silkworm, being terminated by hooks. The first four legs were directed towards the head, the others towards the tail. Since the animal is bent double, all its legs point the same way, and combine to propel the body with the sixth segment foremost. The larva could work its legs, not only from front to back, but also from side to side. When submerged, it extended its body, and swam like a worm. It appeared never to venture into deep water voluntarily, but to regain the shore as soon as possible. The mouth was surrounded by prominences and tufts, which were incessantly drawing water into the mouth, and thus 
bringing a supply of the minute organisms which serve the larva for food.

The description of Réaumur, given above in a condensed form, is in the main a true and satisfactory account. He was, however, mistaken in supposing that the larva turns its back upwards, and that the legs are borne upon the dorsal surface. Moreover Réaumur was quite ignorant of the transformations of Dixa. His successor, De Geer, in this as in many other cases, added fresh information on points left incomplete by Réaumur. De Geer ${ }^{1}$ reared the fly, which he identified as a kind of Tipula. He gives descriptions and figures of all the stages. De Geer shared Réaumur's mistake as to the dorsal and ventral surfaces. Meinert has given the best modern account of Dixa, and has supplied excellent figures of the details of structure of the larva and pupa. ${ }^{2}$

The structure of the larva can be gathered from the figures here given (Fig. 47). The body is bent, as Réaumur says, into the form of a siphon, the fifth and sixth segments behind the head forming the bend. The surface which comes uppermost is, as usual, the dorsal surface, and the locomotive organs are ventral. They consist of two pairs of pseudopods or prolegs, armed with hooks, and borne upon the fourth and fifth segments. On the eighth, ninth, and tenth segments are bunches of setæ which answer to some extent the same purpose; these are called legs by Réaumur. At the tail-end and on the dorsal surface is a respiratory cup, of the same nature as

1 Hist. des Insectes, Tom. VI. p. 380.

2 De eucephale Myggelarver (1886). 
that found in the larvæ of Hydrobius and Pericoma. Valves and flaps and

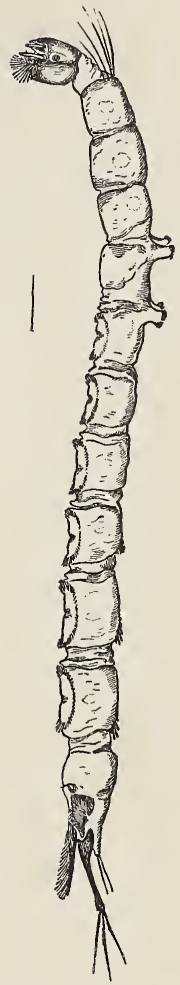

FIG. 47.-Larva of Dixa, in side-view and from above. The species here figured is not described in any of the systematic books which I have consulted. The fly is $6 \mathrm{~mm}$. long, of yellow colour, and with uniformly clear wings. outstanding processes, all fringed with long hairs, exclude the water from a shallow sunk space, upon which the longitudinal tracheal trunks open.

The body is bent from side to side, not from above downwards. Hence the whole of the proper dorsal surface remains dorsal. Six segments (5-10) are protected on the dorsal side by as many shields, all fringed by setæ. ${ }^{1}$

Réaumur's statement that the two ends of the body are in the water, while the middle is out of the water, is liable to mislead. It would be more correct to say that the two ends are turned

1 These shields are not found in all species of Dixa. They are absent in the larva figured by Meinert, which occurs also in England. 
towards the water, while the bend is turned away from it. The larva frequents pools which are overgrown with vegetation. It creeps upon leaves which rise a little way out of the water, and lies upon them with its head and tail close to the edge of the water. The bend is commonly above the water-line, but is completely wetted; it does not break the surface-film. Even when the larva has crept above the water-line it is, strictly speaking, submerged, for it takes with it a watery film; the body is bent into a $\mathrm{V}$, the apex of

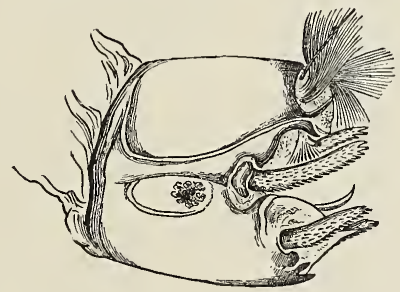

FiG. 48.-Head of larva of Dixa, side-view.

which travels foremost, and each half of the $\mathrm{V}$ alternately shoves the body onwards. Larvæ placed in a cup of water often wander to a distance and perish by drying up. The respiratory cup is the only part of the body which is dry, and this is in free communication with the air. The head is commonly sunk into the water, but close beneath the surface. The ciliary organs which surround the mouth are constantly employed, like those of a Gnat larva, in sweeping microscopic particles into the gullet, and this action is greatly promoted by the extraordinary 
mobility of the head, which can be bent completely back till it touches the prothorax, or screwed round till the line of the mouth lies in the axis of the body. If the larva should slip into deep water, the respiratory cup remains free from water, and buoys up the tail. If the whole body is sunk beneath the surface, a bubble is carried down enclosed in the fringes of the respiratory cup. The larva when thus submerged, swims energetically after the manner of a Chironomus larva, twitching its body this way and that, and making pretty rapid, though unsteady progress. It can readily regain the surface of the water.

The larva of Dixa makes use of the surface-film not only to buoy up its tail, and to keep water out of its air-filled basin, but also as an aid in climbing. When it leaves the water it takes with it a closefitting, contractile film, which binds it to any wettable surface with which it comes in contact. This use of the film will become more evident if we suppose that we have to climb a slippery pole. We grasp it as hard as we can with arms and legs, and should find the task greatly facilitated by a strong band of indiarubber, which embraced both body and pole, and spared us the necessity of grasping. The Dixa larva is bound to the surface of a leaf by its contractile water-film, and can therefore employ all its strength in shoving itself along.

The same principle is turned to account by a Gyrinus when it creeps up a smooth surface, though here only the ventral surface of the Insect is wetted. Mr. Scourfield has shown that certain 
Copepod Crustacea creep out of water by a similar use of the surface-film. ${ }^{1}$

The attitude, the mode of breathing and the mode of feeding observed in the larva of Dixa, are curiously
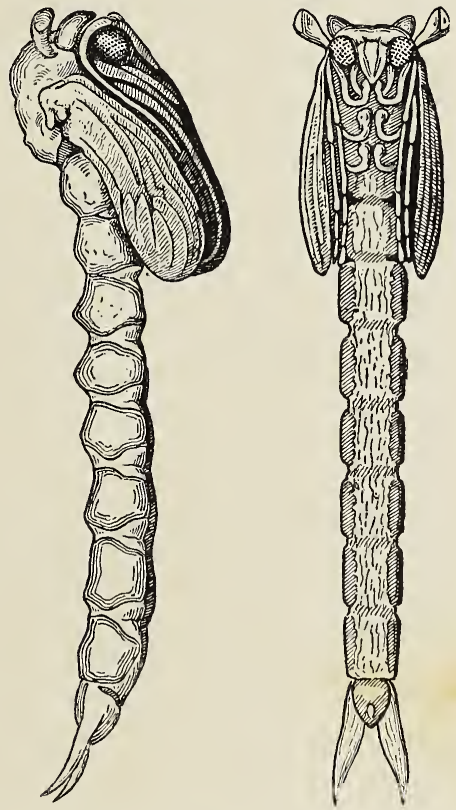

Fig. 49.-Pupa of Dixa in side-view, and from ventral aspect.

like those of a certain Gnat larva, Anopheles. So close is the resemblance that an experienced entomologist has, in a published paper, mistaken one for the

${ }^{1}$ Journ. Linn. Soc. Zool., Vol. XXV. p. I8 (1894). 
other. There are few better examples of adaptive resemblance.

The pupa of Dixa is coiled into a nearly circular disc, the abdomen being bent forwards beneath the thorax. It has a pair of respiratory trumpets behind the head, and either floats in a vertical position at the surface of still water, or lies surrounded by the vegetation which grows on the margin. It moves but little, so far as I have seen.

The larva is of a full black colour, and very inconspicuous upon decaying vegetation. It may be found from spring to late autumn, though in the height of summer, when the transformation occurs, the larvæ become scarce. Though very few English naturalists have seen them, they are probably common enough.

\section{Dicranota.}

At the bottom of muddy pools and slow streams there may often be found small red worms, half buried in the mud. They attain a length of perhaps a couple of inches. The head-end is concealed in mud. The tail-end, which is more slender, projects, and waves to and fro in the water, as if to effect the aëration of the blood. If withdrawn from the mud, the worms throw themselves into tight coils, and sometimes form a tangled mass at the top of the mud. The red colour is due to hæmoglobin in the blood, which courses along fine vessels, as in the Earthworm, to which this animal, which is called Tubifex, is rather closely related. Tubifex moves or withdraws itself into its burrow by means of hooks projecting 
from its body. There are four rows of these, and each ends in two points. This little aquatic worm constitutes the favourite food of more than one Insect, which pursue it, as the larva of the Tiger-beetle does the Earthworm. I have lately investigated the structure and habits of a Dipterous larva which lives upon Tubifex. This is the larva of Dicranota. The full-grown larva is ahout threequarters of an inch long, and of a dirty white colour. Commonly it buries itself in gravel and mud, and may be fished out of the bed of a stream containing Tubifex. It creeps with some rapidity through the mud, and rarely exposes itself to view. It can also swim about in the water with a lashing or serpentine movement not unlike that of the Chironomus larva. Now and then it leaves the water altogether. The food of the Dicranota larva is readily ascertained by observing that the stomach contains a red substance after Tubifex has been supplied to it. The peculiar

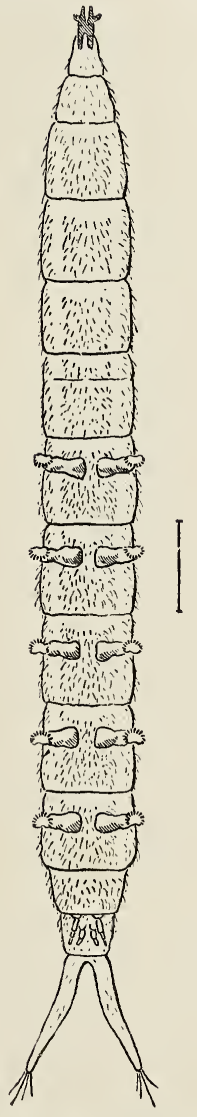

Fig. 50.-Larva of Dicranota bimaculata. This and following figs. are copied from a paper by L. C. Miall in Trans. Entom. Soc., 1893 . 
double crotchets of the worm can also be seen by the microscope in the stomach or intestine. Like some other carnivorous animals, the larvæ can endure a long fast. Before I knew of what their food consisted, I kept them in small vessels filled with earth and water, and found that they lived and moved about actively for several weeks without food. It

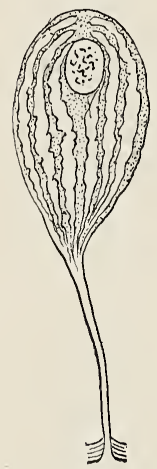

FIG. 5x.-Gland-cell of skin of Dicranota larva, with its duct, opening on the surface.

seems to be well established that certain Ticks, e.g. Argas persicus and Argas reflexus (the Canterbury Tick) can live for at least four years without drawing blood. ${ }^{1}$ In order that the Dicranota larva may be able to pursue the worms, and follow them into the depths of their burrows, it is necessary that it should be able to travel with tolerable speed through mud and gravel. Its body is accordingly furnished with feet suited to such a mode of locomotion. Five segments near the hinder end of the body are provided with paired feet, which resemble the false feet of caterpillars. Each of these is furnished at the tip with three circles of hooks, the terminal ones being the longest. ${ }^{2}$ Almost the whole of the surface of the body is covered by a dense growth of minute pointed hairs, which are directed backwards. In order that

A. D. Michael in Natural Science, Vol. I. p. 202.

2 These circles are not complete, but interrupted variously, as was pointed out to me by Mr. J. J. Wilkinson of Skipton. 
the head may not take any harm from rubbing against hard objects, it can be completely retracted into the body.

The most notable features of the mouth-parts are a pair of mandibles with long curved teeth. The top of the head is defended by a strong shield, from the under side of which, along the middle line, hangs downwards a vertical plate. This plate, as well as the rest of the shield, gives origin to muscles, and especially to the powerful muscles which move the jaws. There is a pair of small antennæ,

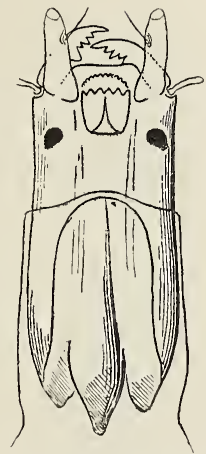

Fig. 52,-Head of larva of Dicranota, ventral surface, and two rudimentary eye-spots on each side of the head. Towards the tail are three pairs of tapering prominences; the hindmost pair is very long, and forms the extremity of the body. These appendages

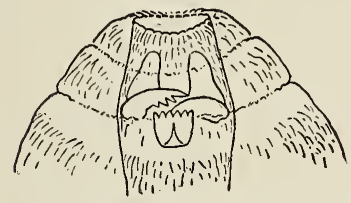

Fig. 53. - Head of larva of Dicranota, retracted into thorax. are supplied with relatively large air-tubes, and are probably of use in aerrating the blood. Other means of respiration are provided in the form of spiracles. As in a good many other Insect-larvæ, which inhabit water or burrow in the earth, there is only one pair of spiracles, which are situated at the hinder end. 
of the body. A large tracheal tube is connected with each spiracle, and runs along the body to the head, giving off many branches to the

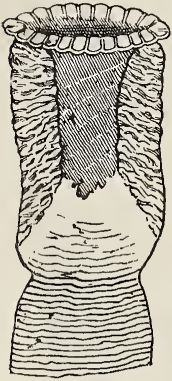

Fig. 54.-Spiracle of larva of Dicranota, seen in side-view as a transparent object. various organs. The spiracle itself consists of a solid cone received within a wider tube, or vestibule. The cone is long and tapering, and apparently impervious. The behaviour of the living larva would seem nevertheless to indicate that the spiracle is actually employed in respiration. When it comes to the surface of the mud, it commonly protrudes the hinder end of its body. This is furnished with the three pairs of prominences already mentioned, which are probably tracheal gills, and also with spiracles. We can therefore understand how it is that the larva seems to be indifferent whether its tail projects into air or water. It will lie for a long time in either condition without signs of uneasiness. When it re-enters the water, after its tail has been exposed to the air, a bubble can often be seen attached to each spiracle.

The pupa, as in most other aquatic Dipterous Insects, is provided with a pair of respiratory trumpets placed just behind the head. These are flattened from before backwards, and have a rather sharp edge. Within each trumpet is an expanded tracheal tube, which blends with the outer integument along the edge. The line of junction is perforated by a regular row of small oval apertures, which no 
doubt serve for the admission of air to the trachea; their minute size must constitute an effective provision against the entrance of water or dirt. Along the back of the pupa are a number of transverse rows of minute spines. Almost the entire surface of the thorax is roughened in the same way. Five of the abdominal segments bear paired prominences on the ventral side. By means of these spines and fleshy processes, the pupa can travel through the mud, and come to the surface, when the fly is ready to emerge. A pupa, when laid upon damp mud, readily moves about, and in no long time establishes itself in a convenient position just below the surface. Many other pupæ of the most diverse sorts, which bury themselves in earth or wood, have some provision of the same kind. The pupa of the Daddy-long-legs is armed like that of Dicranota. Every collector of Moths will recollect the spiny rings of the pupæ of the Clear-wings, the Goat-moth, the Wood Leopard, and the Swifts. The roughening of the abdomen in such cases gives it a sufficient hold on surrounding objects to enable the Insect to creep to the surface before the final change takes

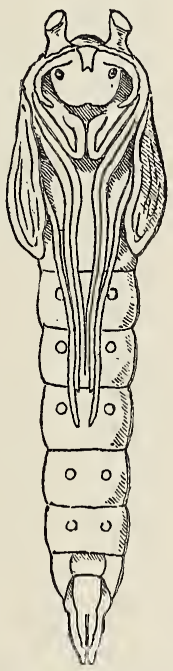

Fig. 55.-Pupa of Dicranota, ventral surface. place, thus avoiding the damage to gauzy or plumed wings, which would inevitably result if the moth or fly emerged in a narrow gallery, or below the surface 
of the ground. As in many other aquatic Diptera, the pupa is notably smaller than the larva. In Dicranota it is only three eighths of an inch long, less than half the length of the larva.

I have never seen the eggs of Dicranota, but the structure of the glands of the female fly leads me to suppose that they are enveloped in a slimy mass or egg-rope, and laid in water.

I have described the anatomy of the larva and pupa pretty fully in the Transactions of the Entomological Society (1893). Since the publication of my paper I have ascertained that Dicranota is not at all uncommon in Yorkshire, and probably in other parts of the country also.

\section{PTYCHOPTERA.}

In shallow muddy pools the larvæ and pupæ of species of Ptychoptera are often plentiful. The whitish bodies of the larvæ can sometimes be seen floating near the surface or lying above the mud, but more frequently the body is buried, and only the tip of the long slender tail protrudes through a small hole. Sometimes the mud is pitted with scores of such holes, like the places in which we find the little red worms called Tubifex. If we dig with a trowel in the mud so pitted, a plentiful supply of the larvæ can often be obtained. They are to be found throughout the year, but the pupæ occur only in the spring and summer.

The body of the larva might easily be mistaken for that of an Eristal:s, on account of its long and 
retractile tail. It can, however, be distinguished from Eristalis by the much more complete head, and by the presence of two slender appendages, one at each side of the root of the tail. A minute examination reveals many other points of difference; indeed, the two larva only resemble one another in certain superficial characters, which immediately depend upon their similarity of habitat.

The head of the larva is hard and small, not unlike that of the Chironomus larva, but with many differences of detail. There is a pair of eye-spots, and two minute antennæ, which can only be made out by close examination. The mouthparts are a good deal like those of Chironomus.

Behind the head come twelve segments, and it is necessary to notice how these are adapted to the life of an animal which has to creep in and through mud.

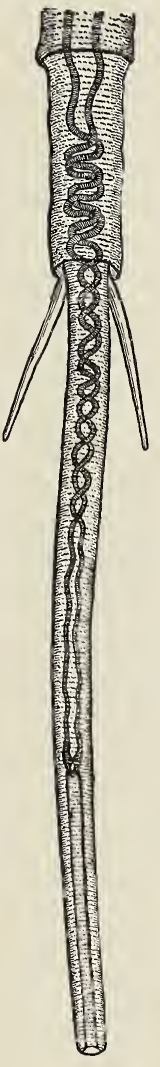

B

Fig. 56.-A, Larva of Ptychoptera paludosa ; B, tail of larva of Ptychoptera, much magnified, showing convoluted air-tubes and lateral appendages. 
Most of the segments are thickened behind, and on each of these annular thickenings a circle of stiff, backward-directed setæ (bristles) is borne. Like the differently arranged setæ of the Earth-worm, these give a sufficient hold to enable the animal to advance by alternate expansion and contraction of its segments. The action is aided by three pairs of hookbearing prominences, or pseudopods, of the same kind as the prolegs of caterpillars.

The body is provided with numerous sensory hairs, and also with two pairs of small vesicles situated on the sides of the body in the
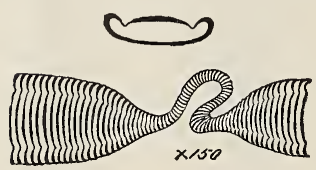

F1G. 57. - Trachea (air-tube) of larva of Ptychoptera, showing constriction. The upper figure shows a cross section of the same, and illustrates the provision for readily enlarging or contracting the tube. tenth and eleventh segments. These are described by Grobben ${ }^{1}$ as filled with a fluid, in which float refractive and transparent globules, three as a rule to each vesicle. A special nerve supplies the vesicle, which dilates to form a ganglioncell, and then tapers to its termination in the wall of the vesicle. These vesicles are considered by Grobben to be auditory, but no adequate reason is assigned.

At the root of the long tail there is on each side a long and slender appendage, which contains a relatively large trachea. This is no doubt, as Grobben says, a tracheal gill. A more important respiratory organ is the long and retractile tail itself, which can,

1 Sitz. d. k. Akad. d. wiss. Wien. 1875. 
as in the Eristalis larva, be adapted to a varying depth of water.

At the extremity of the tail are two openings ${ }^{1}$ by means of which air is passed into the two tracheal tubes, which traverse the length of the tail, and are continued through the whole length of the body. In the centre of most of the segments the tracher become greatly enlarged, the intervening portions, from which many branches are given off, being comparatively narrow. Each tube, therefore, resembles a row of bladders connected by small necks. A cross-section shows that the tubes are not cylindrical, but flattened, and that while the lower surface is stiffened by the usual parallel thickenings, the upper surface is thrown into two deep, longitudinal furrows, so that it is readily inflated into a cylindrical shape, and readily collapses again when the air is expelled. It seems likely that the buoyancy of the larva can thus be regulated, and a larger or smaller quantity of air taken in as desired. ${ }^{2}$

The larva, thus fortified against any interruption of its supply of air, lies at its ease on or in the water, stretching out its long tail to the surface, and breaking the surface-film, like the Eristalis larva, by the extremity of the appendage.

The pupa has a pair of respiratory tubes, which are carried on the thorax, close behind the head. One of these tubes is very long, the other very short and altogether functionless. The long tube is twice

1 Grobben, loc. cit.

2 Grobben observes that in very young larva the main tracheæ are cylindrical, and of uniform diameter. 
as long as the body, and tapers very gradually to its

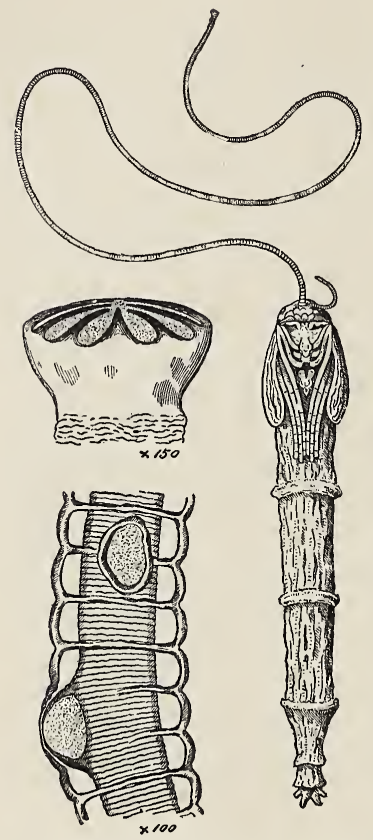

FIG. 58.-Pupa of Ptychoptera paludosa, with long respiratory tube. A second (rudimentary) tube is also seen. The figures to the left show the extremity of the tube, and a portion of the middle, both highly magnified. The trachea lies in the tube. Both thin out at the bladder-like swellings, and come close together, as if to allow a free interchange of gases.

free tip. Here we find a curious radiate structure, rather like the peristome of a moss-capsule, which seems adapted for opening and closing. There is, however, no orifice which the most careful scrutiny has succeeded in discovering. A delicate membrane extends between the teeth, and prevents any passage inwards or outwards of air in mass. The tube encloses a large trachea, the continuation of one of the main tracheal trunks. This is stiffened by a spiral coil, but at intervals we find the coildeficient, while the wall of the tube swells out into a thin bladder. However the tube is turned, a number of these bladders come to the surface. As the pupa lies on the surface of the mud, the filament floats on the top of the water, and the air 
is renewed without effort through the thin-walled bladders. ${ }^{1}$

The head and thorax of the pupa are defended and roughened by many minute projections. The abdomen is softer, but armed with five circles of fine spines. Thus, as in Dicranota and many other Insects, the pupa is enabled to creep to the surface of the ground before the extrication of the fly. Like many other Dipterous pupæ, it has a fair degree of mobility, and can travel about in the ground, so as to choose a situation as convenient as possible in respect of dampness.

\section{Simulium.}

In brisk and lively streams the little, blackish larvæ of Simulium can sometimes be found in countless numbers. They attach themselves by choice to water-weeds, such as float-grass, water-cress, watercrowfoot, and the like. They may also be found on stones, but I believe that the larvæ found in stony streams belong to a different species. In a stream where all the necessary conditions are fully satisfied, where there is a never-failing supply of well-aërated water, plenty of submerged foliage, and plenty of microscopic organisms, the larvæ sometimes abound, looking like small black worms, five-eighths of an inch or less in length. When the leaves are examined by the eye alone, without handling, perhaps hardly a

1 Grobben describes minute orifices in the outer wall of these bladders which I have not myself seen. It is often a matter of the greatest difficulty to decide whether a minute and transparent membrane is completely closed or perforated. 
single larva will be seen. They are clustered for the most part on the under side, and only become visible when the leaf is plucked or turned over. They are most numerous where the current is brisk. In Yorkshire I find them plentiful in weedy streams which come down from the moors, and especially in the rapids above waterfalls. Hagen describes the larvæ and pupæ of Simulium pictipes as abounding in the

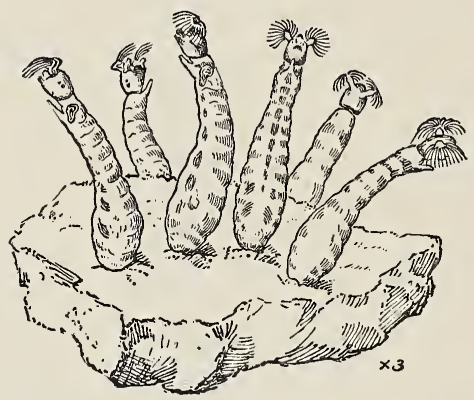

FIG. 59.-Group of larvæ of Simulium attached to a stone.

rapids of the Ausable River, in the Adonirack Mountains. Here the pupa-cases are fixed to the rocks in clusters, which resemble small wasps' nests. ${ }^{1}$ Though the larvæ require well-aërated water, it need not be pure. Streams contaminated with sewage often contain them in great numbers. ${ }^{2}$

1 Proc. Boston Soc. Nat. Hist. Vol. XX. pp. 305-7 (1 880).

2 The species which I have chiefly studied appear to be S. latipes (stony streams) and S. reptans (on water-weeds in rapid streams). 
The food of the larva is altogether microscopic. I have found the stomach filled with the flinty valves of Diatoms and Desmids, with here and there bits of a small Crustacean. A pair of fringed appendages, one on each side of the head, are employed, like the similar apparatus of the Gnat larva, in sweeping particles into the gullet.

The body of the larva is cylindrical, and dilated in the hinder part of the abdomen. The mouth-parts are represented in Fig. 6 I. In addition to these are seen the fan-like appendages, each provided with

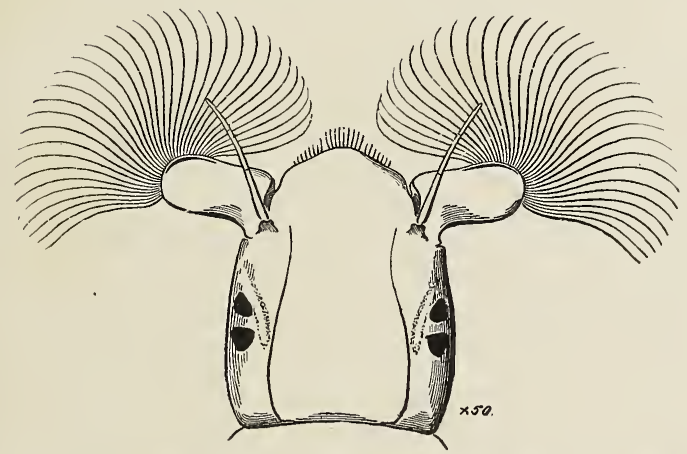

Fig. 6o.-Head of larva of Simulium, dorsal view, showing eye-spots, antennæ, and fringed appendages.

about fifty long filaments, which are feathered along one side, and sweep the food into the gullet. Since the subsistence of the larva depends upon these delicate organs it is not surprising to find that great pains are taken to keep them from being clogged. 
By the help of a lens the larva can often be seen combing them out with its mandibles. There are two

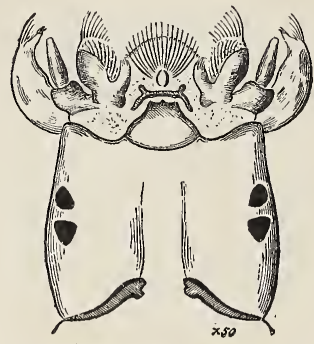

Fig. 6r.-Head of larva of Simulium, ventral view, showing mouth-organs. The eye-spots of the dorsal surface are seen through. pairs of eyes, which are reduced to mere pigment spots, and small threejointed antennæ.

There are two pairs of legs, as in the larva of Chironomus, and these end in coronets of hooks. But in the Simulium larva there is no burrow to cling to, and the legs become greatly modified. Each pair coalesces to form a single organ, which is mainly employed as a sucker. The fore pair, borne upon the first thoracic segment, is however occasionally used in grasping, being opposable to the head. The action of these suckers is easily demonstrated by placing a larva fresh from the stream in a saucer of water. It creeps about like a Leech, applying the two ends of its body alternately to the smooth surface of the saucer. Even in a rushing stream it appears never to be detached against its will. The hooks, not unlike in form to the hooks found on the legs of the Chironomus larva, form concentric rows on the extremity of the fused legs of the Simulium larva. They are probably useful to prevent slipping upon the smooth leaf or slimy stone. In the suckers of a Cuttle-fish we find the same contrivance resorted to. Each sucker is a cup whose cavity can be en- 
larged by muscular pull, so that the pressure within the cup becomes less than the external pressure. The edge of the cup is roughened, as in Simulium: by numerous minute teeth, which prevent slipping.

The larva, when feeding, holds on by its tail-sucker, and sticks its body straight out into the current. But if the currcat is unusually strong, the larva, when not feeding, often doubles up its body, and holds on to the surface of the leaf by both suckers.

The life of a submerged Insect in a rapid current has of course its own special difficulties. The Simulium larva has to creep from leaf to leaf, to change its position as the stream rises and falls, and to avoid dangerous enemies. Of these enemies aquatic larvæ, and especially Caddis-worms, are the commonest and most formidable. In moving about there is always risk of being accidentally dislodged, and the consequences of this might be serious. For if a larva should let go or miss its hold in a rapid stream, what is likely to happen? It seems inevitable that it will be swept away, and who knows where it will come to rest? The little rivulet which I am accustomed to visit for the purpose of observing this larva is a bright clear stream, flowing over water-cress and brook-lime and forget-me-not. A few feet lower down it ends in the wide and stony Wharfe, a stream of quite different character, in which I have never been able to discover a single specimen of the same species. Other brooks in which the larvæ are plentiful, empty themselves into rivers unsuited to an Insect of habits so peculiar-muddy, sluggish, or brackish. But this difficulty has been provided 
against, and I find that the larva is seldom or never swept away, even when its haunts are invaded by a groping naturalist. Its swimming power, I should explain, is inconsiderable, altogether insufficient for propulsion against a rapid stream. If seriously alarmed, the larva lets go, and immediately disappears from sight. But by watching the place attentively, we shall before long see the larva working its way back, and in a

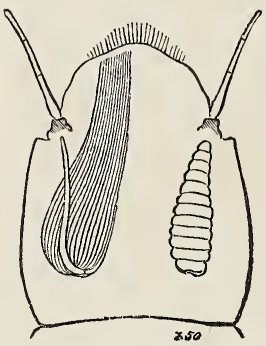

F1G, 62.-Head of larva of Simulium, showing on left side the position and form of the new larval antenna and fringed appendage, which will become external at the next moult ; on right side the new imaginal antenna, whicl will become external after pupation.

minute or two it will be found attached to the very same leaf from which it started, or to some other leaf, equally convenient, which it happens to fall in with. I found the difficulties of observation in fastflowing water crowded with leaves very great, until at last it occurred to me to push a white plate in among the leaves. Then the darkcoloured larvæ became perfectly evident on the white ground, and I was able to see exactly how they managed. When disturbed by the plate, some of them let go, and drift a few inches away. They are not very easily frightened, and most of them remain holding on by their sucker. Those which quit the leaf remain stationary in the torrent or nearly so, and on close observation a thread, or perhaps a number of threads, become visible on the white ground. These threads are in general stuck all over 
with small vegetable particles, like fine dust, which make them much more apparent. The threads extend in all directions from leaf to leaf, and the larva has access to a perfect labyrinth, along which it can travel to a fresh place by help of the current and with the speed of lightning. I suppose that it grasps the thread with its prothoracic claws, for when it comes to rest it is always found holding on by them. To recover its first position is not difficult if the network of threads is intact, or if the larva has even a single thread to grasp. Sometimes it hauls itself up hand over hand, like a Leech or a Looping caterpillar, applying its two suckers alternately to the thread. It can also creep along its thread by means of the prothoracic hooks only. I have often seen the body swept into a position at right angles or nearly so with the thread; then the larva seems to be holding fast by its head. When thus attached, it can travel against the stream at a slow but quite appreciable rate.

Although the larva commonly slides along a thread previously made, and easily seen to be an old one by the small particles which cling to it, it can upon a sudden emergency spin a new thread, like a Spider or a Geometer larva. The new threads are perfectly clean, and consequently invisible even on a white ground so long as they are submerged. I got proof of the formation of fresh-spun threads by dislodging larve which had attached themselves to leaves wiped clean a minute before. But the clearest proof is got by suddenly lifting out of the water a leaf with many larvæ upon it. One or two are pretty sure to let 
themselves drop a foot or more in the air, and the thread can be seen to glisten in the sun, and to lengthen itself at the pleasure of the Insect. The Simulium larva, possessing this power of instantan-

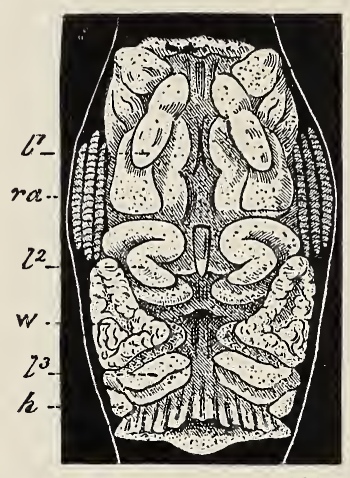

FlG. 63. - Late larva of Simulium, showing changes within the larval skin. $l^{1}, l^{2}, l^{3}$, fore, middle and hind legs of fly ; $r a$, respiratory appendages of pupa ; $w$, wing of fly; $h$, haltere of fly.

eously manufacturing a rope, can hardly be taken at a serious disadvantage.

The salivary glands, which secrete the silk, are unusually large in this larva. They extend the whole length of the body, and then bend forwards for a third of its length. The tracheal tubes are large, and give off a network of fine branches to the skin. These appear to absorb oxygen from the water, for there is no opening into the tracheal system.

When the time for pupation comes, special provision has to be made for the peculiar circumstances 
in which the whole of the aquatic life of the Simulium is passed. An inactive and exposed pupa, like that of Chironomus, may fare well enough on the soft
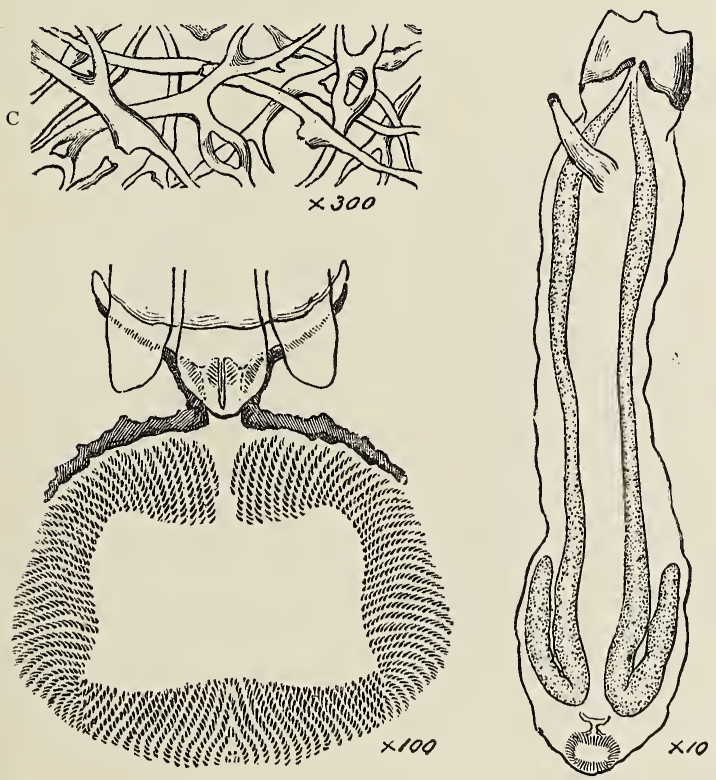

F1G. 64.-Simulium. A, larva in ontline, with salivary glard: B, coronet of hooks at tail-end of larva. C, part of silken cocoon of pupa, showing its interwoven fibres, the product of the salivary glands.

muddy bottom of a slow stream, but such a pupa would be swept away in a moment by the currents in which Simulium is most at home. Before pupation the Insect constructs for itself a kind of nest, 
not unlike in shape to the nests of some Swallows. This nest is glued fast to the surface of a water-weed. The salivary glands, which furnished the mooringthreads, supply the material of which the nest is composed. Sheltered within this smooth and tapering cocoon, whose pointed tip is directed up-stream,

A

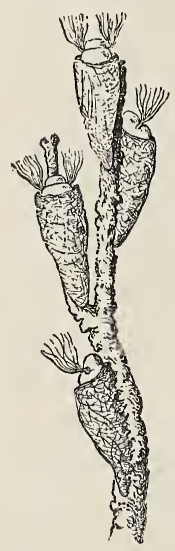

B

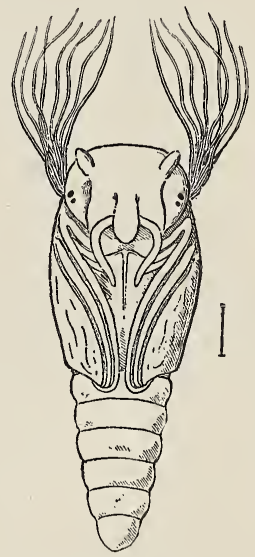

FIG. 65.-A, four pupæ of Simulium in their cocoons, attached to aquatic stem ; B, pupa of Simulium, removed from its cocoon.

while the open mouth is turned down-stream, the pupa rests securely during the time of its transformation.

When the cocoon is first formed, it is completely closed, but, when the Insect has cast the larval skin, one end of the cocoon is knocked off, and the pupa now thrusts the fore-part of its body into the current 
of water. The respiratory filaments, which project. immediately behind the future head, just as in Chironomus, draw a sufficient supply of air from the well-aërated water around. The rings of the abdomen are furnished with a number of projecting hooks, and as the interior of the cocoon is felted by silken threads, the pupa gets a firm grip of its cocoon. If it is forcibly dislodged a number of the silken threads are drawn out from the felted lining.

A serious difficulty now appears. The fly is a delicate and minute Insect, with gauzy wings. How does it escape from the rushing water into the air above, where the remainder of its life has to be passed? This was a question upon which I spent much thought, but in vain. It appeared to me for many months completely insoluble. In the stream at my feet I could see countless pupæ. There were also empty cocoons, containing, as close examination showed, the cast pupal skin of Simulium, still attached to the felted lining, and the last larval skin as well. On the bushes which overhung the stream innumerable Simulium flies were resting. How had they made their way in safety after the last transformation, although their structure was to all appearance extremely ill adapted to such a manœuvre, through the strong current into the upper air? I was at last informed by Baron Osten Sacken of a paper written by Verdat, seventy years ago, in which the emergence of the fly of Simulium is described. ${ }^{1}$ During the

1 Gesch. d. Simulien, Naturw. anz. d. allg. Schw. Gesellsch. (1822). Translated by Osten Sacken, in Amer. Ent. Vol. II. p. 229. 
I86 NATURAL HISTORY OF AQUATIC INSECTS $\mathrm{cH}$.

latter part of the pupal stage, which lasts about a fortnight in all, the pupa-skin becomes inflated with air, which is extracted from the water, and passed apparently through the spiracles of the fly into the space immediately within the pupal skin. The pupal skin thus becomes distended with air, and assumes

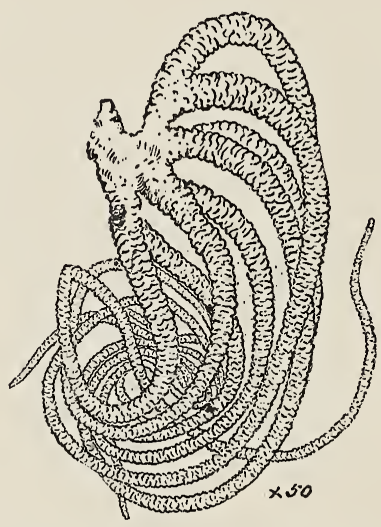

FIG. 66.-Respiratory appendage of pupa of Simulium, consisting of four branched tubes. Removed from beneath larval skin, and therefore unexpanded.

a more rounded shape in consequence. At length it splits along the back, in the way usual among Insects, and there emerges a small bubble of air, which rises quickly to the surface of the water and then bursts. When the bubble bursts, out comes the fly. It spreads its hairy legs, and runs upon the surface of the water to find some solid support up which it can 
climb. As soon as its wings are dry, it flies to the trees or bushes overhanging the stream. ${ }^{1}$

The ascent of the Simulium fly through the waters of a rushing stream is rendered safe by the hairy surface of the body. The surface-film, by which the air is imprisoned, clings to the hairs, and refuses to enter the fine spaces between them. In the same way a covering of velvety hairs prevents the Diving Spider, as well as many diving Insects, from wetting that part of their bodies which bears the spiracles.

The flies of Simulium congregate, sometimes in extraordinary numbers, on bushes and low trees near the streams which harboured the larvæ and pupæ. The males are distinguished from the females by their large heads, a great part of which is covered by the enormous compound eyes. In the male, but not in the female, the upper part of each eye is built up of larger facets than the lower half. No reason is known for this curious feature, which is not unparalleled among Insects. The thorax is of large size, the abdomen small. The legs are little used for walking, but are continually exercised in what look like exploring movements, the flies patting the surface of a leaf with their feet. They are said to

1 Verdat's original description is graphic and worth quotation. When the fly reaches the surface of the water, he says, "tous ses membres se déploient à la fois comme par explosion. Il se tient facilement sur l'eau, où il marche par le secours des pelottes de l'extremité des tarses, qui sont alors bien développés, et il gagne une tige voisine sans se mouiller. En très peu de temps ses ailes sont deployées et affermies. Il quitte son berceau en prenant son essor, se répand partout dans la campagne pour y chercher des alimens et sa femelle." 
suck the juices of leaves and the honey-dew secreted by Aphides. Verdat says that they distend their abdomen with blood. De Geer says that they attack large, smooth caterpillars, sucking their blood. The caterpillars, he adds, do not take much notice of them. ${ }^{1}$ The males love sunshine, and may be seen in swarms high in the air. The females generally remain at lower levels. ${ }^{2}$

In some countries the flies of various species of Simulium have proved a serious plague by the irritation which they cause to men, horses, and cattle. In Hungary and on the lower Danube great losses have resulted. The bite raises a small blister, and rouses the cattle to fury. They rush about wildly, rubbing their hides against rocks or trees. The corner of the eye is the part of man said to be aimed at. Swarms of these flies have greatly annoyed certain Australian exploring expeditions. In Britain the flies of Simulium are perfectly harmless.

The pupæ and flies may be found in great numbers in April and May, and again in August. The Insect winters as a larva, gaining maturity in spring, and laying eggs, which produce the autumn brood.

The eggs are laid on stems and leaves of waterplants, hundreds being attached together in one gelatinous mass. They have a thick shell, and are of a yellow colour. They are like Chironomus eggs in shape, but are much less transparent.

1 Mémoires, Vol. I. p. 328.

2 Osten Sacken, Berl. Entom. Zeits. Bd. XXXVII. (1892).

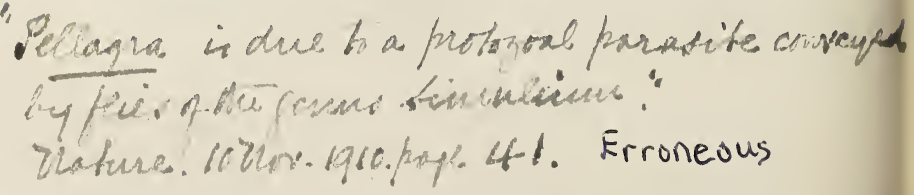




\section{STRATIOMys.}

The curious history of this Insect has been described for us by two master-hands. Swammerdam ${ }^{1}$ bestowed upon it all his skill and industry; and Réaumur ${ }^{2}$ independently worked over the same ground. Réaumur's fourth volume bears the same date (1738) as the second volume of the Biblia Natura, and Swammerdam's investigations were probably not accessible to him at the time of writing.

Several species of Stratiomys are common in Europe. The commonest and best known is $\mathrm{S}$. chamæleon, which is that figured by Swammerdam and probably one of those figured by Réaumur. ${ }^{3}$

The larva of this species is, when full grown, from two to three inches long, being capable of considerable elongation according to circumstances. The body is flattened and elliptical in cross-section, narrowed at each end, especially at the tail-end, which is very slender. Behind the small, horny head come eleven segments, which increase greatly in length and diminish in breadth towards the tail. Each of the first four segments is overlapped by the succeeding one, while the remainder are each overlapped by the segment in front, so as to facilitate a telescopic retraction at either end of the body. The skin is tough and flexible, and defended by a peculiar structure, to

1 Biblia N'atura, pp. 649-694; Pl. 39-42.

2 Mémoires, Tom. IV. Mém. VII. VIII.

3 Pl. 22 and part of Pl. 23. A number of Réaumur's figures belong to the closely related Odontomyia. 

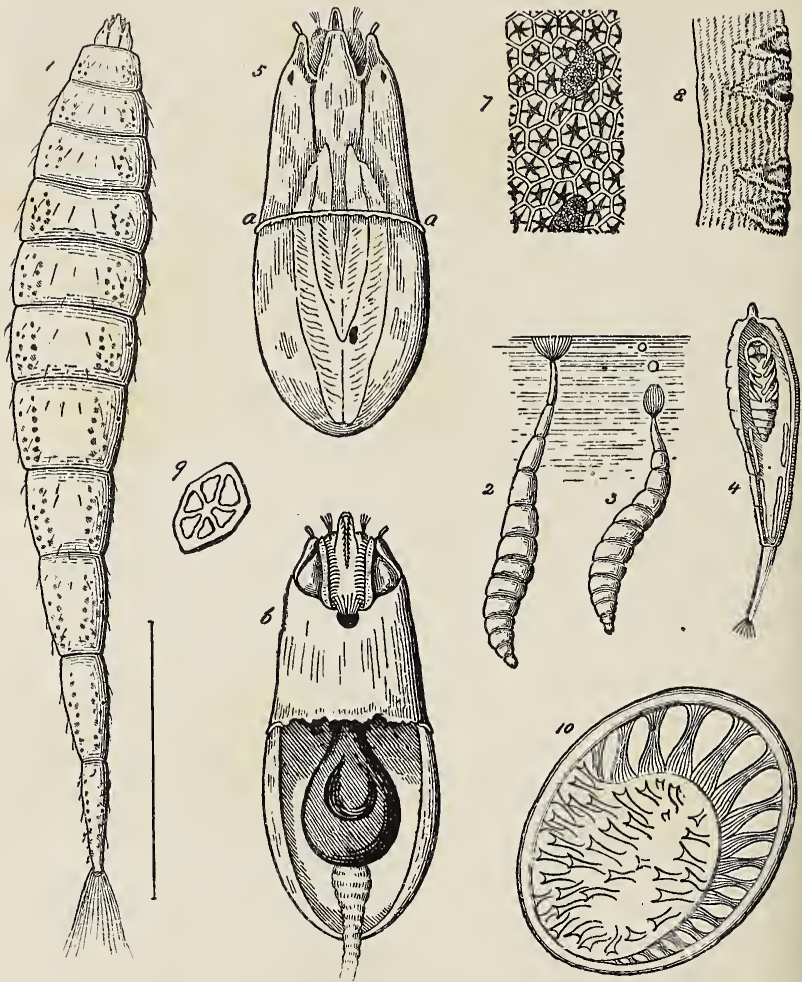

FIG, 67.-Stratiomys chamæleon. I, larva; 2, larva floating at surface of water; 3 , larva descending; 4 , pupa within larval skin $(2,3$, and 4 are from Swammerdam, Biblia Natura); 5 , head of larva, dorsal view, $a$ a marks the attachment of the thoracic integument ; 6 , head of larva, ventral view. The ventral wall is incomplete behind, and the pharynx and gullet are exposed; 7 , piece of integument ; 8, do. in section, with conical, calcareous nails ; 9 , a single calcareous nail, surface view ; ro, spiracle, lying in centre of tail-coronet. 
be described later on, against the attacks of predatory animals. The colour is in some degree protective, consisting of shades of green, brown, and yellow, and exhibiting an irregular pattern of spots and streaks. Stagnant waters of small extent, and especially ditches, are its favourite haunts. The larva of Odontomyia, which is very similar to that of Stratiomys, prefers the shelter of Duckweed and other aquatic plants. Stratiomys occurs in various parts of England, but is reputed rather rare, perhaps because so little attention has been paid by English naturalists to aquatic Diptera.

The head of the larva is greatly reduced, and consists of a middle part, black, horny and pointed, which is separated by deep clefts from the lateral parts. In these clefts lie the palps, which bear strong hairs. A number of hooks arm the mouth. The food consists of microscopic organisms swept into the mouth by the palps.

The extremity of the tail forms a beautiful coronet of branched filaments, about thirty in number, which are accessory to respiration. When this coronet is expanded it forms a basin open to the air and impervious to water, by reason of the fineness of the meshes between the component filaments. Were the larva provided with a basin of the same proportions formed out of continuous membrane it might float and breathe perfectly well, but would find it hard to free itself neatly and quickly from the surface-film when some sudden emergency rendered it necessary to descend. As it is, the plumed filaments collapse and their points approach; the side branches are folded 
in, and the basin is in a moment reduced to a pearshaped body, filled with a globule of air, and reaching the surface of the water only by its pointed extremity. Down goes the Stratiomys larva at the first hint of danger, swimming through the water with swaying and looping movements, somewhat like those of

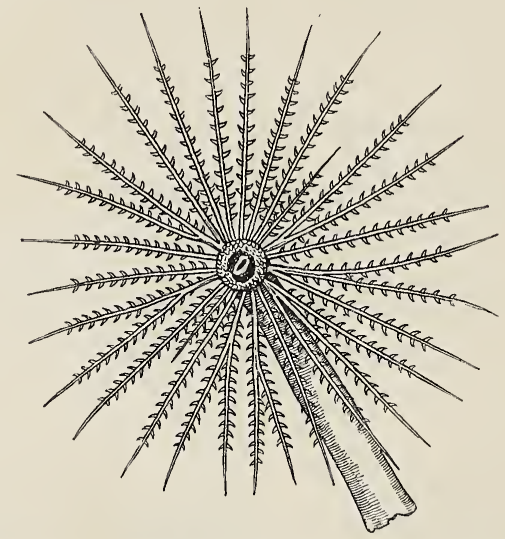

FIG. 68.-Tail-coronet of larva of Strationys chamæleon. From Swammerdam, Biblia Natura.

Chironomus. When the danger is past, it ceases to struggle, and floats again to the surface or swims upwards by a lashing movement. The pointed tip of its tail-fringe pierces the surface-film, the filaments separate once more, and the floating basin is restored.

In shallow water, the last one or two segments are usually bent upwards, so as to reach the surface. 
There are no limbs. The larva moves in the water by vigorous flexion of its body, first to one side and then to the other. It can also creep on earth or mud. Swammerdam observes that, like other Dipterous larvæ, it drags itself along by its mouth when out of the water. Alternate contraction and extension of the segments, aided by the stiff hairs which stand out from the body, are also used as a means of propulsion.

The wider part of the body lodges the alimentary canal, which is very long and thrown into complicated folds. The salivary or silk glands are tolerably large. A pair of very large air-tubes run along the body. Beginning as narrow tubes in the head, they dilate until they attain half the width of the body, gradually narrowing after this until they terminate in oval spiracles which occupy the centre of the coronet. There are nine pairs of spiracles on the sides of the body, which are not open, but take the form of black, circular plates. Branches from the longitudinal air-tubes pass to them on the inside. The second segment, which will ultimately carry the wings, has no spiracles. In the same way the second and third segments of Insect-larvæ which are destined to acquire two pairs of wings bear no spiracles, though closed tracheal tubes running to the surface may often be discovered by dissection in the places where spiracles would be expected.

Stratiomys changes to a pupa in early summer. The larvæ prefer to leave the water at this time, and bury themselves in the earth or in the floating vegetation of a ditch. Swammerdam says that even in a 
vessel containing nothing but water their transformation was not hindered. The Insect becomes rigid; its skin hardens and contracts to some extent; the last segments become distorted. On opening a larva which exhibits these marks of change, the animal will be found to have shrunk and changed its shape. It now presents the form of the

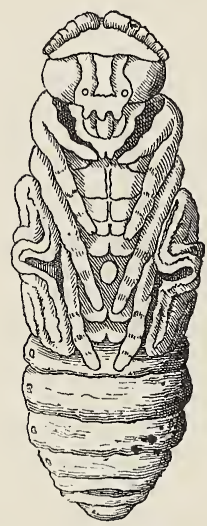

Fig. 69.-Pupa of Stratiomys, removed from larval skin. From Swammerdam, Biblia Natura. future fly, but is shrouded in a silky cocoon, the secretion of the salivary glands, and occupies only the fore part of the space within the larval skin (Fig. 67, 4). Some entomologists have even taken the pupa to be a parasite which had eaten up the larva of the Stratiomys, and undergone transformation in the empty skin. ${ }^{1}$ Remnants of the air-tubes and the cast lining of the intestine moor the pupa, as it were, to the tail of the larval skin. The great reduction in size of Stratiomys during transformation is an extreme case of what may often be remarked in Insects. The larva gets some unknown advantage from a length and bulk which would apparently be inconvenient to the flying Insect.

The peculiar structure of the larval skin now acquires a special value, especially when the pupa is

1 Westwood, Classification of Insects, II. p. 532, quotes such cases. 
not buried in earth, but floating on water. The larva can descend into the water when attacked, but the pupa is too buoyant, and too much encumbered by its outer case, to execute any such manœuvre. Provision has accordingly to be made for the protection of the helpless pupa against its many enemies. It is probable that hungry Insects and Birds mistake the shapeless larval skin, floating passively at the surface, for a dead object. The considerable space between the outer envelope, or larval skin, and the body of the pupa may keep off others, for the first bite of a Dytiscus or Dragon-fly larva would be disappointing. Still further security is gained by the texture of the larval skin itself. The cuticle consists of two layers. The inner is comparatively soft and laminated, while the outer layer is impregnated with calcareous salts, and extremely hard (Fig. 67, 7,8 ). The needful flexibility is obtained by the subdivision of the hard outer layer. Seen from the surface, it is broken up into a multitude of hexagonal fields, each of which forms the base of a conical projection, reaching far into the softer layer beneath. The conical shape of these calcareous nails allows a certain amount of bending of the cuticle, while the whole exposed surface is protected by an armour, in which even the pointed mandibles of a Dytiscus larva can find no effective chink.

Swammerdam once found a pupa of Stratiomys dead within its larval skin. In the abdomen were larvæ and pupæ of a parasitic Insect (perhaps an Ichneumon or a Tachina) which had sprung from eggs laid within the Stratiomys. Neither water nor hard skin can exclude these cruel and insidious enemies. 
The pupa-stage lasts for a very few days and then the fly emerges. The larval skin splits across the third and fifth segments, and also along the middle line between these segments. ${ }^{1}$ The fly then pushes its way out, and Réaumur tells us that it suffers no inconvenience if it emerges from a floating larval skin. The hairs which cover all parts of its body prevent it from being wetted, and it can stand upon the water as upon solid ground. The deserted larval skin, which served as a cocoon, contains nothing but torn tracheal tubes and the cast lining of the gullet and intestine.

When the fly first appears its wings are crumpled, but they soon unfold by injection of blood into their veins and of air into their air-tubes. At this time they bleed if cut, which is not the case afterwards.

The fly has at first sight a Bee-like appearance. Its abdomen is broad and flat, of a full black with yellow patches and spots. The wings when at rest lie one over the other, do not cover the sides of the body, and project beyond it. The antennæ are simpler in structure than those of the Blow-fly; they are commonly described as 3 -jointed, but the socalled third joint is long and 5-ringed, as if formed by the consolidation of as many originally distinct joints. From the back of the thorax two spines stand out towards the abdomen, and hence the name Stratiomys, which means the "armed Fly." The winged Insect haunts flowers, especially heads of Umbellifers, and is most often seen in the neighbourhood of pools and ditches.

1 The exact position of the splits seems to vary according to the species, 
The structure of the antennæ is greatly relied upon by systematists as a mark of the leading groups of Diptera, and the antenne of Stratiomys are considered as intermediate between the many-jointed antennae of the Nemocera (Culex, Chironomus, Tipula, \&c.) and the highly specialised and peculiar antennæ of a Blow-fly or House-fly. This intermediate position of Stratiomys gives a special interest to the manner of its transformation. It is the simplest in structure and life-history, and the most like a Nemoceran, of all the Diptera which retain the larval skin as the outermost covering of the pupa. ${ }^{1}$ Here we find the artifice in its simplest form; it is protective and useful, but does not as yet involve serious alteration in the enclosed pupa. When the larval skin of Stratiomys bursts to allow of the escape of the fly, it bursts after the Nemoceran manner, that is, by splitting longitudinally, though there is also transverse fission. In the Muscidx the anterior segments of the larval skin are detached by a transverse fissure only. The protection afforded by the hardened larval skin seems to have led in the Muscidæ to a very peculiar and interesting process of destruction and regeneration of all the tissues of the body. The old organs break up, and the new organs are developed apparently anew, but really from rudiments developed during the larval stage. (See Chironomus, p. I35.) This pro-

1 Some species of Ceratopogon do not free themselves from the larval skin at the time of pupation, but allow it to encumber the tail of the pupa. The pupa of a certain species of Subula pushes out at the head end of the larval skin and remains sticking there. 
cess, once thought to be peculiar and unique, exhibits gradations too, and passes by many intermediate steps into a mere moult without change of shape. To trace and study these gradations is one of the most interesting of the biological problems of the future. Those who attempt to connect the Nemocera with the Muscidæ will find that Stratiomys is an important link, illustrating as it does the origin of a change which has profoundly modified the lifehistory.

The eggs are said to be attached in overlapping rows to the underside of aquatic plants.

\section{The Rat-tailed Maggot (ERistalis).}

The naturalist who comes across the Rat-tailed Maggot, a common inhabitant of stagnant pools, especially such as are foul with decaying organic matter, should turn at once to that memoir by Réaumur in which he speaks of "two-winged Flies which resemble Bees, Wasps and Hornets." For the sake of those who have not Réaumur at hand I will give the substance of his remarks, but I cannot hope to keep any of the charm of the original. Réaumur discourses in a leisurely way, talking freely of his personal experiences, and handling his subject with the light and amusing manner of an accomplished writer, who must needs be clear, but above all things hates pedantry. It is hard upon so pleasant an instructor that he should be compressed until all his individuality is lost, and those who can should by all 
means read Réaumur's own words rather than my abstract.

He remarks in the first place that there are Dipterous flies so curiously like Bees and Wasps that even an experienced entomologist will hesitate to handle them for fear of being stung. They have the colour, the size, and very nearly the shape of the formidable Insects which they imitate, and like them they haunt flowers. Some of them pass their feeding stage in water. The larva of Eristalis is one of these. It bears a very long tail, on which account Réaumur proposed for it a name which is still current, that of the Rat-tailed Maggot (ver à queue de rat).

The larva has seven pair of short feet set at nearly equal distances, the first being near the head, and the last not far from the root of the tail. The extremity of each foot is circular, and armed like the prolegs of a caterpillar with a large number of fine hooks; the feet can be retracted at pleasure. The hooks are set in a double circle, the circle next to the tip being made up of larger and less numerous hooks than the other. The

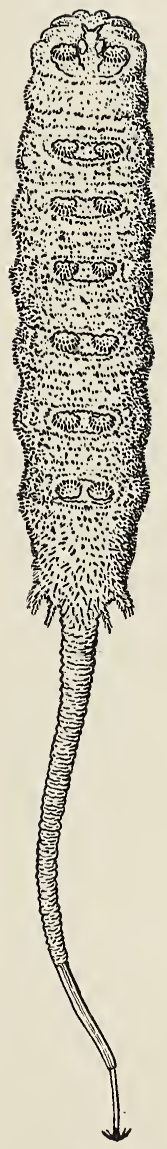

Fig. 70.-Larva of Eristalis, ventral view. 
extremity of the foremost pair of feet is not cylindrical as in the rest, but flattened, and the hooks project from it like the fingers from a hand. ${ }^{1}$

The larvæ of Eristalis were first brought to Réaumur singly; and had been found on the ground. $\mathrm{He}$ did not then know that the larva is really aquatic. One day however he emptied a bell-glass which contained water as well as the remains of many Insects and leaves. The mud at the bottom was black and putrid. In it were seen more than two hundred longtailed larvæ. He washed them in clean water, when they were seen to be of whitish colour. They were divided into parcels, and put into separate vessels, which were filled with water to a depth of two inches. Before long the use of the long tail appeared. At first the larvæ moved about in various ways, some swimming through the water, others creeping on the side of the vessel or at the bottom; but in less than a quarter of an hour all were at rest, their long slender tails just reaching the surface. Some had the hinder end of the body nearly vertical and in line with the tail; others were creeping on the bottom, the tail being nearly at right angles with the body. Some had the tail straight, while in others it was thrown into a single or double curve.

Since the water in the vessel was about two inches deep, the tails were of that length also-very long for larvæ whose bodies were at most two thirds of an inch in length. To ascertain whether they could lengthen them yet more, Réaumur added water to

1 The larva can sometimes be seen to creep upon the underside of the surface-film by means of its feet. 
the depth of another half inch, when the tails were lengthened to the same amount. Again and again water was added, and the tails became lengthened in proportion. When however the depth grew to five and a half or six inches, the larvæ could no longer reach the surface from the bottom. Some crept up the side of the vessel, while others floated up to such a height that they could maintain their communication with the air.

The organ, by means of which the larva is enabled to breathe when its body is several inches under water, descrves close examination. So transparent is the tail, and indeed the rest of the body, especially in young larvæ, that the internal parts can be studied almost as well as if their integument were a tube of glass. It is easy to sec that the tail consists of two tubes, one sliding within the other. The outer and wider tube looks like a prolongation of the bodywall; it is thrown when at rest into innumerable transverse wrinkles. Within it is a second tube, a considerable part of which is brown or nearly black. The smaller tube is the special respiratory organ. The tail can be lengthened by protruding this inner tube from the outer onc. But besides this mode of adjustment, the outer tube is capable of elongation and contraction, being furnished with innumerable annular fibres and increasing in length as it diminishes in diameter. When most extended it is no thicker than a stout thread, and the inner tube resembles a horse-hair.

Mr. J. J. Wilkinson furnishes me with the following additional information respecting the tail of the 
202 NATURAL HISTORY OF AQUATIC INSECTS $\mathrm{CH}$.

Eristalis larva:- "The tail is divisible into three sections. There is an outer sheath, immediately

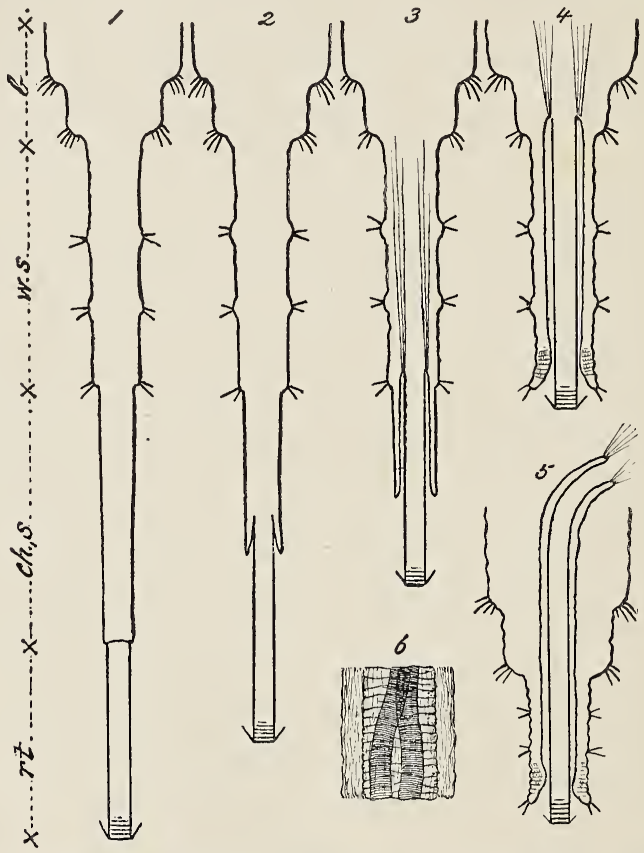

FIG. 71.-Diagrams of tail of larva of Eristalis larva ; I, fully extended ; 5 , completely retracted; $v t$, respiratory tube; chs, channelled sheath; $z s$, wrinkled sheath; $b$, body of larva. In 3 and 4 the retractor muscles are shown; 6 shows the tracher within the respiratory tube and channelled sheath (J. J. Wilkinson).

continuous with the integument of the body; an intermediate sheath, marked by about forty longitudinal furrows, and hence called 'the channelled 
sheath' by Batelli ; and an inner 'respiratory' tube, which encloses the trachex. The outer sheath is much wrinkled transversely, especially when contracted. It bears great numbers of minute hair-like setæ. Batelli says that it is also provided with setæ shaped like Roman swords, and he figures these (Tav. I, Fig. I I). I have found similar objects on both the outer and the channelled sheath, but by examination with a high power could see that they were diatoms, and not setæ. Four pairs of tubercles bearing bunches of setæ project from the outer sheath. There is one pair at the base, where it joins the body, one pair at the tip, and two intermediate pairs. These are set at equal distances, and mark out the surface of the sheath into three equal tracts. The intermediate or channelled sheath is exposed when the tail is completely protruded, but during retraction it disappears more or less within

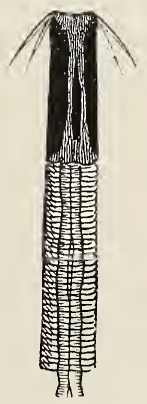

FIG. 72.-Extremity of respiratory tube of larva of Eristalis. the outer sheath. Between the furrows are regular longitudinal rows of small hooklets. The inner or respiratory tube is marked with innumerable transverse folds or wrinkles. Its extremity is firmer and more solid than the rest; here are the external openings of the two tracheal trunks, surrounded by five plumose setæ, which spread out and cling to the surface-film, thus keeping the tip of the tail above water; when forcibly submerged, they carry down a bubble of air. Two tracheal trunks, prolongations of the great longi- 
tudinal air-tubes of the body, run through the tail side by side. In cross-sections made through the respiratory tube they appear

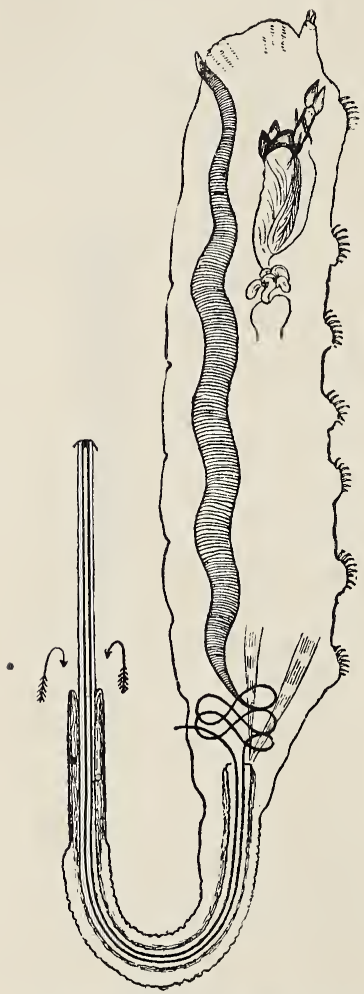

FIG. 73.-Diagram of internal structure of larva of Eristalis, showing the retracted head, the tracheal system, and the telescopic structure of the tail (J. J. Wilkinson). kidney-shaped, the concavities facing each other, but in front of the base of the respiratory tube they become cylindrical. When the tail is completely cxtended the trachere are straightened out, but during contraction of the tail they are thrown into numerous and regular coils, which lie in the hinder part of the body.

"Retraction of the tail is largely effected by six muscles which are attached to the junction of the respiratory tube and the channelled sheaths. When these muscles contract the respiratory tube is withdrawn bit by bit into the channelled sheath, and ultimately into the outer sheath (see Fig. 7I), the external surface of the channelled sheath becoming at the same time folded inwards. This may go on 
until only the tip of the respiratory tube projects from the outer sheath, the channelled sheath disappearing altogether. If further retraction is necessary the muscles of the outer sheath itself come into action, and this sheath shortens to any requisite extent. Its hinder end is furnished with a strong circular or sphincter muscle, which grips the respiratory tube at such times and prevents it from slipping out. The base of the respiratory tube then becomes curved or even doubled up within the body, reaching in some cases almost as far as the head (Réaumur), and the coils of the trachea become very numerous and close. Réaumur and Batelli are inclined to suppose that the coiled trachea play the part of springs and help to effect the protrusion of the tail, but this I cannot think to be correct. The trachex, even if it be admitted that they can act as springs, have no base from which to act. The protrusion of the tail is, I think, entirely due to pressure set up within the body by contraction of its muscular wall. If you take a dead larva with contracted tail between the finger and the thumb, and gently press the contents of the body backwards, the tail will suddenly shoot out to its full length.

"The trachea are continued forwards into the body, becoming dilated into large air-sacs. They are in communication with a pair of anterior spiracles which appear on the upper surface of the first segment. These spiracles are not functional in the larva."

Réaumur says that he often saw a bubble appear at the tip of the tail in a submerged larva. At first 
no bigger than a pin's head this bubble dilated considerably, then contracted, and then dilated again, as if air had been forced out of the tracheal tubes and sucked up again.

I have also to thank Mr. J. J. Wilkinson for the following account of the very peculiar pharynx of the Eristalis larva, based upon his long-continued observations and inquiries. A slighter description of the organ has been published by Batelli. ${ }^{1}$

"The head of the Eristalis larva is soft and capable of changing its shape. It is rounded in front, and when extended, shows two small sensory papillæ, which are carried on the under side. Behind these is the opening of the mouth. The pharynx is lodged in a brown chitinous capsule, below which can some-

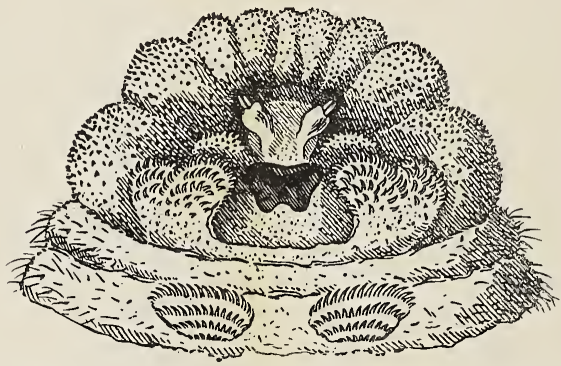

FIG. 74--Head of larva of Eristalis, ventral view, showing mouth and sensory papillix.

times be seen a fleshy process which resembles the tongue of the larva. The larva often puckers up its mouth, so as to conceal its jointed appendages, and

1 Bull. Soc. Entom. Ital., 1879, pp. 77-120, pl. 1-5. 
even the first pair of legs. The fore part of the body is covered with short reddish spines, which vary in shape according to the species examined. In some larvæ they are single-pointed, in others three- or four-pointed, while in a third kind they divide into from sixteen to twenty points.

"The larva possesses a remarkable sucking and filtering apparatus in its muscular pharynx. This is situated in the second and third segments, and forms an oval body, held in its

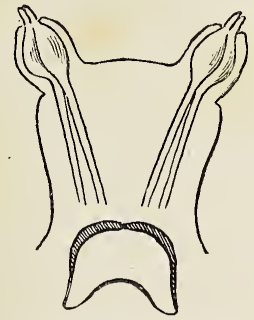

Fig. 75.-Sensory papillæ of larva of Eristalis, with their nerves and ganglia. place by a number of muscles, and stiffened by a complicated chitinous skeleton. Two thin and broad chitinous bands extend along the hinder part of the pharynx; these become narrower and more solid in front, where they give off processes for muscular attachment and for the support of the mouth-organs. Here the chitinous bars unite, and form a strong arch, completed below by a stirrup-shaped piece.

"When the pharynx is opened, it is found to enclose two chambers, an upper and a lower, which are separated by a horizontal floor of unusual construction. The upper chamber is lined by a loose membrane, which dissolves in potash solution. This can be dilated by special muscles. From the hinder end of this chamber proceeds the osophagus, the entrance to which is controlled by a muscular valve. The lower chamber also has a loose lining, which is chitinous, and supported by the chitinous skeleton already 
mentioned. Both chambers are subdivisions of one cavity, and are only distinguished here for convenience of description.

"The partition or floor between the two chambers is formed by nine ribs, which are long, narrow and deep, resembling planks set at equal distances, upon their edges. They are attached beneath to the wall

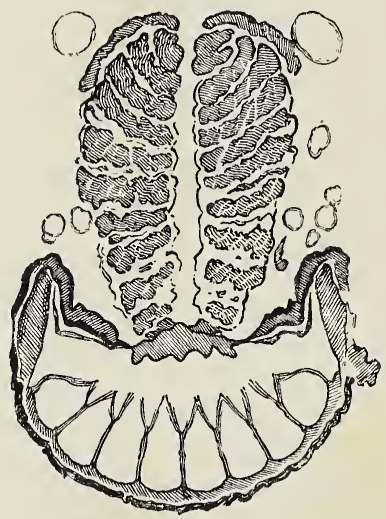

Fig. 76.-C'ross-section of pharynx of Eristalis larva, showing below the fringes of barbules, some open and some closed; above these, the upper chamber; and towards the top of the figure the muscles in paired masses, with tracheal tubes.

of the lower chamber, but their upper edges are free, and carry fringes of numerous and close-set barbules. The outermost rib on each side bears only one fringe, which springs from the inner and upper border of the rib; each of the remaining seven ribs has a pair of fringes, and in cross-section resembles the letter $Y$, the two arms being the fringes, and the stem the supporting rib. 
"The lower chamber communicates with the mouth-opening by a short passage, which is imperfectly divided along its length by a fleshy, tongue-like prominence, the tip of which is beset on its upper surface with innumerable spines. Near the openings of the two branches of the passage, the inner wall of the mouth is armed with a pair of shell-like plates, concave towards the mouth, and bearing upon their concave surfaces numerous prominent ridges.

"The apparatus is employed in the following way. The food of the larva consists of organic particles, scraped from submerged objects by the hooklets around the mouth. When the larva is feeding, its movements resemble those of a pig, working over a heap of refuse with its snout. As soon as a quantity of particles have been detached, the larva dilates the upper chamber of its pharynx by means of the attached muscles. Then the water, bearing the particles with it, rushes into the mouth, and passing through the lower chamber, is sucked into the upper chamber. The current, as it sweeps past, lifts the fringes of barbules. Then the upper chamber contracts, and the superfluous water escapes by the mouth. In doing so, it closes the valve-like fringes. The particles are left clinging to the barbules, and only the filtered water passes out. When a sufficient quantity of food has been collected, the passage into the œsophagus is opened, and the whole mass is swallowed.

"The roughened surfaces of the shell-like plates lie on either side of the tongue-like prominence previously mentioned. A great multitude of cross- 

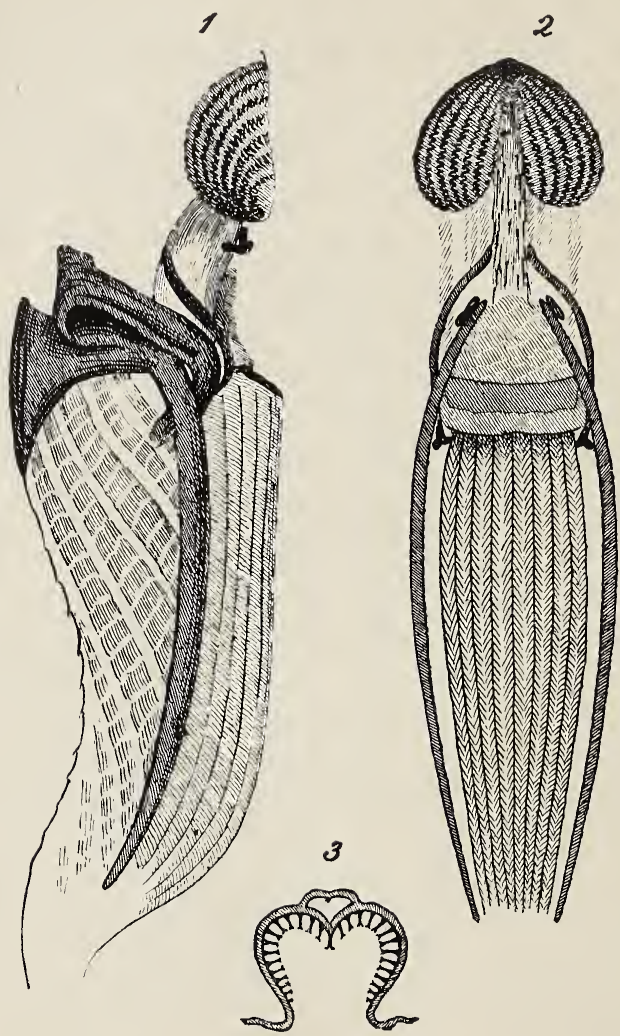

FiG. 77.-Pharynx of Eristalis larva. 1, in side-view; 2, from below, showing the nine fringed ribs of the strainer; 3 , section through shell-like plates (J. J. Wilkinson). 
bars, which in some places pass into teeth, stand out from the ridges. How the plates are employed has not been discovered. They cannot be protruded from the mouth.

"Just in front of the pharyngeal fringes, and in the floor of the passage, is a transverse row of backwarddirected setæ. ${ }^{1}$

"Batelli aptly compares the action of the fringes to that of the strainers of the Baleen Whales."

The larvæ feed upon organic matter, decaying leaves, \&c., found in stagnant water. Réaumur found that when kept in clean water and supplied with bread, they lived until they had completed the larval stage.

When the time for pupation comes the Rat-tailed Maggot quits the water. Its body becomes encrusted with earthy particles which adhere in consequence of the sticky exudation from the skin. When placed on damp loose earth, they enter it and undergo their transformation beneath the surface. For convenience of observation Réaumur kept some larvæ which were ready to change in empty boxes. They glued themselves to the wood, and if only slightly attached by the hinder part of the body, the transformation was successfully effected; but when the whole of the under side stuck to the wood, the larva perished.

These Insects, like the Blow-fly and Stratiomys form a cocoon out of the larval skin. The colour changes from white to yellow; the tail becomes

1 In the larva of the Blow-fly the sensory papillæ, the shelllike plates and the pharyngeal strainer or its equivalent can be observed. See Lowne on the Blow-fly, 2nd ed., Figs. 5 and 8. 
wrinkled, but still retains a considerable length; the body shortens and becomes rather thicker than before. After ten or twelve days the skin is hard and opaque, and to a great extent detached from the pupa within.

After twenty-four or thirty-six hours from the time of pupation two pairs of horns appear at the head end. The fore pair, is about half the length of the other, and the two pairs often curve towards one another. The fore pair, when diligently observed, are found to be present in the larva, but they become much more conspicuous at the time of pupation by the smoothing out of the adjacent parts. The large posterior pair appear for the first time shortly after pupation. These horns are really the respiratory organs of the pupa, as is clearly shown by the large tracheal trunks which enter them.

The process of pupation is similar in Eristalis and the Blow-fly, though more rapid in Eristalis. Twentyfour hours after the posterior horns have appeared, the proboscis, the wings and the legs may be scen by opening the cocoon. The long tail has now no connection with the body of the pupa. Near its base are found a number of coiled tracheal tubes, collected into a bundle. The main tracheal trunks, however, persist.

In a favourable season the fly is ready to emerge eight or ten days after pupation begins. The part of the cocoon contiguous to the four horns is pushed off in two unequal pieces. When this happens two airvesicles appear, one attached to each of the posterior horns; the smaller horns each receive a large trachea. 
Some other two-winged Flies, such as the Blow-fly, which form a pupal cocoon out of the larval skin, emerge by pushing off the end of the cocoon. For this purpose the head of the fly is provided with a vesicle capable of dilation or contraction. Réaumur says that he took it for granted that the fly of Eristalis would emerge in the same way. Finding a pupa in which the part of the cocoon adjacent to the respiratory horns was burst open, he looked into the cavity and saw part of the body of the fly alternately elongating and contracting itself. This he naturally supposed was the head, but on closer examination it proved to be the tail-end of the body. Shortly before the fly emerges it must turn itself completely round in its cocoon, a manœuvre of some difficulty, seeing how nearly the body fills the cavity in which it lies. ${ }^{1}$ The flies appear in early spring, and again in autumn.

Several species of Eristalis or allied Flies camc under Réaumur's notice. Though agreeing in essential points of structure and mode of life, they differed in size, coloration (especially in the winged state) and to some extent in the situations selected for the deposit of the cggs.

More than one species every year laid eggs in buckets partly filled with water, which were kept in Réaumur's garden, and he was able to observe the operation. The winged female flew round the inside of the bucket, as if to explore its surface, and

1 This reversal of the body in the larval skin is a great stumbling-block to the modern reader, and confirmation is necessary before it can be accepted. 
now and then touched the water with her legs. When satisfied as to the suitability of the place, she alighted a few inches above the water-level, and extended her abdomen considerably. The pointed and curved extremity was several times protruded and again retracted. Then the female flew or walked away, and repeated the operation in a fresh place. On searching the spots where the fly had settled, which were usually in the crevices between the staves of the bucket, eggs, sometimes to the number of twenty, were found attached to the wood. They were white, of oblong shape, and not unlike those of the Blow-fly; the surface was finely shagreened. The eggs were viscid, and adhered to the wood.

Living trees often contain cavities formed by decay. When these become filled by rain water, they form favourite sites for the egg-laying females, especially in autumn. One species which is found on trees has the larval tail much shorter than common. Before pupation the larva attaches itself to some object by a viscid exudation from the skin. In another species which also passes its larval stage in the cavities of trees the tail is very short, and flanked by a pair of conical fleshy prominences. At the extremity of the tail the two posterior spiracles are plainly to be seen. At the head end are two small yellowish projections which also communicate with the tracheal trunks. These are the anterior spiracles. A little behind these and more external comes a pair of double hooks. There is also at the extreme fore end of the body, and just above the mouth, a pair of fleshy prominences, as in other rat-tailed maggots. 
The seven pairs of ventral feet are set close to the middle line, and each is fused with its fellow.

Baron Osten Sacken ${ }^{1}$ has shown that the resemblance of the fly of Eristalis to a Bee has caused the curious belief of ancient times that Hive-bees could be produced by the putrefaction of dead animals, and especially from the carcasses of oxen. "The original cause of this delusion lies in the fact that a very common fly, scientifically called Eristalis tenax (popularly the Drone-fly), lays its eggs upon carcasses of animals, that its larvæ develop within the putrescent mass, and finally change into a swarm of flies, which in their shape, hairy clothing and colour, look exactly like Bees, although they belong to a totally different order of Insects. Bees belong to the order Hymenoptera, and have four wings; the female is provided with a sting at the end of the body: the fly Eristalis belongs to the order Diptera, has only two wings and no sting."

Ovid, Virgil, and a crowd of less famous authors vouch for the long-established belief in the miracle. But the prescription for raising a swarm of Bees given by Florentinus, a Byzantine author of about the tenth century A.D., is more explicit and solemn than any other extant. Osten Sacken translates his instructions thus :-

"Build a house, ten cubits high, with all the sides of equal dimensions, with one door and four

1 On the Oxen-born Bees of the Ancients (Bugonia) and their relation to Eristalis tenax, a two-winged Insect. Heidelberg, 1894. London: R. H. Porter. Published in shorter form in Bull. Soc. Entom. Ital., I $\$ 93$. 
windows, one on each side; put an ox into it, thirty months old, very fat and fleshy; let a number of young men kill him by beating him violently with clubs, so as to mangle both flesh and bones, but taking care not to shed any blood; let all the orifices, mouth, eyes, nose, \&c., be stopped up with clean and fine linen, impregnated with pitch; let a quantity of thyme be strewed under the reclining animal, and then let windows and doors be closed and covered with a thick coating of clay, to prevent the access of air or wind. Three weeks later let the house be opened, and let light and fresh air get access to it, except from the side from which the wind blows strongest. After eleven days you will find the house full of Bees, hanging together in clusters, and nothing left of the ox but horns, bones and hair. When the shed is opened, small white animalcules are seen, resembling each other, motionless; then they are observed to grow little by little, to develop wings, and to take the colour of Bees; the wings are at first short and tremulous, unfit for flight ; the limbs are weak; finally, desirous of light the Insects start and knock against the windows, pushing each other."

Virgil's description of the process is very similar. The chamber to be built must have four windows; a young ox is to be slain and his flesh pounded without shedding of blood; thyme and cassia are to be strewed. The words "trunca pedum primo" (with stumps of feet) apply exactly to the larva of Eristalis.

Wasps and hornets were similarly supposed to proceed from the carcasses of horses. Osten Sacken 
attributes this belief to the swarming of the beelike Bot-fly of the horse (Gastrophilus equi) about horses. The belief would be strengthened by the occasional productions of the wasp-like Helophilus (a close relative of Eristalis) from carcasses of the horse, though any other dead body would do as well.

It may be asked whether the ancient husbandmen were not acute enough to find out that their Bees, formed according to prescription, laid no honey; and further, why no Insects, likely to be mistaken for Bees, are seen to issue from carcasses in our own time and country. The experimenters of old were, we must suppose, satisfied to let their swarms of artificially produced Bees fly abroad. It was enough in their eyes to have saved the race from extermination. Bee-keepers, even in the Augustan age, no doubt knew better ways than this of getting swarms into their hives, and the supposed generation of Bees from carcasses was probably a belief rather than a method likely to be tried by practical men. The answer to the second question may be given in Osten Sacken's own words:- "The larva of Eristalis, being aquatic, requires a pool of stagnant water containing putrescent organic matter. A carcass, left in the open air, is at once attacked by the ordinary carcass-loving flies, Lucilia, Calliphora., \&c. During the second stage of putrescence a pool of corrupt liquid is formed about the carcass, and then is the time for Evistalis to appear. In the present age of sanitary police a carcass would never reach this stage." But in Lapland Zetterstedt, as quoted by Osten Sacken, found 
Eristalis hovering about the carcass of a sheep which was immersed in putrid liquid.

The habits of Eristalis tend to bring it about the habitations of man. Hence it is not altogether surprising to learn that it employs the facilities afforded by steamers and the like to increase its range. Like the pig, and still more like the rat and the cockroach, it bids fair to follow traders over the whole world. Baron Osten Sacken, whose unrivalled knowledge of Diptera makes his testimony conclusive, gives the following particulars as to its immigration into fresh countries.

Before 1875 Eristalis tenax was only known to occur in the temperate regions of the old world. During twenty years of residence in North America Osten Sacken never met with a specimen until on Nov. 5 , I 875, he found one on a window at Cambridge, Mass. Next year he observed several specimens at Newport, R.I. The species has now completely overrun the United States, and has occurred in Canada. The invasion proceeded not from E. to W., as might have been expected, but from IV. to E. Eristalis tenax has also been found in New Zealand, but not as yet in Australia. ${ }^{1}$

Note.-An account of the aquatic larva and pupa of Pericoma (see pp. 92, 160), by L. C. Miall and N. Walker, will appear in Trans. Entom. Soc., I 895.

${ }^{1}$ Details are given in Baron Osten Sacken's Oxen-born Bees. 


\section{CHAPTER III}

\section{AQUATIC HYMENOPTERA}

Down to the year 1862 the large orders of $\mathrm{Hy}$ menoptera and Orthoptera had not been ascertained to contain a single aquatic species. ${ }^{1}$ Since that date the Orthoptera have been found to include some semi-aquatic Grasshoppers native to Ceylon and Java (genus Scelymena). The Hymenoptera have proved to contain quite a number of forms parasitic upon aquatic Insects. Amongst these are two minute Insects, described by Sir John Lubbock in the paper cited above. Polynema natans ${ }^{2}$ was found swimming in pond-water by means of its wings. It lived several hours under water without sign of inconvenience, though provided with air-tubes, and breathing apparently through spiracles in the usual manner. ${ }^{3}$

1 Lubbock, Linn. Trans., Vol. XXIV. p. 135 (1863).

2 Westwood (Linn. Trans., 2d Ser. Vol. I. p. 584) thinks that Sir John Lubbock's Polynema should be placed in the genus Anaphes.

3 This is Lubbock's account. Ganin, in the paper cited below, says that there is no trace of tracheal tubes in any stage. The wings, he adds, are hollow sacs filled with blood, and act as gills. 
An immersion of upwards of fourteen hours, however, caused insensibility and apparent death. Both males and females enter the water. In the same pond was found a second species of similar habits, referred to a new genus, Prestwichia.

"Whereas Polynema natans swims with its wings and uses its legs apparently only for walking, the

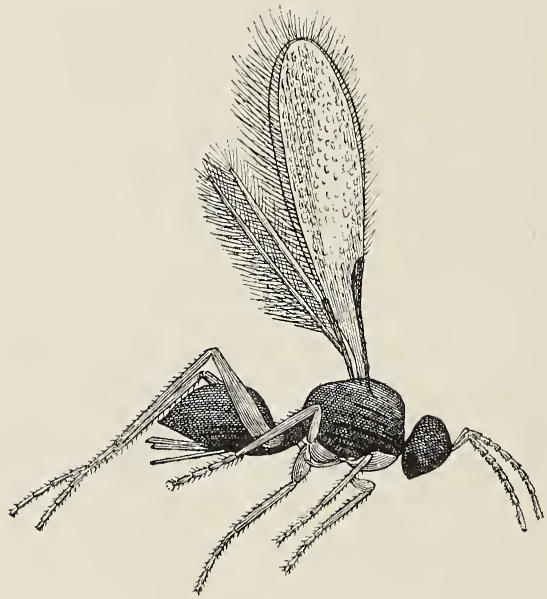

Fig. 78. - Polynema (Anaphes) natans, side-view of female, $\times 30$. From Lubbock.

present species (Prestwichia) when under water, holds its wings motionless, and uses its legs as oars. Though they are neither flattened nor provided with any well-developed fringe of setæ, still they seem to serve their purpose pretty well, and the motion of this species is more rapid than that of the former. 
Both species are fond of creeping along the sides of the vessel in which they are kept, or on the leaves and stems of aquatic plants ; but very frequently they quit their support and swim boldly out into the open water. As the motion in Polynema natans is caused by the wings, it might almost be called a flight ; owing however to the density of the medium and partly to the direction in which the wings act, the movement, though not inelegant, is slow, and is rather a succession of jerks than a continuous progression..... I was unfortunately unable to ascertain whether they could fly; taking my opportunity when they were out of the water, I teased several specimens of Polynema natans with the point of a needle, but never succeeded in making one take to its wings, at least not in air. When walking on the water, however, they sometimes started off suddenly, but always kept close to the surface, so that it rather seemed as if they were carried by some tiny gust of air. We might almost wonder how an animal like this, with no apparent weapons of defence and no great powers of speed, could maintain itself in this world of competition. Protected, however, in its early stages by the victim which it is destroying, it is exposed to its enemies but for a short period of its life; and if, like many of its allies, the eggs of other Insects are the prey which it seeks, speed may be of comparatively little importance. However this may be, we find in the two Insects now under consideration, no peculiarities indicative of an aquatic life. Many waterinsects are more or less boat-shaped, and both in form and position the legs are admirably adapted to 
serve as oars; others again use the hinder part of the body as a fish does its tail. Here we find no such arrangements. In both cases the head is broad; in Prestwichia the hind legs have, indeed, some scattered hairs, but not more so than its terrestrial allies ; nor in Polynema do the wings appear in any way modified to adapt them to their new function. In conclusion, if Polynema natans and Prestwichia aquatica had been extinct species no palæontologist would have suspected that they were aquatic; in the present state of our knowledge there is nothing in their structure which would have suggested such an idea." 1

Both Polynema and Prestwichia are minute, about a millimetre long.

Ganin ${ }^{1}$ has traced the development of Polynema (Anaphes) natans or some closely allied species. The eggs are laid and the early stages passed inside the eggs of a common Dragon-fly, Calopteryx virgo. The female Calopteryx lays her eggs in the cellular tissue of the leaves of the white water-lily (Nymphæa), and it is to discover and penetrate them that the Polynema enters the water. As a rule one egg is laid by the parasite in one egg of the Dragon-fly. If more than one is laid in the same egg, only one attains complete development. The egg of Polynema is flask-shaped, having a short and slender neck at that end where the tail of the larva will ultimately appear. The young larva is motionless and of very simple form. It is enclosed within a transparent cuticle, which again is enclosed by the egg of the

1 Lubbock, loc. cit.

2 Zeits. f. wiss. Zool., Bd. XIX. p. 417 (I869). 
Dragon-fly. The larva before long casts its envelope and appears as a segmented worm-like animal with peculiar provisional organs and especially with a pair of stout hooks at the head end. Rudiments of the permanent appendages then begin to appear. When all the contents of the Dragon-fly's egg have been devoured, which happens in a few days from the time of penetration, the Polynema pupates. The larval appendages dwindle or are cast off by moulting. The last segment enlarges greatly and is converted into the abdomen of the imago. The fly emerges after a pupal stage of ten or twelve days.

We have scanty information respecting a number of aquatic Insects, which, like the terrestrial Ichneumons, lay their eggs in the bodies of living Insects. The larvæ hatch out and devour the bodies of their hosts little by little, delaying fatal injury until the parasite is full grown. One such form, Agriotypus preys upon Caddis-worms. The female was long ago observed to enter the water, and later on Siebold reared it from cases of Caddis-worms. The history of the parasite has recently been more fully explored by Klapálek, ${ }^{1}$ so well known by his researches into the life-history of the Trichoptera. Klapálek finds that in Bohemia Agriotypus commonly attacks the cases of a Caddis-worm known by the name of Silo pallipes. On warm days in April the Agriotypi may be seen swarming like Ants about the banks of the brooks, and also flying above the water. The females descend stems and grasses into the water, and creep under stones on the bed of the stream 1 Ent. Month. Mag. 1889, p. 339. 

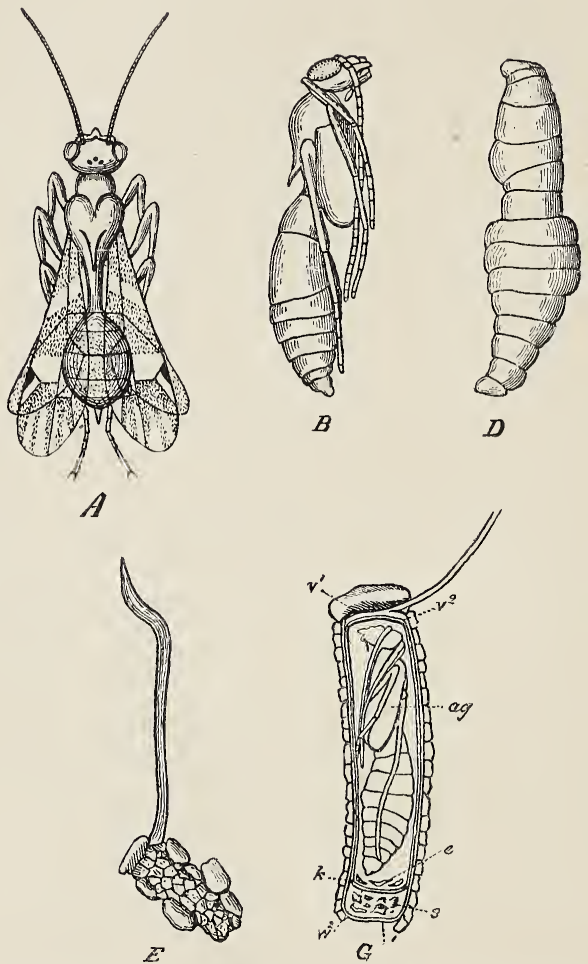

Fig. 79.-Agriotypus armatus. A, imago; B, pupa ; D, larva ; E, Agriotypised case of Silo ; G, section of ditto, showing $v^{1}$, fore operculum ; $z w^{1}$, hind ditto of case ; $s$, remains of Silo larva; $a g$, pupa of Agriotypus; $e$, remains of cast larval skin of ditto. From Klapálek. 
in search of victims. The larva of the parasite spends its whole life under water and inside the case of a Caddis-worm. Its host is not mortally injured until it has prepared for pupation. Like a healthy Caddisworm, it makes its case fast and closes it up. Then the Agriotypus larva devours it, and crams the remains into the hinder part of the case. It then proceeds to moor the case by a long band, which it secretes from its own salivary glands, and which is the external indication of an agriotypised Caddis. Within the case it spins its cocoon, changes to a pupa about September, and winters before emerging as a winged fly. Klapálek believes that this aquatic Ichneumon is very common. 


\section{CHAPTER IV}

\section{AQUATIC CATERPILLARS}

AMONG the commonest of Moths are some small, delicately marked species which abound in the neighbourhood of ponds, lakes and marshes. The patterns on their wings have suggested the popular name of China Marks. One of the species so designated has in its first stage the habits of an ordinary caterpillar. It feeds upon the Elder, and is common in gardens. Other species feed upon the leaves of water plants, and are in various degrees adapted to an aquatic life. We owe to Réaumur the first mention of an aquatic caterpillar, that of Hydrocampa nymphæata, from which is bred the Brown China Marks Moth. He visited, about the middle of June, a pond covered with the floating leaves of Potamogeton natans, and found that the plants harboured numerous larvæ, which fed upon the leaves, and also used them as a means of concealment. In some cases a small bit of the leaf was bitten out to an oval shape, and fastened by silk threads to another part of the leaf, forming a flattish lens-shaped prominence. In most cases, however, both leaves were 
bitten through, and the two pieces, quite similar in shape and size, fastened together with silk, formed a movable sheath which protected the body of the larva, as it crept about in search of food.

The larva itself is about an inch long when full grown. The body is thickish towards the middle, but narrowed at the two ends. It appears smooth to the cye. Its colour is nearly white, but with a tinge of yellow ; the upper surface of the thorax is darker. The head, which is small and half-retractile, is dark brown or nearly black. Like most land caterpillars,

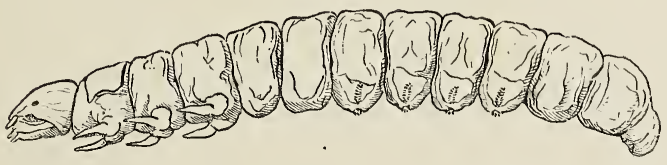

Fig. 8o.-Larva of Hydrocampa nymphxata, side-view.

it is provided with sixteen legs, the last pair being very short. The spiracles or breathing pores have the usual number and arrangement. Although the larva is constantly submerged, it breathes air like other caterpillars; Réaumur found that when it was oiled, so as to cut off the supply of air through the spiracles, it died in less than a quarter of an hour. If the larval case is opened under water, it is found to be full of air, and the larva perfectly dry within it. The larva is indeed incapable of being wetted. A multitude of very fine and close-set prominences cover its whole body, and between 
these the surface-film is unable to penetrate. The case is not completely closed. An opening is necessary in order that the larva may push out its head and the fore-part of its body for the purpose of feeding or locomotion. We should be inclined to suppose that, on these occasions, the sheath would fill with water, but this does not happen. The edges of the opening are elastic, so that they open only under pressure, and then to just such an extent as allows the body of the Insect to protrude. The unoccupied cleft is so minute that the surface-film of water is unable to penetrate. Réaumur describes the operation of making a sheath. The larva lays hold of the under side of the leaf, and gnaws a piece of it into the desired shape. Then it carries the piece in its mouth, and brings it against another leaf in such a position that the two under-surfaces are in contact. The leaves are a little concave beneath, and thus, when brought together, they do not lie flat, but enclose a lens-shaped cavity. The bits of leaf are then fixed by threads of silk, and the second leaf is cut to the same size and shape as the first. The largest sheath which I have seen was $I \frac{5}{5}$ in. by $\frac{3}{4} \mathrm{in}$. The larva is commonly found on Potamogeton early in the summer, but later on, when the leaves of the Water-lily appear, it seems to prefer these both for food and for the manufacture of its sheaths. It is often found upon another aquatic plant, viz. the Water Starwort (Callitriche verna). Before pupation, the Insect creeps up the stem of a tall waterplant, and attaches its sheath to this well out of the water. The sheath is now lined with a cocoon of 
close-woven silk. ${ }^{1} \quad$ The pupa resembles that of a small terrestrial Moth. It breathes by three pairs of welldeveloped spiracles, carried on prominent warts which stand out from the sides. of the thorax. There is a short ventral projection of unknown use. The emergence of the Moth has not been described.

Réaumur discovered the eggs of the Moth, which are laid on the under side of the leaves, near the edge, and enclosed, as is so often the case with aquatic Insects, in a transparent jelly. From fortyto one hundred eggs are arranged with great regularity in one patch, and according to Réaumur, the female Moth protects the mass by glueing a piece of leaf over the whole. ${ }^{2}$ The larvæ hatch out in July or August, and at once begin to make their own sheaths.

Müller has added some interesting facts to Réaumur's account. ${ }^{3} \mathrm{He}$ tells us that the young larva, which is about $\mathrm{I} \cdot 8 \mathrm{~mm}$. long, is completely wetted with water. Its spiracles are rudimentary, and do not communicate with special air-tubes. The surface of the body has at first no pointed prominences, such as those which at a later time prevent the skin from being wetted. It must depend for its supply of air upon the oxygen dissolved in the water, though it has no gills or branchial organs of any kind. The sheath which it makes for its own

1 Réaumur says that the cocoon is attached to a submerged leaf, but this does not agree with what I have observed.

${ }^{2}$ I have found the eggs completely exposed.

3 "Beob. an im Wasser lebenden Schmetterlingsraupen," von G. W. Müller, Zool. Jahrb. VI. p. 6i 7 . 
protection is wetted, full of water, and fixed. The larva at this time excavates the leaves of Potamogeton, scooping out the soft green substance for its nourishment. It moults several times, without any important change in its form or habits. The cold season comes round, and there is still no change, except that the larva feeds less. The following April it begins to feed actively again, and makes a fresh sheath, but still its mode of respiration remains unchanged. In May and June, it for the first time begins to make sheaths filled with air, and its cuticle is now provided with long conical prominences, interspersed with smaller ones, which act like velvet, and prevent the surface of the body from being wetted. The spiracles now open for the first time, and the larva breathes the enclosed air. After this it moults once or twice more before undergoing pupation.

Buckler ${ }^{1}$ has related the history of Hydrocampa stagnata. The larvæ feed on the Bur-reed (Sparganium), riddling the pith with holes, and biting away the sides of the leaves. They hibernate in the cold months, begin to feed again in April, and emerge as Moths in the height of summer. The full-grown larva is $\frac{7}{8}$ in. long, and tapers both ways from the third segment. The pupal sheath is made of bits of leaf woven together, and moored to a floating leaf. It lies horizontally, either partly or entirely submerged. Sheaths are also attached to submerged parts of the plant. Inside the sheath is a cocoon of white silk, quite dry and filled with air, which closely invests the pupa.

1 Entom. Monthly Mag., Vol. XIV. (1877-8), pp. 47-103. 
The Duckweed, so common on stagnant water, harbours another species of aquatic caterpillar, Cataclysta lemnæ, which produces the Moth called the Small China Marks. The larva of this species is smaller than that of nymphaeatc, and of variegated brown colour. The top of the thorax is darker, the head small and yellowish, and usually concealed in the prothorax, which is horny and shining. The spiracles are very minute. This larva makes its sheath of leaves of Duckweed, attached together by silk, or of the hollow stem of some aquatic plant, closing in such cases one of the open ends with leaves of Duckweed or bits of larger leaves. It exhibits two distinct larval stages, like those of nymphaata, an earlier branchial stage, which lasts till the second moult, and a later tracheate stage. The life-history is completed in one season, and there appear to be two generations in the year. The pupa may be distinguished from that of nymphaata by its long antennary sheaths, which reach to the end of the body. The female Moth runs about on the surface of the water, and lays eggs, three or four together, on the under side of the leaves of Duckweed.

The species described above, though living in water throughout their earlier stages, are nevertheless during most of their lives air-breathers. An allied caterpillar, Paraponyx stratiotata, possesses a more complete adaptation to aquatic life, namely, branchial respiration. Paraponyx was first described by De Geer, to whom we are indebted for an excellent description. The larva of this species frequents the spiny leaves of Stratiotes, the Water-soldier, a plant which is a 
favourite resort of a number of Snails, Leeches, Polyps, and other animals. Paraponyx also occurs on Anacharis (Buckler).

De Geer found a Paraponyx larva walking on the leaf of Stratiotes, under water. He placed it in a vessel, and next day found that it had cut out a piece of the leaf, and made a sheath for itself, bringing the two concave sides together, as nymphaata does with Potamogeton. The larvæ fed greedily on the leaves of Stratiotes. The sheath allowed the water to enter freely, and the larva was completely wetted. In some cases, the bases of the leaves were merely tied together with silk, and not cut. The larva grows to upwards of an inch in length. It is of a pale transparent or yellowish green. The head is brown, deeply cut out behind, and capable of being retracted into the prothorax. The antennæx are longer than in most caterpillars, and several-jointed. Along the sides of the body are found transparent branchial filaments supplied by special air-tubes. Some of the filaments are single, others spring three or four together from a common point. There are six tufts on some segments, eight on others, not counting the single filaments; the prothorax has none. The branchial filaments are passive, and unlike those of the Ephemera, cannot be separately moved.

Though the branchial filaments are fixed to the body, the body performs regular respiratory movements, like those of a Caddis-worm or a Chironomus larva. Buckler tells us that night and day, at intervals of from one to three minutes, the larva rapidly undulates its body up and down, the hinder end, by 
which it holds on, being motionless. The movement lasts for twenty seconds. At these times the filaments are depressed and pointed forwards, instead of radiating as usual. All the segments, except the second, third and last, carry black spiracles, those of the second, third and fourth abdominal segments being much larger than the rest. The spiracles are not however open, and are functionless. De Geer imitated Réaumur's experiment of oiling the stigmata. The result was very different in the case of Paraponyx; one larva when immersed in olive oil lived eight days, and spun against the side of the vessel.

The Insect passes the winter as a larva, and in captivity at least, feeds the whole time. In June De Geer observed that cocoons were formed between the young leaves of Stratiotes, well below the surface of the water. The cocoon is grey outside, but lined with close white silk. A large opening is left in the outer envelope of grey silk, whose function is uncertain. De Geer thinks that it may serve for the escape of the Moth, or else for allowing free access of water. The pupa has three pairs of prominent spiracles. It is submerged, but the cocoon which it inhabits is filled with air. Pupæ removed from the cocoon, and placed in saucers of water, lived for several days, but ultimately perished without producing Moths. Others when taken out of the cocoon and placed in air, perished quickly. Others again, when placed with one side of their bodies in water and the other side in the air, survived, and produced Moths. These facts appear to indicate that the stigmata are actually employed by the pupa for respiration. As the cocoon 
is completely submerged, the emerging Moth must float up through the water. The Moths, which are by no means uncommon, appear in June, July, or August, and may be seen disporting themselves on the surface of the water. They lay greenish eggs on floating fragments of leaves, and the eggs hatch out in eight days.

There is, as we have seen, some discrepancy in the accounts of the pupation of Hydrocampa nymphæata. Some observers have recorded that the pupa-case is attached to submerged leaves, while others have found it fixed to stems well out of the water. But all agree that the pupa-case of Paraponyx is often to be found attached below the surface, and it becomes a question of some interest how the air-breathing pupa can under these circumstances obtain the moderate supply of gaseous air which it requires. A fact contributed by Dr. Schmidt-Schwedt 1 may furnish the answer to the question. Schmidt-Schwedt found that beneath the pupal cocoon of Paraponyx the leaf of Stratiotes ${ }^{2}$ is pierced by a number of small holes, which, as thin sections prove, pass into the air-filled spaces which are so common in aquatic plants. It may be that Paraponyx, like Donacia, draws its supply of air, during the pupal stage,

1 Berl. Entom. Zeits., Bd. XXXI. p. 332 (1887). The author does not believe that these openings in the leaf are actually employed as a source of respirable air, but his reasons are of a general kind, relating to the excess of oxygen in the gas evolved from a living leaf, and not very convincing to myself.

${ }^{2} \mathrm{He}$ calls it by mistake Pistia stratiotes, a very different plant. 
from wounds made in the tissues of the leaf, but the essential facts still require confirmation by other observers.

Another aquatic caterpillar of which very little is known, is Acentropus niveus. The larva has not been described, but it is said to live on Potamogeton pectinatus. The pupa makes a silken cocoon, and the Moth emerges in July. 


\section{CHAPTER V}

\section{CADDIS-IWORMS (TRICHOPTERA)}

A CONSIDERABLE part of this chapter is translated from one of the most interesting and characteristic of Réaumur's memoirs. The original is to be found in the third volume of his History of Insects. ${ }^{1}$

This is one of many excellent memoirs by Réaumur which we have occasion to cite. A short account of the naturalist who did so much for the study of Insects seems due to his memory.

Réaumur was born at Rochelle in 1683 . He was enjoined to study law, the profession of his father, but science led him away, and as his means rendered him independent of a lucrative profession, he became a student of Mathematics and Physics. His first publications treated of Geometry, and were so highly valued that when only twenty-four years of age, he was elected a member of the Academy of Sciences. In I 7 IO he undertook the direction of a vast and important work, the first great treatise on technical education. This was the Description des Arts et

1 The passages extracted from Réaumur are put in inverted commas, 
Métiers, published by the Academy with the help of the French Government. It led Réaumur to make a long series of discoveries of much practical and scientific interest. We find him investigating the tension of cords, and proving that, contrary to the belief of practical men, they are weakened by torsion (twisting). He experimented on the ductility of metals, the lustre of pearls and fishes, the growth of shells, the colour of the turquoise, the crystalline form of certain metals and the manufacture of steel, which he is said to have introduced into France. Tinplate too, which had always been imported from Germany, was first made in France according to the method taught by Réaumur. He endeavoured to reproduce the porcelain of the Chinese, but failed to get the desired product, though he discovered the kind of white glass still known as Réaumur's porcelain. He brought into practical use the ancient method of hatching eggs by artificial heat, showed how to preserve eggs from putrefaction by greasing the shell, and suggested improvements in the hanging of carriages and the fitting of axles. Among his countless researches are treatises on the production of spiders' silk for commercial purposes, on the purple of the ancients, on the sealing of tubes by mercury, on gold in the rivers of France, on the Torpedo and its electrical organ, on the fossil shells of Touraine, and on the phosphorescence of shells.

The thermometer by which Réaumur is best known to the public was constructed on an original plan. He divided the liquid contained in the bulb and the tube up to the freezing point of water into a thousand 
equal parts. The degrees were marked so that each corresponded to an increase of volume equal to one of the thousand parts. It happened that the alcohol (not pure alcohol) which he used to fill the thermometer dilated $\frac{80}{1000}$ of its volume during the rise of temperature from the freezing to the boiling point of water, and Réaumur was thus led to divide the corresponding part of the tube into eighty degrees. Hence the scale which was long used, almost to the exclusion of others, in continental countries.

Among the many physical inquiries pursued by Réaumur are those which relate to the evaporation of snow and ice during frost, and to the action of freezing mixtures.

Natural History was a favourite study with Réaumur throughout his life, and gradually took almost entire possession of his time and energies. Among his early researches are a description of the organs of locomotion in Star-fishes, and experiments to prove that the Cray-fish and Lobster have the power of reproducing lost limbs. In I 734 began the publication of his magnificent History of Insects, which though incomplete, fills six quarto volumes abundantly furnished with plates. The life-histories of many Lepidoptera, Caddis-flies and Aphides, of the larvæ which prey on Aphides, of the Cicada, of gall-making Insects, of various Diptera, of the Sawflies, of Bees and their economy, of Wasps, Ichneumons, Ant-lions, Ephemeræ, Dragon-flies, and lastly of the Horse-tick, Hippobosca, occupy these elaborate and beautiful memoirs. The patient and sagacious observations here recorded in language of transparent clearness 
have been the delight of generations of naturalists, and will be so again when the rage for names and lists has abated. The History of Insects includes no Beetles or Orthoptera. These would no doubt have been added in time, but for the accident which in 1757 caused Réaumur's death. He left a multitude of portfolios filled with notes and observations.

In one great zoological controversy of that age Réaumur took up a hesitating and upon the whole an unfortunate position. The prevalent opinion respecting corals was, that the polyps were flowers, the soft cortex a plant, and the hard part mere unorganised stone. The researches of Count Marsigli (I III) were believed to give strong support to this interpretation. Peyssonnel in 1727 communicated to Réaumur, and through him to the Academy of Sciences in Paris, observations which were based upon long study of the Mediterranean corals. He pointed out that the so-called flowers could extend and contract their parts, that they persisted throughout the year, and that they had the composition of animal bodies. Réaumur produced Peyssonnel's communication, but kept back the author's name, subsequently giving as his reason that Peyssonnel would have run risk of contempt as the propounder of views so adventurous. Réaumur proceeded to give his own views as to the nature of corals, which were completely orthodox, and completely mistaken. Many years later the discovery of the Hydra and Plumatella by Trembley reopened the question, and Réaumur now perceived his mistake. He encouraged fresh inquiries, candidly accepted their results, which 
were altogether favourable to Peyssonnel, and published in the preface to the sixth and last volume of his memoirs a clear and eloquent exposition of the animal nature of Zoophytes. This was in 1742. Peyssonnel never received due recognition of his services to Natural History, and his views were treated coldly until they were at length enforced with greater knowledge by John Ellis, to whom fell the rewards of the discovery.

Réaumur spent much of his time at his country residences, one in Saintonge, the other at Bercy near Paris. He avoided public offices, and his fortune rendered him careless about increase of wealth. When the Regent Orleans granted him a pension of 12,000 livres, he asked that it should be allotted to the Academy of Sciences for technical experiments.

Except for a quarrel with Buffon, which no longer interests us, Réaumur's scientific career was happy and tranquil. He was of kindly disposition, and a favourite in all circles

Réaumur writes in a fluent and animated style. He does not disdain personal incidents, illustrations from every-day life, nor anything which may kindle the reader's interest. Some have called him diffuse, but his supposed diffuseness is only the leisurely manner of a writer who addresses a wide circle of readers. $\mathrm{He}$ is never in a hurry, never enters into dry and technical discussions, never wastes his reader's time. His speculations, even when antiquated, are worth the attention of those who would enter into the thoughts of a sagacious and most productive investigator. 
I now begin the Natural History of the Caddisworms with some extracts from Réaumur.

"One of the objects," says Réaumur, "which makes most impression upon the common run of travellers, is the variety of dresses put on by the inhabitants of different countries. We may well wonder that men who have only one end in view, viz. to protect themselves against the cold, should make use of so many diffcrent means of attaining their object. What a difference there is between the dress of men in civilised and in barbarous countries! How great a variety in the dress of the different civilised countries, and of the different savage countries! The changes of fashion show clearly that the form of our dress is not always founded upon use or convenience. Insects, like men, form coverings for themselves out of very various materials, but the covering of each species is invariable. Nature has taught each what is best suited for its own use. Insect larvæ made use long before us of skins, wool, cotton and silk; but besides these, they employ other materials which never enter nto our own clothing. Some of these larvæ make themselves coarse clothes, which might be compared to those of savages; others display a higher degree of skill. We shall give some examples of both kinds.

"Belon tells us that the old French name for these aquatic larvæ is charrées [carts, or anything dragged along]. They are found in small streams and brooks, in ponds and lakes, in a word in any piece of water which has plants living in or around it. Vallisnieri observed them carefully, and was the first to give an 
account of them in his "Gallery of Minerva." $1 \mathrm{He}$ says that they feed upon leaves of celery, ranunculus, and water-dock as well as upon other aquatic plants. [Caddis-worms are usually vegetable feeders, but not exclusively so. They devour larvæ of Chironomus, Ephemeræ and other aquatic animals. Some are altogether carnivorous, e.g. the Hydropsychidæ. When hungry, Caddis-worms devour one another. They do not attack the end of the case, which can be defended, but tear it open in the middle.]

"Among these aquatic larvæ there are many species which I have not learnt to distinguish. The commonest of all is much larger than the case-forming larvæ which I have just mentioned as living upon land. ${ }^{2}$ None of them are true caterpillars, but all change to four-winged flies. We will consider the stages through which they pass, after we have examined their mode of life.

"The body of these larvæ is lodged in a silken tube, to the outside of which are fastened fragments of different substances, selected for the purpose of strengthening and defending it. The sheaths may be quite irregular, rough and prickly, or smooth and symmetrical. When the old sheath becomes too narrow or too short, the larva makes a fresh one. ${ }^{3}$ Sometimes the new sheath differs more from the castoff one than our dress of to-day differs from that of our

1 Works, folio edition, Vol. I. p. 37.

2 Case-forming Lepidoptera.

3 It is much more common for the larva to enlarge its case by adding to the wider end, and cutting off the old and useless part, 
grandfathers. But with these aquatic larvæ it is not a question of caprice or fashion ; their dress is carefully adapted to the actual needs of life. They employ very different materials, and the kind of material largely affects the dress which they put on. They make use of whole or nearly whole leaves, bits of leaves, and these of a great number of species, or little sticks and straws. Others use seeds, roots, grains of sand and gravel, or the shells of water-snails and bivalves; in short, all the materials which can be found in water are employed by particular Caddis-worms. In some sheaths one only of these materials is employed, and these are the most neatly constructed. In other sheaths a number of different materials are made use of, so that the larva is dressed, so to speak, in rags and tatters, and its covering is altogether shapeless.

"Every sheath is a hollow cylinder with an opening at each end. The fore end, out of which the head and the six limbs can be passed, is wide. The hinder end is narrow, and closed by a circular silken plate with a hole in it. [The hinder end is often quite open. Some species make cases of uniform width.]

"If the sheath is made of leaves, it may take a flattish form, wide in proportion to. its depth, but there are few of this kind. [Limnophilus pellucidus.] In general the shape is cylindrical. Some sheaths are covered externally by bits of rushes or small twigs glued together and arranged lengthwise. Sometimes the rushes are so artfully joined that they look like a grooved cylinder without joints, but it is rare to 
find one in which some shred does not spoil the look of the sheath by projecting beyond the rest. This irregularity, as we shall presently see, is really necessary to the complete suitability of the sheath. In the cases of the larvæ of Phryganeidæ the bits of leaves are arranged with great regularity in a spiral manner. (See Fig. 82, I, p. 256.)

"A larva sometimes picks up a reed, split into two. If its sheath is entirely made up of small bits, and therefore wants firmness, it will fasten these bits of reed to the outside, bringing them as close together as possible. Some sheaths are made up of such fragments of reed; in others small straws, such as those of Equisetum, are arranged transversely to the axis of the body [Limnophilus rhombicus], so that the cross-section shows a circle within a polygon, the angles of the polygon being produced. Such cases are naturally very rough, but they often exhibit a kind of symmetry.

"Lastly there are sheaths which are built up, partly longitudinally and partly transversely, the fragments being ill-arranged and wanting in symmetry. Here a large irregular piece of wood has been fastened on, there a bit of stone, or it may be a shell. Some are entirely made of bits of shell, all the shells belonging tc one species. [This is often the case with Limnophilus flavicornis.] I have seen some which are made up of little bits of the shells of water-snails, and others made of bivalve shells, the two valves being still united. Singularly enough, they are sometimes built up of living animals. What should we think of a savage who should cover his body, not with furs, but 
with living musk-rats and moles? This is what these Caddis-ivorms do. The snails and small mussels are still alive within their shells, though they are fastened down to the sheath of the Caddis-worm so completely that they cannot move on their own account.

"It is common enough for the Caddis-worms which make their sheaths of fragments of shell to fasten along each side a stick which passes beyond the sheath at each end. [Limnophilus lunatus, Anabolia, Halesus radiatus, \&c.] These sticks may be as long again as the rest of the sheath, and almost equal to it in diameter. Such a sheath is like a house fixed between two beams higher than itself. In other instances there is only one such stick, and sometimes the sticks thus added are short and stout.

"Most of the sheaths of Caddis-worms are so heavy that they would make a trying load for the Insect if it walked upon dry land. Living in the water, however, the Caddis-worms can creep along the bottom or go up and down the weeds with an ease which shows they are not over-burdened. [There are species which make heavy cases of gravel, and never leave the bottom.] It is plain, when we come to consider it, that a sheath which would be too much for the strength of the Insect in air may be easily carried about in water, if the mean specific gravity of its different components is pretty nearly equal to that of water. This is the reason for the irregular and awkward pieces of wood which so often spoil the symmetry of the sheath. The Caddis-worm, though it cares little about the shape of the vegetable fragments which it fastens to its sheath, is generally 
careful to select such as have a suitable specific gravity.

"The larvæ cannot swim, or can only swim badly, and they usually creep about. In the act of creeping, the head and fore-part of the body are thrust out of the sheath, and the larva drags itself along by its six legs. This operation is often greatly facilitated by the buoyancy of the vegetable fragments attached to the sheath. [Some young larvæ can swim very fairly. In spring and early summer a small Caddisworm, which is common in ponds, may be seen to swim rather rapidly through the water with the help of its long, fringed hind-legs. The movement is a little jerky, but the larva, carrying its case, can move through the water in any direction in a straight line.]

"Caddis-worms have six hard and jointed legs. They have no false abdominal feet, like those of caterpillars. The head is protected by armour of a brown colour. The first ring of the thorax is of the same texture and colour, and bears a short pair of legs. The second ring is also brown and hard, and carries the second pair of legs; the third ring is yellowish with brown spots, and carries the third pair. The rest of the body is made up of nine rings, which are white, soft and transparent. On the first of these nine abdominal rings are three fleshy prominences more or less conspicuous in the different species. One of these projects from the upper surface of the ring, while the other two are lateral; all can be retracted at pleasure. They are hollow at the tip, and when the Insect is taken out of the water, they 
are kept moist by a liquid which flows from them. Is it possible that these prominences help in respiration?"

Mr. T. H. Taylor has, at my request, examined these retractile processes with care. His inquiry is still incomplete, but has already yielded results of interest. The processes are believed to be best developed in the Phryganeidæ, but as yet little has been done to study the various families comparatively. The processes in question are absent in those Caddisworms which construct no movable sheaths. The median tubercle may be the most completely retractile of the three ${ }^{1}$ the lateral ones are armed at their extremities with peculiar scales, notched at the extremities.

The fact that these processes are absent in the Caddis-worms without sheaths suggested that they might possibly be used to regulate a flow of water through the sheath. On supplying powdered carmine to a living Caddis-worm, the presence of a current of water, passing in at the head-end, is readily demonstrated. A Caddis-worm, removed from its case, performs undulating movements with its abdomen. Other tube-dwelling larvæ, such as those of Chironomus and Paraponyx, maintain a current of water in contact with their bodies in a very similar way. In order to study the movements. of a Caddis-worm under something like normal conditions, I proposed to Mr. Taylor to supply a naked Caddis-worm with

1 This is the case with Phryganea grandis; in some other Caddis-worms the median tubercle is not more retractile than the others. 
small plates of mica, in the hope that a transparent case might be obtained. This expectation was perfectly realised. The Caddis-worm made a shapely and sufficiently transparent case of mica, and permitted the following observations to be made, which I quote from Mr. Taylor's notes :- ${ }^{1}$

"When Phryganea grandis is at rest it is retracted within its sheath, the tips of the legs alone projecting from the opening. The front part of the animal as far back as the third abdominal segment is arched, and comes close up to the top of the sheath, while the rest of the body reclines on the floor to which the hooks at the tail end are firmly attached. The animal is not however still, but at intervals waves its body up and down, causing a stream of water to flow through the case from the head end. The undulations begin at the second abdominal segment, and pass backwards to the tail end just as in a piece of string which is fixed at one end and waved up and down at the other. The rest of the body is kept steady so that the stream of water has a free admission. This seems to be effected by the lateral processes of the first abdominal segment, which can be pressed against the sides of the case and kept from slipping by the spines which cover their points. The median tubercle is different in form and structure from the lateral ones, and can be protruded or retracted with great ease."

1 The trial succeeded most readily with Limnophilus rhombicus and an undetermined 'Caddis-worm. Phryganea grandis was very reluctant to cover its body with mica, and only did so after long exposure. 
Supposing that the lateral processes are mainly used for securing the body to the inside of the sheath, the use of the adjustable median process can be guessed at. It is the third screw, so to speak, which tightens the whole arrangement, and regulates the distance of the body from its enclosing tube. The thoracic legs, it is obvious, are otherwise employed when the animal is creeping or feeding.

I have lately seen a passage of Dr. SchmidtSchwedt's, ${ }^{1}$ which shows that he had arrived at a similar explanation of the processes in question.

It is singular that Réaumur should offer the improbable suggestion that these retractile processes are respiratory organs, and then go on immediately to describe the true respiratory organs of the larva.

"The rest of the abdominal rings are provided with organs whose use it is not easy to describe. They consist of a great many white and soft filaments, of which there are two bunches in the upper half of each ring. At times the Insect moves them about, or spreads them like a plume. At other times they are laid flat, and meet across the back. I am much inclined to suppose," says Réaumur, "that these offer some analogy with the gills of Fishes." [The tracheal gills of Caddis-worms vary in their arrangement in

1 He says that the larva moves its abdomen up and down, most probably to renew the water which bathes its body, and that the fringed sides, by increasing the breadth of the abdomen, add to the effect. "The fleshy processes of the first abdominal segment find their use here; the body is kept by them more in the middle of the sheath, and the flow of water on all sides of it is thus greatly promoted." Zacharias' Tier-und Pfanzenwelt des Sïsswassers. Bd. II. p. 97 (I89I). 
the different species, but are usually wanting or imperfect in the thorax and the first and last abdominal segments; they are in several rows and either simple or branched: Fine air-tubes lead from them to the main air-trunks of the body.]

"At the hinder end of the body is a pair of horny hooks, which take firm hold of the under side of the

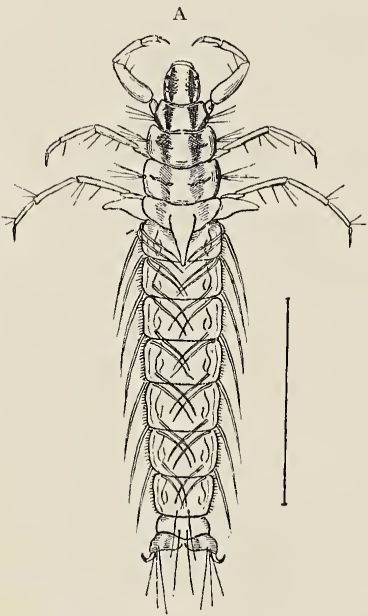

B

C
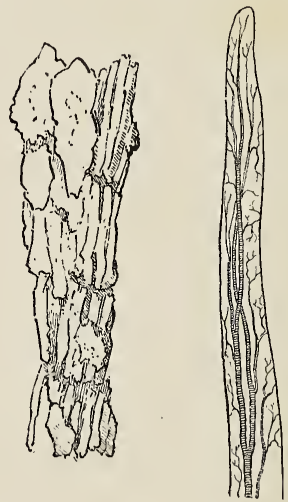

Fig. 8I.-Phryganea varia. A, Larva ; B, its case; C, a tracheal gill.

sheath. Indeed, if we attempt to remove the larva by force, it can almost be pulled in pieces before it will let go; to remove it without violence from its sheath, it is best to split open the sheath. [Anglers know of a readier method than this: A pin, gently inserted into the narrow end of the 
sheath, soon dislodges the larva.] On looking at the under side of the head with a lens, we see that the mouth-parts are tolerably like those of caterpillars and other vegetable-feeding larvæ. On each side of the mouth is a pair of strong toothed mandibles, well adapted for cutting and shaping the materials of which the sheath is composed, or for dividing the food. Further back is a pair of maxillæ with threejointed palps, while the labium is represented by three pointed triangles, which taper backwards and are armed with teeth along the fore-edge. [The labium is often of simple structure and ends in two minute palps.]

"The silken lining which comes next to the body of the larvæ shows that they can spin, and it is not difficult to see the thread, either with a lens or with the naked eye, for it is much coarser than that of most caterpillars. I believe that the thread issues from the same place as in caterpillars. I have traced it to the middle of the labium, where the spinneret of a caterpillar is situated. However, I have since suspected that the spinneret of the Caddis-worm is not situated here, but further back, in front of the base of the first pair of legs. Here is a soft curved prominence directed towards the head, which looks like a spinneret. I have not, however, seen any thread attached to it. [The curved spine between the forelegs is not the spinneret, but an organ whose function is as yet unknown. The true spinneret is close behind the mouth. Réaumur does not say anything about the silk-gland. As in Chironomus, Simulium, etc., the secretion of the salivary glands forms the silk. 


\section{NATURAL HISTORY OF AQUATIC INSECTS cH.}

The glands are enormously developed in Caddisworms, and may be three times as long as the body.]

"If we remove a Caddis-worm from its sheath without injuring either, and then lay the two side by side, the Caddis-worm at once enters its case, head foremost. It is not so foolish as some other kinds of larvæ which fail to recognise their own sheath when they have once left it, and would rather make a new one than put on a second time the covering which has been stripped off them. The front opening is the only one by which the Caddis-ivorm can enter. As it enters head first, its position is now reversed, but the sheath is sufficiently wide for the Caddisworm to turn round inside. I have seen a Caddisworm with its head and limbs projecting as usual from the front opening, by which it had re-entered head first the day before, after being forcibly extracted.

"Though Caddis-iworms will return to their sheaths, it is not because they are too lazy to make new ones, Wishing to see them at work, I took a Caddis-worm in the beginning of April, stripped it of its case, and put it into a glass dish with various bits of leaves soaked in water. In less than an hour it had made a new sheath of fragments of leaves. It is true that the sheath was rather shapeless, and seemed to be made of odd pieces slightly fastened together. However, it served to conceal the body completely, and the Insect could drag it about wherever it went.

"I turned this Caddis-worm out of its case a second time, as I had not sufficiently observed its mode of 
proceeding. This time I put it into a saucer of white earthenware, half full of water, taking care to throw in bits of straw, hay and wood. For nearly threequarters of an hour the larva crept about feeling the sticks and straws without deciding how to make use of them. They did not appear suitable to the work in hand. Perhaps they were too light, for they were not yet perfectly soaked in water. Then I broke up the two sheaths from which the larva had been successively expelled, and threw them into the water. Some of the fragments floated while others sank to the bottom. I threw in also bits of leaves, and it was not long before the Caddis-worm had found what it wanted. It fixed upon a fragment of leaf nearly as long as itself, and much broader. The hinder part of the body moved up and down so that the bunches of filaments carried upon it were seen to wave to and fro. While this was going on, the head was busily employed. The larva cut off bits of the leaf, and passed its head to and fro between them, as if in the act of spinning, and very shortly the pieces were fastened together. Thus the work went on until in a short time the sheath concealed the fore part of the body. It gradually grew until the whole body was covered, but so far the work was very rough, and spaces could be seen between the fragments. The sheath was moreover too large for the body, and accordingly several pieces were slipped inside and fastened down one after another. There happened to be in the saucer a branch of a water plant with nearly cylindrical leaves of about the dimensions of a common pin. The Caddis-worm cut several bits 
out of these leaves, and fastened them to its sheath, placing some of them transversely in the manner already described. When the outside of the sheath had taken the desired form, the larva worked at the inside, spinning a silken lining of a substantial kind. I have since seen several larvæ of the same species at work, making new sheaths, lengthening or strengthening the old ones, adding new fragments either to increase or diminish its weight, and all that I have been able to see was merely a repetition or an adaptation of the operations just described. [The cases of small stones or sand are the hardest to make. A Caddis-ivorm will complete one of these in five or six hours.]

"In some species (such as Phryganea grandis) the sheath appears to be rolled spirally round, like a ribbon wound upon a stick. I have seen bits of oak leaf arranged in this way along some very large sheaths which I found in a pond in the Bois de Boulogne. Some of these were only covered for part of their length by bits of broad leaves, the rest being occupied by narrow strips arranged side by side so as to form a spiral band extending to the higher end of the sheath. The larvæ which inhabit these last sheaths have two parallel curved bands on the front of the head.

"The larvæ of a very small species [Triænodes bicolor] are also covered by a spiral band, and look as if a green ribbon had been bound round them from head to foot. The dress of the larvæ is like our own in one respect; it is much handsomer when it is new. The colour changes in time from a beautiful green to 
a dirty brown. The spiral in this last species consists of a vast number of pieces, which increase in size by imperceptible gradation. We have often to use a lens to see that the band is not perfectly continuous. The leaves of which it is is composed are usually leaves of duckweed cut square. I believe that the fly of this species carries its wings crossed one upon another and laid horizontally.

"All Caddis-worms find it difficult to live in water which is contaminated, or in small vessels. They will last longer out of the water than in a very scanty supply or in foul water. M. Baron sent me several larvæ of a common species from Luçon to Paris by post. When they arrived they had been five or six days out of water; however, they were still alive and I saw them walk."

The Caddises exhibit something of that versatility which characterise the whole class of Insects. Thus we have species with moveable cases (the great majority); species with fixed cases or retreats which the larva quits at pleasure ; forms adapted to stagnant water, others adapted to life in torrents. Some marine species will be noticed in Chapter XII. Lastly, there are terrestrial forms. The larvæ of Enoicyla live in moss at the foot of trees, often far from water. They have no tracheal gills. The female flies are practically wingless, an indication in other orders of Insects of indiscriminate feeding and a plentiful supply of food. E. pusilla occurs in England, and other species are known. ${ }^{1}$

The variety of the cases manufactured by Caddis' McLachlan, Trichoptcra of the European Fauna. 

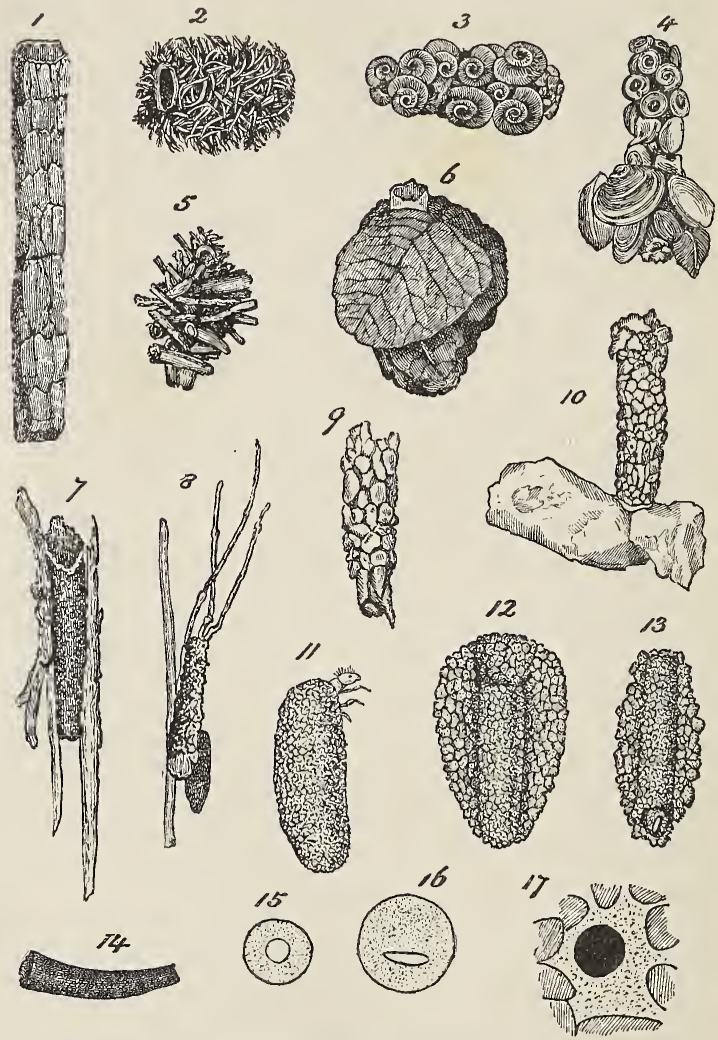

Fig. 82.-Cases of various Caddis-worms. r. Phryganea grandis ; 2, Limnophilus rhombicus; $3,4,5, \mathrm{~L}$. flavicornis; $6, \mathrm{~L}$. pellucidus; 7 , Anabolia nervosa ; 8 , Limnophilus lunatus ; 9, Stenophylax nigricornis (larval case); ro, do. (pupal case); II, Hydroptila MacLachlani ; 12, I3, Molanna angustata; 14 $_{4}$, Sericostoma ; $\mathbf{1}_{5}, \mathrm{~S}$. pedemontanum, anter:or closing membrane; 16 , posterior ditto ; 17, Micropterna nycterobia, posterior ditto. $\mathrm{x}-8$, and $\mathrm{I}_{4}$ are from MacLachlan, Sci, Gossip, 1868, the rest from Klapálek. 
worms is very great. A number of forms, characteristic of particular species, genera, and families are here noted. The information given is for the most part taken from McLachlan's Trichoptera of the European Fianc.

Bits of leaves or stems placed side by side so as to form a spiral band, passing many times round the case, which is open at both ends, tapering when small, parallel-sided later. Still water. Fam. Phrygancida. Trianodes forms a similar but more tapering case.

Case of entire or nearly entire leaves of trees, flattish and irregular. Still water. Glyphotalius.

Case of fibres or sticks placed transversely, sometimes with shells added. Still water. Limnophilus rhombicus.

Various materials, but especially shells of water mollusks. Still water. Limnophilus favicornis.

Case of sand, bits of grass, etc., to which long pieces of wood are added. Still water. Limnophilus lunatus.

Curved cylindrical tube of fine sand. Still water. Limno. philus vittatus. When the tube, as in this case, is curved, the convex side is next to the back of the larva.

Case cylindrical, of bits of dead leaves, joined by their edges ; closed with stones before pupation. Shallow running water. Limnophilus auricula.

At first of vegetable fragments arranged obliquely to form a cylindrical tube, afterwards of stones only. Pupal case shorter, and more conical, closed with stones, and attached a number together to stones. Still water. Limnophilus griseus.

Case of sand, cylindrical, scarcely curved, mouth-end oblique. Pupal case shorter, attached a number together by the mouthend. Running water. Limnophilus extricatus.

Case of small stones and vegetable matter. Long twigs attached to one end. Mouth-end oblique. Running water. Anabolia.

Case of small stones, fixed or lodged in the bed of a stream. Stenophylax.

Case of small stones. In swift, clear streams. Micropterna (see Fig. 82, I7.) 
Case of vegetable fragments arranged longitudinally or obliquely. Often with a long piece of wood at one end. Pupal case closed with stones. Running water. Halesus radiatus.

Case curved and tapering behind, of stones and vegetable matter, the stones at the tail-end. Swift streams; the larva attaches its case in the strongest currents. Halesus auricollis.

Case of small stones or sand, cylindrical. Streams. Sericostoma.

Case flattened, often with larger stones attached at the sides. Rivers and streams. Goera.

Case quadrangular, of vegetable matter. Rivers and canals. Brachycentrus.

Cases slender, straight, tapering tubes of fine sand, attached a number together to the stones of streams. Oligoplectrum.

Case of sand, spirally wound like a snail-shell. S. Europe, America, \&c., \&c. In still water. Helicopsyche.

Case of fire sand, curved, cylindrical. Still or running water. Fam. Leptocerida.

Case of sand overspread by a sandy shield which projects over the head of the larva. De Geer calls this a "Tortoiseshell case." Still water. Molanna.

Case of sand, slightly curved, cylindrical. Tail-end closed by a blackish membrane with a central slit. Before pupation the mouth is closed by a single stone. Clear, sub-alpine streams. Odontocerum albicorne.

Straight or slightly curved, cylindrical cases of fine sand; tail-end cut off before pupation. Usually in rivers and streams. Leptocerus.

Case of sand, with long twigs attached. Slow streams, canals and tanks. The larva has the legs, especially those of the third pair, unusually long. Mystacides.

Case much curved, of fine sand or mud lined with silk. In the spray of waterfalls. Adicella.

Case of hardened silk. Standing and running water. Setodes.

Cases fixed, of stones, occasionally inhabited by several larvæ. Still or running water. Some Hydropsychida.

Larva loosely covered by silken threads, forming a snare. Pupa in solid stony case. Clear rapid streams. Plectrocnemia.

Larva covered by vegetable debris, \&c., until pupation. Rapid streams. Polycentropus. 
Larva makes silken channels on the surface of stones, which become covered with slime, but prepares firmer cases before pupation. Streams and springs. Tinodes.

Cases of small stones. Pupa enclosed in a brown cocoon, instead of lying free within the case. Torrents. Rhyacophilida.

Cases of silk, movable, with foreign bodies attached, resembling small seeds, slit at each end, at either of which the larva can protrude its head. Sometimes moored by threads. Fixed by strong threads before pupation. Standing or running water. Fam. Hydroptilida.

I now resume Réaumur's account. "It is not only in the manufacture of their sheaths that these larvæ exhibit industry. They have subsequently to be transformed into pupæ in order to emerge as wiriged Insects. The pupa is no better fitted to defend itself against the attacks of its enemies than the chrysalis of a Moth. Carnivorous Insects abound in the water as on land or in the air. Accordingly the Caddisworm, before undergoing its transformation, provides for its safety during the time when it can no longer defend itself. It does not, however, quit its sheath, but closes up the two ends with plates composed of silk or of some other material. In its pupal condition it continues to breathe air dissolved in water; to secure a constant supply of fresh water, the plate which closes each end of the sheath is pierced with holes like a strainer or grating, made of coarse threads of silk. Thus the pupa is furnished with an ample supply of fresh water, flowing through its sheath, while it is sufficiently protected against carnivorous Insects.

"The pupæ may be found in their cases in May and June, but there are probably some which pass the 
winter in this state. In the month of March I have found in the water cases with perforated ends, and on opening them the pupa was seen. I placed some of these pupæ in water, where they lived several days during which time they waved the hinder part of their body to and fro [no doubt for purposes of respiration].

"These pupx possess some peculiar features which deserve a moment's attention. The body is white with a citron tinge. On each side there is a narrow black band extending over the four last rings. The tail ends in a small fleshy fork. On the back are bunches of white respiratory filaments, and also four or five brown spots, which under the microscope are seen to be furnished with spines directed backwards. The four wings are plainly to be seen folded and enclosed in the pupal skin, as in Lepidoptera. The head is small in comparison with the body. On each side is a great black eye, and a little below this a beak like that of a parrot. Above this beak may be seen a tuft of hairs which gives the whole head some resemblance to that of certain Birds, but on close examination it can be made out that what at first sight looked like a beak consists of two hooks [the mandibles], which unite in front, and are crossed at the points. These hooks lie beneath a fleshy projection which carries the tuft of hairs. They are different in shape from any possessed by the larva. The Caddis-fly has no such organs at all. These are therefore parts peculiar to the pupa; of what use can they be, seeing that the pupa takes no food? It is probable, as Vallisnieri supposes, that they are 
useful only at the time when the fly is about to emerge, and that they serve chiefly or solely to break
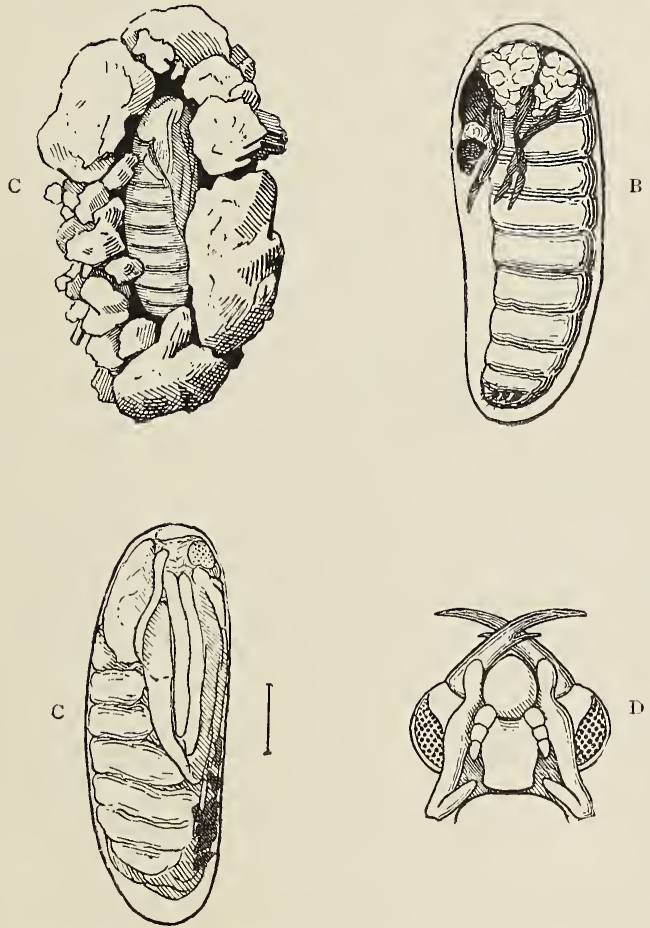

FIG. 83.-Pupa of Hydropsychid Caddis-worm. A, case of small stones, seen from attached side, with enclosed pupa ; B, larva within case, preparing to pupate ; C, pupa ; D, pupal head, showing large hooks (mandibles).

down the gritty partition which closes the sheath. Vallisnieri has seen in the end of June pupæ which 
had broken down the perforated ends of their sheaths, and had partly emerged. He has also seen such pupæ transformed into flies. I have had flies which emerged in the beginning of April, having probably passed the winter as pupæ in their sheaths.

"Sometimes the sheath of the larva is longer than necessary for it in the pupal stage. In such cases perforated partitions are formed across the tube at two points, but if the larval case is short, the perforated plates are fixed at the two extremities. I have seen at times the perforated ends of the pupal sheaths move in and out according as the Insect sucked the water in or expelled it. These pupal sheaths are generally attached to some fixed object, and the sheath is fixed before the perforated plates are added."

The pupal case is often a good deal shorter than that in which the larva dwelt. Before pupation the larva makes provision for its security during the resting stage. Various plans are employed by different species. Some close the ends of the tube with the silken sieves described by Réaumur; others (Limnophilus auricula, L. griseus, Halesus) with stones; Odontocerum with a single stone. Micropterna sequax is said by Pictet ${ }^{1}$ to make its case at first of leaves; as the larva grows it adds stones, until at last the case is entirely stony. When pupation approaches, the case is lengthened with larger stones, and closed at the wide end. Then the larva proceeds to bury the narrow end vertically in the mud, until only the large stones at the wide end are visible. To accom1 Recherches sur les Phryganides, p. 133. 
plish this it turns round in its case, and works with its head and legs projecting from the narrow end till a hole is made of suitable size to receive the case, after which it resumes its ordinary position. The cases are commonly secured by silk threads to stones or other objects.

De Geer describes the process of pupation and the escape of the fly. ${ }^{1}$ Having found cases just closed with silken sieves, he opened one, and found within it a larva not yet transformed. It had, however, lost the power of moving its limbs, which seemed paralysed, though the abdomen was capable of vigorous movement. ${ }^{2}$ Next day the larval skin was cast. The pupa now exhibited all the parts of the imago, enveloped in a pupal skin, but not glued down, as in a Lepidopterous chrysalis. The antennæ and legs were free; a point of importance in connection with the emergence of the imago.

The fly does not emerge beneath the water, adds De Geer. The pupa first extricates itself from its case by the help of the hooks described above. Then it climbs up the stones or aquatic plants until it gains the air, attaches itself by the claws of its legs, and throws off the pupal skin. The pupa, when liberated from its case, swims and runs about with surprising agility. Swimming is mainly effected by the pair of

1 Móm. sur les Insectes, II, 546, 516.

2 The mobility of the abdomen of the pupa is a point of practical importance. The respiratory movements kept up by the abdomen of the larva are equally necessary in the next stage, and the pupa has the lateral fringe of hairs, the tracheal gills, and every other requisite for maintaining a flow of water through its case. 
intermediate legs, which are broad and fringed with hairs. Sometimes the fore legs are fringed also. Fritz Müller remarks that certain pupæ of Caddisflies, which are not submerged, want these hairy fringes, an interesting verification of the interpretation commonly accepted. ${ }^{1}$ The pupa commonly swims back downwards. Some of the smaller species do not creep out of the water, but float to the surface, and the fly in such cases escapes from the floating pupa skin after the manner of a Gnat.

The dorsal surface of the pupal abdomen commonly bears a number of hooks or groups of hooks, which are no doubt used, like the very similar hooks of many Lepidopterous and other pupæ, for movement within the cocoon.

Some mention should be made of the Caddisworms which do not carry about cases. These belong to the families Hydropsychidæ and Rhyacophilidæ, and are found usually in rapid streams. They have retreats, often common to several larvæ, which are fixed and not portable, often consisting of stones fastened by silk threads to one another and to a larger stone. The larvæ seek their food abroad, lurking in crevices. They are sometimes, if not always, carnivorous, preying upon Ephemeræ, Simulium larvæ, and the like. In these larvæ the lateral fringe of hairs upon the abdomen and the retractile processes of the first abdominal segments are wanting, a confirmation of the explanation given of these structures, viz., that they aid in promoting a stream of water through the confined tube of the ordinary 1 Nature, March 20, I879. 
Caddis-worms. The tracheal gills may be numerous and unusually large, or altogether absent. The anal feet are unusually long and powerful, two-jointed, and armed with strong hooks for grappling. Just before pupation, the larva constructs a pupal case of stones firmly fastened together. Enclosed in this, its respiratory requirements are much the same as those of ordinary Caddis pupæ. Accordingly tracheal gills, if not present earlier, now appear, and the sides of the abdomen are extended laterally by processes which resemble, in their effect at least, the ordinary lateral fringes.

I am indebted to Mr. T. H. Taylor for the following interesting particulars respecting the mode of life of the larva of Plectrocnemia :-

"Plectrocnemia finds its home in streams where the water flows swiftly over a stony bed. If a stone be lifted out, the under side is often found to be covered with patches of mud from which brown larvx emerge and begin to crawl over the surface. The muddy particles are evidently held together by some binding substance, and the whole forms the retreat of the Caddis-worms, corresponding to the cases of Phryganea. When a larva is placed in a vessel of clear water, it at once begins to explore its new quarters, and eventually selects a site for its dwelling. This is made of silken threads secreted by the large silk glands, and when completed the structure consists of a tube considerably longer and broader than its occupant, and open at both ends. It is supported and strengthened by a meshwork of silken threads, which spread out for a 
266 NATURAL HISTORY OF AQUATIC INSECTS $\mathrm{cH}$. considerable distance, and are attached to the surrounding objects.

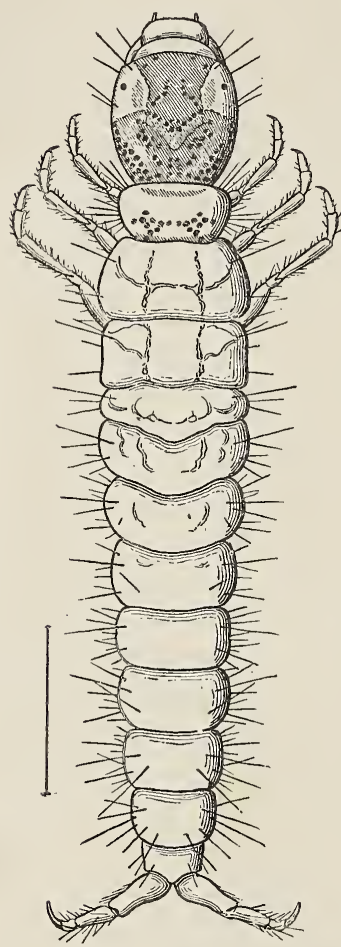

Fig. 8.--Larva of Plectrocnemia (Fam. Hydropsychidx).

"Through this transparent case it is easy to observe the larva clinging by its feet and anal hooks to the threads, and to watch its movements. Like other Caddis-worms, it sets up a current of water through the tube by swaying its body up and down. The respiratorystream enters at the head end, and flows out behind.

"Plectrocnemia possesses no gill-filaments, and apparently the only structures analogous to gills are five finger-like processes on the last segment. These are capable of being completely withdrawn. The absence of processes on the first abdominal segment is interesting. Assuming that they serve to keep the larva steady by pressing against the side of the case it is essential that they should act upon a rigid support. Here, however, 
there is no firm resisting surface, and the processes are not developed. Had they been true respiratory organs, we may conjecture that they would have been retained to supply the place of tracheal filaments, which are altogether wanting.

"From time to time the larva turns round in its case, and even leaves it for a short space. Generally, however, it remains quiet inside, apparently on the alert for prey. If a Chironomus or other small aquatic larva approaches, it is almost certain to get entangled in the network of silken threads. At once the Caddis in its retreat perceives the presence of a possible victim. The long hairs which cover the body are possibly tactile, and reveal slight disturbances of the silken network. The Plectrocnemia then proceeds warily to determine the cause of the disturbance. Should the Chironomus be entangled near the middle of the tube, the Caddis-worm does not hesitate to bite its way through the side, and its jaws very soon quiet the struggles of the prey.

"There is some resemblance between the snare of the Plectrocnemia and the web of a Spider, but the Plectrocnemia is effectually concealed by the mud which clings to its retreat. In captivity it forms a web which is free from foreign particles, and allows all its manœuvres to be observed."

"The Caddis-fly," says Réaumur, "exhibits some marked peculiarities of its own. In a classification of Flies, we might assign to them the name of papilionaceous, that is, Flies which at first sight resemble Butterflies. These papilionaceous Flies have four wings, of which only the two upper are visible when 
the Insect is at rest. In this position the upper wings are nearly flat above, then they bend at an angle and slope downwards. These two upper wings are moderately transparent, but appear opaque when they overlie the others. It is their opacity which causes them to resemble Butterflies' wings, but on close examination we see that they have none of the scales which are characteristic of the wings of Lepidoptera [but are clothed with hairs]. The lower wings are very transparent [and usually folded fan-wise]; they consist of a colourless or slightly bluish gauzy membrane. The fly immediately after emergence, and for some days subsequently, has a greenish tint; then it gradually turns dark. The six legs are long, but the fly does not stand high above the surface on which it rests. The antennæ are very long, longer than the body, gradually tapering, and of many joints. The eyes are compound, like those of other Flies and Butterflies. The mouth bears implements very unlike those of the larva or pupa. There are [no mandibles, but] four palps, two above and two below, besides a very small proboscis [labium? The tarsi are five-jointed]."

The eggs of Caddis-flies are laid in water or on water-plants, or on trees overhanging a stream, or sometimes far from water. ${ }^{1}$ They are often of green colour, and are laid many together in a mucilage which swells out as soon as it comes in contact with water, forming a cylindrical egg-rope, or in some cases a flat disc. As soon as the larvæ are hatched,

1 McLachlan, Entom. Month. Mag., Vol. XVI., p. 135 (1878). 
they begin to make cases for themselves. We have very little information as to the actual process of egg-laying. Female Caddis-flies have been seen to descend into the water, and are not uncommonly found in a dirty condition, as if they had been immersed in muddy water. The last joints of the legs are often much dilated in the female, but not in the male fly. This points to resting on the surface of the water during egg-laying.

Entomologists are by no means agreed as to the proper position of the Caddis-flies (Trichoptera) in the system of Insects. Réaumur treated them as a particular sort of Lepidoptera, calling them teignes aquatiques. In favour of a close alliance with that order might be alleged the four wings, clothed with hairs, essentially agreeing with the scales of Lepidoptera, and sometimes not unlike them in form; the attitude of the wings and antennæ of the resting Insects, which is very like that of some small Moths; and the reduction of most of the mouth-parts of the imago to functionless rudiments, as in many Moths. The maxillary and labial palps are, however, much more complete than in most Lepidoptera. ${ }^{1}$ Even the mode of life of the larva, the aquatic habitat, and the sheath or case can be matched among Lepidoptera. The pupa of Micropteryx, a genus of Tineina (small Moths), resembles a Caddis-pupa in the circumstance that its appendages are not glued down, but distinct and mobile. Moreover, the large pupal mandibles are used to extricate the Moth from its subterranean

${ }^{1}$ In Micropteryx and some other Lepidoptera the palps are as well developed as in most Trichoptera. 
cocoon in a very Trichopterous manner. ${ }^{1}$ These considerations are of various degrees of importance, and some of them would not carry much weight with the systematist. Those naturalists who, like the writer, are compelled by their ignorance of systems to take all their views on such matters from other people, will acquiesce in Mr. McLachlan's opinion that in any linear arrangement the Trichoptera and Lepidoptera must not be widely separated.

It might be supposed that Caddis-worms, being immersed in water as well as protected by a case, would be free from the destructive attacks of Insectparasites. Mr. McLachlan has, however, mentioned a Dipterous parasite which infests Limnophilus, one of the Caddis-worms, and a short account of an Ichneumon (Agriotypus), which preys upon another Caddis-worm, is given in the section on Aquatic Hymenoptera (p. 223).

Many of the contrivances of Insects are not confined to a single order. The singular habit of laying eggs in living larvæ is shared by Hymenoptera and Diptera ; Lepidopterous, Dipterous, Hymenopterous, and Coleopterous larvæ mine in the thickness of a leaf; Hymenoptera, Diptera, Coleoptera, and Rhynchota practise the art of making galls on plants; societies with a common dwelling exist among Hymenoptera (Bees, Wasps, and Ants), and also among Pseudo-neuroptera (White Ants); the Dipterous Leptis vermileo imitates the pit-falls of the Ant-lion (Neuroptera). Hence it is in accordance with the great adaptability of the Insect-organisation

${ }^{1}$ Dr. T. A. Chapman, Trans. Ent. Soc., 1893, p. 255. 
that more than one order should furnish examples of larvæ which protect themselves by cases constructed out of foreign particles. Not only the Caddis-worms, but certain Bectles, Lepidoptera, Diptera, and Neuroptera have learnt this art. The larvæ of Clythra construct leathery cases which they drag about with them; the head is protruded from one end, and when full-fed, the Insect changes to a pupa within its case. The larvæ of Cryptocephalus form cases too. ${ }^{1}$ Among Lepidopterous larvæ the Coleophoridx, the Tineidx, and the Psychidx are casebuilders, commonly carrying their cases about and undergoing their transformations within them. Some of these land caddises are described by Réaumur in his most graphic manner in the memoir cited. Chironomus and Tanypus (Diptera) construct fixed cases out of vegetable fragments, and Lyonnet ${ }^{2}$ figures and describes what is probably a Chironomus, of which he says that it weaves together the confervæ of the ditches, and forms out of them a sheath open at both ends, and enlarged towards the middle. The sheath is so flexible as to yield to all the undulating movements of the inhabitant. The larva drags itself and his sheath along by its mandibles and fore legs. If the sheath becomes entangled, it quits it and soon makes another. The Insect pupates within

1 Fowler, British Coleoptera, Vol. IV., pp. 286-7.

${ }^{2}$ Rech. sur I Anat., E.o., de diff. Espìces d'Insectes, pp. I79-183, pl. xvii., Fig. 2. De Haan, the editor of this posthumous work of Lyonnet, names (with some hesitation) the Insect a Tanypus, but its habits are surely those of a Chironomus. I have never met with this larva. 


\section{NATURAL HISTORY OF AQUATIC INSECTS}

its sheath. Lastly, the larva of Hemerobius and Chrysopa (Neuroptera) cover their bodies with the skins of Aphides.

It must not be supposed that little or no progress has been made in the investigation of the Natural History of the Trichoptera since the last century. Much excellent work has been done of late years, especially by Pictet, ${ }^{1}$ McLachlan, ${ }^{2}$ Fritz Müller, ${ }^{3}$ Klapálek, ${ }^{4}$ and Morton. ${ }^{5}$ We have now fair accounts of the structure and mode of life of many species ; the indispensable work of classification, which was hardly even attempted by Réaumur, has made satisfactory progress, and the special student is thereby spared much confusion and loss of time. Unfortunately it is hardly possible to give to a beginner any intelligible account of this valuable mass of detailed work. Those young naturalists who seek for work more promising than records of parish distribution would do well to master and extend the results achieved by the writers named. Such work will bring them into actual contact with the problems of nature.

1 Rech. pour servir à l'Histoire et l'Anatomie des Phryganides (1834).

2 Monograph of British Caddis-fies (1865); Revision and Synopsis of the Trichoptera of the European Fauna (1874-80).

3 Zeits. f. wiss. Zool., XXXV. (1881); Zool. Anz., I879; Ent. Soc. Trans., 1870.

${ }_{4}$ Arch. der Naturw. Landesd. von Böhmen, VI. 5 ; VIII. 6. (I $888-93)$.

5 Ent. Month. Mag. I 882. 


\title{
CHAPTER VI
}

\author{
SIALIDAE
}

\section{The Alder Fly (Sialis)}

ONE of the very commonest of aquatic Insects is the larva of Sialis lutarius. It is found in ponds and slow streams. A muddy bottom is one requisite; hence Linnæus' specific name, lutarius, which means muddy. The larva creeps about actively on or in the mud, seeking its food, which consists of other aquatic animals. I find that in captivity it will eat Caddisworms and Ephemera-larvæ, and authors mention having found fragments of Insects in the alimentary canal. The length of a full-grown larva is about an inch, and the greatest width one sixth of an inch. The body tapers a little towards the head, and very gradually to the slender and long-drawn-out tail. The six legs are strong and well suited to walking. Each ends in a tarsus of two joints, bearing a pair of pointed claws. The head is provided with a pair of antennæ, a pair of long, curved and pointed mandibles, which sufficiently indicate the carnivorous habits of the larva, and the other mouth-parts usual in biting Insects. From the sides of the first seven 
abdominal segments, or rather from the membranous inter-segmental spaces just in front of them, stand out as many pairs of long, tapering, five-jointed
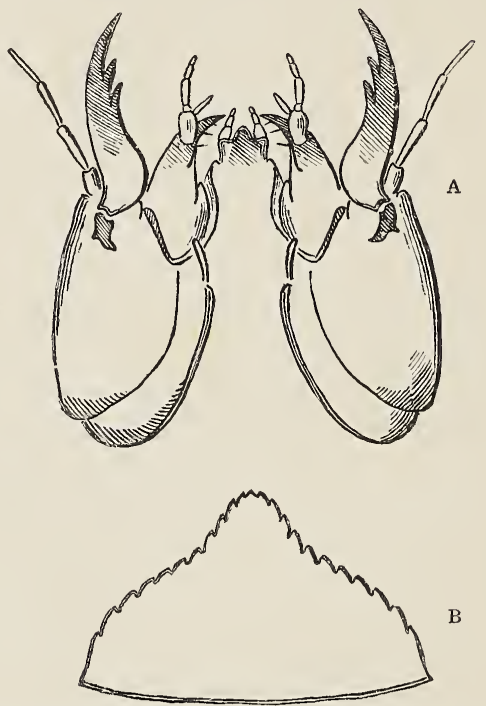

FIG. 85.-Mouth-parts of larva of Sialis. A shows, in order from without inwards, the antenna, mandible, maxilla, and labium. B, the mentum (base of labium).

appendages. $^{1}$ These are fringed on opposite sides with hairs in regular series, and each is traversed by a sinuous, branching tracheal tube. A stream of blood,

1 Pictet (Ann. Sci. Nat. Zool., 2e Série, V. pl. 3) shows eight pairs of four-jointed gills, and his figure has been copied by other authors. Roesel has the right number, viz. seven, but his figure is too small to show the number of joints. 
carrying along colourless corpuscles, can be seen by the microscope to flow at each pulsation of the dorsal vessel into the space which surrounds the trachea. These appendages are tracheal gills, very like those of many other aquatic larvæ. There are no tracheal gills to the eighth and ninth segments. To the ninth abdominal segment is attached the long tail, which appears to represent a tenth segment. It is fringed, and contains two tracheal tubes, much resembling indeed two ordinary tracheal gills completely fused together. In the usual position the tracheal gills curve upwards and backwards, and it is only in the dead larva that they lie confusedly as in Fig. 86. It is said in some books that they can be employed as fins for swimming,

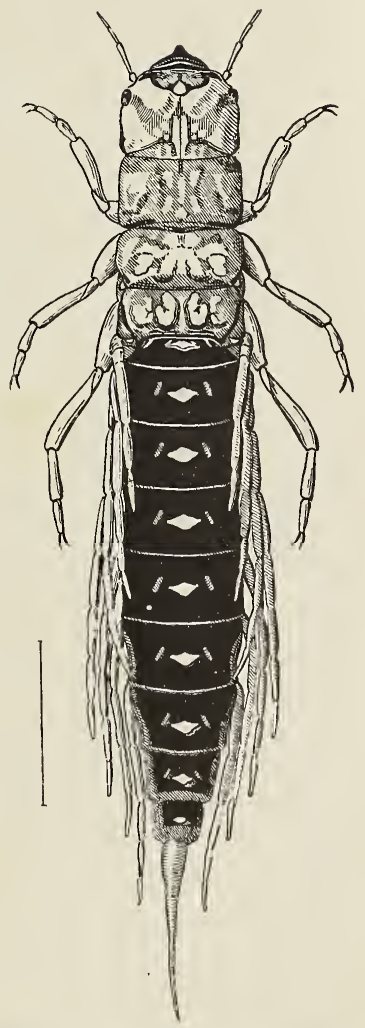

FIG. 86.-Larva of Sialis. The jointed respiratory appendages of the abdomen are in the living larva curved upwards and backwards. 
but this is not the case. The larva creeps by means of its six legs, sometimes aiding its progress by an undulating, side-to-side movement of the abdomen. In a confined space it may often be seen to move its abdomen in vertical undulations, which cause a swirl in the water, and no doubt promote respiration.

Several aquatic larvæ, not at all closely related to Sialis, have similar tracheal gills. Gyrinus and Orectocheilus are examples taken from the Coleoptera. One peculiarity of the gills of Sialis, viz. their division into joints, is shared by a Dipterous larva, Dicranota. It is worth notice that aquatic Insects, living side by side under identical conditions, should show so great a variety of respiratory organs. Some have tracheal gills, not all of one kind ; others breathe by spiracles ; others have no special respiratory organs at all.

Though the Sialis larva lives in water, and can spend months without coming to the surface, as I have found by observation of captives, it can survive a rather prolonged exposure to air. Full-grown larvæ, taken out of the water before the time of transformation has fully come, and placed on damp earth, walk about till they find a convenient crevice, and then bury themselves. They live and retain the power of active movement for days when thus secluded. This faculty of enduring exposure to dry conditions is useful, as will shortly be seen, on two occasions, which inevitably occur during the lifetime of the Insect-viz., immediately after hatching, and before pupation.

In May or June, when the larva is full-fed, it quits the water and seeks a place where it can bury itself 
in the earth. For this purpose it will often travel far from its native pool, and I have lately found one creeping on the surface of the ground six yards from water, though the season was dry, and the soil common garden mould, not particularly retentive of moisture. This larva had climbed up a concrete wall, made its way through a thicket of Cotoneaster, and reached an open flower-bed. When the Insect has found a place to its mind, it enters the earth, excavates a little cell, casts the larval skin, and is transformed into a pupa, which has the legs and wings free from the body, though enclosed in special sheaths. There are spines on the abdominal rings, as usual in pupæ which have to make their way to the surface of the earth ready for the emergence of the imago. After two or three weeks the fly emerges-a heavy awkward Insect with black body, and four large and coarse wings, which are clear but with conspicuous black veins. The female fly is one third larger than the male. At first sight the winged Insect might be taken for a Caddis-fly, for the wings are rather opaque, longer than the body, and form a sort of roof sloping steeply away on either side. The body is stouter and heavier than that of a Caddis-fly, the antennæ shorter in proportion, though still of good length, and the mouth-parts much more complete. The wings too differ considerably from those of the Caddis-fly. A winged Sialis flies heavily, and is easily caught. When threatened it tries to escape by running rather than by taking wing. The female lays patches of dark brown eggs on leaves, stones or palings not far from the water. There may be several 
hundred eggs in one cluster, cylindrical with rounded ends, and closely packed together. From the free end of each egg a small pointed and whitish projection is given off. When the larvæ hatch out, they travel to the water, where they have to spend about a year before attaining the winged state. I have often seen the fresh-hatched larvæ wriggling out on leaves many yards from the nearest stream or pond. How they find out the way, and whether or not many perish from taking a wrong direction, I do not know. Anglers have called this the Alder Fly, no doubt because it is often found on the alders which overhang streams. In some old books it is called May Fly, a name which is better suited to this Insect than to Ephemeridx, which emerge in various months of the summer season. 


\section{CHAPTER VII}

PERLID E

\section{STONE-FLIES (PERLA)}

IN streams, and especially in clear streams which flow down from the hills along stony beds, the larvæ of Perla are plentiful during early summer. Lift any good-sized stone, as large as the hand or larger, and it is likely that two or three dusky objects, resembling small Shrimps, will run along it to seek the side which is turned away from the light. In the stream which I have most diligently frequented two aquatic larvæ occur side by side on such stones. One is that of Baetis (Ecdyurus) fluminum, an Ephemerid; the other that of a Perla. The Baetis is smaller than the Perla, though a good inch in length when of full size, and has three tails. The Perla is somewhat larger, and has only two tails.

In June the larvæ of Perla leave the water, and shortly after the winged flies emerge. The stones which border the brook are now strewn with larvaskins, curiously like living larvæ in shape, but dry and empty. Along the back of the thorax is the 
280 NATURAL HISTORY OF AQUATIC INSECTS $\mathrm{cH}$. gaping slit by which the fly escaped. The eyes, legs, jaws, and wing-

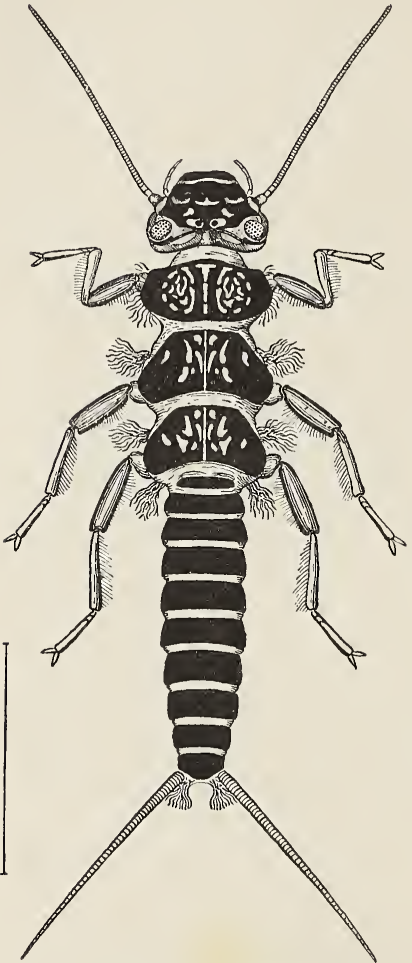

FiG. 87.-Larva of Perla bipunctata (bicaudata). sheaths, as well as the rings of the body, are so perfect that the outer form of the larva can be described from such a cast skin. Not only these external organs, but also the lining membrane of the great air-tubes, and that of the fore part of the alimentary canal, including the armature of the gizzard, can be made out in the cast skin, a proof that these structures are formed by

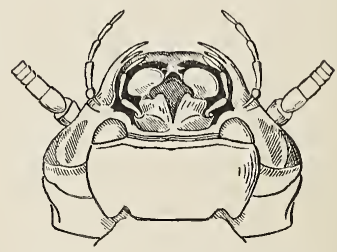

FIG. 88.-Under side of head of larva of Perla bipunctata (bicaudata).

folding of the outer integument into the respiratory openings and the mouth. 
It is easy to observe the escape of the fly. A fullgrown larva creeps out from the stream, sometimes to a distance of several feet, and seeks a stone on which it can securely fix its hooked feet. Then the old skin begins to swell. Air is passed into the narrow space between it and the new skin beneath, which though still soft and flexible, is now complete in all its parts. Before long the back of the thorax splits lengthwise. First the new thoracic slin shows itself, then the head and antennæ appear, and the wings are drawn out of their sheaths. The legs of the fly are next freed, and when these have got a sufficient hold of the ground, the abdomen and tail-filaments are withdrawn. The newly emerged fly is still soft and pale-coloured, but in a few hours or even, in some species, in a few minutes, the organs of locomotion become firm, and the Insect takes to flight.

In spite of its large wings the imago is a poor flier, turning with difficulty, and showing little power of avoiding an obstacle. It is easy to capture it with a net or even with the hand. Like a Grouse, it whizzes along with great effort and nearly in a straight line. The habits of the winged Perla do not call for great agility. The males and females mate on the ground, near the place of emergence. The fertilised eggs, which are oval and black, project from the end of the abdomen of the female, being loosely fastened together by a transparent skin. These are dropped into the water, and the work of the winged generation is at an end.

From these eggs small aquatic larvæ issue, which may be found plentifully in the same streams during 
282 NATURAL HISTORY OF AQUATIC INSECTS CH.

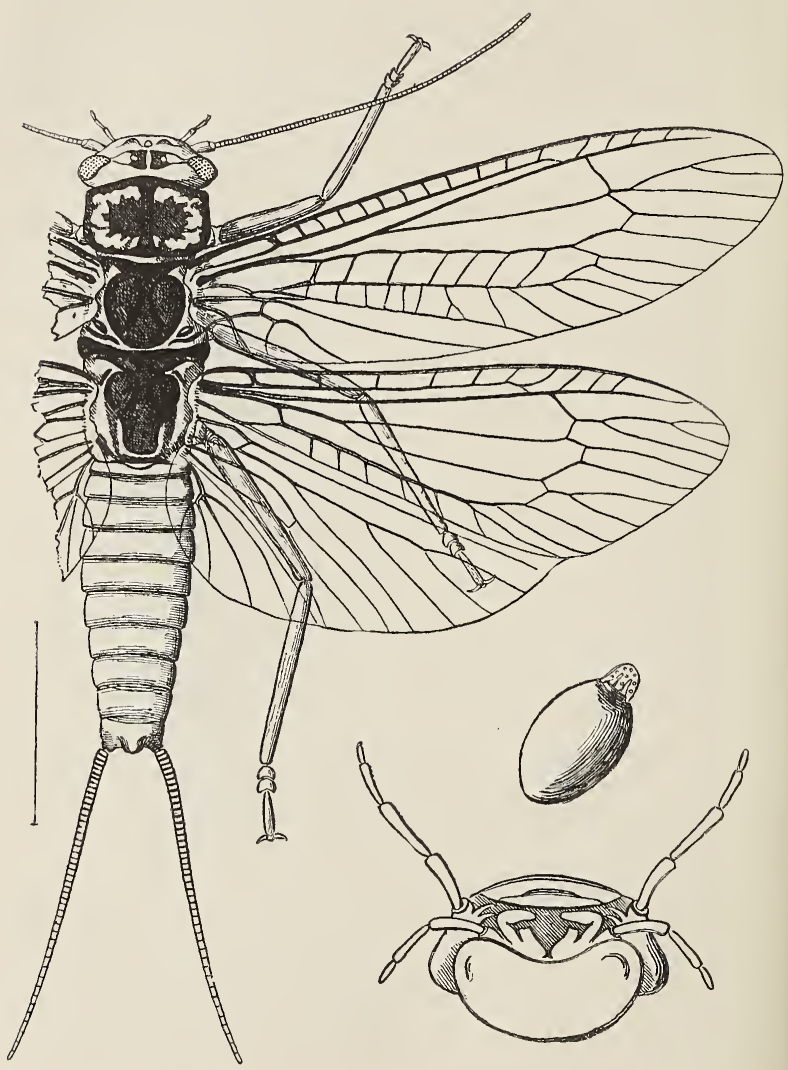

FIG. 89.-Perla bipunctata (bicaudata). Mouth-parts of do. ; egg of do. 
late summer and autumn. They hide themselves during winter, but reappear early in spring. From this time they feed actively, capturing and devouring all the weaker inhabitants of the stream, until the time comes to quit the water. I have found in the stomach as many as five empty heads of Chironomus larvæ. The jaws of the larva resemble those of a Beetle or Cockroach. The mandibles are stout, and armed with small pointed teeth; both pairs of maxillæ are well developed, and provided with good-sized palps.

It would naturally be expected that a larva so entirely aquatic as that of Perla would possess respiratory organs of the nature of gills, and this is actually the case. At the base of each leg, and just above it, is a tuft of filaments, supplied by fine, branching air-tubes. A little behind each of these bunches of tracheal gills, and in the flexible skin which unites the thoracic segments, or unites the last thoracic segment to the first abdominal, is another bunch. There are thus twelve thoracic gills (six pairs) in the larva of Perla. Finally, just inside the base of each tail-filament is another gill. ${ }^{1}$ It will be noticed that, as in Crustacea, the gills are placed where the movements of the appendages can either wave them to and fro, or set up a swirl in the water. The living larva rises and sinks continually (when not travelling about) by a slight movement of the legs, and this movement is probably of use in respiration.

In an Ephemera larva the tracheal gills are com-

1 Palmén, Morph. d. Trachecn-systems (1877). The description in the text applies to certain large species, such as Perla bipunctata. 
pletely cast at the last moult, when the spiracles open for the first time and allow air to pass directly into the tracheal tubes. In Perla, however, the tracheal gills persist, though in a greatly reduced form, after the spiracles have opened. In the winged fly the gills can be discovered with a lens in exactly the same places where they occur in the larva. This fact, which was established by Palmén, was of great use to him in refuting a view which had been extensively adopted-viz., that spiracles are derived from previously existing tracheal gills. It was supposed that the casting of the gill in all cases opened a way into the tracheal system, which was previously closed. In the winged Perla, however, minute tracheal gills, project from every thoracic spiracle. They are probably quite useless. The chief theoretical interest of Palmén's arguments is that they dispose of a theory which implied that Insects were primitively aquatic, and became adapted to aerial respiration by the conversion of their gills into air-slits. On the contrary, it is on all grounds probable that Insects were primitively terrestrial, and that the various adaptations to aquatic conditions are secondary. Where Insects possess gills, these are not primitive organs possessed by the more typical Insects, but relatively late acquisitions, developed as it were casually, and with a marked relation to the peculiar needs of the family or small group in question. No organs of an Insect are more variable in position, number and structure than the larval gills, and this is one proof that they were not inherited from a common ancestor, but acquired by many small groups independently of one another. 


\section{CHAPTER VIII}

\section{MAY-FLIES (EPHEMERID $/)^{1}$}

Tine first useful account of the life-history of an Ephemera that we meet in zoological literature is to be found in Swammerdam's Biblic Nature. The species investigated by him is now named Palingenia longicauda. The larva is common in the large, slow and muddy rivers of Holland. Swammerdam's history, a good deal abridged and annotated, is here reproduced in English as an introduction to the Mayflies or Ephemeræ. Some particulars respecting the author, taken from Miall and Denny on the Cockroach, are prefixed.

Swammerdam's great posthumous work, the Biblic Nature, contains about a dozen life-histories of Insects worked out in more or less detail. Of these the May-fly (published during the author's lifetime, in I675) is the most famous; that on the Honey Bee the most elaborate. Swammerdam was ten years younger than Malpighi, and knew Malpighi's treatise on

1 The names used by modern naturalists are employed wherever the species described by Swammerdam and Réaumur can be clearly identified. 
the Silkworm - a not inconsiderable advantage. His working-life as a naturalist comes within the ten years between 1663 and 1673 ; and this short space of time was darkened by anxiety about money, as well as by the religious fanaticism, which in the end completely extinguished his activity. The vast amount of highlyfinished work which he accomplished in these ten years justifies Boerhaave's rather rhetorical account of his industry. Unfortunately, Boerhaave, whom we have to thank not only for a useful sketch of Swammerdam's life, but also for the preservation of most of his writings, was only twelve years old when the great naturalist died, and his account cannot be taken as personal testimony. Swammerdam, he tells us worked with a simple microscope and several powers. His great skill lay in his dexterous use of scissors. Sometimes he employed tools so fine as to require whetting under the microscope. He was famous for his inflated and injected preparations. As to his patience it is enough to say that he would spend whole days in clearing a single caterpillar. Boerhaave gives us a picture of Swammerdam at work which the reader does not soon forget. "His labours were superhuman. Through the day he observed incessantly, and at night he described and drew what he had seen. By six o'clock in the morning in summer he began to find enough light to enable him to trace the minutiæ of natural objects. He was hard at work till noon, in full sunlight, and bareheaded, so as not to obstruct the light; and his head streamed with profuse sweat. His eyes, by reason of the blaze of light and microscopic toil, became so weakened that he could not 
observe minute objects in the afternoon, though the light was not less bright than in the morning, for his eyes were weary, and could no longer perceive readily."

Swammerdam's Life of an Ephemera follows :-

"The winged Palingenia (Fig. 9I) is an Insect with four wings, two small antennæ, six feet, and two long, hairy filaments, which stand straight out from the hinder end of the body. It lives at most five hours in the winged state. Every year it appears on the banks of the Rhine, the Maas, the Waal, the Leck, and the Yssel, appearing on the surface of the water about the feast of St. Olof and St. John. The flies may be seen in the air for three days together. Those which appear on the first day die the same evening, and the same thing happens on the second and third days. Then a whole year has to elapse before they are seen again.

"When the female has emerged from the water and cast off her skin, she passes the contents of the double ovary into the water, but first she moves to and fro on the surface of the water as if in sport, and flits about with rapid exploring movements. Immediately after the eggs are passed into the water, they are fertilized by the male, ${ }^{1}$ which has previously emerged and cast off a delicate membrancous skin. The eggs, thus passed into the water and fertilized, sink slowly, and are scattered over the mud at the bottom of the stream. The form of the eggs contributes to this mode of dispersal;

1 This is a mistake. The eggs are fertilized in other Ephemeræ, and no doubt in Palingenia too, while still in the body of the female. 
they are rounded discs, which sink at different rates ; hence if a number of the eggs are gently lowered into the water on the point of a knife, they are seen to spread as they descend. ${ }^{1}$

"How long the eggs lie on the bottom of the river, and how many days elapse before the larvæ emerge, is known only to God. Something might be made out upon these points if any one would search the bottom of the stream at frequent intervals, or keep the eggs in a basin with water and mud.

"Some time after the descent of the eggs, a crowd of minute worms, each with six legs, makes its appearance. These do not differ in shape from the older larvæ. Their growth is so slow that after a year, viz., in the following June, they are only a third of the length of the larva then ready to enter the winged state. At the end of another year the larva are twice as long, but three years are required before they attain their full size. ${ }^{2}$ Not only do these larvæ of different ages differ in size, but also in the degree of development of the wings. The small larva, a year old, exhibit no trace of wings; after two years the wings are visible, and enclosed in special sheaths; at the end of the third year they are quite plain and ready to burst forth.

1 If a handful of ivory counters are thrown into deep water, some descend edgewise, and reach the bottom long before others, which happen to take a horizontal position. Some such difference of position and not of specific gravity, seems to be referred to by our author.

${ }^{2}$ Confirmation of this is desirable. Some Ephemeræ spend one, and some two years as larvæ, but no other case of an Ephemera remaining a larva for three years is on record. 
" These larvæ are rarely, if ever, seen swimming in the water. It is true that they can swim by a kind of serpentine movement, bending the head now down, now up, but they always keep to the banks out of reach of the current. They can very rarely be seen out of the mud, in which they make for themselves long cylindrical and horizontal burrows.

"As the Bees in their own wonderful way make homes out of wax, so the larvæ of the Ephemera excavate out of mud the tubes in which they dwell. If they are taken out of their tubes, they can only creep readily when the bottom is so flat as to support the whole length of the body. Although they are ordinarily immersed in water and can swim, I have found on taking a number of them out of their tubes, that they at once fall on their backs as if paralyzed, and are not able to right themselves. But within their burrows they can move quickly backwards and forwards. The same is true of various other larvæ which burrow in trees, fruits, leaves or galls. The Cossus when taken from its hole in a tree covers its whole body with a web, and supported by this, it is able to make a new hole in the wood, but if left without support, or some fixed object against which the body can be pressed, it is quite unable to bore. The larva of the Ephemera is so helpless outside its tube, that if while swimming in the water it ceases to exert itself, it falls at once to the bottom, and there lies upon its back.

"As soon as the larvæ escape from the egg, they set about making their burrows, and these are gradually increased in size as the larva grows. The All-wise 
Creator has provided them with limbs suitable to their work. The fore limbs are fitted for digging, as in the Mole or Mole-cricket. Besides their feet, the larvæ are also provided with jaws, each with two tceth, like the pincers of Crabs, and these are well suited for working in the mud. The larvæ may be seen at work if they are placed in water mixed with a little mud. If the mud is not sufficient to cover the whole body, they conceal first the head, then the body, and then the tail, endeavouring all the time to complete their dwelling. Anglers assure us that when the water of the rivers sinks, the larvæ work decper and deeper into the mud, rising again as the water rises. This, I suppose, is indispensable for their breathing. They are provided with many air-tubes for distributing the air throughout the body. Access of air would be stopped if they remained below after the water had risen. I have often found that when taken out of their tubes and placed on wet sand, they much prefer creeping out of the water to burying themselves in the sand. The reason of this may be that the warmth of the water is injurious to them, as well as the want of mud.

"As to the food of these larvæ, it would be hard to say what it was without the help of dissection, but by this means I have discovered that they feed upon mud only. Whenever the body is opened, mud is found in the stomach and intestinc. In the same way certain caterpillars feed upon the same substance of which they make their homes. ${ }^{1}$

1 Like Earthworms and many other burrowing animals, the larva of Palingenia probably feeds not upon the mud itself, but upon vegetable fragments scattered through it. The food of 
"The full-fed larvæ pass from their burrows into the water, and thence into the air, but as no animal is without its enemies, so these larvæ, as soon as they enter the water are pursued by Fishes, and when they leave the water for the air, they are immediately liable to be devoured by Birds. All anglers know that the larvæ make excellent bait for Fishes. When they emerge from the water, they are often thick as falling flakes of snow. Hence the Dutch proverb, Het isser soo digt, als Haft (as thick as May-flies). At all times of the year when the weather is favourable for fishing, these larvæ form an excellent bait. When the waters are high, it is not easy to fetch them out of the mud, and it becomes necessary for some one to strip himself naked and go down after them. I have sometimes sent a man into the water to procure a supply of larvæ for dissection. The larvæ are tenacious of life, and live long on the hook, but when taken out of their tubes and placed in water mixed with earth, they do not live more than two days. To keep them alive, they should be placed in wet sand or mud. In this way I have seen the older larvæ live four days, the younger ones eight days; but when completely submerged, they cannot long be kept alive. ${ }^{1}$ If it is desired to send live larvæ to

the larvæ of different species varies considerably. Some feed upon living Crustacea, and have a "weel" in their throat to prevent the escape of the victims. I have seen such a structure, not unlike that of Corethra, very plainly in a cast skin of an Ephemera larva, which I was unfortunately unable to determine.

1 It seems strange that a larva which is habitually submerged should perish when submerged in captivity. The explanation 
a distance, there is no better way than tying together stems of the great reed, and causing the larvæ to creep into them.

"The body of the larva is divided into fourteen distinct segments. The first forms the head, the

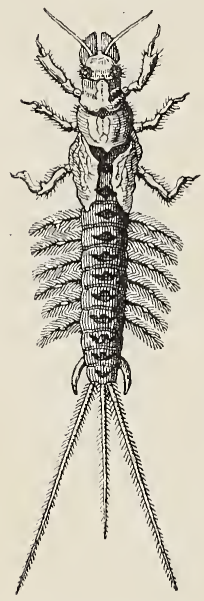

Fig. 9o.-Larva of Palingenia longicauda, male. From Swammerdam, Biblia $\mathrm{Na}$. three next the thorax, and the remaining ten the abdomen. Upon the head are seen the eyes, and just beneath them the delicate antennæ, divided each into five joints ; below these are the mandibles, and again below these the hairy, membranous maxillæ, which are like those of Crabs or Shrimps. The first pair of thoracic limbs are adapted by their shape for digging. Their most powerful action is outward, and in this way they are able to throw out the mud as a Mole throws out earth. Each of the fore-feet is formed of four joints and a single claw. The second thoracic segment is protected above and below by a shield-like plate; it bears a pair of limbs, each consisting of five joints and a claw, and on the probably is this. Under natural conditions the larvæ of Palingenia inhabit slowly running water, which not only supplies dissolved air for respiration, but brings down the food upon which they subsist. The captives were no doubt kept in vessels of standing water. Few aquatic animals can long survive the change from running to standing water, 
sides of the segment [in advanced larva] are the sheaths of the wings. Air-tubes ramify upon the sheaths, and shortly before a moult, the wings may be seen within them, folded up in a wonderful and beautiful manner. The third thoracic segment bears the second pair of wings, which are much smaller than the first, and also a pair of five-jointed legs. The first segment of the abdomen is smooth and provided with no appendages, the next six segments are furnished with gills, which are in incessant movement. In the Lobster, Crab, and Sepia, ${ }^{1}$ which in many respects approach the structure of Insects, we find the gills formed and arranged in nearly the same manner, though with this difference that in Crabs and Lobsters the gills are enclosed by a hard carapace, while both in them and in the Sepia they are more concealed than in the Palingenia-larva. The eighth and ninth segments of the abdomen are simple and smooth. The tenth or last abdominal segment is furnished with three hairy filaments; besides these, there are two small curved appendages (claspers) which are not so conspicuous in the female. ${ }^{2}$ To these are added in the male yet another pair of small appendages beneath the others.

"The colour of the larva, when very small, is pale blue, verging upon green. This colour belongs rather to the viscera than to the skin. The eyes are dark

1 The correspondence between the gills or any other organs of Sepia, and those of an Insect, is very far from close.

2 On the under side of the last abdominal segment of female Ephemera, a pair of minute appendages can be made out. which are the parts intended by Swammerdam. 
brown, and the back speckled with dark spots, which become larger with age.

"The male larvæ are distinguished in the first place by the eyes, which are twice as large as in the female. The body of the male, however, is much smaller than that of the female, as in all other Insects which I have observed. ${ }^{1}$ The effect of this difference in size, is that space is allowed for the vast number of eggs formed in the female. The male has longer tail filaments, and possesses moreover three or four appendages, placed partly on the sides and partly beneath, which in the female are inconspicuous or wanting altogether.

"The larva is harmless and inoffensive. If roughly handled, it bends its head towards the breast, and stiffens its body. There is nothing more wonderful in these creatures than the play of the branchiæ which stand out from both sides of the body. They move so regularly, distinctly, and incessantly, as to excite admiration in the beholder.

"I come next to consider the transformation of this Insect. The change is effected so rapidly that it seems to consist merely in slipping off two integuments and unfolding certain appendages. In order to make it quite plain what is the difference between the swimming larva and the flying Insect, I will first describe the internal organs as they occur in both stages. Here I follow a path trodden by no one

1 Since Swammerdam's time a good many exceptions to this rule have been noted, among the rest, the Stag-beetle, Dynastes, Megasoma, many Dragon-flies, the Honey-bee and other Bees, Methoca, \&c. See Darwin's Descent of Man, chap. X. 
before. I will not however lament, with Clutius, the rarity of books dealing with this subject. Nature is the best revealer of her own wonders. Though books may be useful, if they truly represent the phenomena of nature, I pity those who trust to the observations of others, and impose fictions upon themselves and their readers.

"I will describe the methods which in the year I670 I employed to investigate the anatomy of the larva.

"The male, which is easily distinguished by its large eyes, is fastened with the finest needles, back downwards, upon black paper or linen in a wooden dish. Then having cut through the skin, we see a watery fluid flow out, which is the true blood of the animal, though it is not red in colour as in the Earthworm or in Quadrupeds. I have found nothing bettei for opening the skin than fine scissors, for lancets, however sharp, tear the parts. Then with the finest scalpel, or the point of a needle, the skin is gently separated from the parts beneath. Under the skin is found a delicate membrane, and beneath this the muscles of the body-wall, some of which pass directly from one segment to another, others obliquely or transversely. Others again serve for moving the limbs. Within the muscles is a very delicate membrane, upon and within which lies the fat, consisting of minute white vesicles. Next we find the osophagus, stomach and intestine. The œesophagus, like a thin thread, passes from the mouth into the thorax, and expands to form the crop. The crop, when distended with food, or with air injected from a fine glass tube, 
is smooth externally, but internally it is thrown into a reticulation of folds. It appears to be provided with multitudes of fine vessels, but if these are carefully examined with a magnifying glass, it will be found that they are really air-tubes, which supply all parts of the body, whether external or internal. Beyond the crop comes the stomach, then the small intestine, the large intestine or colon, and lastly the rectum. The small intestine is provided internally with a number of folds resembling the valvular folds of the small intestine of man. In the colon are longitudinal muscular valves, rather like those which form the manyplies of the ruminant stomach. The delicate rectum leads to the exterior of the body. A pair of muscles is attached, one on each side, to the rectum, and serves for pressing out its contents. Since the larva feeds upon mud, we commonly find the crop and intestine filled with mud. When the time of transformation is approaching, the animal ceases to feed, as also do the Cossus, the larva of the Bee, and the Silkworm. Hence the intestine becomes transparent at the time of transformation.

"A pair of tracheal trunks wind in a serpentine manner along the sides, and send branches to all the organs. The tracheæ consist of numerous rings held together by delicate membranes. At the time of moult the lining of the air tubes is cast, though I have not seen this in Palingenia. It is, however, very conspicuous in the Silkworm, where, at the time of moult, hundreds of the delicate air-tubes cast their lining membrane. I find it difficult to discover the external openings of the air-tubes, since they do not 
open into the mouth or throat as in other animals. After long examination, I believe that I have discovered the openings on the under side of the thorax, nearly in the same place as I afterwards found them in Grasshoppers, where, however, they are easily seen. Since the Palingenia-larva lives in water and mud, it is natural that the openings should be narrow and hard to discover. ${ }^{1}$ From these observations it is clear why the Palingenia larvæ, when the water of the river rises, creep upwards and betake themselves to new tubes, in order that they may get the air which they require to breathe. For the same reason they follow the water as it sinks, lest they should be surrounded with air, and dried up. When the air-tubes are examined in an Insect which has been dead some days, so that the viscera have turned black, they appear like pearls, or bright silver on a dark ground. The firmness of their texture prevents them from rapid decay, and they preserve their shape for a considerable time. To make sure whether air is really contained in these vessels or not, it is only necessary to compress them with the point of a needle under water, when bubbles

1 Swammerdam is mistaken in supposing that there are such openings in the larva of Palingenia or other Ephemeridæ. At times of moult indeed the future spiracles are momentarily opened to permit the removal of the old lining of the air-tubes, which comes off with the cast skin. Lubbock (Linn. Trans., Vol. XXV., p. 480) says that this does not happen with the larva of Chloeon dimidiatum, except at its last moult. Only in the imago (winged $\mathrm{fly}$ ) and the sub-imago (a stage peculiar to Ephemeridæ, in which the imago is shrouded in a thin skin, formed within the proper pupal skin) do the thoracic and abdominal spiracles serve for the admission of air. 
of air will be seen to issue. In a dried larva torn across, the air-tubes are very easily seen, for they retain their shape, and remain open when all the other parts have dried up. The six large gills which stand out from each side of the body are all provided with large air-tubes, three to each gill, as also are the five pairs of golden-yellow fins beneath, by means of which the larvæ swim. ${ }^{1}$ Some other observations which I had made upon the gills and their vessels have been lost, and I cannot recollect what they were. I do not know, for instance, what is the use of the plume attached to the first pair of gills, and I can now give no more information about them than can be gathered from the figure. ${ }^{2}$

"The heart lies on the dorsal surface as in other Insects. It swells out in the middle of each segment, just as Malpighi represents it in the Silkworm. I do not agree with this author in saying that the larva is furnished with more than one heart, and I have only very rarely seen any contraction of the heart in the larva of Palingenia.

"The nerve-cord consists of eleven ganglia. From the first of these, or brain, the optic nerve can be seen

1 In Palingenia, as in many other Ephemeridx, each tracheal gill consists of a plate or lamina and a bunch of respiratory filaments. Swammerdam calls the laminze "gills," and the filaments "fins," though both form parts of one set of organs.

2 In addition to the six gills described by Swammerdam there is another in front, probably the plume referred to in the text. The lamina of the fore pair in Swammerdam's figure is too large in comparison with those which succeed (Vayssière, Org. des Larves des Ephémérines, Ann. Sci. Nat. Zool. I882, p. 5). 
to spring. In the same way the nerves of the body are given off from the ten other ganglia. Paired connectives issue from each ganglion, and unite it to the next, so that the cord appears to be divided along a considerable part of its length. The nerve-cord may be demonstrated in an uninjured larva, by inflating the body with air from behind. By this means the cord is pressed against the integument, and can be seen with a lens, or even with the naked eye.

"There are two ovaries in the female, resembling the ovaries of Fishes. Each is supplied with innumerable air-tubes. The eggs are so small that they cannot well be observed without the aid of a lens. They are of a flattened oval form, and of white colour. Their small size in comparison with that of the adult Insect is explained by the fact that the larvæ grow for three years before they arrive at maturity.

"The emergence of the fly takes place in warm and still weather. Shortly before emergence, the wings are observed to become prominent, though still enclosed within the larval skin. The intestine is emptied, and the colour of the animal changes in consequence.

"When all is ready, the larva quit their burrows, and swim freely in the water. The time of emergence is usually towards evening, and always in the summer months. In the year $167 \mathrm{I}$, I saw the Palingenia flying about from the $13^{\text {th }}$ of June.

"When the larve have left their burrows, they make their way with all speed to the surface, and the transformation is effected with such rapidity that even the most attentive observer can make out little, except 
that the winged fly suddenly darts out from the midst of the water. It is possible to observe what is taking place by going on the stream in a boat, catching with the hand larvæ which are about to emerge, and slightly pressing the thorax so that they cannot disengage themselves from the larval skin.

"How, we may ask, are the wings expanded with such speed? We might suppose that they are provided, like the wings of Earwigs, with muscles, which can suddenly expand the wings, or at pleasure fold them up again within their narrow sheaths. But the wings of the Palingenia are not provided with muscles, and it appears that they are expanded by sudden injection of blood from the heart. If the wings at the time of emergence are wounded, they bleed freely. Air injected into the air-tubes may also help to render them stiff and dry. If the wings of a larva ready for emergence are cut off and thrown upon the surface of water, they can be seen to expand, though detached from the body.

"When the Palingenia has quitted the water it makes its way at once to some place where it can settle, and then it immediately casts a second very delicate and transparent skin, which covers the whole body. This second moult, following so rapidly upon the former one, does not materially change the shape or appearance of the Insect.

"At the time that the Palingenia leaves the water, the external form of the body undergoes conspicuous change. The gills are completely cast, leaving only small rudiments on the sides of the abdomen. At the same time the jaws, the larval feet, and the 
sheaths of the wings and tail-filaments are shed; the antennæ, which were previously conspicuous, become far more delicate, and also much shorter in the winged Insect than in the larva. The eye, which was flat and smooth in the larva, is changed into a many-faceted, compound eye. The legs and tail-

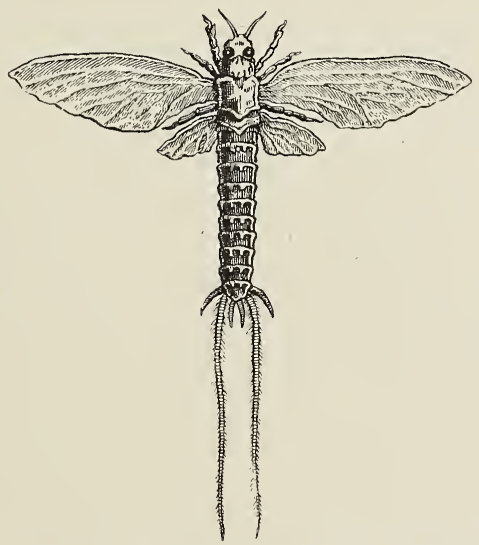

FIG. 9r.-Fresh-emerged fly of Palingenia longicauda, male. From Swammerdam, Biblia Natura.

filaments become as long again as they were in the larva, while the third or middle tail disappears altogether. ${ }^{1}$

${ }^{1}$ In those Ephemeridx which, like Palingenia, lose the middle filament at the last moult, it is observed that there are only two filaments in the fresh-hatched larva. To these the third is added. When the fly emerges, the third filament is no longer to be seen. 
"When the winged fly has become completely free, it again seeks the water, and floats upon the surface from time to time, as if in sport. Now and then it rests upon the water with the help of its long tailfilaments, the wings being folded together. The hairs, with which the tail-filaments are so abundantly provided, prevent the Insect from sinking. The same may be observed in other Insects, like the larva of the Gnat, which employ their hairs and the air entangled in them, to float upon the surface. I believe, but am not certain, that while the male Palingenia during transformation moults twice, the female moults once only. ${ }^{1}$ The male may be distinguished by the larger size of the eyes, which are twice as great as in the female. The tail-filaments of the female are shorter by a third than those of the male. The colour of the male is more ruddy than that of the female. Lastly, the male, in addition to the two long tail-filaments, has four minute appendages, which can hardly be made out in the female.

"The female deposits her eggs upon the surface of the water, where they are fertilized by the male, as in the case of Fishes. ${ }^{2}$

"In the adult condition these Insects do not eat, as is the case with various other Insects also. The mouthparts and alimentary canal of the winged fly are completely useless and empty. Hence the lightness

1 That is, the female remains in the subimaginal skin, or transparent covering described above, while this is cast by the male. This statement is not confirmed by observation of other Ephemeræ.

${ }_{2}$ This is a mistake, as mentioned above, 
of the body, and the short duration of the winged Insect. After emergence they do not live more than five hours at the most, that is from six or half past six in the evening to eleven. I have observed the length of their duration in the winged state by keeping the winged Insects in a box.

"Vast numbers perish at the moment of their emergence, being devoured by Fishes. Those which escape from the water are devoured in large numbers by Swallows and other Birds. If they escape this peril, and return to the surface of the water, many fall a prey to Fishes. At the time when the winged Palingenia abounds, it has been observed that the Trout are fatter and better flavoured.

"It is well known to all persons who frequent rivers, that the Ephemeræ appear in continual succession for three days. A few may be seen on the fourth or even on the fifth day.

"What I have related concerning Palingenia differs in many particulars from the account given by Mouffet, Aldrovandus, Johnston, Clutius and others, but I am far from judging or blaming them. It may easily be that these naturalists have described a different species from mine, but I would recommend every one who desires to know the truth about these things to learn himself of Nature, for Nature can teach in a short space of time more than any one can learn in a long course of years from many books.

"While studying the life-history of Palingenia, I became acquainted with other species. None of these live so short a time in the winged state as Palingenia. In the month of June I 670, at Sloten near Amsterdam, 
I saw in the evening a great crowd of small Flics, a little larger than Gnats. So many settled on my clothes that I was completely covered with them, and great numbers left their thin pellicles behind on my clothes. I observed that they betook themselves to the water, and sported there like Palingenia. The larvæ of this second species do not live in mud, or make tubes, but live for the most part on stony or sandy bottoms. They are tougher and hardier than Palingenia, and their skin is more like that of a Crab or a Shrimp. They have gills along the sides of the body. If any one in the month of June takes stones out of the Rhine, the Leck, or other of our native streams, he will see many of the larvæ clinging to them. I have seen the same thing in the Loire, the Seine, and other rivers of France."

Réaumur gives us a very lively account of one species of Ephemera (Polymitarcys virgo), besides notices of some others. The following is a condensed translation of the twelfth memoir of his sixth volume.

"Many kinds of Flies are doomed to perish on the very day on which they emerge, and are hence called Ephemeræ or Dayflies. Some do not even see the light of the sun; they emerge after he has set, and die before he rises again ; others live an hour or even half an hour only.

"The wings of the adult Ephemera are transparent, and shorter as well as broader than those of common Flies. There are two pairs, ${ }^{1}$ the fore

${ }^{1}$ Sometimes reduced to one, the hind pair being undeveloped in certain species. 
pair being considerably the larger. When the Insect is at rest, the wings are carried vertically, as in most Butterflies.

"The body ends behind in two or three long filaments, which are very fragile. The winged Ephemeræ often have these appendages more or less imperfect.

"Though the duration of the winged Ephemeræ is so short, they live a long time as larvæ in the water. Swammerdam supposes that the species described by him remains three years in the larval stage. Some species known to me live two years as larvæ, and many others about one year.

"During its aquatic life the Ephemera undergoes no conspicuous change, except that the pupa, or nymph, exhibits on its thorax the sheaths of wings, which are altogether wanting in the larva. ${ }^{1}$ There are six jointed legs, a head furnished with biting jaws, and slender, many-jointed antennæ. The abdomen is ten-jointed, and ends in two or three long filaments.

1 The aquatic period of an Ephemera does not admit of definite subdivision into stages. The fresh-hatched larva has commonly neither tracheal gills nor any trace of wings. Rudiments of gills shortly appear, and become larger and more complex at each succeeding moult. Before they have attained their complete development the rudiments of the wings are often apparent. The gradual acquisition of the imaginal structures is facilitated by the unusual number of moults. In Chloeon dimidiatum as many as twenty-one larval moults have been observed by Lubbock. "In moulting the insect does not split the skin of the thorax, as is so generally the case, but merely that on the upper part of the head. It is wonderful, indeed, how it can escape through so small an orifice" (Lubbock, Linn. Trans., Vol. XXIV., p. 68). 
"Some Ephemera larvæ make burrows; others lead a free life. The sides of the abdomen bear a number of paired tufts, which are moved up and down with great rapidity. They have been taken by some authors for fins, but it is enough to refute this notion to observe that they are moved most energetically when the larva remains stationary. They are gills, as their microscopic structure shows. In some Ephemeræ they stand out from the sides of the body like the oars of a galley, ${ }^{1}$ in others they are upright or curved over the back. ${ }^{2}$ There may be six or seven pairs of gills, beginning at the first or second abdominal segments; the last three segments never bear gills. In the larva of Ephemera vulgata each gill consists of two branches of nearly equal size, which are each fringed with filaments like a feather. Two airtubes traverse each branch and filament. In another Ephemera larva [that of Chloeon dipterum] the gills form plates or leaflets, each of which is doubled in two, and the trachere, instead of projecting, run in the thickness of the leaflet. These gills work backwards and forwards, and often all are moved simultaneously though sometimes the last pair remain motionless when all the rest are moved. ${ }^{3}$ In the larva of Polymitarcys virgo each gill consists of two long and

1 This is the case, for example, with the larva of Baetis (Ecdyurus) fluminum, a large species found abundantly between and beneath the stones of clear streams.

2 Ephemera vulgata, Polymitarcys virgo, \&c.

3 The last pair of gills in the Chloeon larva have the leaflet flat, and not folded in two. In the six other pairs the two leaflets are more distinct from one another than Réaumur's description implies. 
narrow leaflets, traversed by central trachex, and fringed along the fore edge by close-set filaments.

"Polymitarcys is the commonest species in the neighbourhood of Paris, and the one best worth study. The winged fly appears for three or four days in succession in most years, and affords a curious spectacle. On coming out of doors in a morning, we see the pavement strewn all over with pretty flies rather like Butterflies. Sometimes they lie so thick as to hide the pavement completely, and this sight is repeated three or four days running. Our surprise is increased when we learn that these Insects issue from the rivers, in which they pass their early stages. It is hard to imagine that so many can come forth from the water at the same time -all the more because on searching the river one might fail to find a single

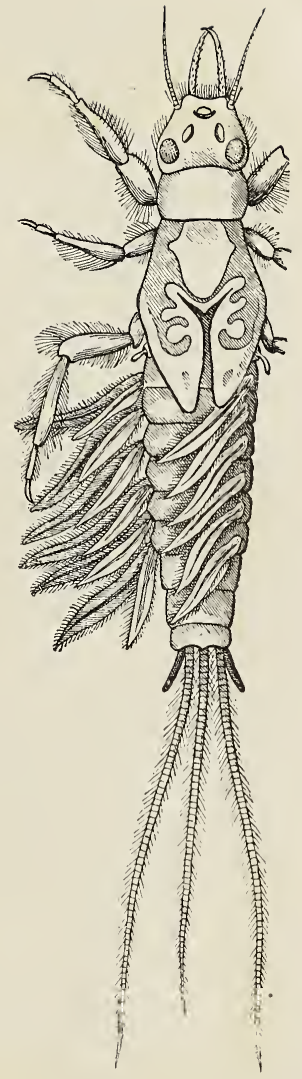

FIG. 92. - 1arva of Polymitarcy's virgo, $\times 6$. From Vayssiere. The tracheal gills of the left side are displayed. 
Ephemera there, though we should expect to find them heaped together by the thousand.

"The larva of Polymitarcys rarely swims free in the water; it has a burrow excavated in the earthy bank of the river. From the level of the water for two or three feet downwards the bank is everywhere drilled with holes a quarter of an inch or less in diameter. The holes take for the most part a horizontal direction. The passage returns upon itself to a second outlet close to the first, as may be seen by slicing a clod of the earth horizontally, when a U-shaped burrow is exposed, the two limbs being separated only by a slight partition of earth, which is often broken down. The larva can therefore enter or leave its burrow without being obliged to creep backwards. Earth of the consistence of clay or marl is best suited to the purpose; gravel cannot be made to answer. The lining of the burrows is much finer than the surrounding earth, and appears to be laid down in an even layer by the larva. The burrow is proportioned to the size of its inhabitant; a full-sized one is more than a quarter of an inch in diameter, and over two inches long, measured from one end to the other along the curve. In such a burrow the larva is freely exposed to the water, while protected from the attacks of Fishes. Its food consists of earth, from which it removes by digestion all nutritive matter.

"I suppose that the larval stage occupies two years, and that in the last few months of the second year signs of wings appear; at this time half-grown larvæ, destined to mature in a subsequent season, are abundant. 
"The head of the larva is furnished with slender, many-jointed antennæ, a pair of long, curved mandibles, well suited to the excavating of carth, and behind these with two pairs of maxillx, the hind pair being united to form the labium. The fore legs are stout, as if for digging; they are directed forwards, as also are the legs of the sccond pair, while those of the third pair turn backwards. I have seen larvæ, when taken from their holes and placed in a bucket of earth and water, use their forc legs to make a fresh hiding-place.

"The larvæ of Polymitarcys are very hard to please in the matter of fresh water; they perish in four or five days if placed in large buckets full of water; those of some other species, such as Chloeon dipterum, on the contrary, will live for months in shallow vessels without renewal of the water, and will there undergo their transformation.

"The Ephemera described by Swammerdam (Palingenia longicauda) emerges about St. John's Day; the fly of Polymitarcys much later, viz., in midAugust. Palingenia appears about six o'clock in the evening, Polymitarcys at sun-down or later. Differences of temperature and other less obvious causes render the appearance of the flies earlier in some seasons than in others.

"In 1738 I resolved to attend to the emergence of the fly, and engaged an angler of Charenton to warn mc when the first signs appeared, which were expected between St. Laurence's Day and "Notre Dame d'Août," that is, between the Ioth and I 5 th of August. This year the flies appeared on the I8th. On the 
Igth I received warning from my angler, and the same day, three hours before sunset, I took his boat to examine the banks of the Marne and Seine. Where the shore was level and sheltered from the wind, heaps of dead Ephemeræe could be seen. During this excursion by water I removed some clods of earth which were riddled with holes, and placed them in a large bucket of water as near as possible in their original position. The sides of the clods exhibited larvæ partly or completely exposed. At length the sun set. At that time Ephemeræ were to be seen flying here and there over the Seine, but at half past seven the number showed no important increase. I crossed over into the Marne, where there seemed to be still fewer. At about eight o'clock the coming on of evening and the flashes of an approaching thunderstorm caused me to return into an arm of the Marne, which washes the stairs leading from my own garden. I had the bucket containing the Ephemera-larvæ carried into the garden, but as soon as the men had reached the top step they cried out that a prodigious number of Ephemeræ were emerging. I seized one of the lanterns with which they had come to meet me, and ran to sec what was going on. All those clods which stood out of the water were covered with the flies, some beginning to cast their skin, others nearly free, others ready to take flight, while in the water beneath were larvæ whose transformation was less advanced. While I was examining the contents of the bucket the storm broke, and forced me to take refuge in the house. Before leaving the bucket I threw over it a cloth, to prevent the Ephemeræ from 
flying away. In half an hour I was able to return to the garden and take off the cloth, when the number of winged Ephemeræ was found to be greatly increased, and still increasing. Many took to flight; still more were drowned. The element lately so essential to their life had now become deadly to them.

"Ephemeræ, attracted by the light, came from a distance and were drowned in the bucket. In order to spare them, and to examine more carefully those which were uninjured, I covered the bucket once more with the cloth, and held the light beneath. The cloth was speedily covered with Insects, which were taken off in handfuls.

"So far I had taken no notice of what was going on by the river, but now the exclamations of my gardener, who had gone to the foot of the stairs, attracted my attention. I then saw a sight beyond all expectation. The Ephemeræ filled the air like the snow-flakes in a dense snow-storm. The steps were covered to a depth of two, three, or even four inches. A tract of water five or six feet across was completely hidden, and as the floating Insects slowly drifted away, others took their place. Several times I was obliged to retreat to the top of the stairs from the annoyance caused by the Ephemeræ, which dashed in my face, and got into my eyes, mouth, and nose.

"It is singular that nocturnal Moths, which shun the light of day, should be attracted by the lights in our rooms, and still more singular that these Ephemeræ, which emerge only after sun-down, and perish 
before sunrise, should be drawn so powerfully towards a lantern. The person who held the light had a bad time of it; in a few moments he was covered with the flies, which came in all directions as if to overwhelm him. The luminous sphere about the light was crossed at all angles by the orbits of the circling Insects, which after performing one or two revolutions, fell to the earth.

"After half an hour or less the swarms were less dense, and by ten o'clock only a few scattered Ephemeræ could be seen on the river, while no more came round the light.

" Next day the Ephemeræ appeared in undiminished numbers, but on August 2 Ist they hardly amounted to one-third of the previous flights. Each day they appeared between a quarter and half past eight; from nine to half past nine they filled the air, while by ten o'clock they had almost ceased to fly.

"In the afternoon of the 2 Ist the air was cold for the time of year, the thermometer standing at $\mathrm{I} 7^{\circ} \mathrm{R}$. $\left(70^{\circ} \mathrm{F}.\right){ }^{1} \quad$ One might suppose that heat would hasten the transformation of these larvæ, as it hastens the development of the chrysalis or the egg of other Insects. However, in spite of a relatively low temperature, the flies emerged at the same hour as before.

"On the 22 nd the thermometer fell to $15^{\circ} \mathrm{R}$. $\left(66^{\circ} \mathrm{F}\right.$.);

1 I have given in brackets the accepted equivalents on Fahrenheit's scale of the readings quoted by Réaumur from his own thermometer. They are obviously too high. Réaumur's thermometer was somewhat differently graduated from any modern ones. 
it rained several times during the morning and poured all the afternoon. In the evening the Ephemeræ appeared at the usual time, though in smaller numbers, most of them having already emerged. Rain was falling, though in less quantity. It appears, therefore, that whatever the weather on the day of emergence-warm or cold, sunshine or rain-the Ephemeræ quit the water at a fixed hour.

"What becomes of the prodigious swarms of Insects when they no longer fly through the air? They are for the most part already dead or dying. A large part fall into the river from which they issued. The Fishes enjoy a feast, and the French anglers speak of the Ephemeræ as manna-e.g., they say the manna has begun to appear; there was a good fall of manna last night.

"Whether devoured by Fishes or not, those which fall into the water soon perish. More lingering but not less certain is the fate of those which descend upon the banks or the neighbouring fields. Heaped one upon another, and unable to move, they die by inches, the last survivors perhaps seeing the rising of the sun.

"I returned to Paris on the 22nd at ten o'clock at night, but left instructions to have the Ephemeræ watched on the following days. They appeared in constantly diminishing numbers for four or five days longer. ${ }^{1}$

1 Polymitarcys does not occur in the British Isles, though it is plentiful in the large rivers of the Continent. I have seen swarms of winged insects, rivalling those described by Réaumur, at Dinant on the Meuse. 
"The Ephemeræ issue from the water in order to perpetuate the species. As soon as they emerge, the females are ready to lay their eggs, and actually do so. The rapidity with which they cast the larval skin is truly wonderful. We cannot take our arm from the slecve of a coat more readily than the Ephemeræ extricates its abdomen, wings, legs, and its long tail-filaments from their sheaths. During the operation they rest upon objects standing out of the water or upon the water itself. The thorax splits lengthwise, and the rest of the business of extrication is over in a mement. I have often tried to stop it half-way, in order to see how the wings are folded in their sheaths. But though I crushed the head as soon as it appeared, the act of emergence went on all the same. So also when I plunged emerging Ephemeræ into spirits of wine, they completed their moult before perishing. The long tail-filaments are often broken during extrication. The cast skin is sometimes carricd up into the air, clinging to the tail-filaments, and an Ephemera in this state seems twice as long as usual.

"The fly of Polymitarcys virgo is about threcquarters of an inch long, not counting the long tailfilaments. The hind wings are very small in comparison with the fore wings, which are in outline like those of many Butterflies, though they are not scaly, but transparent. The fore legs are very long and directed forwards, ${ }^{1}$ the others short, perhaps too short, for the fly cannot readily rise from a flat surface and

1 Probably, as in other Ephemerx, these long fore legs are used by the male to seize the female. 
take wing. I found that when Ephemeræ fell upon a napkin spread over my knees, they could only rise into the air with the help of their long tail-filaments, which gave a momentary support to the body.

"The male fly of Polymitarcys has the middle tail-filament much shorter than the two others, and only from one-sixth to one-eighth of their length. Two pairs of appendages project from the under side of the extremity of the abdomen of the male, which seem to correspond to the clasping organs of other male Insects.

"The eggs produced by the female fly are intended to be laid in the water of the river, but as if in ignorance she often deposits them on any object on which she may happen to alight. The eggs are grouped in two oval masses, from one-third to a quarter of an inch in length. I counted 350 eggs in one such mass. The short life of the winged female compels her to deposit her 700 or 800 eggs at once, without much discrimination of likely and unlikely places. When the bucket containing a lantern and covered with a cloth attracted Ephemeræ from a distance, many of these laid their eggs on the cloth. The female turns up the extremity of the abdomen nearly at a right angle, and the orifices of the two oviducts, which open behind the sixth [the figure seems to indicate the seventh] abdominal segment, are exposed; from these the two clusters of eggs are passed out at the same time. When the eggs have been discharged, two vesicles, apparently filled with air, project from the orifices of the oviducts; these are probably either principal or subsidiary aids in the 
act of cxpulsion. The air, which dilates the vesicles and cxpcls the eggs, may be taken in by the two pairs of large thoracic stigmata.

"Ephemeræe which are not dazzled by light or otherwise led astray skim the surface of the water, and support their bodics upon it by means of the tail-filaments while engaged in egg-laying. The specific gravity of the eggs is higher than that of water, and they fall at once to the bottom. Therc the eggs soon become scattered, for the jelly in which they are imbedded is soluble in water. I have placed scveral egg-masses over night in vessels of water; next morning the eggs were spread over the bottom, quite loose, though in regular groups. If placed in alcohol they cohere, for alcohol does not dissolve the jelly.

"How are the eggs fertilised? How can time be found for their fertilisation in the brief space during which the winged Ephemeræ are active? I have no precisc information to give on these points; the time of emergence renders it hard to observe directly what happens. ${ }^{1}$

"Swammerdam has observed the habits of an Ephemera (Palingenia longicauda) which emerges carlier in the day than Polymitarcys, and takes to flight more than two hours before sunset. Hc thinks that in this species the eggs are fertilised by the males in the water, after the manner of Fishes. But it is hard to understand how eggs which, like those of Polymitarcys, fall to the bottom as soon as they

1 De Geer has cleared up this difficulty, as will be seen further on. 
are liberated, can be thus fertilised. ${ }^{1}$ Again, how is it that I never saw the males fertilise the egg-clusters, which had been laid on a cloth or napkin? If the female could be so mistaken as to lay her eggs where they could not possibly be hatched, why should not the males fertilise them in such situations?

"I prefer to suppose that the males unite with the females, but that the act of union is very brief. Indeed, I have seen something of the sort, though only by the help of lights held near the surface of the water. I with others caught pairs of the Insects which appeared to be attached. When holding a napkin over my knees, I saw the males mount upon the females and apparently unite with them. Lastly, the male is provided with appendages near the extremity of the abdomen which seem to be suitable for grasping the female.

"I do not know how long it takes for the eggs to hatch, for those which I saved were put into a vessel of water, which was not changed. Running water is probably necessary.

"The great fecundity of the females and the sheltered situation in which the larvæ dwell, explain the extraordinary numbers of the winged flies. Every year is not, however, equally prolific in swarms of Ephemeræ. The short duration of the winged state requires the assemblage of great numbers of the same species. If these Insects emerged a few at a time and on many successive days, the males and

${ }^{1}$ It is pretty certain from subsequent observations that the eggs of Ephemeræe are fertilised in the body of the female before they are laid. 
females could hardly meet before their brief life was ended. To some allied species, which emerge in scanty numbers, a longer span has been conceded. One such Ephemera I kept alive for six or seven days, and it might have lived longer had it not been restrained from flying abroad." 1 [Here ends Réaumur's account.]

De Geer supplements the observations of Réaumur by a number of interesting particulars. In Sweden, where he lived, the prodigious swarms of Ephemeræ do not occur, though many species are found in sinaller numbers.

The first kind which he describes is Ephemera vulgata, whose larva is very common in ditches, ponds and slow streams, where it burrows in the mud or hides beneath stones. It can walk on the bottom, and also swims at times, drawing up the legs, and propelling itself by an up and down movement of the abdomen. The larval antennæ are rather long, and the slender mandibles (which are crossed) extend considerably in front of the head. There are six pairs of tracheal gills, which extend over the back and point towards the tail ; each consists of a double leaflet fringed with long, hollow filaments, in which fine air-tubes run. The legs are flattened and fringed with hairs. The three tail-filaments are longer than the body, and each is fringed with hairs on both sides. [In some species-e.g. Chloeon dipteruin and

1 Observations and experiments made since Réaumur's time render it probable that the life of an Ephemera may be prolonged by captivity. Mating and egg-laying seem to hasten the end. 
Polymitarcys - the lateral filaments of the larva are fringed on the inner side only.]

"The recently emerged fly," says De Geer, "settles on trees, plants, walls, \&c., near the water which harboured the larva. Here it fixes itself by the hooks of the feet, usually with the head downwards, and rests until the last or subimaginal moult is at hand. ${ }^{1}$

"The fore legs of the male fly are very long, as in other Ephemeræ, and raised from the ground, so that they look like antennæ. They can be brought down

1 In some Ephemeridic I have seen the sub-imago (imago enclosed in a transparent skin) emerge from the larval skin under water, and float up. In other cases (Baetis fluminum, for instance) the larva creeps out of the water, like Perla, and the cast larval skin is left on the shore.

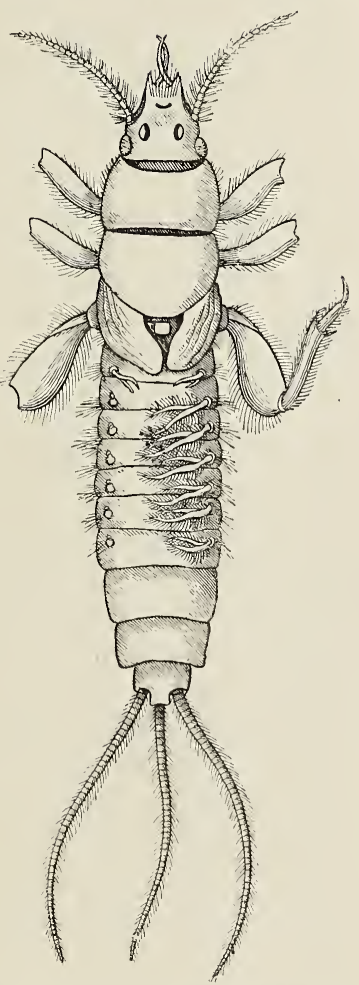

Fig. 93.-Larva of Ephemera vulgata, $\times 5$. From Vayssière. The fore and mid legs are cut short, and all the tracheal gills of the left side, except the first, are cut across. A small tuft of hairs appears close to each gill, which probably serves to keep off foreign particles. 
for walking, but owing probably to their unusual length, the gait of the male Insect is slow and awkward. At the extremity of the fore leg are two flattened appendages, diverging from one another, and armed with minute spines, as if to improve the holding-power of the legs. ${ }^{1}$ In the female the fore legs, though not so long, are raised, as in the male, The male has also claspers at the end of the abdomen. much larger compound eyes than those of the female (as in many other Insects) and longer tailfilaments.

"The eggs are discharged all at once, in the form of a yellowish-white, oblong disc, which is dropped into the water, probably as the female flits over the surface. It sinks at once, and the eggs separate from one another. ${ }^{2}$

"The flies emerge at the end of May or the beginning of June, always towards sunset. Some hundreds may be seen together, dancing in the air, usually around some tall tree. The males greatly exceed the females in number. They rise by the action of the wings, and when they have ascended five or six feet above the tree, allow themselves to sink slowly, the wings being outspread and motionless, and the long tail-filaments raised and widely separated. Late

1 In some species the fore leg of the winged male has a sort of kink or angle, which may be used to hold the female (Baetis, Chloeon).

2 The process of egg-laying seems to exhibit great variety in the different species of Ephemerida. Females of Baetis fluminum, Chloeon dipterum, and Chloeon Rhodani have been found among stones under water, as if they had descended to lay their eggs there. 
in the evening they all disappear, and rest upon plants throughout the night and the following day. The duration of the winged state was not determined with certainty, but it is short. The flies continue to emerge for fifteen days or more in succession.

"I have often seen the union of the male and female. High in the air I have seen a male out of a swarm of Ephemeræ seize a female, and remain attached to her; they flew away to the top of a wall where they settled together. The wall was too high for me to see distinctly, but I could make out that one of the pair, no doubt the male, curved the abdomen round as if to seek the female. Swammerdam was no doubt much in error in supposing that the eggs of Ephemeræ are fertilised in the water.

"After publishing these imperfect observations, I was several years later amusing myself by the contemplation of the aërial dances of swarms of Ephemeræ, composed of males only, as they usually are, when I perceived that if a female mixed in the swarm, as often happened, two or three males pursued her, until one of them succeeded in flying away with her. The pair ordinarily sought the top of a wall or the summit of a tree, but two or three couples placed themselves conveniently for observation on the leaves of a neighbouring bush. I could see that the male placed himself beneath the female, and curved his abdomen upwards to gain the orifice of the oviduct. The affair was ended in a moment, and the male flew away. I should have been glad to observe the use of the long fore legs and of the claspers of the male, but my attention was fixed upon the movements of the 
abdomen of the male, and it is impossible to take notice of a number of things at once.

"Captive Ephemeræ of this species survived two or three days, while those of Chloeon dipterum survived several days after acquiring wings." 1

We owe to F. J. Pictet, a celebrated naturalist of Geneva, some interesting particulars of the life-history of Ephemeræ. His classification of the larvæ according to their mode of life is instructive, though it is to be regarded rather as a description of some wellmarked larval forms than as a zoological system of any kind. He arranges the larvæ as belonging to one or other of the following groups:-

I. Burrowing Lari'a.-To this section belong the Palingenia described by Swammerdam, the Polymitarcys described by Réaumur, and with less pronounced habits the Ephemera vulgata, which forms the chief subject of De Geer's observations. The body is long, the head small, and the fore legs adapted for digging. We may add that the respiratory organs bear many filaments, and are therefore suited to passive aëration of the blood by means of a current of water, as well as capable of active respiratory movements. These larvæ inhabit slow streams with shores of clay or earth, and make their burrows in the banks. Their food is finely divided organic matter.

Leptophlebia connects groups I and II. It has the tracheal gills filamentous, but united by a membrane at the base. The legs show no adaptation to digging. It occurs on the banks of the Rhone in

${ }^{1}$ Winged individuals of this species have since been kept alive more than three weeks. 
company with Heptagenia, sheltering itself in the mud.

II. Larve with flattened bodies.-Ecdyurus fluminum, a large species found in clear, stony streams in hilly districts, or Heptagenia, will serve to exemplify this section. All parts of the body are flattened out; the head is semi-circular and the legs very broad. This flat shape enables the larva to cling to stones, and escape the full force of the stream. The leaflet of the gill is well developed, and the filaments small. They make no burrows, but when disturbed they swim with tolerable ease. They are carnivorous, and prey upon small aquatic larvæ.

III. Swimming Larve.-The common Chloeon, which is found in pools, ditches, and small rivulets, is adapted for swimming in preference to other modes of locomotion. The legs are weak, but the tailfilaments, all broadly fringed on both sides, form an efficient tail-fin. The tracheal gills consist of leaflets without filaments. The larvæ feed on small animals which they find among aquatic plants.

IV. Creeping Larva.-Here Pictet places some larvæ of which Ephemerella is the best example. Not possessing limbs adapted for digging, nor means of rapid locomotion of any kind, it inhabits streams of moderate swiftness. The tracheal gills, which are reduced to four pairs, are protected by large and firm leaflets. To escape its enemies and pounce unseen upon its prey, it covers its body with a thin layer of mud, which clings tenaciously to the fine hairs with which the integument is furnished. Some Perlidæ, as Pictet remarks, have the same instinct. So has an 


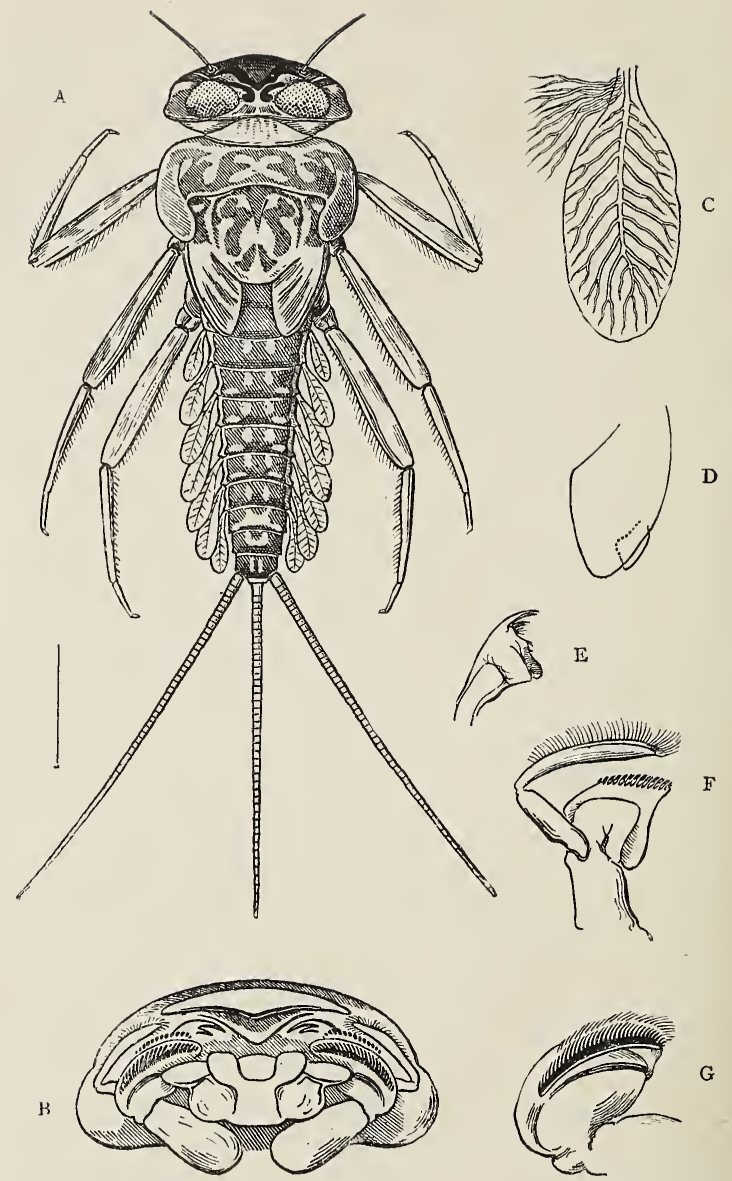

FIG. 94--Larva of Baetis (Ecdyurus) fuminum. A, the larva ; B, mouth-parts of do. ; C, one of the tracheal gills; D, the two wing-covers of the right side; E, mandible; $F$, maxilla and its palp; $G$, maxilla, more highly magnified. 
aquatic Beetle (Georyssus pygmæus) which is found adult under stones in running water. Helophorus and Elmis also disguise themselves with mud, ${ }^{1}$ and I suspect that Nepa is yet another example.

Such groups as these are merely short descriptions of the adaptive modifications of particular species or small groups of species. It would be easy to add to the number by adopting a different principle of formation. Vayssière, for example, defines five groups of Ephemeræ according to the modifications which the larval respiratory organs may assume. ${ }^{2}$

His group I. includes those larvæ in which the tracheal gills consist of both leaflets and filaments. (This nearly agrees with Pictet's group of Burrowing Larvæ).

II. receives those in which the tracheal gills consist of leaflets only.

III. has the filaments of the tracheal gills protected by an overlying leaflet.

IV. has the hinder tracheal gills overlaid and protected by the enlarged leaflet of the second pair, the first pair of gills becoming practically suppressed.

V. contains some very peculiar and interesting larvæ in which the mid-thoracic segment extends backwards over all the tracheal gills, forming a special respiratory chamber, which opens behind or by three special apertures of small size. In this last group the arrangement becomes similar in principle to that adopted in Decapod Crustaceans (Lobster, Crayfish,

${ }^{1}$ Kirby and Spence, Vol. II., p. 258.

2 Org. des Larves des Ephémérines, Ann. Sci. Nat. Zool., I 882, p. 33 . 
\&c.) except that the external wall of the respiratory chamber is formed in the Ephemeræ by a backward extension of the midthorax, instead of by a downward extension of the carapace, as in the Decapods. To this peculiar group belong a singular American form, Bætisca, and an Old World genus, Prosopistoma, found in the Rhone, Garonne, \&c., and described by Dr. Em. Joly and Vayssière.

The eggs of Ephemeridæ are often furnished with singular appendages which in some cases prevent their being swept away by currents of water. In Ephemera vulgata ${ }^{1}$ the eggs are described by Dr. H. Grenacher ${ }^{2}$ as possessing striated caps of reddish-brown colour which invest both poles of the egg. ${ }^{3}$ A mushroomshaped stalk serves as a base and springs directly from the end of the egg. This is of firmer consistence than the striated part, whose numerous and closeset fibres radiate regularly from it. The fibres had previously been described by Leuckart ${ }^{4}$ as bundles of spermatozoa, but Grenacher points out that they are to be found in all stages of development within the larval oviduct, and not merely after fertilisation, as Leuckart's interpretation requires. No definite information as to the function of these striated egg-caps has been obtained. According to Leuckart, the eggs of some species of Ephemeridæ bear them at one end only, others at both ends.

Grenacher has also described what appear to be

1 Grenacher's words are : larvæ belonging to Ephemera s. str.

2 Zeits.f. wiss. Zool., Bd. XVIII. (I 868), pp.-95-98.

3 A similar striated cap is seen in the ovarian egg of the Gnat.

4 Müllers Arch. I855, p. 200. 
long anchoring threads attached to the eggs of Ephemera vulgata. From 8 to 12 of these are fixed to a zone which encircles the egg transversely towards one end. The whole arrangement is repeated at the other end of the egg. Each thread bears a small knob at its free end, and these knobs apparently become entangled at the bottom of the stream and moor the eggs. 


\section{CHAPTER IX}

\section{DRAGON-FLIES (ODONATA)}

SOME Insects have at length impressed the popular imagination with great distinctness, and among these is the Dragon-fly. It is a little remarkable that until modern times no Insect, except such as are either useful to Man, or noxious in a striking degree, should have commanded serious attention. During the last hundred and fifty, or, at most, two hundred years, mankind in Western Europe has begun for the first time to take an interest in the natural history of Insects without reference to their profitableness or to the annoyance which they cause. The ancients cared little for any Insect except the Bee, and no other Insect plays a considerable part in classical literature, though the Wasp, the Gnat, and the Gad-fly figure occasionally in poetry or fable. It is a curious proof of the general indifference to Insects that, until comparatively modern times, no literary use was made of the extraordinary and easily observed transformations of Butterflies. Indeed, there is, I believe, no familiar Greek word of the classical period for a Butterfly. A real popular interest in Natural History founded upon observation is one of the latest fruits of the Revival 
of Learning. During the course of the eighteenth century, the discoveries of Swammerdam and Réaumur slowly made their way into the thoughts of the people, and some acquaintance with the lifehistory of Insects is now to be counted upon in every reader. The death-like repose of the chrysalis and the emergence of the Butterfly, the short life of the winged Ephemera, and the transformation of the Dragon-fly from a sluggish larva lurking in pools to a glorious winged creature flying swiftly through the air, are now among the every-day illustrations of the preacher and moralist, and form a highly characteristic feature of modern literature.

It is easy to see how the Dragon-fly in particular came to strike the imagination. Its size and beauty, its singular form, its swiftness and strength, are conspicuous to every observing eye. In its habits and life-history we find the most emphatic contrasts. There is the contrast between a sordid life in a muddy pool and the animated life of a creature strong in flight. The graceful form and lovely colours of the winged Insect are combined with fiercely carnivorous tastes. The slender body, adorned with rare and pure colours, the delicate gauzy wings, and the great eyes with the play of light in them, should be associated, we fancy, with the sweet juices of flowers or some other delicate food. But when we capture a Dragon-fly on the wing, and open its mouth, we find it filled with a black mass of small Insects, held over for mastication at a time of repose.

In the days when as school-boys we found the 
summer half-holiday all too short for the exploration of pond and stream, the Dragon-fly larva, with its dingy colours, its forbidding shape, and its predatory habits, excited the keenest curiosity. We saw it stretch out its great paw and secure an unsuspecting victim. Some of us watched with eager eyes the emergence of the winged fly. Most of us were satisfied, however, to read a prosaic abridgment of

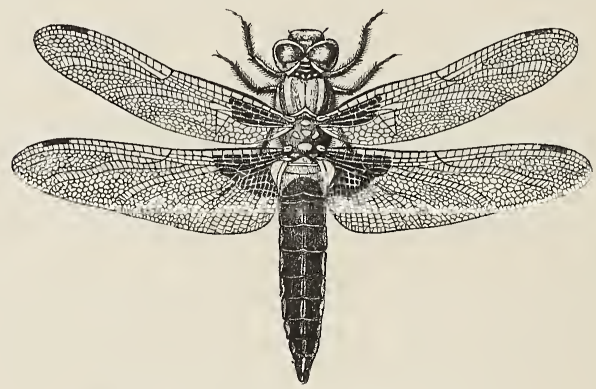

FIG. 95.- Libellula depressa. From Charpentier.

that vivid description of the process of extrication, which, with so much else, we owe to Réaumur. Either by observation or by reading we all know enough of that marvellous change to feel the beauty of Tennyson's verses :-

To-day I saw the dragon-fly

Come from the wells where he did lie,

An inner impulse rent the veil

Of his old husk; from head to tail

Came out clear plates of sapphire mail.

He dried his wings : like gauze they grew,

Thro' crofts and pastures wet with dew

A living flash of light he flew. 
The larvæ inhabit water, for the most part standing water, where they subsist by capturing living animals of all kinds, Insects, Snails, Tadpoles, and even Fishes. The skin is moulted several times during this stage, which is believed to occupy as a rule a year or more. For some time before the emergence of the winged Insect, the rudiments of the wings become externally visible, and in this state the Insect is sometimes called a pupa. There is, however, no stage corresponding to the resting-stage of the Lepidoptera.

The larvæ of the numerous species of Dragon-fly exhibit external features by which it is easy to distinguish and group them. Some of the smaller species have three pointed, semi-transparent plates (tracheal gills) projecting from the end of the body. These are recognised at a glance as Agrionidæ. In the remaining Dragon-fly larvæ, the tracheal gills are not conspicuous. If the abdomen is comparatively broad and flat, and shorter than the hind legs, we know that the larva belongs to the Libellulidæ. In Eschnidæ the abdomen is slender and longer than the hind legs.

The larva is not at all nimble. It often remains for hours nearly motionless, clinging with its legs to some water-weed. When it walks, the movement is steady but not rapid. It has another mode of locomotion which may be called swimming. In larvæ of Agrionidæ the abdomen is bent first to one side and then to the other. This sculling movement drives the body forwards with moderate speed. Libellulid larve can propel themselves more rapidly, 
332 NATURAL HISTORY OF AQUATIC INSECTS CH. but not continuously, by the sudden ejection of water from the tail. In air the water can be spirted to a distance of several inches. It is, however, only a very

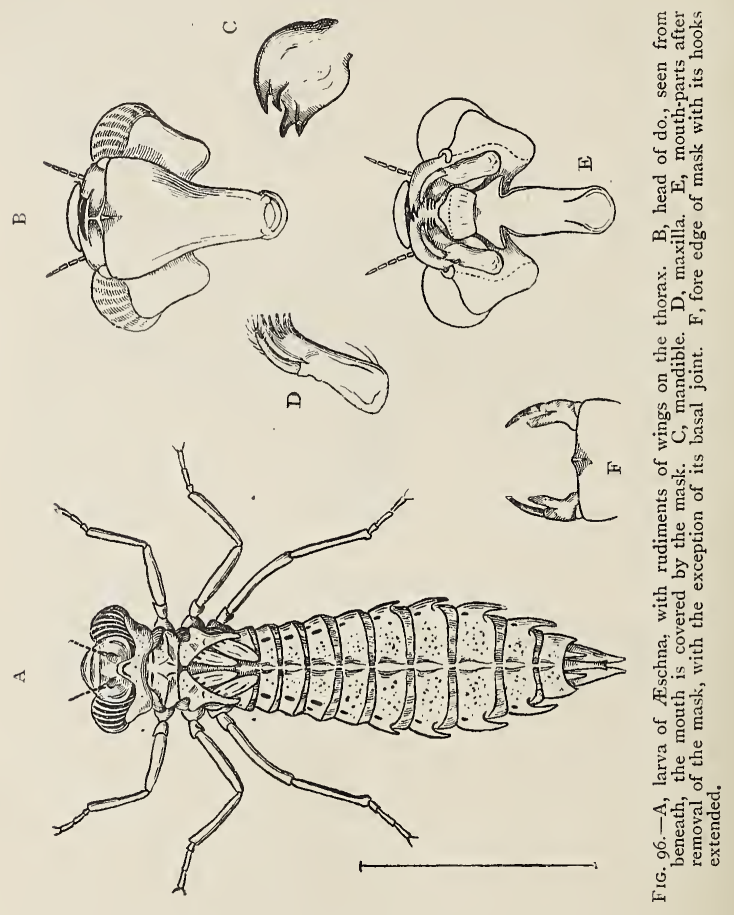

slow or inattentive animal which could be captured by the direct pursuit of a Dragon-fly larva. It trusts chiefly to its sombre coloration and its motionless 
attitude. The larva clinging to a stem in the shady recesses of water-weeds is not easily distinguished, and the absence of movement removes the chief risk of discovery. In the same way, the Hare in long grass, the young Plover on a heath, the Trout in a pool, are all concealed from view by their not very close imitative coloration, but when they move, even an ill-trained eye observes them. Until they move, the eye is not focused upon them at all, but a moving object is noticed even when out of focus. The policy of the slow Dragon-fly larva is to lie still and

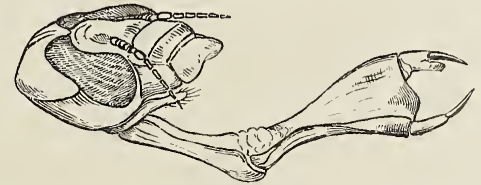

FIG. 97.-Head of larva of Eschna, in side-view, with mask projected to seize prey.

wait till its victim comes within easy reach. Then of course it must be quick as lightning. It does not usually make a spring, but stretches out an arm-like appendage of the head, and seizes its prey. The appendage so employed is a peculiar modification of a pair of limbs attached to the head, and called the second pair of maxillæ. ${ }^{1}$ In Insects these appendages form the third pair of jaws, and are fused more or less completely into a labium or under-lip, which closes in the back of the mouth. The labium of the Dragonfly larva is carried on a jointed arm, and usually

1 Other explanations of the origin of these parts have been given, and the question is not easily settled in a decisive way. 
much expanded at the end. Side-pieces, corresponding to the labial palps, are attached, and there is commonly a pair of spines or claws, which secure the struggling victim. The details of the structure vary according to the species. When the larva is at rest the apparatus is folded up, the broad joint being spread over the front of the mouth, while the arm is bent backwards between the fore-legs. In Libellulid larvæ the side-pieces can be brought together in the middle line like the jaws of a rat-trap, which they further resemble in their toothed edges. No more murderous weapon exists among animals than this.

We must next consider how the submerged larva obtains its supply of air. In the broad-bodied Libellulid larvæ, a pair of large spiracles can easily be seen on the dorsal surface behind the head (between the narrow prothorax and the mesothorax, i.e. between the fore and middle segments of the thorax). In the larvæ of Agrionidæ the same spiracles are hidden, but can be made out by careful search. Another pair of thoracic spiracles can be discovered by dissection. These openings have been usually supposed to be completely closed during the aquatic stage. Réaumur found that oiling the spiracles did not destroy life, as it does in ordinary air-breathing Insects, and this fact has often been quoted as decisive proof that the spiracles are not really open in the Dragon-fly larvæ. Réaumur himself draws no such conclusion, but allows that the oil possibly did not adhere to the wet surface, or that the spiracles closed and shut out the oil. He might have given a third explanation as an alternative, viz., that the larvæ 
do not depend upon their spiracles even when they are open, but are able to breathe in other ways also.

The late Dr. Hermann Dewitz left behind him some valuable experimental notes, which show, among other things, that the respiration of Dragonfly larvæ is effected in more than one way. ${ }^{1}$

$\mathrm{He}$ endeavoured, in the first place, to ascertain whether the spiracles, and especially the large thoracic spiracles, were as completely closed as had been assumed. For this purpose he employed various methods. Sometimes the larva was placed in more or less dilute alcohol, when a train of bubbles issuing from one (seldom from both) of the large thoracic spiracles would often establish the fact that they were pervious. Gentle warming, and even cooling, produced like results in many cases. When a thin glass beaker, containing a live larva, was held in the hand, the rise of temperature was often enough to cause bubbles to issue from the spiracles. Useful information was got also by placing living larvæ in water that had been boiled to get rid of dissolved air, and afterwards cooled. The larvæ were enabled to reach the surface by climbing up a stick, and note was taken of the way in which they came up. If they came up head foremost and pushed part of the thorax out of the water, this was a distinct indication that they relied mainly upon their thoracic spiracles. Some larvæ, under these circumstances, come up backwards, with the head down, and push the tip of the abdomen out of the water-an obvious proof Zool. Anz. Bd. XIII., pp. 500-504; 525-53I (I891). 
that the process of rectal respiration (to be explained later on) is more efficient than tracheal respiration. In other experiments, either the spiracles or the rectum was closed by collodion.

By such means as these Dewitz ascertained that, in young larvæ of Eschnidæ, the thoracic spiracles are not pervious, though those of adult larvæ, almost ready for transformation, are. In boiled water young

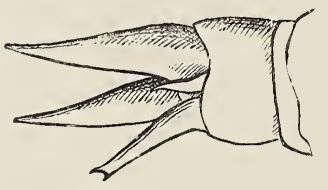

Fig. 98.-Extremity of abdomen of larva of Æsschna. 'The plates are separated to allow the admission of water. Eschnid larvæ always bring the tip of the abdomen to the surface, older ones either the tip of the abdomen or the thoracic spiracles. Young Eschnid larvæ die when the rectum is closed by collodion; older larvæ endure the stoppage of either rectum or spiracles, but die if both are stopped.

In Libellulidæ the fore pair of thoracic spiracles are developed and become pervious much earlier than in Æschnidæ. In old larvæ the spiracles are more important as a means of respiration than the rectum.

Young larvæ of Agrionidæ have the thoracic spiracles pervious, but not fully functional. Dewitz thinks that the muscular apparatus for inspiration by the spiracles is not yet developed. When placed in boiled water they crept up the stick, but never pushed any part of the body out of the water. The surface-layer was apparently sufficiently aërated for their purpose. Sometimes they waved the abdomen to and fro, as if to increase the efficiency of their 
tracheal gills. Advanced larvæ are able to use their spiracles, and when placed in boiled water, creep up the stick head foremost, throwing the body into a horizontal position when the surface is reached, so as to expose the spiracles to the air.

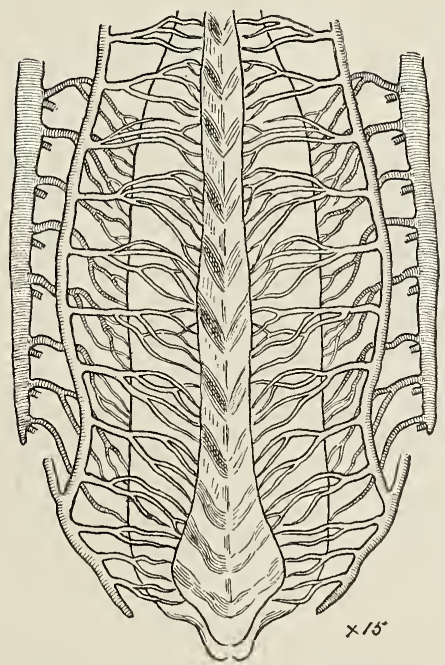

FIG. 99.-Part of respiratory organ in rectum of Eschna larva. One of the six muscular bands occupies the middle of the figure. The ventral tracheal trunk is seen giving off branches to the wall of the rectum. Another trunk, more dorsally placed, is shaded. A third, which runs above the rectum, is omitted.

From all these observations it is clear that the larvæ of Dragon-flies, especially in their later stages, fill their tracheal tubes directly from the atmosphere to a much greater extent than had been previously supposed. 
Though the spiracles are often open during at least the later part of the larval existence, they cannot, of course, be employed when the Insect is actually submerged, and other means of respiration are required in addition.

An Agrionid larva is provided with three leaflets at the tail-end, which in Calopteryx are nearly as long as the abdomen. These are useful in swimming,

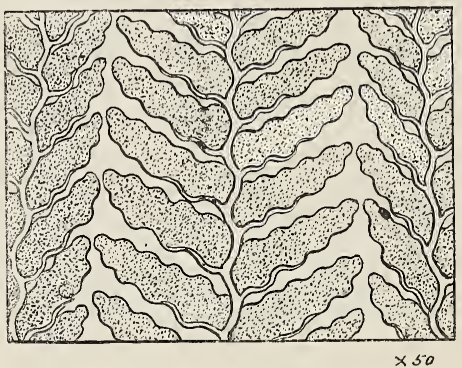

FIG. 100.-Part of three rows of respiratory folds from cuticular living rectum of Aschna larva. The shaded parts are abundantly supplied with tracheal tubes. The leaflets appear to be connected with a central trachea, but this is not really the case.

but microscopic examination shows that they serve for respiration also. Each leaflet is covered with a network of air-tubes, and, we can have little doubt, absorbs dissolved air from the water, passing it into the main trachex, which supply the chief organs of the body. In the other families the abdomen ends in five valves, three of which are commonly larger than the rest, and can be brought to a point or widely separated at pleasure. When they open, they disclose the outlet of the intestine, which is guarded by three 
fleshy folds, corresponding in position to the three valves. Within these is a somewhat capacious chamber (the rectum) whose wall exhibits a complicated and interesting structure. Six thick longitudinal bands, separated by thin and flexible membranes, seem to be intended to allow great distention without risk of stretching the delicate epithelium or cellular layer. Each longitudinal band bears a double row of transverse folds, which enormously increase the epithelial surface, and at the same time lodge tracheal branches. Oustalet estimates that there are no fewer than 24,000 of these folds. The tracheal branches enter larger and regularly arranged airtubes, which in turn open into the main trunks running the length of the body.

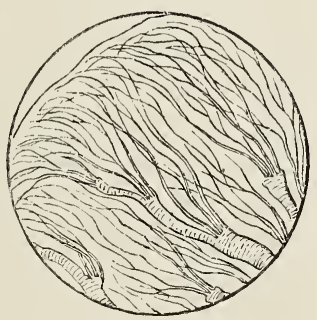

Fig. Ior. - A small part of one leaflet, highly magnified, showing many fine tracheal branches. The portion shown is marked by a small circle in Fig. Ioo (lower left-hand corner). A large volume of water can be sucked into the rectum at pleasure, and from this the trachex draw a fresh supply of oxygen. The vitiated water can either be expelled gently, or, when the larva requires to propel its body forwards, with considerable force. An Agrionid larva, Calopteryx, has similar rectal gills, besides external tracheal gills.

Under strictly natural conditions, Dragon-fly larvæ may increase the effectiveness of their respiratory organs by means already mentioned in connection 
with Dewitz's experiments. Thus, Agrionid larvæ sway their abdomen from side to side, and Æschnid larvæ often come to the surface and take air directly into the intestine. These expedients are most frequently resorted to when the water is foul.

The escape of the Dragon-fly from its larval skin is described by Réaumur in his usual lively style, and I think that the reader will like to have his account as nearly unabridged as possible. ${ }^{1}$

"Most, perhaps all, of the larvæ of Dragon-flies," says Réaumur, "must live ten or eleven months beneath the surface of the water before they can undergo transformation; there may possibly be Dragon-flies produced in autumn from eggs laid in spring; if so, the larvæ, enjoying the season most favourable to growth, develop faster than the rest. [Such cases are not certainly known to occur, though they are probable enough ; certain large Dragon-flies are believed to live two and even three years as larvæ.] However this may be, from April to the end of September, and even to the middle of October, Dragon-flies emerge every day.

"The change which is to convert an aquatic Insect into an inhabitant of the air takes place out of the water. All the larvæ, however, which one sees either wholly or partially out of the water are not absolutely ready to become winged. Often when they have

1 The original is to be found in the eleventh memoir of Réaumur's sixth volume. Here as elsewhere Réaumur is not very careful to distinguish the various species described, but many of his observations seem to have been made upon Æschna cyanea, which is very common both in France and in England. 
crept an inch or two out of the water they return thither, after taking a breath of air ; but those which have made a longer excursion, it may be several feet upon the land, and especially those which are found clinging fast to stems or branches, are making ready to cast their skin and to become flies.

"I have found larvæ belonging to the same species which underwent their transformation an hour or two after issuing from the water, while others passed a whole day before liberation. The operation takes some time, but the observer will be so much occupied by the interest of the details, that he will not willingly leave it half finished. One can read, so to speak, in the eyes of the larva, whether it is ready for transformation or not. Within a quarter or half an hour of the time of liberation the eyes, which were previously dull and opaque, become bright and transparent. This change does not really take place in the larval eyes themselves, but is due to the pressing close against them of the eyes of the fly, which have already acquired all their brilliancy.

"In order to enjoy again and again the spectacle of the transformation, it is desirable to collect a considerable number of larva of the same species and to keep them in water. When the cast skins show that some of the flies have emerged, the margin of the water should be searched at different hours of the day for larvæ which have crept out. They commonly rest some time in order to dry themselves thoroughly before proceeding further. At length the larva begins to seek a place convenient for its operations. It often grasps a plant and holds on to it with its head 
upwards. The two hooks with which each leg is provided secure the body in its place.

"When the larva has thus fixed itself, internal changes take place. The first visible effect is that the skin cracks along the back of the thorax, and the thorax of the fly becomes visible through the cleft. The part which first appears swells, and, like a wedge, helps to enlarge the cleft, which extends to the foreedge of the thorax, then along the neck, and finally to the level of the eyes, whence lateral clefts proceed on either side. At this time the fly is able to dilate its head like a Blue-bottle fly under like circumstances. In proportion as the cleft becomes prolonged, more and more of the body of the fly is exposed. At length the head is completely withdrawn, and appears so large, that one has difficulty in believing that it could immediately before have been enclosed within the larval head. When the head and thorax are free, the legs are drawn out of their sheaths, and to disengage these more readily, the fly arches itself backwards. At this time there can be seen on each side two white strands, which remain attached to the thoracic part of the larval skin. These are [the linings of] the four great tracheal trunks, and are drawn out from the four thoracic spiracles. After this the fly throws her head further and further back, until at length the body is supported only by the hindermost segments, which still remain enclosed in the larval skin.

"At this time the legs of the fly are completely free and distant from their sheaths. For two or three minutes they are moved about, as if to try their 
flexibility. Then they come to rest again, and are kept perfectly still. When I first saw an emerging fly thus motionless, I thought it dead or dying, exhausted perhaps by its efforts. It remained more than a quarter of an hour in this position, and I have seen others motionless for nearly half an hour. I was about to cease observing in despair, when I discovered that the fly had been merely waiting till its limbs had gained the necessary firmness, and till its strength was restored. The next operation required much exertion. The body, which was previously bent backwards, was, by a sudden spring, arched in the opposite direction. The head was brought back to the top of the sheath, the legs clasped the sides of the cleft, and attached themselves firmly. It is plainly essential that the hooks should become completely rigid before this manœuvre could be executed. After this the Dragon-fly had to extricate the hinder part of her body. She bent the abdomen double, withdrew it completely, and then extended it in a straight line.

"Though the Dragon-fly was now free, it had a very different appearance from those which range the fields. It seemed deformed. The abdomen, though longer than the sheath from which it had issued, had not yet acquired its full length. The wings seemed little larger than when they were enclosed in their sheaths. They were turned edgewise, laid side by side, and folded up like a fan, or like a leaf in the bud. Not only were they folded along their length, but also transversely. The wings expanded so rapidly that it was difficult to get a faithful drawing made of 
them. At this time the fly carefully avoids spreading her wings, for though they afterwards become firm as sheets of talc, they are at present soft as wet paper. It is important to avoid the slightest derangement, or even contact with one another. The abdomen is carefully bent into such a position as to avoid touching them. As the wings expand, we can see the veins spreading further and further apart and the folds becoming effaced. The expansion is apparently due to the injection of liquid into the veins. When I took a fly which had perished during extrication, I found that the wings were soft, and could be expanded by the fingers; but as soon as they were released, they returned to their original folded condition. The expansion of the wings is usually completed in less than a quarter of an hour, but when first expanded they are not yet firm or dry enough for flight. More than two hours are often necessary before the wings can be spread out horizontally, and two or three hours more are required before they are able to support the weight of the body. All the time that the wings are expanding, the abdomen is being gradually prolonged. When the Dragon-fly first emerges, its colours are faint, but they gradually increase in distinctness and brilliancy."

The process of egg-laying has its difficulties, for, while the female Dragon-fly is apparently ill-fitted to enter water, the larvæ which escape from the eggs cannot endure more than a short exposure to air. The plan pursued seems to vary in the different species. It is said that some Dragon-flies merely drop the eggs, singly or in groups, into the water. 
or short-winged. The eggs are enveloped in mucilage, and attached to submerged plants.

We pass next to those aquatic Rhynchota which seek their food beneath the surface of the water. Though primarily adapted to a submerged life, they leave the water at times to seek a fresh haunt, and fly very well. These excursions are usually made at night.

The family Nepidæ (Water Scorpions) includes two very common forms, Nepa and Ranatra, which agree in the possession of fore-legs completely modified as instruments for seizing live prey. The antennæ are short and concealed. The respiratory tube consists of two long spines. Each spine is hollowed, and forms a demi-canal. When brought together, they make a tube, whose continuity is maintained by a multitude of hook-like bristles which project from the opposed edges. The tube conducts air to a pair of spiracles situated near the hinder end of the body and at the base of the tube; these are the only apertures for the admission of air. A Nepa or Ranatra may sometimes be seen to creep backwards along a submerged weed until the tip of its breathingtube breaks the surface of the water. The mechanism for interlocking the two halves of the tube closely resembles that found in the proboscis of a moth. The fore-legs of Water-scorpions are solely prehensile. They are strong and pointed, but without the usual small terminal claws. They can be folded in two like a clasp-knife. The fore-legs of Mantis, a predatory Orthopterous Insect, furnish a close parallel in many ways to those of the Nepidx. The Water- 
354 NATURAL HISTORY OF AQUATIC INSECTS $\mathrm{cH}$.

scorpions are rather sluggish in their movements, and creep about in a leisurely way on the bottom of ponds. Nepa feeds mostly on small Insects, Ranatra upon the Water-flea (Daphnia) and other aquatic animals. The form of the body differs remarkably in the two genera. Nepa is broad and flat, Ranatra

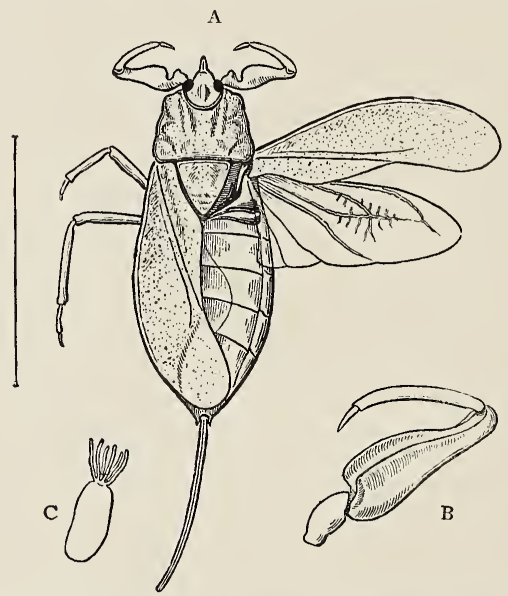

Fig, 107,-A, Water-scorpion, Nepa cinerea. B, fore leg, enlarged, showing groove in femur which receives the rest of the limb. C, egg.

extremely elongate. Ranatra is nearly black; Nepa of a dark ash-colour, and very inconspicuous except when the wings are spread, when the top of the abdomen is seen to be of a brick-red. Nepa lays its eggs in chains. Each cgg is shaped like a shuttlccock, seven filaments radiating from one end and clasping the next egg. The eggs of Ranatra have 
only two slender filaments which do not clasp. Each egg is laid separately in a notch cut in a submerged stalk. The fresh-hatched larva of Ranatra has no respiratory tube, and perhaps does not take in gaseous air at all. In the larva of all Nepidx the tube is short.

The remaining aquatic Rhynchota which we have to describe are the Notonectidx or Water-beatmen. These Insects are very common in stagnant waters,

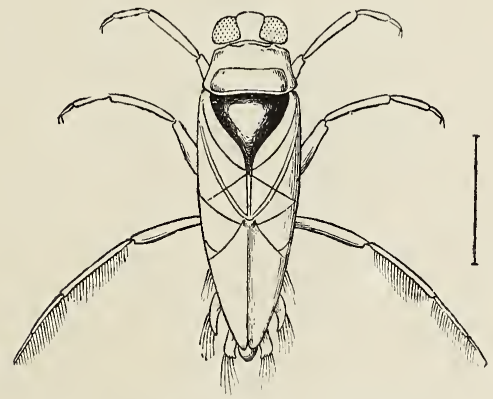

FIG. 108. - Wattr-boatman, Notonecta glauca.

Backswimner

one of them, Notonecta, occurring in profusion where decaying organic matter provides subsistence for the animals on which it preys. In the Water-boatmen the hind-legs are developed as oars, and become flattened, fringed with hairs, and useless for locomotion on land. Of the two genera most commonly met with, one, Corixa, swims about like a Waterbeetle, with the back upwards, but the other, Notonecta, with the back downwards. Like most other 
aquatic Rhynchota they fly very well. Corixa flies at night, and has been seen to fly into an open window in August, being attracted by a light. The head in both genera is transversely elongate, the eyes large, and the antennæ concealed, as in Nepidæ. The mouth, as in other Rhynchota, is suctorial, and armed with a stout proboscis, rather long in Notonecta, short in Corixa. The proboscis is piercing, and

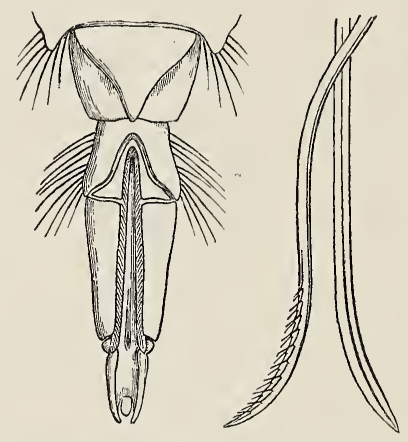

FIG. Iog.-Rostrum and setæ (mandible and toothed maxilla) of Notonecta glauca.

capable of inflicting a slight wound on the hand of anyone who seizes the Insect. The body is velvety and overspread with a glistening air-film, which is conspicuous on the under-side, but elsewhere hidden by the wings. Notonecta is inflated by air to such an extent that it is very buoyant; it has to cliıg to weeds or other fixed objects when it wishes to remain below, and as soon as it relaxes its hold it rises to the surface. This uncommon buoyancy is probably 
connected with the peculiar attitude of the Insect. The air is so lodged in and around its body as to make the ventral side the lighter, and this floats upwards. When it reaches the surface, the tips of the expanded oars and the tail press against the surface-film and keep the head submerged. In this position the Notonecta breathes at ease, but is ready to make a sudden spring without suffering any delay from the difficulty of wetting its body. Now and then it swims back upwards for a few strokes, but soon assumes its ordinary position. Corixa is much less buoyant, and can remain as long as it pleases at the bottom of a glass bowl, where there is nothing to cling to. The hindermost abdominal spiracles, we might expect, would be large in Notonecta, considering that when it reposes, only the extremity of the body is in contact with the air. In reality they are very minute. Larger spiracles, well defended by hairs to prevent the accidental entrance of water, are found on the sides of the thorax. To these the air is led by a singular passage. The side of the body which floats uppermost is keeled along the middle line. On each side of the keel and between it and the lateral edge, runs a long row of elastic hairs, while a second and parallel row runs along the edge itself. These rows of hairs enclose a watertight covered way, leading to the thorax, and along it the air is guided to the large thoracic spiracles. Now andirthen one of the long oars is drawn over the abdomen, as if to urge the air more rapidly along the passage. ${ }^{1}$ Corixa breathes in a different fashion.

1 Schmidt-Schwedt, in Tier-und Pflanzenwelt des Sïsswassers. 
The tail is not brought to the surface, but the air passes directly into the thoracic spiracles. In cold weather Corixa, like other aquatic Rhynchota, buries itself in the mud at the bottom of a pool, and is often smeared with mud when it reappears in early spring. ${ }^{1}$

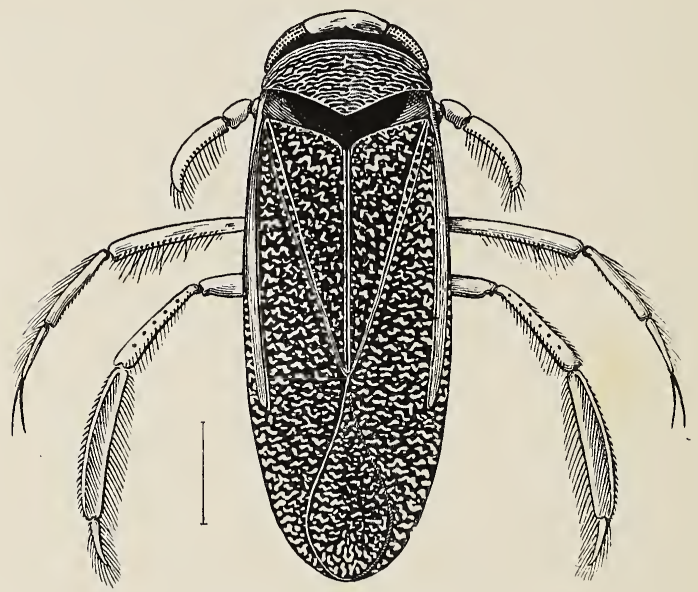

FIG. I ro.-Corixa Geoffroyi.

Schmidt-Schwedt says that Corixa uses its fore-legs to play a tune upon the snout. Captive specimens were observed to utter a tolerably loud and sustained note of an evening. The Insects were at such times submerged. He observed that the note was produced simultaneously with the movement of the fore-leg.

1 Douglas, Ent. Mon. Mag, Vol. III. p. 25. 
Notonecta is said to make a noise like the word chew repeated three times running. The Insect at such times rubs its fore-legs together. ${ }^{1}$

Bruyant has lately described a similar music executed by the very minute Sigara minutissima. ${ }^{2}$ This little Water-boatman occurs among Myriophyllum and Ceratophyllum in the lake of Chauvet (Auvergne) and has also been found in the freshwater sponge. Though only a millimetre $\left(\frac{1}{25}\right.$ in.) long it makes a very distinct stridulation, and the characteristic sound led to the discovery of the Insect in a new site. The middle and hind legs are adapted for swimming. The fore-legs are very short, and end in a singlejointed tarsus, which is armed with stiff hairs. These play upon the rostrum and make a noise like that of a comb rubbed along a sharp edge.

Sigara is not the only aquatic Insect which inhabits the freshwater sponge. The larva of Sisyra, a Hemipterous Insect, is very frequently found in the larger pores. A Caddis-worm (Leptocerus) burrows in the substance of the sponge, and in summer an undetermined Dipterous larva is occasionally met with in the same situation. ${ }^{3}$

The process of egg-laying by Notonecta has been studied by Régimbart. ${ }^{4}$ The Insect attaches itself firmly by its fore and middle legs to a submerged stalk, buries its rostrum in the plant, as if to gain additional support, and makes an incision with the

1 1'. Redfern, in Brit. Assoc. Report, I 859. Sections, p. 173.

2 Comples rendus, 1894.

- Weltner, in Tior- und Pflanzenwelt des Süswassers.

* Ann. Soc. Entom. France, 1874 , p. 204. 
armed ovipositor. The work is executed by a backward and forward sawing motion, and occupies about a minute. Then the egg is passed into the incision, about one third of its length remaining outside; the exposed extremity corresponds to the head of the future embryo. It will be seen that this is nearly the same procedure as that adopted by the female Dytiscus (p. 4I, Fig. 3).

The eggs of Corixa are in general glued to submerged ${ }^{\circ}$ objects. In certain species they are very numerous and densely massed. This is particularly the case with the eggs of two Mexican species (C. mercenaria and C. femorata) which have long served as an article of food to the Mexicans. They are gathered in the lakes of Chalco and Texcuco, which adjoin the city of Mexico. Reeds are set in bundles in the shallows of the lakes, and upon these the Water-boatmen lay their eggs, which are gathered and detached by beating. They are made into cakes with meal, and are said to have an agreeable acid taste. Great deposits of former layings of eggs are said to form at the bottom of the lakes, and to grow steadily in extent. ${ }^{1}$

A Sialid Insect of North America (Corydalus cornutus) forms large flat, rounded masses, composed of two or three thousand eggs, on the leaves of trees overhanging water. An extinct Corydalus of Tertiary age has left countless fossil eggs in the freshwater beds of the Laramie group, Colorado. The eggs are massed into elongate, cigar-shaped bundles, which are $5 \mathrm{~cm}$. (2 inches) long. Each is estimated to 1 Girard, Traité d'Entomologie, Tom. III. p. 846. 
contain about two thousand eggs. The fossil eggs were probably laid in water, like those of the Mexican Corixæ, and it is not unlikely that the lakes of Mexico may hereafter yield masses of fossil eggs like those of the Laramie beds. ${ }^{1}$

1 Scudder, "Tertiary Insects of North America," U.S. Geol. Surv. of the Territories, 1890. 


\section{CHAPTER XI}

THE IVATER SPRING-TAIL (PODURA)

I wILL begin the account of the Water Spring-tail by a short notice of De Geer, the Swedish Réaumur, to whom we owe the first account of this animal, and also a host of accurate and interesting observations on almost all kinds of Insects.

Baron Charles De Geer was born in 1720 . He came of a Dutch family long settled in Sweden. One of his ancestors, Louis De Geer, came over from Holland in the time of Gustavus Adolphus, and introduced better methods of smelting iron than had previously been known. He set up foundries for cannon, brass-works and manufactories of small arms. He brought Belgian workmen to the celebrated mines of Dannemora, and formed them into a colony which long retained its foreign character. Louis De Geer acquired great wealth, which he spent freely upon public and benevolent objects. He was ennobled, and founded a family distinguished for power of more than one kind. The naturalist, Charles De Geer, was brought up in Holland. It is said that his interest in Insects was roused at an early 
age by some silkworms given him to rear. He studied at Utrecht, and afterwards at Upsal, where he was one of the pupils of Linnæus. He inherited large property from an uncle, and, among the rest, succeeded to an interest in the mines of Dannemora. These had been inundated by water, and De Geer contrived machinery to free them and render them workable again. He was skilful in the management of his large estates and liberal in his gifts, especially to charities and schools. His Mémoires pour servir ì l'Histoire des Insectes occupy seven large quarto volumes with many plates, and include descriptions of upwards of 1,500 species. De Geer is a less pleasing writer than Réaumur, whom he endeavoured to imitate, but more concise and methodical. He had the advantage of early training in the system of Linnæus, and instead of the picturesque but at times rather indefinite names employed by Réaumur, he employs a precise nomenclature. De Geer is always painstaking and trustworthy, and many of his descriptions are clear, spirited, and full. The first volume of his Mćmoires appeared in 1752 , and we are told that its sale was so discouraging that he burnt many copies to relieve his indignation. When he decided, in spite of this want of public interest, to carry on the work, he sent free copies of the later volumes to those who had been so enterprising as to subscribe for the first, The first volume is now very rare, and the difficulty of obtaining the entire work has appreciably hindered the knowledge of De Geer's researches. The German translation is much used in place of the original French. De Geer died in 1778 , 
and his seventh and last volume appeared shortly afterwards in the same year. This last volume gives his views upon the classification of Insects. He regarded the characters drawn from the wings as of primary importance, but attended also to the structure of the mouth-parts and to the mode of transformation. His system was on the whole the best of its century.

The first paper ever published by De Geer ${ }^{1}$ was written at the age of twenty. In it he describes four small Insects belonging to what is now called the order of Thysanura. ${ }^{2}$ The Thysanura are all of small size and wingless ; they undergo no transformation ; many leap about by means of a forked appendage attached near the end of the abdomen to its underside, and are hence called "Spring-tails." Leeuwenhoeck had previously found and described Thysanura. but De Geer's account is fuller and more exact. Of his four species two, now called Podura aquatica and Isotoma palustris, were found on the surface of water, De Geer's account of Podura aquatica is here quoted in brief.

In the month of February he observed good-sized black patches floating on small pools of water. Closer examination showed that the patches were made up of small Insects clustering together and moving incessantly. Though resting on the water, they were never wetted. When touched with a stick the Insects dispersed, but gathered together again as

1 Acta Soc. Reg. Scient. Upsal., Vol. I. (1743), p. 279. The paper was read in 1740 .

${ }^{2}$ Seven species are described by De Geer in the last volume of his Mémoires (1778). 
soon as the stick was taken away. They were only one twelfth of an inch long, and entirely black. The body ivas cylindrical, divided into segments, and tapering sharply at the hinder end. The head carried a pair of short, mobile, four-jointed antennæ and a number of simple eyes. The legs were short, and ended in single claws. The tail, as De Geer very naturally calls the forked appendage, could be bent forwards beneath the body, and then, being forcibly extended, could throw the Insect like a skip-jack into the air. De Geer remarks that the spring remained extended for a little while after the Insect alighted, and was then gently drawn forwards. The act of leaping seemed to him clumsily performed, for the Podura generally fell on its back, and wriggled about to regain its natural position. When undisturbed, it moved on the surface of the water by a slow creeping action.

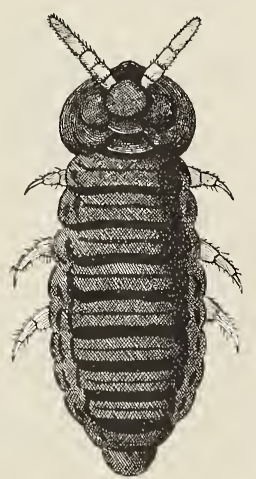

FIG. III-Podura aquatica. $\times$ 30. From Lubbock.

White specks were seen floating on the water among the black masses, and these De Geer found to be cast skins of the Podura.

De Geer gives a clear figure of the forked spring, and notices also a little rounded prominence between its branches. This is now considered to be an organ of adhesion, and De Geer himself so describes it at a later time in another Thysanuran. Many of the 
terrestrial species are able to support themselves on smooth vertical surfaces by help of this adhesive organ, which opens by a slit, and gives passage to a fleshy sucker.

The aquatic Spring-tail, says De Geer, perished in two or three hours when removed from the water, and its body shrunk as if by evaporation. He was inclined in I 740 to suppose that the tubercle mentioned

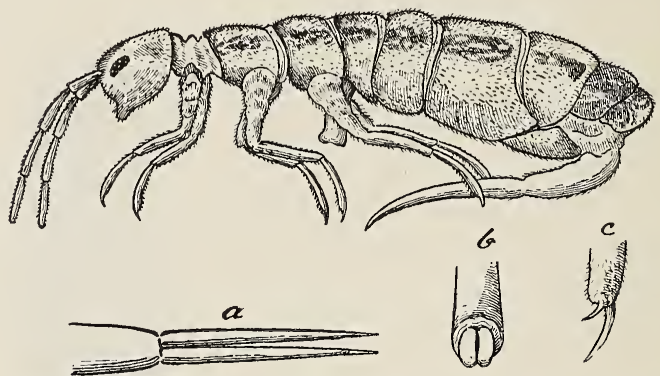

FIG. I 12,-Isotoma palustris (Aquatica cinerea of De Geer). $a$, the forked appendage or spring; $b$, the adhesive organ, or ventral sucker, seen also between the hind legs in the upper figure; $c$, claws at extremity of leg. $\times 60$.

above sucked up water for the supply of the body when the Spring-tail floated on its native pools. Having placed some of these Insects in a vessel completely full of water, he observed that they crept to the bottom, and lived for several days. They did not apparently possess any power of swimming.

The smaller and less common Isotoma palustris is also described, but De Geer gives little information as to its habits.

It is easy to find aquatic Poduræ in ditches and 
ponds, for they are plentiful and widely distributed. During the summer months they spring, like Sandhoppers, from the surface of the water, and then repose tranquilly upon it. They are black, with a mixture of white individuals, which are fresh-moulted. How is it that they are never wetted by the water?

The microscope shows that the body is covered with short and close-set hairs. Into the minute spaces between these the surface-film cannot penetrate, and the trifling weight of the body is insufficient to press it as a whole beneath the surface. Were the body once wetted, it would be hard for the Insect to force its way through the surface-film into the air. It is equally hard for it to make its way through the surface-film into the water.

What has the size of the creature to do with its power of swimming or sinking? you may ask; the size surely does not affect the specific gravity of its body. No, but it affects the proportion which the contour of its body bears to its weight. In similar figures the contour increases or diminishes directly as any linear dimension, but the weight as the cube. A minute Insect has accordingly a far greater contour in proportion to its weight than a large Insect of precisely similar form, and therefore encounters greater resistance from the surface-film. The resistance in the case of the aquatic Spring-tail is, as we have seen, so great that it can leap from the surface of the water and alight upon it again without ever breaking through. I see that in various books on Natural History this power is attributed to the extraordinary elasticity of the spring. But no elas- 
ticity would suffice if the Insect were of large size. Take a stone of half a pound weight, and throw it upon water; it sinks at once. Crush the same stone to fine powder, and scatter a small quantity upon the water; the lighter particles will float for a long time.

Can the aquatic Spring-tail descend beneath the surface? I was long persuaded that it could not. In my aquarium this species abounds, and propagates itself from year to year, feeding, as I suppose, upon Duckweed and other floating vegetation. I have never once found it beneath the surface. But out of doors and in wintry weather I believe that it descends, as so many other aquatic Insects do, for shelter from the cold. It may also, I have some reason to suppose, feed on submerged vegetation when the surface is free of weeds. I once brought home a collecting bottle full of decaying vegetable matter and water. When I came to look at it closely, two or three Poduræ were floating on the surface. After an hour or two there were eight or ten. This led me to think that they must have come up from the depths where they had previously been lurking. Once at the surface, they were unable to descend again. I placed a number in a beaker half full of water and saw them run and leap upon the surface. I chased them with a small rod till they became excited and alarmed, but they were wholly unable to escape by sinking. Even when alcohol was added to the water, and the surface tension lowered thereby, the dead bodies of the Poduræ floated as before. It was only when they were placed upon strong alcohol that they became wetted, 
and after a considerable time were seen to sink. But where water-plants with floating leaves grow, the Poduræ can descend at pleasure. They will not attempt to do so if they are well off at the surface; but when food is scarce, or the temperature low, they may occasionally be seen to drag themselves through the surface-film by grasping the stem with their strong and hooked legs, and so descending. When the Podura climbs downwards into the water it is still unwetted, and enclosed by a film of air which clings to its hairy body. It can remain for many hours submerged without inconvenience.

Like some aquatic Beetles the Podura probably buries itself for weeks together in the mud at the bottom of ponds, and thus escapes the severity of winter cold.

The small, metallic-coloured, carnivorous Flies of the family Dolichopodida commonly seek their prey in the neighbourhood of streams and pools. Hence the naturalist in search of aquatic Insects cannot fail to find them almost daily and hourly, sometimes in swarms, sometimes singly. They come to rest on the grasses, herbs, or bushes near to water, on stones in the bed of a stream, or even on the surface of the water itself. Some rival the Pond-skaters in the agility with which they dart to and fro upon the surface of rapid streams; others hover incessantly in the spray of waterfalls. At least one species of Dolichopodida preys upon Podura aquatica, and it is probable that many flies fresh-hatched from a variety of aquatic pupa fall victims to these swift and destructive enemies. 


\section{CHAPTER XII}

INSECTS OF THE SEA-SHORE

IT has been a surprise even to professed naturalists, even to men who have made Insects the study of years, to discover that Insects have contrived to occupy not only the surface of the earth, the soil beneath the surface, the air, the freshwater streams, and the freshwater lakes, but even the sea beach and the sea itself. Seventy years ago, that is, previous to Audouin's study of the habits of Aëpus, very few entomologists had thought it worth while to search for Insects among the refuse cast up by the tide. That air-breathing Insects should betake themselves to places where they might be covered by the salt tide, seemed incredible, even to those who were familiar with the many Insects which haunt our rivers and ponds. And yet, even before Audouin's time, Lyonnet, Treviranus, and Straus-Dürckheim had observed the singular power of certain Insects to endure complete immersion. Their observations, however, failed to impress the minds of naturalists. The supposed impossibility of Insect-life on the seashore between tide-marks was based upon no experi- 
mental evidence, but merely upon vague impressions. Had it come into the minds of the naturalists of $\mathrm{I} 820$ to make the trial which Plateau made in 1872 , they would have better appreciated the hardiness of terrestrial Arthropods, and the ease with which they submit to hours and even to days of submersion in water. Plateau took a number of land Beetles of various kinds, devoid of special organs for carrying down a supply of air, and found that they could endure complete immersion in fresh water for two, three, or even four days. The Beetles became torpid, but recovered on being restored to the air. ${ }^{1}$ Many aquatic Insects, which dive with the greatest ease, do not survive more than a very few hours under like conditions. Gyrinus struggles violently when detained beneath the surface, and perishes in about three hours, while Aphodius becomes perfectly still and senseless, but recovers after an immersion of fifty hours. $^{2}$

Insects submerged in water behave as a rule like Insects placed in an atmosphere devoid of free oxygen. They cease to struggle in a few moments, and pass into a state of torpor, which may be greatly prolonged without fatal results. Certain larvæ and pupæ live for weeks or months buried deep in earth or in vegetable refuse. It is almost impossible to kill certain Insects in a moderate time by carbonic

1 Rech. physico-chimiques sur les Articulés aquatiques (Bull. Ac. Roy. Belg. 1872).

2 Gyrinus is an Insect of much more active habits than Aphodius, and the aquatic Insects experimented upon by Plateau are in general more active than the terrestrial species 
acid or nitrogen, though they quickly become unconscious and motionless in such gases.

The saltness of sea-water might be expected to prove disagreeable if not injurious to Insects, but there is little proof that such is actually the case. Insects, when forcibly submerged, survive about as long in salt water as in fresh. Many Insects are not easily wetted by water. The hairs with which some are covered and the dense, glossy chitin of others prevent effectual wetting. The surface-film of water will not pass into small openings, such as the mouth, or the spiracles, or the spaces between close-set hairs. Larvæ however, which live in water, and are thoroughly wetted by it, cannot endure the change from fresh water to salt. I placed thirteen living Chironomus larvæ in salt water, and found that in four hours five had died, while the rest were extremely languid. In eight hours all were dead. By gradual acclimatisation even such larvæ as these can make themselves at home in salt water. Packard dredged up live Chironomus larvæ in Salem harbour, and not a few Dipterous larvæ of various species have been found established in brine-vats. Plateau has drawn up a list $^{1}$ of near eighty species of Insects and Arachnida, which, though they cannot swim and though they breathe only gaseous air, inhabit the sea-shore, and undergo daily or at least frequent submersion. The list will no doubt be largely increased by the future labours of naturalists.

The Insects of the sea-shore are mostly very small. 1 "Les Myriopodes Marins," Jour. de l'Anat. et Phys. (1890). 
Very few species attain such a size that they can be seen at a distance of four or five feet; a length of four millimetres is somewhat uncommon.

On the verge of the beach, especially where it is flat and sandy, there will commonly be found a line of black sea-weed, cast up by the spring-tides. In the damp and fermenting mass beneath the surface of the sea-weed, innumerable maggots thrive, and produce throughout the year black Flies, which are rather like the common House-fly, but have longer wings and smaller bodies. The Flies sometimes emerge in dense swarms, but more commonly settle here and there on the heap of weed, especially in cold weather. They occasionally fly a few miles inland and visit flowers. The black pupæ are buried in the weed. This is the Dipterous Insect known to entomologists as Cœlopa frigida. The maggots and pupæe easily survive a short immersion in salt water, to which they are occasionally, but not frequently, subject.

Another Dipterous fly is very common on the shore. This belongs to the same large family, Muscidæ, as the House-fly, but to the Acalypterate division, and is named Actora æstuum. It is of small size and abounds in summer on the wet sand and foam at the very verge of the tide. The larvæ are believed to feed upon thrown-up seaweed (Fucus vesiculosus), and are covered at every tide. The body is ten to fifteen millimetres long, cylindrical, and covered with short hairs. It is a good deal like the Leatherjacket (larva of the Daddy-long-legs), and like it bears a number of conical fleshy processes at the 
tail end. Eight of these form a semicircle on the dorsal side, and in their midst are two spiracular plates, each bearing three spiracular openings. Four others stretch horizontally along the chord of the semicircle, and another pair lie one on each side of the anus on the ventral side. ${ }^{1}$

A small Chironomid, probably Thalassomyia Frauenfeldi, is common on our shores. The larva has been described by Johnston as an Annelid, under the name of Campontia cruciformis. It closely resembles the Blood-worm of our ditches, except that it has a green instead of a red tinge. A specimen of the larva has been dredged off the Isle of Man from a depth of over ten fathoms, and Mr. Swainson has often found them on Zoophytes upon the sea-shore at St. Anne'son-the-Sea. The flies are often plentiful on the edge of the retreating tide. ${ }^{2}$

Several species of the brilliant, raptorial Dolichopodidx (see p. 369) haunt the surf and breakers of the sea-shore, where no doubt they find their prey.

The Beetles of the sea-shore include a host of small Carabidæ, predatory Insects, which lurk under stones or burrow in wet sand. The terrestrial species have been known to enter water in pursuit of their prey. Bertrand, for instance, observed Carabus clathratus chasing aquatic Insects in water five centimetres deep. ${ }^{3}$ The Carabidæ of the sea-shore usually under-

${ }^{1}$ H. Gadeau de Kerville, Soc. Entom. de France, Vol. LXIII., p. 82 (I 894). The fly has not been reared from the larvæ described, but it is probably that of Actora æstuum.

${ }^{2}$ Swainson, Brit. Naturalist, June, 1894.

${ }^{3}$ Quoted by Plateau, loc. cit. 
go daily immersion, and become motionless when covered by water.

Two European species of Aëpus have been more carefully studied than the rest of the marine Carabidæ. They run about on stones, sea-weed, sponges,

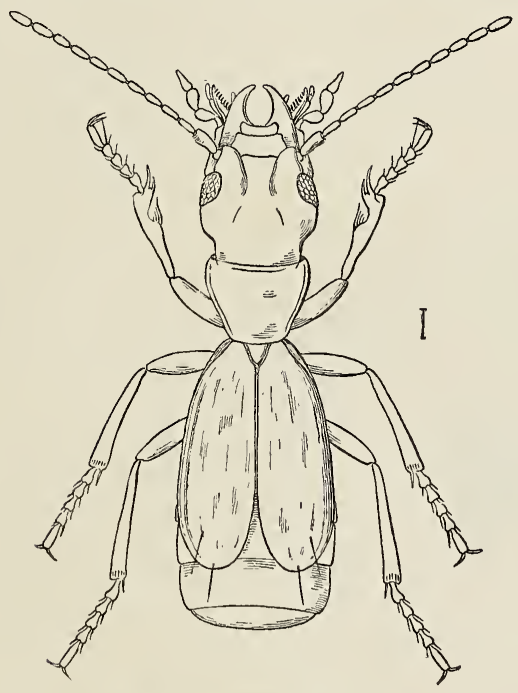

FIG. Ir3.-Aëpus Robinii.

etc., at low water. Being like most other Carabidx, incapable of flight, they cannot avoid the rising tide. As soon as it reaches them, they creep under stones and remain motionless. The body is flattened, and covered in every part with hairs which entangle air (Audouin). There is a large pair of air-sacs in the 
abdomen, as I learn from Mr. Hammond, which are no doubt uscful during prolonged submersion. The cyes are very curious. A chitinous plate protects and almost entirely covers them, leaving only a small round central hole. The form of this plate suggests that it may be employed as a kind of pin-hole camera. Mr. Hammond, who called my attention to this peculiarity, has drawn it in fig. II4. The tibia of the fore leg is provided with a peculiar comblike organ (sce fig. I 16 ), which

A

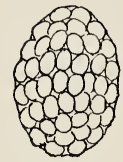

B

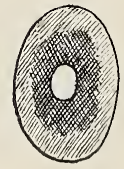

C

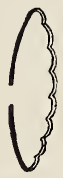

FIG. Ir4.-Eye of Aëpus. A, External surface showing facets. B, Perforated plate, front view. C, section. looks as if it might be uscful for cleaning the antennæ or limbs. Such an apparatus is not uncommon in Beetles. I am indebted to Mr. W. F. Baker for the following remarks upon the tibial comb :-

"If the forc leg of the common Bcetlc, Pterostichus niger, be cxamined closely, a decp notch protected by a large spinc will bc found on the lower side of the tibia; this notch is armed with stiff, finc hairs. I was for a long time unable to imagine what purpose it could serve. After inspecting all the Beetles in my collection, I found that this peculiar feature was restricted to the Geodephaga, though in some of the Staphylinidxe a somewhat similar structure, consisting of a spine and fine hairs without any notch, could 
be observed. Among the Geodephaga species of Broscus, Callistus, Harpalus, Amara, Calathus, Anchomenus, Clivina, Dyschirius, Chlænius, Pterostichus, Stomia, Aëpus, Loricera, Demetria, and Bembidium have the tibial comb in its complete form. All the species which possess it frequent moist, dark and dirty places, hiding under stones or logs of wood, burrowing in the earth, or creeping under the decaying bark of trees. The comb on the fore leg of the Honey-bee suggested that the similar structure in Beetles might be employed for the purpose of cleansing the an-

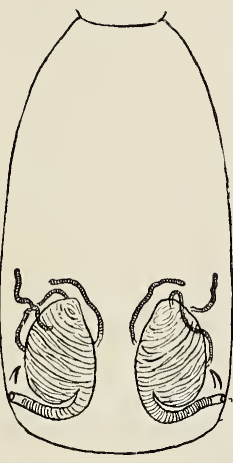

FIG. I15.-Abdomen of Aëpus in outline showing air-sacs in situ. tennæ from dirt contracted in confined situations. To test this, I smeared with gum the antennæ of Pterostichus niger, and set the Insect free in a box whose bottom was strewn with fine sawdust. After running wildly about and seeking to escape the Beetle made a careful examination of its prison, waving its antennæ, and feeling the ground with them continually. The sawdust soon began to clog the antennæ, and then the Beetle would stop, raise its fore leg, bring the antennæ into the comb by a movement of the head, and draw it through, thus effectively clearing it of loose particles. One piece of sawdust clung so tight that three distinct pulls were required to remove it. The Beetle then 
378 NATURAL HISTORY OF AQUATIC INSECTS $\mathrm{CH}$.

endeavoured to cleanse its comb with the tarsus of the middle leg, but went about it in a very clumsy fashion.

"I was then satisfied that the comb is really used to cleanse the antennæ. I next endeavoured to find out how Beetles which have similar habits but no comb cleanse their antennæ. It would

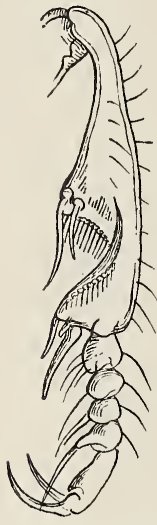

FIG. II6.-Part of fore leg of Aëpus, with comb upon tibia. take too long to relate all the experiments which I have made, but to be brief, they do what is necessary by the help of the spines on the tarsus (Carabus), or those on the tibia or tarsus (Notiophilus, Leistus, and Nebria), or by rubbing the antennæ against plants and other objects (Elaphrus). The operation often takes up a considerable time where no comb can be employed."

Aëpus is often found among small molluscs (Rissoa, Lasaea) and is believed to prey upon them. Another little Carabid, Cillenum or Bembidium laterale, can often be seen in thousands upon refuse washed up by the tide. It is regularly submerged.

The family of Staphylinidæ (Rove-beetles) includes several marine species. Bledius is common on sandy shores near high-water mark. There are fifteen British species. They prefer a smooth expanse of sand thinly coated with mud, and here throw up little hillocks, half an inch or so in height. Hundreds of these hillocks form one colony. On sandy shores 
the patches inhabited by Bledius may be so numerous as to form a nearly continuous line miles in length. The Beetle shovels out the sand backwards with its hind legs. When covered by the tide, which is an unusual event, it remains still in its burrow. On warm evenings just after sundown they fly about in great numbers, never rising high, but keeping near the surface of the sand. The same species which haunt the shore occur also in marshy ground in inland places near the sea. Bledius arenarius is about three and a half millimetres long; its body is narrow and rather cylindrical.

A Carabid Beetle, Dyschirius, preys upon the larvæ and pupæ of Bledius. It is a restless creature, constantly running in and out of the galleries, and has an insatiable appetite. It is of about the size, or smaller than its victims. Several species, both of Bledius and of Dyschirius, occur on our coasts. A number of other marine Staphylinidæ have been described. Micralymma is common on rocky shores, and resembles Aëpus in its habits.

A few marine Caddis-worms are known. One is found between tide-marks in Lyttleton Harbour, New Zealand, and forms its sheath of the coralline seaweeds. ${ }^{1}$ The Rev. A. E. Eaton has found plenty of small Hydroptilidæ in salt or brackish streams on the borders of the Sahara. Mr. Swainson has fished up a living Oxyethira from the incoming tide of the Ribble, but it is not yet proved that this Caddisworm is a true inhabitant of the sea. ${ }^{2}$ Philanisus

1 MacLachlan, Journ. Linn. Soc., "Zoology," vol. XVI. p. 417 (1 883).

2 British Naturalist, Dec., I 894. 
380 NATURAL HISTORY OF AQUATIC INSECTS $\mathrm{CH}$. plebius and a species of Molanna are additional instances. ${ }^{1}$

Not even the waters of the sea can exclude $\mathrm{Hy}$ menopterous parasites. M. Moniez ${ }^{2}$ has discovered a minute Proctotrupid under stones on the sea-shore at Aigues-Mortes in company with marine Crustacea. The habits of this Insect have not been investigated.

Aëpophilus, so called, because it is often found in company with Aëpus, is a small Bug, only three millimetres in length, which inhabits fissures of rock not far from low water. The adult Insect is found only in the month of October.

A number of marine Thysanura have been discovered. There are also False-scorpions, Acari, and at least two Centipedes which inhabit the shore. It is much to be desired that the mode of life of this varied and interesting assemblage of marine animals should be more closely inquired into. ${ }^{3}$

The Insects of the beach hardly ever swim. On a wave-beaten shore the mere attempt to swim would be extremely risky. But far out at sea Insects may safely trust themselves to the surface of the waves. Their action is not however to be called swimming. They run on the surface of the water, like a Velia or a Hydrometra.

The Insects in question are Halobates and Halo-

1 "Challenger" Reports, "Zool.," Vol. VII.

2 Rev. Biol. du Nord, r 894.

${ }^{3}$ Professor G. S. Brady and I are endeavouring to collect information concerning the Insects of the sea-shore, and would value the assistance of naturalists who have opportunities of observation. 
batodes. Several species are known. They inhabit all the great tropical and sub-tropical oceans, often hundreds of miles from land, appearing on the surface in calms, or when there is a swell without wind-waves. They appear of a brilliant white, either wholly or as to their legs, but this is due entirely to a bubble of air which overspreads the close-set hairs of the integument. When removed from the water or examined closely, they are seen to be dark-coloured. They run rapidly on the sea, and are said to dive occasionally. What becomes of them in stormy weather, and where the eggs are laid and hatched, has not been found out. They feed upon the floating bodies of dead marine - animals, and may be secn to run out from such objects when alarmed by the approach of a boat. These Insects belong to the Rhynchota (Hemiptera), and in some respects come pretty near to such forms as Hydrometra or Velia. They are peculiar in never exhibiting a trace of either pair of wings. The fore legs are of moderate size, the middle legs of enormous length, and in Halobates fringed with hairs. The hind legs are not so long as the middle legs. The whole animal has a superficial resemblance to a longlegged spider. The mesothorax, on which the middle legs are carried, is extremely large, and the abdomen of insignificant size. 


\section{CHAPTER XIII}

THE CONTRIVANCES OF AQUATIC INSECTS

THE aquatic Insects described in the foregoing pages have been selected on no philosophical principles. They are merely such as I have happened to come across in my rambles by pond and stream. But even this chance collection of aquatic species may yield interesting results if studied from a suitable point of view. Every independent worker has his own notions as to the point of view which is particularly important and interesting, and I fear that we are apt to be unjust to those who do not share our tastes. I will not again occupy time and space by justifying my own preference, which inclines me chiefly to study the wealth of contrivance which is exhibited by these obscure creatures.

Let us first of all run over the modes of locomotion practised by aquatic Insects. The Pond-skaters stand or run upon the surface of the water, which they dimple but do not break. The Water Spring-tail or a small Gerris can leap from the surface-film, and alight upon it unwetted. ${ }^{1}$ The Whirligig Beetle

${ }^{1}$ A small Copepod Crustacean, Pontellina mediterranea, is said to do the same. (Ostroumoff in Zool. Anz., October, I S9t.) 
(Gyrinus) darts to and fro upon the surface, changing its course every moment by slight adjustments of its peculiar paddles, but when alarmed it dives into the depths beneath. The larvæ of the Gnat, Dixa, Pericoma, Anopheles, Stratiomys, and Hydrobius suspend themselves from the surface-film by an unwettable basin at the tail-end of their bodies, which admits air to the spiracles, and at the same time allows the head and jaws to sweep through the water in search of food. Some aquatic larvæ (Eristalis, for instance) may be seen at times to creep upon the underside of the surface-film. The same manœuvre is practised by other aquatic animals, such as the leech-like Triclads, the Pond-snails, and Cyclas. These have been erroneously said to creep upon the air. A very simple experiment will show that the body is at such times completely immersed. If a little lycopodium powder is sprinkled over the water, the light grains are not parted when the animal creeps beneath them. In some cases, for instance in the Triclads, the body is heavier than water, and sinks in a moment if it is detached from the surface-film. A drop of water let fall upon the creeping animal will send it to the bottom. The Water-boatman (Notonecta) is buoyant, and comes to rest in an inverted position, with its tail and the extremities of its oar-like legs resting upon the surface. It is then well placed for intercepting drowned or drowning Insects. Whenever it chooses to leave the surface, its oars propel it swiftly through the water, and the air is so distributed throughout its body that it swims most easily in its resting position, that is with its back downwards. 
The resting position, moreover, brings the spiracles within reach of a fresh supply of air, though not in this Insect actually to the surface. Dytiscus when at rest has its spiracles fully exposed to the air. If such Insects are disabled, they have only to cease to struggle in order to gain the surface in that position which is most convenient for breathing. Swimming beneath the surface is accomplished with various degrees of efficiency. The winged Dytiscus is perfectly adapted for submerged navigation. The even contour, the glossy surface, the powerful oars, fringed with bristles, working simultaneously, and feathering during the return-stroke, the steering action of the intermediate legs, the arched back, and the angulated keel will delight those who can appreciate a finished piece of mechanism. The soldering of the broad bases of the oars to the thorax, and to the fore part of the abdomen as well, stiffens the body, and it may be prevents the loss of power which would result from the incessant squeezing out of water enclosed between the basal joint and the body. I suspect that there is a further mechanical advantage in this structure which I am at present unable to explain. Polynema travels about in the water by the help of its wings, like a Penguin. Many long-bodied Dipterous larvæ move by a lashing action, striking the water sideways and instantly reversing the stroke. In Corethra and the Gnat the lashing action of the larva is aided by a fin composed of close-set bristles. The Simulium larva runs about its network of silken threads in the water of a rapid stream, holding on by one or both of its clusters of hooks, and throwing out a new thread whenever 
necessary. Some Dragon-fly larva swim by striking the water with the long abdomen and its terminal plates; others make sudden rushes by the violent expulsion of water from the intestine. Slow larva creep by legs, hooked tubercules, backward-pointing hairs, and the like. Not a few pupæ, both aquatic and terrestrial, bear spiny rings which aid in creeping, and enable them to make their way to the air when the fly is about to emerge.

Or we may review the contrivances which enable aquatic Insects to capture their food. The perforated suctorial mandibles and the mouth-lock of the Dytiscus larva, the mask of the Dragon-fly larva, the "weel" which entangles the struggling victims of the Phantom larva (Corethra), the clasp-knife mechanism of the prehensile fore legs of the Water Scorpion, the snare of the Plectrocnemia larva, the ciliary organs of many aquatic Dipterous larve, and the pharyngeal strainer of the Eristalis larva are varied in design, perfect in execution. But our admiration for these wonderful implements is mingled with another feeling. The weapons of carnivorous Insects are a little too like a collection of instruments of torture.

The respiration of aquatic Insects may be altogether like that of the terrestrial species, except that the gaseous air to be taken into the body is not so readily procured. We have seen how the wing-covers, the felted back, and the dorsally set spiracles of the winged Dytiscus combine to secure an ample supply of air every time that the Insect floats or swims to the surface. Hydrophilus and Hydrobius employ their peculiar antenna in breathing; Notonecta its 
386 NATURAL HISTORY OF AQUATIC INSECTS $\mathrm{cH}$.

oar-like legs. Donacia and perhaps the pupa of Paraponyx tap the air-chambers of submerged plants. The larvæ of Ptychoptera and Eristalis have respiratory tails, which can be protracted or withdrawn, but each has a mechanism peculiar to itself. The long respiratory filament of the Ptychoptera pupa is altogether different from both. Nepa and Ranatra breathe by a pair of valves, which cohere to form a tube, and conduct air to the spiracles. Other aquatic Insects breathe only dissolved air, and this in many different ways; by the outer skin, or by bunches of thin-walled tubes, occupied in some cases with tracheæ, in others with blood-spaces, or by flat plates which can be waved to and fro, or by intestinal folds. Tube-dwelling larvæ have their own difficulties and remedies. Chironomus larvæ, Caddis-worms, and some aquatic caterpillars which inhabit sheaths made out of leaves, maintain a flow of water through their tubes by incessant undulation of the body. This operation is aided by peculiar structures, such as fringes of bristles, retractile processes which regulate the distance of the body from the wall of the tube, and so forth. The Chironomus larva employs hæmoglobin as a means of storing up oxygen. The spiracles of almost any Insect, whether aquatic or terrestrial, abound in singular features, nearly all unstudied at the present time. The spiracles of Dytiscus are among the wonders of nature; it would take a lifetime to master their details.

Attack and Defence call forth yet more contrivances. Protective resemblance, concealment within burrows, by webs, by portable cases, by fixed cases, 
by the transparency of the body, are a few of the arts practised by aquatic Insects, cither in self-defence or as a means of pouncing unseen upon their prey.

The egg-laying of aquatic Insects is attended with special difficultics, somc of which spring from the fact that the female fly is in general ill-fitted to enter the clement in which the carlier stages have to be passed. These fresh difficultics are met by fresh contrivances. The egg-ropes of Chironomus, the egg-raft of the Gnat, the anchoring threads of the eggs of Ephemera, the floating cocoon of Hydrophilus, are adaptations of peculiar interest. Dytiscus, Notonecta, Ranatra, and certain Dragon-flies lay their eggs in incisions made in submerged plants. But even these carefully hidden eggs are scarched out by such egg-destroyers as Polyncma, which lay in them their own eggs, from which proceed the parasites which will in the end devour their undeveloped host.

I might go on to cnumeratc fresh contrivances under such heads as the constructions of aquatic Inscets, the emergence of the winged fly, the defences of resting pupæ, and so on, but the subject is incxhaustible, and the heaping-up of examples proves wearisome. In past ages all these would have been cited as fresh proofs of a wisdom and beneficence which wc arc unable even to comprehend, far less to imitate. And whatever the cool scientific spirit may have done to weaken that interpretation, the beauty and completeness of natural adaptations comc upon us at times with overwhelming force. It is with peculiar interest that we observe how physical principles, the discovery of which is among the latest 
triumphs of human science, were long ago turned to practical account by some of the most insignificant of Insects. Many of thesc natural contrivances secure the safety, and increase the happiness of living creatures. But there is a dark side to the picturc.

In the Theodicécs and Natural Theologies, which now fill whole libraries, we shall find little mention of the murderous instincts of animals, or of the cruel weapons which are placed at their service. Yet the ravages of carnivorous Quadrupeds, Birds, and Insects are as obvious as any of the operations of naturc. The miscry caused by internal parasites is less conspicuous, but cven more perplexing. The Dragon-fly and the Dytiscus are not altogether pleasing objects of contemplation, but the Ichneumons secm to go beyond all that the cruclty of despots has imagined. That innumcrable Inscets should bc caten up alive by parasites, which spare the vitals of their victims lest they should perish too soon, that this miscrable existence should be protracted until pupation, so that the devourcr should find a safe shelter during its own resting-stagc-these are facts which show us that Nature is not everywhere bencficent. Of the same kind are the facts related conccrning some of the fossorial Hymcnoptcra. I can never read Fabre's Souvenirs Entomologiques without a shudder. The operations which he has brought to light with such diligence, and described with such animation, impress me much as do the tales told of the Well of Cawnpore or the Ice-tower of Avignon, What may be the solution of the mystery, and how 
so much benevolent foresight can be reconciled with so much cruelty, it is not for the naturalist to explain, though the mere naturalist finds it hard to shake off these thoughts when they have once come up in his mind.

The beginnings of mercy and unselfishness appear in the behaviour of wild animals to their young. Social animals are called upon for a morc habitual exercise of the same attributes, and it is perhaps the social state which has chicfly moderated the selfishness of Man; it is the social instinct which leads him to pity even the humblest victims of the struggle for existence.

When we have to tell what we have seen and found, it is our business to give a true account, disguising nothing, and keeping nothing back. But let us be careful not to speak as if our little plummets had sounded the depths of the universe. Those who have surpassed their fellows in the improvement of natural knowledge, have always been the first to admit that what they have come to know is lost in the infinitude of the unknown. 

INDEX 



\section{INDEX}

ABRIDGED LiFE-Histories, 20

Acentropus, 235

Actora, 373

Aepophilus, 380

Aepus, 375

A eschnidæ, 33r

Agrionidx, 33 I

Agriotypus, 223

Alder Fly, 273

Anglers' Names for Aquatic Insects, 28

Anopheles, 92, I63

Aquatic Beetles, 30

Caterpillars, 226

Flies, 97

Hymenoptera, 219

Insects, Anglers' Names for, 28

Contrivances of, 382

Equilibrium of, 15

Groups of, 28

Wintering of, 18

Baker on Hydrobius, 89

on Tibial Comb of Beetles, 376

Batelli on Eristalis larva, 203

Beetles, shapes of, 6 food of, 6

Bledius, 378

Buckler on Hydrocampa, 230 on Paraponyx, 232

Burgess on mouth of Dytiscus larva, 45

CADDIS IVORMS, 124, 223, 236 Narine, 379
Carabidæ, Marine, 374

Cataclysta, 23I

Caterpillars, Aquatic, 226

Ceratopogon, 155, 197

Chironomus, 122, 197, 25 I

Development of, I $_{5} \mathrm{I}$

Cøiopa, 373

Collection of Aquatic Insects, I 14

Contrivances of Aquatic Insects, $3^{82}$

Corethra, I13, I 2 I, I4 I, 384, 385

Corixa, 355

Corydalus, Eggs of, 360

Culex, 97, 121, 14I

DE GEer, Life OF, 362 on Caddis-worms, 263

on Ephemera, 3 I 8

on Mochlonyx, I 2 I

on Paraponyx, 23 I

on Thysanura, 364

Development of Chironomus, I 5 I

of Polynema, Ganin on, 222

Dewitz on Respiration of Dragonfly larva, 335

Dicranota, I64

Diffusion through living membranes, 38

Diptera, Aquatic, 97

Divided Eyes, 34

Dixa, 92, 157

Dolichopodidre, 369,374

Dominance, Marks of, 8

Donacia, 93 
Dragon-flies, 328

Dragon-ily larvæ, 385

Escape from larval skin, 340

Dyschirius, 379

Dytiscus, $39,89,384$

Eggs of Aquatic Insects, I $46,326,360$

Ephemera, De Geer on, 3i 8

Ephemeridre, 285

Pictet on, 322

Vayssière on, 325

Equilibrium of Aquatic Insects, I 5

Eristalis, 198, 383

Flies, Aquatic, 97

Ganin on Development of Polynema, 222

Gerris, 349,382

Gnat, 97, I 45

Great Water-beetle, 6I

Gyrinus, 30

H.EMONIA, 93

Halobates, 380

Halobatodes, 380

Helophorus, 89

Hemerobius, 44, 45

Hurst on Gnat pupa, 104, I44

Hydrobius, 87

Hydrocampa, 227

Hydrometra, 349

Hydrophilus, 6I

Hymenoptera, Aquatic, 219

IMAGINAL FOLDS, I 35

Insects, Dominance of, 8

in Brine, 2, 372

of the sea-shore, 370

originally terrestrial, 4 variety of habitat of, 7

Invasion of the Waters by Insects, 3

Isotoma, 366

KLAPÁLEK ON Agriotypus, 223
LAKER ON HydROPHILUS, 86

Lepidoptera, Aquatic, 226

Libellulidæ, 33I

Live Natural History, 24

Lowne on Suckers of Dytiscus, 55

Lubbock on Polynema, 219

Lyonnet on Hydrophilus, 64 Life of, 62

MAY-Flies, 205

McLachlan on Caddis-worms, 257

Meinert on perforated mandibles, 45 on Dixa, I 59

on Tanypus, 155

Micralymma, 379

Micropteryx, 269

Miger on Hydrophilus, 73, 84

Mochlonyx, I2I

Mosquito, 109, II I

Moult of Insects, I 34

Miiller, G. W., on Hydrocampa, 229

Muscidæ, I39, 197

Myrmeleon, 44, 45

NEFA, 353

Nepidæe, 353

Nitzsch on Hydrophilus, 75

Notonecta, $3^{8} 3$

Notonectidæ, 355

ODONATA, 328

Osten Sacken on Oxen-borr Bees, 21 5

on Eristalis in America, \&c., 218

Oxyethira, 379

PæDogenesis, 23

Palmén on Perla, 283,284

Palingenia, 285

Paraponyx, I24, 23I

Parthenogenesis, 23

Pericoma, 92, 21 8

Perla, 279

Phantom Larva, II4

Pictet on Ephemeridæ, 322 
Plateau on Suckers of Dytiscus, 55,59

Plectrocnemia, 265

Podura, 362

Polymitarcys, 304

Polynema, 21 9, 304

Pond-skaters, 349,382

Prestwichia, 220

Ptychoptera, I 70

\section{Ranatra, 353}

Rat-tailed Maggot, I 98

Réaumur, Life of, 236 on Egg-raft of Gnat, 112 on Eristalis, 198, 213 on Escape of Dragon-fly from larval skin, 340 on Hydrocampa, 227 on Polymitarcys, 304

Respiration of Aquatic Insects, I 8

Rhynchota, Aquatic, 346

Schiödte on Perforated MaNDibles, 45

Schmidt-Schwedt on Corixa, $35^{8}$

on Donacia, 94

on Notonecta, 357

on Paraponyx, 234

on retractile processes of Trichoptera, 249

Scourfield on Copepods and Surface-film, I62

Sea-shore, Insects of the, 370

Sialis, 273

Siebold on Donacia, 95

Sigara, 359

Simmermacher on suckers of Dytiscus, 55

Simulium, I4 I, I 75, 25 I
Sisyra, 359

Sponge, Insects living upon the Freshwater, 359

Spring-tail, Water, 362,382

Staphylinidæe, Marine, $37^{8}$

Stone-fly, 279

Stratiomys, 92, I 89

Swammerdam, Life of, 285

on Gnat larva, IOI

on Palingenia, 285

on Stratiomys, I 89

Surface-film of WVater, I 2, 99, 367

TANypus, I4 I, I52

Taylor on Plectrocnemia, 265

on Retractile Processes of Trichoptera, 247

Thalassomyia, 374

Thysanura, De Geer on, 364

Marine, 380

Tipula, I40

Trichoptera, 236

VAYSSIERE ON EPHEMERID.£, 325

Verdat on Simulium, I87

Viviparous reproduction, 23

Water as a Sphere of Life, I

Boatman, 355

Scorpions, 353

Spring-tails, 302, 362

Surface-film of, I 2, 99, 367

Whirligig Beetle, 30, 382

Wilkinson on Pharynx of Eristalis larva, 206

on Tail of Eristalis larva, 201 


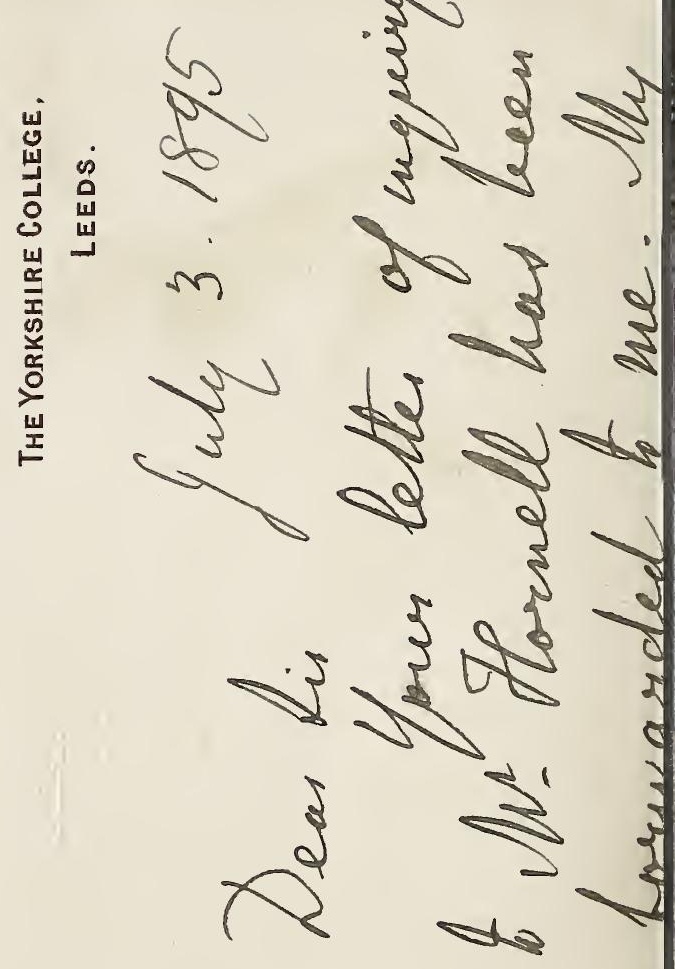




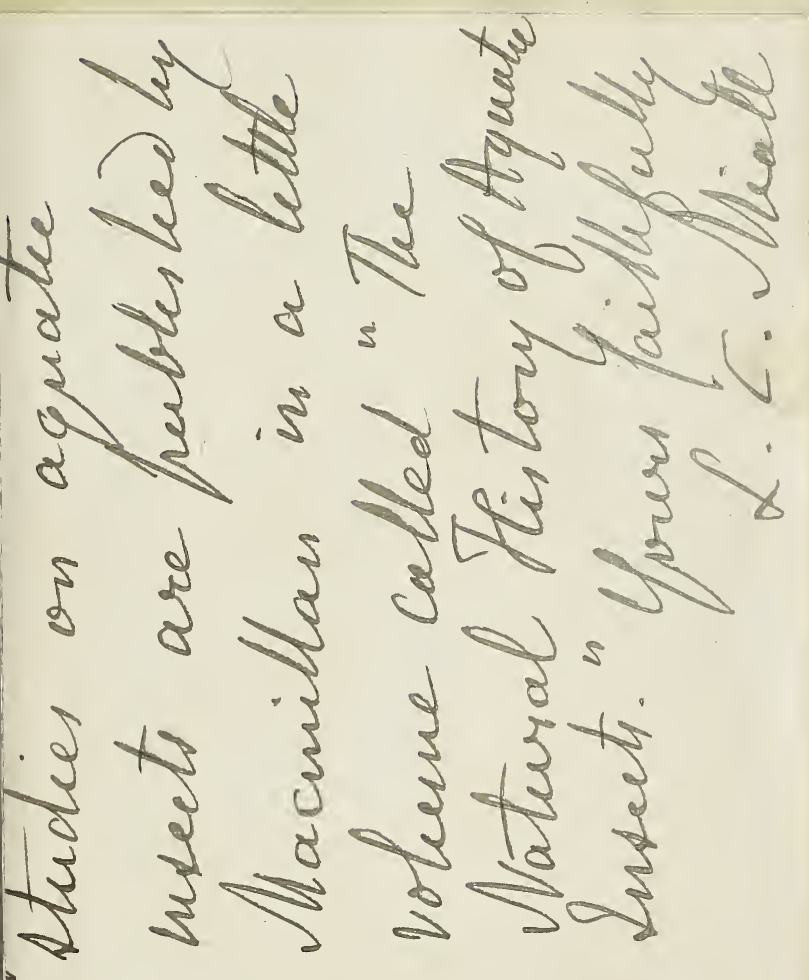




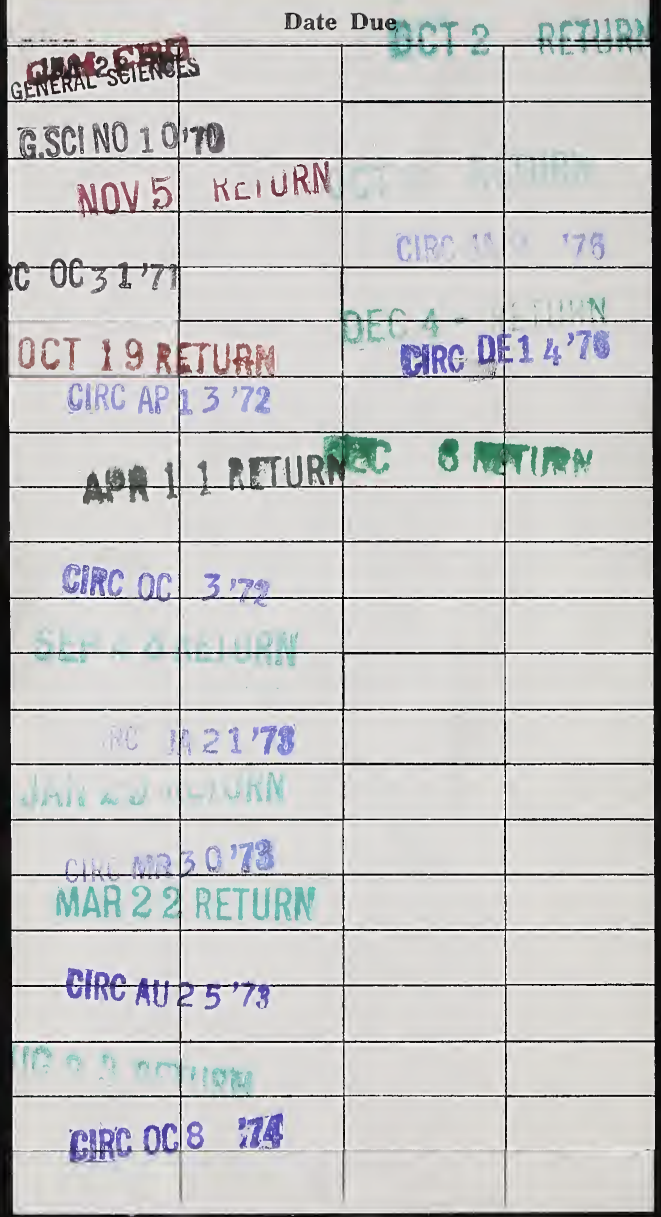




\section{$44042 \%$}

QL 467 M61 c. 2

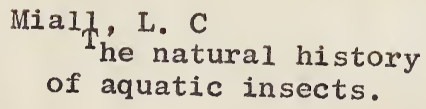
of aquatic insects. 


\section{QL 467 M61 c.2}

Miall, L. C. (Louis Compt

The natural history of aquatic SCI/TECH

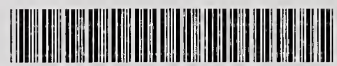

$\begin{array}{llll}0 & 0004 & 6979 & 951\end{array}$ 